\title{
Island biogeography of plants and humans
}

\author{
By
}

Fabio Mologni

\author{
A thesis submitted to \\ Victoria University of Wellington \\ in fulfilment of the requirements for the degree of \\ Doctor of Philosophy
}

Victoria University of Wellington

(2022)

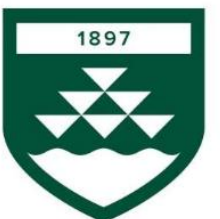

TE HERENGA WAKA 
This thesis was conducted under the supervision of

\author{
Professor Kevin C. Burns (Primary Supervisor) \\ Victoria University of Wellington, \\ Wellington, New Zealand \\ Doctor Peter Bellingham (Secondary Supervisor) \\ Landcare Research - Manaaki Whenua, \\ Lincoln, New Zealand
}




\section{Abstract}

Islands have always attracted considerable research effort due to their unique geography and biota. However, the biogeography of islands still presents substantial challenges. For instance, islands often sustain high rates of plant invasions. The distributional patterning of exotic species on islands though is still poorly understood. Additionally, while species vary strongly in their life histories, rarely plant traits have been integrated with the investigation of the island biogeography of plant species. Islands are also commonly struck by storms and strong winds of oceanic origin, yet how ocean-borne disturbances affect island plant communities is unclear. Finally, in the last 50 years, researchers investigated the insular distribution of virtually every known taxon, but very little is known about variation in human population sizes on islands. The goal of this thesis is to investigate these understudied aspects within the theory of island biogeography framework in vascular plant species and humans.

To better understand plant invasions on islands, I compared the relationships between native and exotic species richness and island characteristics on 264 islands offshore Northern New Zealand. Native and exotic species displayed broadly similar biogeographical patterns; however, exotic species exhibited subtle, yet distinctive, invasion patterns. Trends in species richness were also scale-dependent, and increasingly for exotic species.

Second, I integrated plant life-history traits within the theory of island biogeography framework to investigate how exotic species with different traits relate to island characteristics on 264 islands offshore Northern New Zealand. Exotic species with traits associated with high invasion rates (i.e. high island occupancy rates) were more similar to native species both in occupancy and in relationships with island characteristics. Moreover, they were less commonly associated with human-related variables. 
Third, I assessed how distributional patterns of native and exotic plant species varied depending on different levels of ocean-borne disturbances on 97 small New Zealand islands. Overall results show that both native richness and composition varied with different levels of disturbance. In striking contrast, distributional patterns of exotic species remained unchanged. Differences between natives and exotics might reflect a lack of coastal specialists in the exotic species pool.

Lastly, I explored relationships between human population sizes and island characteristics on 10 archipelagos worldwide, for a total of 486 islands. Overall results showed that, just like other animals, humans are strongly structured geographically. However, relationships between human population sizes and island characteristics vary markedly among archipelagos, often reflecting specific social, political and historical circumstances.

This thesis combines with a growing body of research on plant invasions on islands. It provides a fresh perspective on the subject by assessing previously overlooked aspects of the invasion process, such as the scale-dependency of the relationships between exotic species richness and island characteristics. Additionally, it integrated a trait-based approach within the theory of island biogeography framework. It also provided a test of how species of different biogeographic origins respond to varying levels of ocean-borne disturbances. Lastly, this work includes what is, to my knowledge, the first global test of the island biogeography of humans. 


\section{Acknowledgments}

Like every project, I couldn't have finished this one alone. First, I thank my supervisors, KC Burns and Peter Bellingham, for the time, the patience and the teachings. Thanks also to all collaborators, in particular Even Tjorve for all the long conversations and the invaluable suggestions. I thank Ewen K. Cameron and Anthony E. Wright for collecting and organizing hundreds of data I used in chapters 2 \& 3 and Kohi Dinh for laying the foundations for the development of these two chapters. Sarah Richardson, for facilitating data collection for chapter 3, and Lisa Woods, for helping with statistical analysis in chapters $2 \& 5$. Finally, I thank the anonymous reviewers whose comments improved chapters $2 \& 3$.

Friends and colleagues' support was essential. I thank first all my lab mates and colleagues for sharing with me this journey. Thanks, Ganges, for putting up with me during my daily rants, for teaching me how to cook Mee Goreng properly and for the literally endless list of favours I owe you for (thanks, really). Thanks, Tom, for all Bananagrams matches and long discussions and Lorenzo for all the coffees and walks (and the conversations during them). Thanks, Blue for bringing fun and laughter in the lab (Chur!) and Matt because... "Biddick!". Thanks, Joe, for the chocolate, the pottery and all the caustic comments (What would have I done without?). Lizzy, Manuel and Rossella because you made this degree more tolerable. Thanks to all my Italian and Irish friends, life divide us, but the time spent together remains: Giovanni, Alessandra, Fede, all the Davides e the Stefanos (How many of you are there??), Andrea, Arianna, Martina and all the Bionats, Daniel, Michela, Ivan, Judy, Jaquie, Frances and all Oxfam. Thanks, Franco, because everyone's got "that professor" that make them love a discipline and because you were right, in the end, science and poetry are not that far away. And if I forgot someone, be patient (o perhaps not, and make me get you a beer, dam it!). Thank you, Sara, because this journey wouldn't even have started without you. And I thank our families, both, because they supported our choice to move to the other side of the planet and bore 
our obvious allergy to phone and video calls. Thanks, Mamma, Stefano, Andrea, Lara, Valentina, Rina, Luisa, Riccardo, Elena, Marco, Davide, Stefania, Rosanna but especially thanks to all my nephews and nieces - Francesco, Chiara, Diego, Serena e Gregorio (Welcome!) - because in the end, it's you that carry the weight of our choices. Thanks, Papa and Nonna, because roots are not where you are, but where memory is. 


\section{Ringraziamenti}

Come tutti i progetti, anche questo non l'ho portato a termine solo. Ringrazio prima di tutto I miei supervisors, KC Burns e Peter Bellingham, per il tempo e la pazienza spesi e tutto quello che mi hanno insegnato. Ringrazio tutti I collaboratori, in particolare Even Tjorve per le lunghe conversazioni e I preziosi consigli. Ringrazio Ewen K. Cameron and Anthony E. Wright per aver raccolto e organizzato centinaia di dati utilizzati nei capitoli $2 \& 3$ e Khoi Dinh per aver posto le basi al lavoro che ho svolto in questi due capitoli. Inoltre, ringrazio Sarah Richardson, per aver facilitato la raccolta dati del capitolo 3, e Lisa Woods, per il suo contributo all'analisi dei dati dei capitoli $2 \& 5$. Infine, ringrazio i reviewers I cui commenti hanno contribuito a migliorare i capitoli 2 \& 3.

Il supporto di amici e colleghi e' stato essenziale. Ringrazio innanzi tutto I miei lab mates e colleghi per aver condiviso con me questo percorso. Grazie Ganges, per aver sopportato I miei sproloqui quotidiani, per avermi insegnato come cucinare i Mee Goreng come si deve e per la lista letteralmente infinita di favori che ti devo (Grazie, davvero). Grazie Tom per le partite a Banagram e le lunghe discussioni e Lorenzo per tutti I caffe e le camminate (e tutti i discorsi che abbiamo fatto durante). Grazie Blue per la nota di allegria che porti nel lab e Matt perche'... "Biddick!". Grazie Joe per il cioccolato, la pottery e I commenti caustici (come avrei fatto senza?). Lizzy, Manuel e Rossella perche' avete reso questo degree piu sopportabile. Grazie a tutti gli amici italiani, spesso ci si perde per strada, ma le storie trascorse insieme restano: Giovanni, Alessandra, Fede, tutti I Davidi e gli Stefani (ma quanti cavolo siete?), Andrea, Arianna, Martina e tutti I Bionats, Daniel, Michela, Ivan, Judy, Jaquie, Frances e tutto Oxfam. Grazie Franco perche' tutti hanno "quel professore" che gli ha fatto amare una disciplina e perche' avevi ragione, nei fatti scienza e poesia non sono cosi distanti. E se ho scordato qualcuno, abbiate pazienza (o magari no, e fatevi offrire una birra, diamine!).

Ringrazio Sara, perche' questo percorso non sarebbe nemmeno iniziato senza di te. E le nostre famiglie, entrambe, per aver supportato la nostra scelta di trasferirci in capo al mondo e sopportato 
la nostra evidente allergia per le videochiamate. Grazie Mamma, Stefano, Andrea, Lara, Valentina, Rina, Luisa, Riccardo, Elena, Marco, Davide, Stefania, Rosanna ma soprattutto grazie a tutti I miei nipoti - Francesco, Chiara, Diego, Serena e Gregorio (Benvenuto!) - perche' alla fine siete quelli che piu’ di tutti portano il peso delle nostre scelte. Grazie Papa e Nonna, perche' le radici non sono dove stanno i miei piedi, ma dove e' la mia memoria. 


\section{Contents}

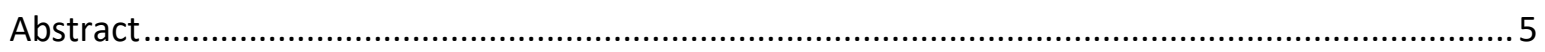

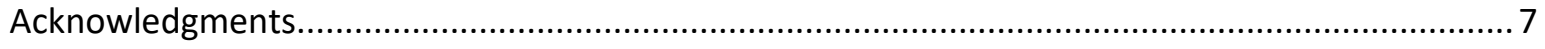

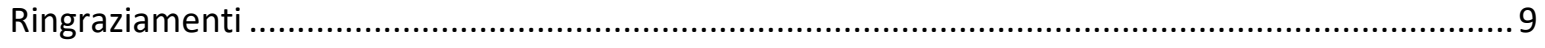

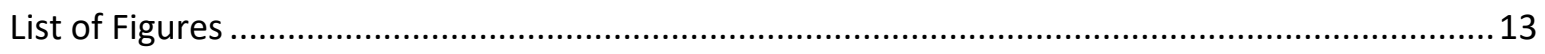

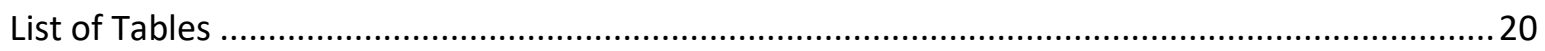

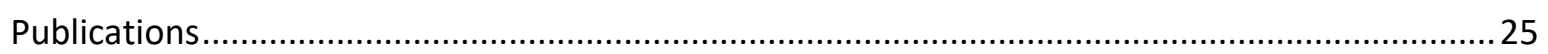

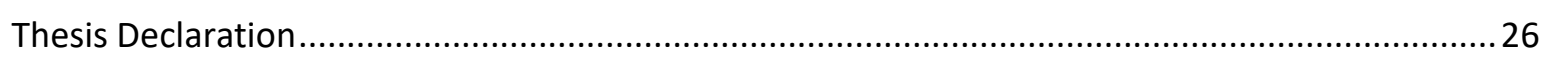

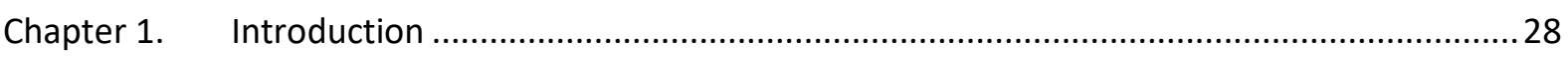

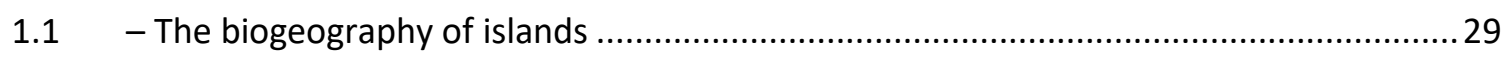

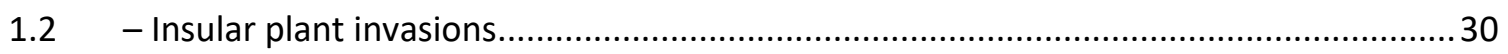

1.3 - Integrating island biogeography, functional and invasion ecology .......................... 31

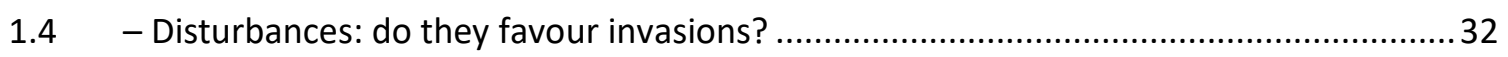

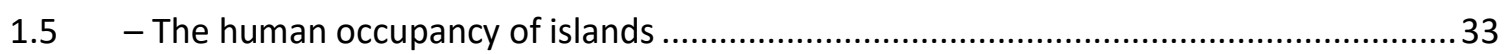

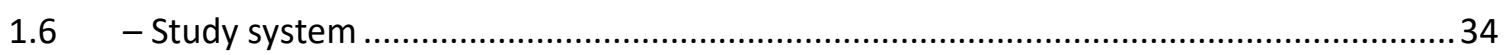

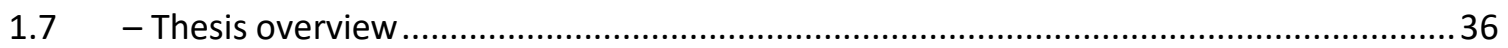

Chapter 2. Similar yet distinct distributional patterns characterize native and exotic plant species richness across islands in New Zealand ...........................................................................40

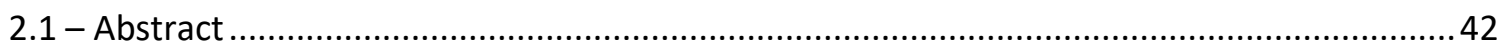

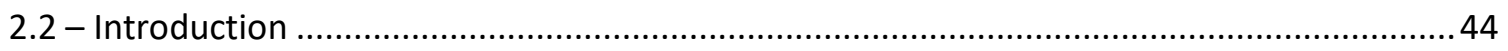

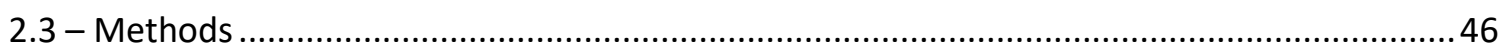

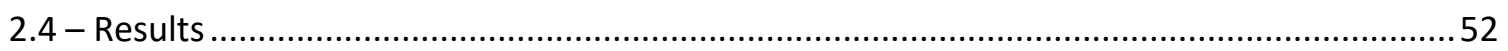

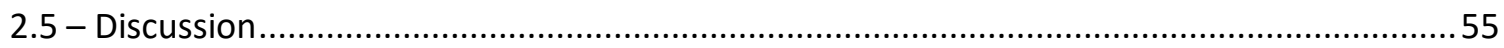

Chapter 3. Functional traits explain species richness and island occupancy of exotic plants on

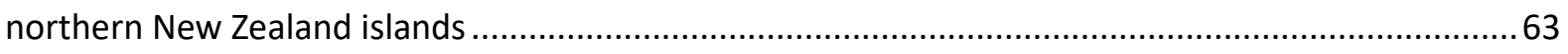

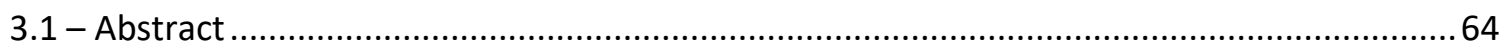

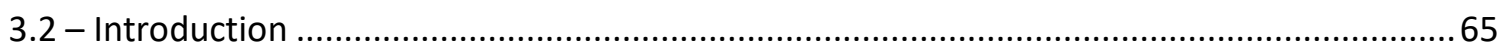

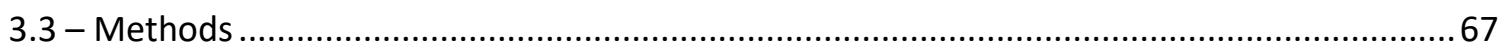

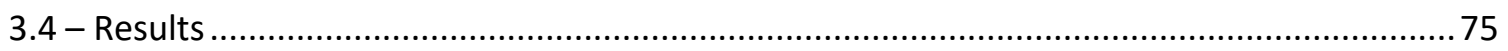

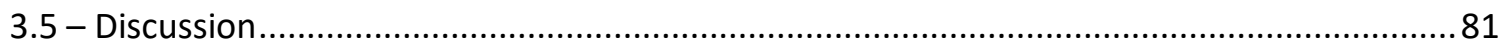

Chapter 4. Different levels of disturbance influence the distributional patterns of native but not exotic species on New Zealand small islands.....................................................................9. 91

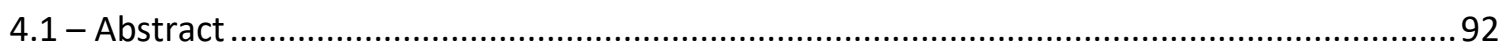

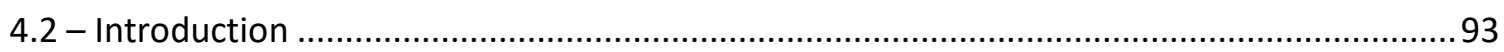




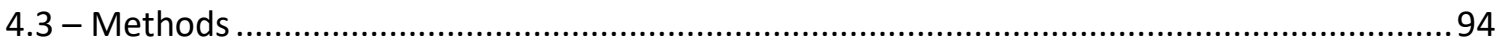

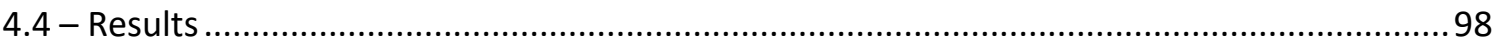

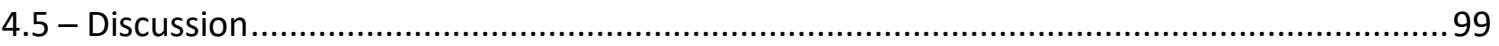

Chapter 5. The Island Biogeography of Humans ................................................................... 105

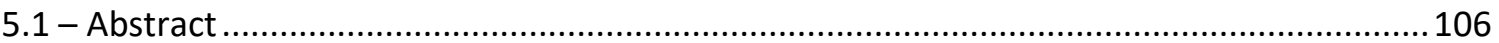

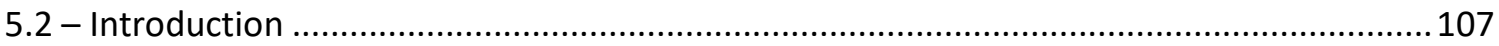

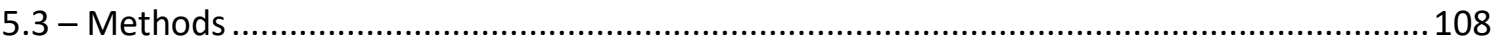

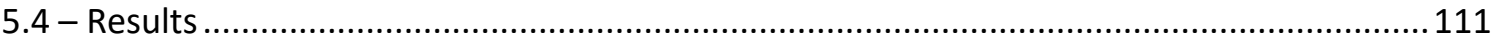

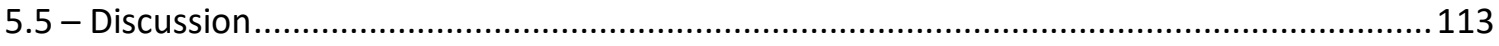

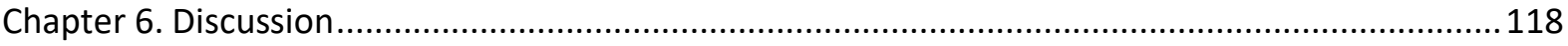

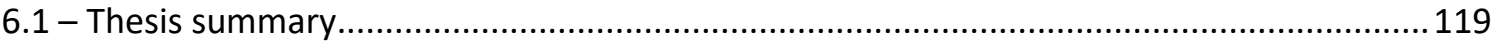

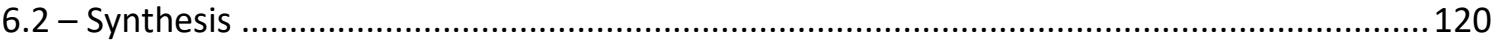

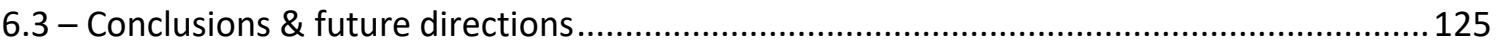

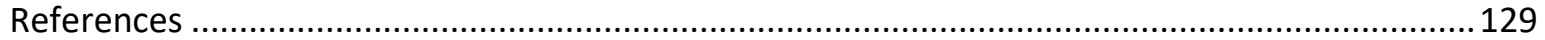

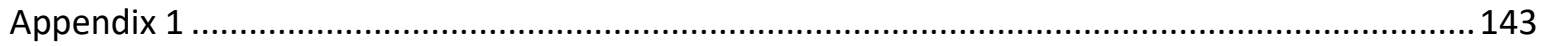

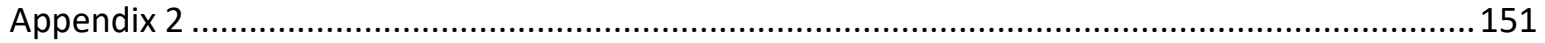

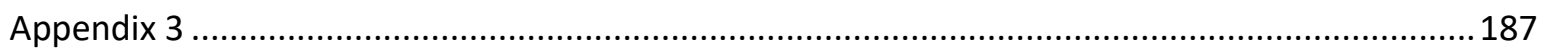

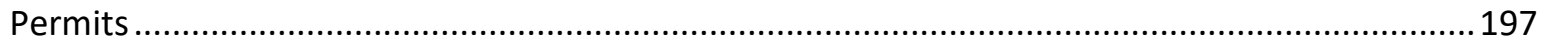

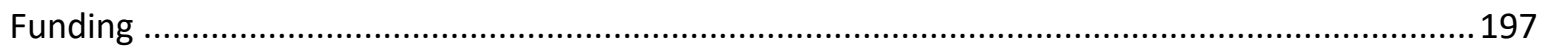




\section{List of Figures}

Figure 2.1 - Map of the study area off the Northern coast of the North Island of New Zealand and a photograph of a typical island.

Figure 2.2 - Positive relationship between exotic plant species richness and native plant species richness on 264 islands off the north coast of New Zealand. Symbol colours represent unexplained (residual) variation in exotic plant species richness. Heavily invaded islands are coloured red, while relatively under-invaded islands are coloured green. Both axes are logarithm (+1) transformed to conform to assumptions.

Figure 2.3 - Relationships between uncorrelated (residual) variation in the native-exotic richness relationship and island (A) area, (B) isolation, (C) exposure to ocean born disturbances, (D) latitude and $(E)$ distance from the nearest urban area on 264 islands off the north coast of New Zealand. Symbol colours represent unexplained (residual) variation in exotic plant species richness. Heavily invaded islands are coloured red, while relatively uninvaded islands are coloured green. For each graph, the coefficient and the significance of its t-test are given (level of statistical significance: ${ }^{*} \mathrm{P}<$ $0.05, * * P<0.01, * * * P<0.001)$. To conform to assumptions, area was log-transformed, isolation arcsine-transformed and distance from the nearest urban area root squared-transformed.

Figure 2.4 - Scale-dependent variation in relationships between plant species richness, island area (vermilion points), isolation (blue points) and exposure to ocean-borne disturbances (green points) on 264 islands off the north coast of New Zealand. Analyses of native species richness are shown at left and analyses of exotic species are shown at right. The top set of graphs illustrates the 'sequential deletion' method. Each point represents a separate linear model with the largest islands in the study system sequentially deleted. The bottom set of graphs illustrates the 'moving window' method. Each point represents a separate linear model on just 70 islands. Each point, moving left to right along the $\mathrm{x}$-axis, represents a new set of 70 islands, wherein the largest island in the set was replaced with the next smallest in the following island in the series. The coefficient of determination ( $r 2)$ is shown on the $y$-axes of all four graphs. On the top row, the $x$-axis shows the number of islands removed at each regression, while the bottom row represents the number of separate analysis conducted. 60 
Figure 3.1 - Number of islands occupied by exotic species with different (a) growth forms and (b) dispersal modes. On the $y$-axis is the number of islands occupied by each species, log-transformed, while on the $x$-axis are trait categories. In the box on the top right is a comparison with native species.

Figure 3.2 - Linear models illustrating relationships between exotic species richness with different growth forms and island characteristics on 264 New Zealand offshore islands. On the $y$-axis is species richness (partial residuals), while on the $x$-axis are island (A) area (log scale), (B) isolation, (C) exposure to ocean born disturbances, and (D) distance from the nearest urban area. Trendline (model predicted slope) and relative confidence interval (95\%) colours represent graminoid (yellow), forb (vermilion) and woody species (brown). Trendline types indicate significant (solid, $\mathrm{P}<0.05$ ) or non-significant (dotted) relationships. P-values for significant $(P<0.05)$ or not significant (NS) differences among trends are at the bottom right. To conform to assumptions, species richness was $\log (+1)$ transformed, area log-transformed, isolation arcsine-transformed and distance from the nearest urban area squared-transformed. In the box on the top right is a comparison with native species (N).

Figure 3.3 - Linear models illustrating relationships between exotic species richness with different dispersal modes and island characteristics on 264 New Zealand offshore islands. On the $y$-axis is species richness (partial residuals), while on the x-axis are island (A) area (log scale), (B) isolation, (C) exposure to ocean born disturbances, and (D) distance from the nearest urban area. Trendline (model predicted slope) and relative confidence interval (95\%) colours represent animal-dispersed (dark blue), unspecialized (dark green), short-distance (light blue), and wind-dispersed species (light green). Trendline types indicate significant (solid, $\mathrm{P}<0.05$ ) or non-significant (dotted) relationships. Pvalues for significant $(P<0.05)$ or not significant $(N S)$ differences among trends are at the bottom right. To conform to assumptions, species richness was log (+1) transformed, area log-transformed, isolation arcsine-transformed and distance from the nearest urban area squared-transformed. In the box on the top right is a comparison with native species $(\mathrm{N})$. .83

Figure 3.5 - Linear models illustrating relationships between the average seed mass of exotic and native species with different growth forms and island characteristics on 264 New Zealand offshore islands. On the $y$-axis is average seed mass (partial residuals), whereas on the $x$-axis are island ( $A$ ) area (log scale), (B) isolation, (C) exposure to ocean born disturbances, (D) distance from the nearest 
urban area and (E) conservation areas. Colours represent graminoid (yellow), forb (vermilion) and woody species (brown). In plots A to $D$, trendline (model predicted slope) and relative confidence interval (95\%) are represented. In plot E, light hues indicated publicly managed conservation areas, dark hues other islands. Significant relationships $(P<0.05)$ are illustrated by solid trendline $(A-D)$ and asterisks $(E)$. P-values for significant $(P<0.05)$ or not significant $(N S)$ differences among trends are at the bottom right. To conform to assumptions, species richness was log $(+1)$ transformed, area logtransformed, isolation arcsine-transformed and distance from the nearest urban area squaredtransformed. In the box on the top right is a comparison with native species (N).

Figure 3.6 - Linear models illustrating relationships between the average seed mass of exotic and native species with different dispersal modes and island characteristics on 264 New Zealand offshore islands. On the $y$-axis is average seed mass (partial residuals), whereas on the $x$-axis are island (A) area (log scale), (B) isolation, (C) exposure to ocean born disturbances, (D) distance from the nearest urban area and (E) conservation areas. Colours represent animal-dispersed (dark blue), unspecialized (dark green), short-distance (light blue), and wind-dispersed species (light green). In plots A to $D$, trendline (model predicted slope) and relative confidence interval (95\%) are represented. In plot $\mathrm{E}$, light hues indicated publicly managed conservation areas, dark hues other islands. Significant relationships $(P<0.05)$ are illustrated by solid trendlines $(A-D)$ and asterisks $(E)$. P-values for significant $(\mathrm{P}<0.05)$ or not significant $(\mathrm{NS})$ differences among trends are at the bottom right. To conform to assumptions, species richness was log $(+1)$ transformed, area log-transformed, isolation arcsine-transformed and distance from the nearest urban area squared-transformed. In the box on the top right is a comparison with native species $(\mathrm{N})$.

Figure 4.1 - Map of the study area (top), two of the surveyed islands (centre), a typical plant community (bottom left) and the landscape (bottom right) of the study system. 95

Figure 4.2 - Compositional differences among 97 islands off the coast of Wellington, New Zealand. On the $y$-axis are Jaccard similarity indexes, while on the $x$-axis are inner and outer islands. On top are all species (a), below native (b) and exotic (c) species. Symbol colours indicate all (greys), native (greens) and exotic (reds) species, whereas hues show inner (lights) and outer (darker) islands. Asterisks indicate significant differences between inner and outer islands. 
Figure 4.3 - Distance-decay relationships on 97 islands off the coast of Wellington, New Zealand. On the $y$-axis are Jaccard similarity indexes, while on the $x$-axis is the distance between each pair of islands. From the top are all (a), native (b) and exotic (c) species. Symbol colours illustrate all (greys), native (greens) and exotic (reds) species, whereas hues indicate inner (lights) and outer (darker) islands. On the top right are significant ( $p$-value in bold) or not significant (NS) differences between inner and outer islands.

Figure 5.1 - Map of the globe displaying the investigated archipelagos

Figure 5.2 - Map representing the effect of isolation, latitude and longitude on human population size on archipelagos across the planet. From top left: Channel Islands (A), Zhoushan (B), Samoa (C), Kuril Islands (D), Shetland (E), Northern New Zealand (F), lonian Islands (G). Arrow direction and shade (light to dark) show increasing population size. Arrow colour show isolation (green), latitude (purple) and longitude (yellow). Country codes follow the International Organization for Standardization alphabetic codes (ISO 3).

Figure A.2.1 - Frequency plots for plant species richness (native and exotic) and island characteristics of 264 islands off the north coast of New Zealand.

Figure A.2.2 - Correlation matrix displaying the Pearson's correlation coefficient between island characteristics of 264 islands off the north coast of New Zealand. Only one variable was retained if the coefficient was above 0.80 . Correlation was tested on transformed variables. Area, perimeter and elevation are log-transformed, isolation arcsine-transformed and urban is squared-transformed. Isolation is the total amount of landmasses surrounding each island within a radius of $1.500 \mathrm{~m}$, minus the value of 1 . Urban is distance from the nearest urban area.

Figure A.2.3 - Correlation plots for island characteristics displaying a Pearson's correlation coefficient above 0.80 . 175

Figure A.2.4 - Residuals plot of the native-exotic richness relationship for 264 islands off the north coast of New Zealand. 
Figure A.2.5 - Relationships between native and exotic plant species richness and island characteristics on 264 New Zealand offshore islands. On the $y$-axis is species richness and on the $x$ axis are island (A) area, (B) isolation, (C) exposure to ocean born disturbances, (D) latitude and (E) distance from the nearest urban area. Trendline types indicate native (solid) and exotic (dashed) species. Trendline are represented only for significant relationships. To conform to assumptions, species richness was log $(+1)$ transformed, area log-transformed, isolation arcsine-transformed and distance from the nearest urban area squared-transformed

Figure A.2.6 - Scale-dependent variation in relationships between plant species richness, island area (vermilion points), isolation (blue points) and exposure to ocean-borne disturbances (green points) on 264 islands off the north coast of New Zealand. Analyses of native species richness are shown at left and analyses of exotic species are shown at right. The graphs illustrate an analysis similar to the 'sequential deletion' method. In this case though, islands are ranked from smallest to largest. Each point represents a separate linear model with the smallest islands in the study system sequentially deleted. The coefficient of determination $(r 2)$ is shown on the $y$-axis while the $x$-axis shows the number of islands removed at each regression.

Figure A.2.7 - Number of islands occupied by native species with different (a) growth forms and (b) dispersal modes. On the $y$-axis is the number of islands occupied by each species, log-transformed, while on the $x$-axis are trait categories. 179

Figure A.2.8 - Linear models illustrating relationships between native species richness with different growth forms and island characteristics on $264 \mathrm{New}$ Zealand offshore islands. On the $y$-axis is species richness (partial residuals), while on the $x$-axis are island (A) area (log scale), (B) isolation, (C) exposure to ocean born disturbances, and (D) distance from the nearest urban area. Trendline (model predicted slope) and relative confidence interval (95\%) colours represent graminoid (yellow), forb (vermilion) and woody species (brown). Trendline types indicate significant (solid, $\mathrm{P}<0.05$ ) or non-significant (dotted) relationships. To conform to assumptions, species richness was log $(+1)$ transformed, area log-transformed, isolation arcsine-transformed and distance from the nearest urban area squared-transformed. 
Figure A.2.9 - Linear models illustrating relationships between native species richness with different dispersal modes and island characteristics on 264 New Zealand offshore islands. On the $y$-axis is species richness (partial residuals), while on the $x$-axis are island (A) area (log scale), (B) isolation, (C) exposure to ocean born disturbances, and (D) distance from the nearest urban area. Trendline (model predicted slope) and relative confidence interval (95\%) colours represent animal-dispersed (dark blue), unspecialized (dark green), short-distance (light blue), and wind-dispersed species (light green). Trendline types indicate significant (solid, $\mathrm{P}<0.05$ ) or non-significant (dotted) relationships. To conform to assumptions, species richness was log $(+1)$ transformed, area log-transformed, isolation arcsine-transformed and distance from the nearest urban area squared-transformed.

Figure A.2.10 - Linear models illustrating relationships between the average seed mass of native species with different growth forms and island characteristics on $264 \mathrm{New}$ Zealand offshore islands. On the $y$-axis is average seed mass (partial residuals), whereas on the $x$-axis are island (A) area (log scale), (B) isolation, (C) exposure to ocean born disturbances, (D) distance from the nearest urban area and (E) conservation areas. Colours represent graminoid (yellow), forb (vermilion) and woody species (brown). In plots $A$ to $D$, trendline (model predicted slope) and relative confidence interval (95\%) are represented. In plot $\mathrm{E}$, light hues indicated publicly managed conservation areas, dark hues other islands. Significant relationships $(P<0.05)$ are illustrated by solid trendline $(A-D)$ and asterisks (E). To conform to assumptions, species richness was log $(+1)$ transformed, area logtransformed, isolation arcsine-transformed and distance from the nearest urban area squaredtransformed.

Figure A.2.11 - Linear models illustrating relationships between the average seed mass of native species with different dispersal modes and island characteristics on 264 New Zealand offshore islands. On the $y$-axis is average seed mass (partial residuals), whereas on the $x$-axis are island (A) area (log scale), (B) isolation, (C) exposure to ocean born disturbances, (D) distance from the nearest urban area and (E) conservation areas. Colours represent animal-dispersed (dark blue), unspecialized (dark green), short-distance (light blue), and wind-dispersed species (light green). In plots A to $D$, trendline (model predicted slope) and relative confidence interval (95\%) are represented. In plot $\mathrm{E}$, light hues indicated publicly managed conservation areas, dark hues other islands. Significant relationships $(P<0.05)$ are illustrated by solid trendlines $(A-D)$ and asterisks $(E)$. To conform to assumptions, species richness was log $(+1)$ transformed, area log-transformed, isolation arcsinetransformed and distance from the nearest urban area squared-transformed. 
Figure A.2.12 - Correlation matrix displaying the Pearson's correlation coefficient (upper right) and relative correlation plots (lower left) between island characteristics of 97 islands off the coast of Wellington, New Zealand. Variables were retained only with coefficients lower 0.80 . In the centre are frequency plots for each island characteristics. Area, dist (distance), height and RU (rugosity) were log-transformed, slope and dist_dwe (nearest dwelling) square root-transformed while exp (exposure) and elev (elevation) were not transformed.

Figure A.2.13 - Relationships between native and exotic species richness (partial residuals) and island area, isolation, height, exposure, elevation, slope and nearest dwelling on 97 islands off the coast of Wellington, New Zealand. Green and red colour illustrate native and exotic species, respectively, while light and dark colours indicate inner and outer islands, respectively. Solid lines indicate significant relationships, while dashed lines display non-significant relationships. In each graph is displayed the coefficient of significance of an ANCOVA test between inner and outer islands (significant t-test are in bold). To conform to assumptions, species richness $(+1)$, area, isolation and height were log-transformed, slope and nearest dwelling were square root-transformed and exposure and elevation were not-transformed.

Figure A.2.14 - Correlation matrices for 10 archipelagos across the globe. Variables were removed from model with correlation coefficients above 0.8. Area was always preferred over elevation and isolation over latitude or longitude. Latitude was preferred over longitude. Elevation though was maintained in the model if the effect was opposite from that of island area (i.e. positive effect of area, negative of elevation). Island area and elevation were log-transformed (but elevation was not transformed for the Kuril Islands), isolation, latitude and longitude were not transformed (except for isolation, square root-transformed for Northern New Zealand and Hawaii, log-transform 186 


\section{List of Tables}

Table 2-1 - Results from linear regression models exploring the relationship between native and exotic species richness and island characteristics on 264 islands off the coast of New Zealand. Entries are estimate, standard error, $\mathrm{t}$ and $\mathrm{p}$ values. In bold are significant relationships. The last row shows the adjusted $r$-squared for each model. Statistical significance: ${ }^{*} \mathrm{P}<0.05,{ }^{* *} \mathrm{P}<0.01,{ }^{* * *} \mathrm{P}<0.001 .52$

Table 3-1 - Species richness of exotic and native species with different growth forms and dispersal modes on 264 islands offshore New Zealand. A description for each category is provided.

Table 3-2 - Seed mass of exotic and native species subdivided by growth forms and dispersal modes on 264 islands offshore New Zealand. Columns represent trait categories, species richness (after removing those lacking seed mass data), mean seed dry mass (geometric mean) and its geometric standard deviation. The last column includes $t$-values extracted from a generalized linear model (GLM) with quasipoisson distribution comparing exotic and native seed dry mass for each set trait (in bold when significant).

Table 4-1 - Differences in how the richness of native and exotic species respond to island characteristics on 97 islands inside and outside Wellington Harbour, New Zealand. T and p-values testing for discrepancies between inner and outer islands are reported (in bold if $p<0.05$ ). The last column specifies the typology of the relationship between species richness and island characteristics, and differences on inner and outer islands.

Table 5-1 - List of archipelagos investigated and associated number of islands, hemisphere, continent and climate.

Table 5-2 - Generalized linear models exploring the relationship between human occupancy and island characteristics on 10 study systems worldwide. Entries are estimates ( \pm standard errors) and tvalues. Significant relationships are in bold $(p<0.05)$. Area and elevation and were log-transformed (but elevation was not transformed for the Kuril Islands), isolation, latitude and longitude were not transformed (except for isolation, square root-transformed for Northern New Zealand and Hawaii, log-transformed for the Ionian Islands). 
Table A.2.1 - Explained variance $\left(R^{2}\right)$, delta AIC $(\triangle A I C)$ and model probabilities (AICW) of isolation buffers for predicting the residuals of the species-area relationship. The isolation buffer with the highest model probability was retained.

Table A. 2.2 - Moran's Index for spatial autocorrelation of the variables employed in this study. Entries are independent and dependent variables, Moran's Indexes, z-scores and p-values. Latitude was excluded as not suitable for testing.

Table A. 2.3 - Chi-square test of independence for the richness of growth forms and dispersal syndromes employed investigating patterns of species richness across 264 New Zealand offshore islands.

Table A. 2.4 - Chi-square test of independence for the richness of growth forms and dispersal syndromes employed investigating patterns of species seed mass across 264 New Zealand offshore islands.

Table A. 2.5 - Contingency table of growth forms and dispersal syndromes for exotic and native species.

Table A. 2.6 - Species omitted from analyses. Entries are the number of species omitted, the corresponding proportion of exotic and native species, the reason for exclusion and the analyses they were excluded from

Table A. 2.7 - List of generalized linear models (GLM) with quasipoisson distribution comparing the occurrence of species with different functional traits and origin (i.e. exotic and native). Columns are the compared set of species, $t$-value, $p$-value and the level of significance (alpha). Alpha levels are adjusted with a Bonferroni correction, or divided by the number of tests run in each case. Significant p-values are in bold. 157 
Table A. 2.8 - Results from multiple linear regressions exploring the relationship between exotic and native species richness of different growth forms and island characteristics on 264 New Zealand offshore islands. To conform to assumptions, species richness was log $(+1)$ transformed, area logtransformed, isolation arcsine-transformed and distance from the nearest urban area squaredtransformed. $T$ and $p$ values are reported for each island characteristic. Statistical significance: ${ }^{*} \mathrm{P}<$ $0.05, * * \mathrm{P}<0.01, * * * \mathrm{P}<0.001$. 158

Table A. 2.9 - Results from multiple linear regressions exploring the relationship between exotic and native species richness of different dispersal syndromes and island characteristics on $264 \mathrm{New}$ Zealand offshore islands. To conform to assumptions, species richness was log (+1) transformed, area log-transformed, isolation arcsine-transformed and distance from the nearest urban area squared-transformed. T and $p$ values are reported for each island characteristic. Statistical significance: ${ }^{*} \mathrm{P}<0.05,{ }^{*} \mathrm{P}<0.01,{ }^{* * *} \mathrm{P}<0.001$.

Table A. 2.10 - Results from multiple linear regressions exploring the relationship between exotic and native average seed mass of different growth forms and island characteristics on $264 \mathrm{New}$ Zealand offshore islands. To conform to assumptions, average seed mass and area were logtransformed, isolation arcsine-transformed and distance from the nearest urban area squaredtransformed. T and $p$ values are reported for each island characteristic. Statistical significance: ${ }^{*} \mathrm{P}<$ $0.05,{ }^{* *} \mathrm{P}<0.01,{ }^{* * *} \mathrm{P}<0.001$.

Table A. 2.11 - Results from multiple linear regressions exploring the relationship between exotic and native average seed mass of different dispersal syndromes and island characteristics on 264 New Zealand offshore islands. To conform to assumptions, average seed mass and area were logtransformed, isolation arcsine-transformed and distance from the nearest urban area squaredtransformed. T and $\mathrm{p}$ values are reported for each island characteristic. Statistical significance: $* \mathrm{P}<$ $0.05, * * \mathrm{P}<0.01, * * * \mathrm{P}<0.001$.

Table A. 2.12 - ANCOVA tests investigating how among exotic growth forms and dispersal syndromes relationships with island characteristics differ. Above is species richness, below is species seed mass. $F$ and $p$ values are reported for each island characteristic. Significant $p$-values in bold. To conform to assumptions, average seed mass and area were log-transformed, isolation arcsine-transformed and 
distance from the nearest urban area squared-transformed. Statistical significance: ${ }^{*} \mathrm{P}<0.05,{ }^{* *} \mathrm{P}<$

$0.01, * * * P<0.001$

Table A. 2.13 - Plant species found on 97 islands during field surveys. Entries are species' family, binomial name and status (i.e. exotic or native).

Table A. 2.14 - List of parameters used to investigate patterns in species richness on 97 small islands off the coast of Wellington, New Zealand. For each parameter, unit of measurement, range, mean, standard deviation and description are provided. Values for range, mean and standard deviation are provided for all islands (all), islands inside (inner) and outside (outer) the harbour. 164

Table A. 2.15 - Native and exotic species richness on 97 small islands off the coast of Wellington. For each group, range, mean and standard deviation are provided. Values are provided for all islands (all), islands inside (inner) and outside (outer) the harbour.

Table A. 2.16 - Variance inflation factor for the variables included in the two models. Values above 3 indicates high collinearity between two variables. 166

Table A. 2.17 - Results from multiple linear regression models exploring the relationship between the plant richness of native and exotic species and island characteristics on 97 islands off the coast of Wellington, New Zealand. Entries are $t$ and $p$ values on inner and outer islands for each group of species. Statistical significance: ${ }^{*} \mathrm{P}<0.05,{ }^{*} \mathrm{P}<0.01,{ }^{* * *} \mathrm{P}<0.001$

Table A. 2.18 - Distance-decay relationships of native and exotic species on inner and outer islands. Entries are $t$ and $p$ values. Significant differences are reported in bold. Significant relationships are in bold. 168

Table A. 2.19 - Results of linear and quasipoisson models contrasting Jaccard similarity indexes and distance-decay relationships of inner and outer islands for all, native and exotic species. Entries are $t$ and $p$ values. Significant differences are reported in bold. 
Table A. 2.20 - Full list of online sources consulted for population sizes, island area and elevation. For island area and elevation, the Island Directory (http://islands.unep.ch/isldir.htm, Dahl 1991) and a topographic map (https://en-nz.topographic-map.com/, Yamazaki et al. 2017) were also consulted.

Table A. 2.21 - Island characteristics of 10 archipelagos across the globe. Entries are mean and standard deviation for area, elevation, isolation, latitude and longitude. 171

Table A. 2.22 - Overdispersion parameter and model chosen for statistical analyses for 10 archipelagos across the globe.

Table A.3.1 - Characteristics of 264 islands offshore northern New Zealand. Island location (longitude and latitude) are not publicly available due to private ownership and issues of data sovereignty of concern to Māori. The data is publicly available from the Manaaki Whenua data repository at https://doi.org/10.7931/ndkt-zw49.

Table A. 3.2 - Characteristics of 97 islands offshore Wellington harbour, New Zealand. 194 


\section{Publications}

\section{Published}

Mologni F, Bellingham PJ, Tjørve E, Cameron EK, Wright AE, Burns KC (2021) Similar yet distinct distributional patterns characterize native and exotic plant species richness across northern New Zealand islands. Journal of Biogeography 48:1731-1745. https://doi.org/10.1111/jbi.14110

Author contributions: research design (FM, PJB, ET, KCB), data collection (FM, PJB, EKC, AEW), data analysis (FM, ET, KCB), writing, submission, and revision (FM, KCB).

\section{In review}

Mologni F, Bellingham PJ, Cameron EK, Dinh K, Wright AE, Burns KC (revised \& resubmitted) Functional traits explain species richness and island occupancy of exotic plants on northern New Zealand islands. Biological Invasions.

Author contributions: research design (FM, PJB, KCB), data collection (FM, PJB, EKC, KD, AEW), data analysis (FM), writing, submission, and revision (FM, PJB).

Mologni F, Burns KC (In review) The Island Biogeography of Humans. Ecography.

Author contributions: research design (FM, KCB), data collection (FM), data analysis (FM), writing, submission, and revision (FM, KCB).

\section{In preparation}

Mologni F (In prep.) Different levels of disturbance influence the distributional patterns of native but not exotic species on New Zealand small islands. 


\section{Thesis Declaration}

I declare that this written submission is my own work. All material derived from literature has been cited and referenced. No part of this thesis has been previously submitted for another degree at this or any other institution.

Chapters 2, 3, 4, and 5 were written as individual papers. Therefore, some repetitions are inevitable between different sections of this work. Chapters 2, 3 and 5 contain relevant contributions from my supervisors, Kevin C. Burns and Peter J. Bellingham. Chapter 2 and 3 also contain contributions from Ewen K. Cameron, Khoi Dinh, Even Tjørve and Anthony E. Wright.

I thank my supervisors for the insightful comments on chapter 4 and for encouraging me to publish it as a sole author. 
Chapter 1. Introduction 


\section{1- The biogeography of islands}

Islands have long fascinated biologists (Carlquist 1974). Observing the insular biota inspired much of Darwin's and Wallace's landmark work (Darwin 1859, Wallace 1880). Since then, islands have been the focus of considerable research effort (Lomolino 2016, Patiño et al. 2017). The interest in islands derives from their unique features: they are discrete, replicable entities, which allows researchers to isolate single processes and factors (Whittaker and Fernández-Palacios 2007). Moreover, while variable in their characteristics, they are simplified systems if compared to continents. Islands also host a unique biota, including a disproportionately high number of endemic species (Whittaker et al. 2017). Despite attracting much interest, understanding the biology of islands still presents substantial challenges (Warren et al. 2015, Patiño et al. 2017).

One of the most prominent works developed around islands is the theory of island biogeography (MacArthur and Wilson 1967). MacArthur and Wilson elaborated a mathematical model which describes the number of species on an island as a product of two main processes: immigration and extinction. The number of immigrants is regulated by the geographic isolation of an island. Remote islands are more difficult to reach, thus housing fewer species. Conversely, the size of an island controls extinction rates. Larger islands can host a greater number of species, thus lowering extinction rates. Similar mathematical models, focused on meta-population dynamics, identified the same two key variables in influencing population sizes (Hanski 1994). Several studies have revealed the picture to be more complex (Brown and Kodric-Brown 1977, Lomolino 1990, 2016, Whittaker et al. 2017) and several other factors can account for the number of species on an island (Denslow et al. 2009, Essl et al. 2019, Fois et al. 2020). However, after 50 years, the Theory of Island Biogeography still represents a general framework for understanding patterns of species richness on islands. 


\section{2- Insular plant invasions}

Biological invasions describe the expansion of a species to a new geographical region, typically with human mediated dispersal (Sinclair et al. 2020). After introduction, many species can successfully spread in a new range, often displacing native species in the process (Dostál et al. 2013). Furthermore, exotic species are often shared among countries. An unintended outcome is biotic homogenization, or the increase in genetic, taxonomic and functional similarity between spatially separated communities (McKinney and Lockwood 1999). The intensification of travel, commerce and relationships across the globe is promoting this process to an alarming degree (Lockwood et al. 2005). Therefore, biological invasions represent one of the greatest challenges to the conservation of local biodiversity worldwide (Simberloff et al. 2013).

Islands are often regarded as global biodiversity hotspots. Despite accounting for only $3.5 \%$ of the total Earth's land area, they contain 15 to $20 \%$ of all terrestrial species, of which a large number are endemic (Whittaker et al. 2017). Therefore, islands are particularly vulnerable to the introduction of new species. For instance, Pacific islands often contain as many exotic species as native species (Sax and Gaines 2008). With 43.9\% of all vascular plant species exotic in origin ( $n=$ 1798, Brandt et al., 2021), and 85\% of 2229 native plant species endemic (McGlone 2006), New Zealand is a striking example of this trend (Hulme 2020). One way to better understand plant invasions on islands is to investigate discrepancies in distributional patterns of both native and exotic species richness.

The number of exotic species inhabiting oceanic islands often increases with the number of native species (Lonsdale 1999, Seabloom et al. 2007, Sax and Gaines 2008, Denslow et al. 2009, Dyer et al. 2016, Carpio et al. 2017). One explanation is that both groups respond similarly to broad-scale variation in environmental conditions (Fridley et al. 2007, Stohlgren et al. 2007, Tomasetto et al. 2019). For instance, the relationship between species richness and island area is consistently 
reported as positive for both native and exotic species (Baiser and Li 2018). Conversely, speciesisolation relationships are sometimes contradictory. While natives generally decline in number with isolation (Kreft et al. 2008, Weigelt and Kreft 2013, Negoita et al. 2016), this is not always the case for exotics (Moody 2000, Kueffer et al. 2010, Blackburn et al. 2016, Moser et al. 2018). Several other factors had been investigated in the past, such as topographic complexity (Hu et al. 2011, Yu et al. 2012), climate (Kreft et al. 2008, Arianoutsou et al. 2010), substrate (Pretto et al. 2012) and age (Chown et al. 1998, Fattorini 2010). However, whether native and exotic respond similarly to island characteristics is still unclear (Rojas-Sandoval et al. 2020). Understanding which factors drive the richness of native and exotic species is essential to predict invasion success on islands and, ultimately, develop effective management plans to protect insular communities.

\section{3- Integrating island biogeography, functional and invasion ecology}

MacArthur and Wilson's model (1967) provides a simple and effective tool to describe patterns in species richness on isolates. However, it assumes species to be functionally equivalent. Instead, they often exhibit different life-history traits. Species with similar suites of traits employ analogous strategies, which influence their fitness (Pérez-Harguindeguy et al. 2013, Reich 2014). Functional traits, or specific morphological, physiological and phenological features shared among species, have been extensively used to address many ecological and evolutionary questions (Bellingham and Sparrow 2000, Olden et al. 2004, Caccianiga et al. 2006, Grime and Pierce 2012, Warren et al. 2015, Burns 2016a, 2019, May et al. 2017), including the field of invasion ecology (Van Kleunen et al. 2010a, Guo et al. 2018, Hulme and Bernard-Verdier 2018a, b). However, their use in island biogeography is limited and their role in explaining the spatial distribution of island plant species understudied (Patiño et al. 2017, Ottaviani et al. 2020). 
Functional traits may illustrate the ability of exotic species to colonize and persist on an island, influencing their invasion success (Ottaviani et al. 2020). For instance, species producing a larger number of seeds and with a short lifespan have higher propagule pressure (i.e. the number of seeds arriving at a site at a given time), and thus higher invasion rates (Lockwood et al. 2005, Mason et al. 2008). Likewise, species with high dispersal capabilities have more chances to reach both near and remote islands (Carlquist 1974, Heleno and Vargas 2015, Arjona et al. 2018). By contrast, species with low seed production, long lifespans and low dispersal capabilities will likely colonize fewer, less isolated islands (Higgins, Nathan, \& Cain, 2003; Pérez-Harguindeguy et al., 2013;). Finally, more generalist species might more effectively colonize a larger number of habitats (Denelle et al. 2020), and thus islands. Perhaps they also utilize more opportunistic colonization pathways associated with humans (Sinclair et al. 2020). Identifying which traits are associated with high invasion rates and investigating their relationships with island characteristics might allow conservation bodies to more efficiently focus their efforts in managing insular plant invasions.

\section{4- Disturbances: do they favour invasions?}

Disturbances encompass all discrete events that remove plant biomass (Grime 1977, Whittaker 1995), regardless of their nature and origin. Islands are particularly susceptible to perturbations, especially ocean-related. For instance, the catastrophic effect of hurricanes and cyclones on islands in the Caribbean and the Pacific has been well documented, both on landscape (Terry 2007), ecosystems (Zimmerman et al. 1996) and plants (Hjerpe et al. 2001, Morrison and Spiller 2008, Morrison 2010). However, also less strong events (i.e. waves, salt spray and wind shear) can impact the insular biota (Abbott 1977, Whittaker 1995). Earlier studies found that this type of events can reduce the habitable area for plant species (Neufeld et al. 2017), increase their extinction rates (Burns and Neufeld 2009) and reduce plant species diversity (Abbott 1977). However, the 
biogeographical role of ocean-borne disturbances is still poorly understood, especially regarding less catastrophic events (Whittaker 1995, Burns 2016b).

Whether disturbances facilitate invasions is contentious (Denslow et al. 2009, Moles et al. 2012). Disturbances vary greatly in intensity, regime and, most importantly, type (Keeley and Brennan 2012, Moles et al. 2012, Jauni et al. 2015). For instance, anthropogenic disturbances are typically associated with plant invasions (Blackburn et al. 2008, Pretto et al. 2012, Chiarucci et al. 2017, Paudel et al. 2017). Instead, disturbances of natural origin have contrasting effects on exotic species (Hobbs and Huenneke 1992, Safford and Harrison 2001, Moles et al. 2012). Natural disturbances can promote (Bellingham et al. 2005, Alba et al. 2015), prevent (Smith and Knapp 1999), or have no effect on plant invasions (Stohlgren et al. 1999, Suding and Gross 2006). While on islands ocean-borne disturbances generally have a negative effect on plant species (Abbott 1977, Burns and Neufeld 2009, Neufeld et al. 2017), their effect on exotics is still understudied (Burns 2016b).

\section{5- The human occupancy of islands}

Species colonize islands in predictable ways (MacArthur and Wilson 1967). Since the inception of island biogeography over 50 years ago, the insular distribution of species has been extensively explored (Patiño et al. 2017). Theoretical models were developed to investigate species distributions at different taxonomic levels (i.e. metapopulation dynamics, theory of island biogeography, MacArthur \& Wilson, 1967; Hanski, 1999). These models enabled biologists to empirically quantify the island distribution of plants (Abbott 1977, Weigelt and Kreft 2013, Barajas-Barbosa et al. 2020), mammals (Lomolino 1990, Russell et al. 2004), birds (Sampson 1980, Blackburn et al. 2008), reptiles (Ficetola and Padoa-schioppa 2009, Novosolov et al. 2013, Helmus et al. 2014), fish (Sandin et al. 2008, Pinheiro et al. 2017), invertebrates (Toft et al. 2016, Schmack et al. 2020), fungi (Peay et al. 
2007, Glassman et al. 2017, Donghao et al. 2020) and even bacteria (Bell et al. 2005, Lear et al. 2013). However, the human biogeography of humans is still largely unexplored.

The first record of island colonization by a hominid species dates to almost a million years ago (Bednarik 1999). Since then, humans have colonized virtually every island in the world (Keegan and Diamond 1987). Understanding when and how humans colonized islands has long been the focus of researchers (Kirch and Joanna 1994, James Dixon 2001, Anderson et al. 2014, Walter et al. 2017, Napolitano et al. 2019, Ihara et al. 2020). However, these questions were approached mostly from an anthropological perspective. By contrast, ecologists have focused on the impact of human populations and activities on island ecosystems and biota (Ellis 2019, Santos et al. 2021), also within the island biogeography framework (Sax et al. 2002, Kueffer et al. 2010, Helmus et al. 2014, Guo 2015). Despite a call for an integration of biogeographical principles in understanding distributional patterns of humans on islands (Keegan and Diamond 1987), an overarching explanation for the variation in insular human populations has yet to be established.

\section{6- Study system}

In this thesis, I investigate patterns of species distributions across different island systems. In chapters 2-4, I selected two different study systems both encompassing islands offshore New Zealand's North Island. New Zealand is an island country located in the South Pacific, approximately $2000 \mathrm{~km}$ from the nearest continental landmass, Australia. It is formed by three main islands, North, South and Stewart; hereafter referred to as the mainland. The main islands are surrounded by a large number of smaller islands: 890 of over 1 ha in size (Carter et al. 2020).

The first study system comprises 264 offshore islands off the northern coast of the North Island. This set of islands stretches over $600 \mathrm{~km}$ from the northwesternmost and the southeasternmost island, encompassing $4^{\circ}$ of latitude and $7^{\circ}$ of longitude $\left(34-38^{\circ} \mathrm{S}, 172-179^{\circ} \mathrm{E}\right)$. 
They range from very small islets to large islands ( 0.0021 ha to 27,721 ha), some are intertidal islands (i.e. reachable on foot during low tide), while others are $50 \mathrm{~km}$ from the coast. Their geological composition is diverse (volcanic $=51.51 \%$, sedimentary $=46.21 \%$, mixed $=2.27 \%$ ) and were all connected to the mainland during the last glacial maximum. Exceptions are the Poor Knights Islands, not connected to the mainland for at least 1 mya (Fleming 1979), and the two youngest volcanic islands, Rangitoto and Whakaari/White Island, which are still active (Clarkson et al. 1986, Campbell and Landis 2009). Warm, temperate rainforest characterize these islands as other wet areas at low latitudes of New Zealand (Dawson 1988, Grubb et al. 2013). The original vegetation was though cleared and burnt after human settlement and, in many cases, the forests were replaced by an agricultural landscape (Bellingham et al. 2010). More recently, some islands were abandoned while others are still farmed. New Zealand endured two waves of human colonization. The first one by Maori, the indigenous people of New Zealand, and the second by European. Currently, people of both ethnicities still inhabit $41(15.5 \%)$ islands.

The second study system comprises 97 intertidal islands located along the Wellington coastline. They represent a set of small, rocky outcrops $\left(0.825-166 \mathrm{~m}^{2}\right)$ and they are situated in close proximity to the coastline. Most islands are of homogeneous geological composition (i.e. greywacke) (Burns 2015) and recent origin. The coastline was uplifted by approximately 6 meters in 1855 during one of the most intense earthquakes hitting New Zealand (Burns 2016b). These islands often house seabird colonies, which enrich the soil with guano (Grant-Hoffman et al. 2010, Ellis et al. 2011). Numerous storms strike the region, mostly originating in southern latitudes (Pickrill and Mitchell 1979). Vegetation on rocky outcrops along the Wellington coast is dominated by a few low growing, stress-tolerant species, with leathery or succulent leaves (Dawson 1988). These islands are all close to main roads and inhabited areas. 
Lastly, in chapter 5, I selected 10 different island systems across the globe. A total of 486 islands were investigated. Archipelagos were chosen to reflect the various climatic, geographic and environmental settings present on the planet.

\section{7-Thesis overview}

In this project, I explore biogeographical patterns of vascular plant species and humans on islands. I used an island-based approach to investigate their relationship with island characteristics. My goals are to (1) explore differences in patterns of native and exotic species richness on islands, (2) examine relationships between plant functional traits and invasions within the island biogeography theoretical framework, (3) assess how richness and composition of native and exotic species vary depending on different levels of ocean-borne disturbance, (4) investigate the insular distribution of humans and its spatial variation on a global scale.

In chapter 2, I explored differences in patterns of native and exotic species richness by assessing their relationship with island characteristics (i.e. area, isolation, exposure to ocean-borne disturbances, latitude, distance from the nearest urban area). First, I evaluated the relationship between native and exotic species richness. Next, I explored how the richness of native and exotic species relate to island characteristics. I then identified over- and under-invaded islands by investigating how the residual variation in the native-exotic richness relationship relates to island characteristics. Finally, I tested for scale-dependency in the relationships between island characteristics and the two groups of species. 
In chapter 3, I quantified a few, simple life-history traits (i.e. growth forms, dispersal modes) and assessed which are distinctive of the species that invade most islands. Afterwards, I tested whether the richness and seed mass of exotic species with distinct growth forms and dispersal modes vary differently with island characteristics (i.e. area, isolation, exposure to ocean-borne disturbances, distance from the nearest urban area, conservation areas). Lastly, I asked whether results differ for native species.

In chapter 4, I selected a set of small intertidal islands subject to varying levels of disturbance originated by the ocean (i.e. inside and outside Wellington Harbour). Then, I tested whether the richness of native and exotic species differ in their relationship with island characteristics (i.e. area, isolation, height, elevation, slope, nearest dwelling) depending on island location. I then calculated Jaccard similarity indexes to assess whether composition and spatial turnover differ on inner and outer islands for the two sets of species.

In chapter 5, I investigated the island biogeography of humans. First, I selected 10 island systems across the globe. Next, I empirically tested the relationship between human population size and several island characteristics (e.g. area, elevation, isolation, latitude and longitude). I then explored how relationships between population size and island characteristics vary among different archipelagos.

In chapter 6, I discuss the results of previous chapters. The first three chapters of my thesis combine with a growing body of literature investigating differences in the distributional patterns of native and exotic species. By using a range of techniques (e.g. residuals) and approaches (e.g. traitbased) I was able to identify fine differences in how native and exotic species relate to island 
characteristics. Chapter 2 also included the first test for the scale-dependency in the relationship between native and exotic species richness and island characteristics. Chapter 5 provides what is, to my knowledge, the first global test of the human biogeography of islands, representing a potential starting point for future studies investigating insular distributional patterns of humans. 


\section{Chapter 2. Similar yet distinct distributional patterns characterize native and exotic plant species richness across islands in New Zealand}




\section{$2.1-$ Abstract}

Aim A better understanding of plant invasions on islands can be gained from comparing patterns of exotic and native species richness. I asked four questions: (1) Is exotic species richness on islands related to native species richness? (2) If they are related, does this result from similar responses of native and exotic species to specific island characteristics? (3) Is residual variation in native-exotic richness relationships associated with distinctive island characteristics? (4) Are relationships between species richness and island characteristics scale-dependent, and do they differ between native and exotic species?

Location Northern New Zealand

Taxon Vascular plants

Methods I conducted field surveys and augmented my field data with previously published surveys to quantify the number of native and exotic plant species on 264 islands. I then explored the relationship of species richness and several island characteristics (e.g. area, isolation) using multiple and iterative regression techniques.

Results Seventy-two percent of among-island variation in exotic species richness was positively related to native species richness. Both native and exotic richness increased with island area, and declined with isolation and exposure to ocean-borne disturbances (a proxy for salt spray, wave action, etc.). However, exotic species responded more strongly to these three variables. Exotic richness also decreased with latitude and the distance from the nearest urban area, but native species did not. Island area was a better predictor of species richness on larger islands, while isolation and exposure were better predictors on smaller islands. Scale-dependent relationships between species richness and island characteristics were stronger for exotic species. 
Main conclusions Insular distribution patterns of native and exotic plant species richness are governed by similar biogeographic principles. However, in New Zealand, exotic species exhibited subtle, yet distinctive, invasion patterns preferring larger, less isolated, less exposed islands that were located at higher latitudes, and closer to urban areas. 


\section{2 - Introduction}

Biological invasions are a major threat to biodiversity worldwide (Whittaker and Fernández-Palacios 2007, Simberloff et al. 2013, Liao et al. 2020). Invasions by exotic plant species can gradually displace native species, resulting in global floristic homogenization (Pyšek and Richardson 2006, Qian and Ricklefs 2006, Castro and Jaksic 2008). Although floristic homogenization is widespread (Arianoutsou et al. 2010, Stotz et al. 2019), it is especially pronounced on islands for reasons that have yet to be fully resolved (Lonsdale 1999, Pyšek and Richardson 2006, Castro and Jaksic 2008, Kueffer et al. 2010).

The number of exotic species inhabiting oceanic islands often increases with the number of native species (Lonsdale 1999, Seabloom et al. 2007, Sax and Gaines 2008, Denslow et al. 2009, Dyer et al. 2016, Carpio et al. 2017). A variety of mechanisms may promote positive native-exotic richness relationships (Fridley et al. 2007, Burns 2016b, Smith and Côté 2019). Perhaps the simplest explanation is that both groups respond similarly to broad-scale variation in environmental conditions (Fridley et al. 2007, Stohlgren et al. 2007, Tomasetto et al. 2019).

The theory of island biogeography predicts that larger islands contain more species because they can support larger populations, which are less prone to extinction (MacArthur and Wilson 1967). It also predicts that less remote islands have more species, because they are more likely to intercept randomly dispersing propagules. In addition to area and isolation, islands can vary strongly in topography (Hu et al. 2011, Yu et al. 2012), climate (Kreft et al. 2008, Arianoutsou et al. 2010), disturbances of oceanic origin (e.g. salt spray, wave action, storms) (Burns and Neufeld 2009, Neufeld et al. 2017), and human occupation (Blackburn et al. 2016, Paudel et al. 2017), all of which can potentially regulate the number of native and exotic species (Moody 2000, Stohlgren et al. 2006, Kueffer et al. 2010, Moles et al. 2012).

Although exotic species richness on islands is often linked to the native species richness (Lonsdale 1999, Qian \& Ricklefs 2006, Sax \& Gaines 2008), covariance between native and exotic 
richness can be weak. For example, although native and exotic species richness were positively related among islands in the South Pacific, the relationship explained less than half the among-island variation (Denslow et al., 2009, c.f. Long et al., 2009). This suggests that distinctive processes, operating differently on exotic and native species, are the reason for residual variation in nativeexotic richness relationships.

Relationships between species richness and island characteristics can also be scaledependent. Scale-dependency, which refers to when ecological patterns and processes vary with spatial scale, is pervasive in ecology (Wiens 1989, Swenson et al. 2006, Powell et al. 2013, Fung et al. 2019) and has been extensively explored in island biogeography. Studies typically focus on the effect of spatial scale on species-area relationships (Lomolino and Weiser 2001, Tjørve and Tjørve 2017, Guo et al. 2020), with a few also accounting for other island characteristics (Giladi et al. 2014, Menegotto et al. 2020, Schrader et al. 2020). The processes responsible for scale-dependent variation in species-area relationships are also poorly understood (Turner and Tjørve 2005). No previous study has tested whether scale-dependent relationships in insular species richness differ between native and exotic species.

To better understand patterns of invasion of exotic plant species on islands, I quantified the richness of 1677 vascular plant species on 264 islands off the northern coast of New Zealand. Naturalised exotic plant species comprise $43.9 \%$ (1798 species) of New Zealand's total vascular plant flora (Brandt et al. 2021), and 85\% of the 2229 native plant species are endemic (McGlone 2006). I used multiple and iterative regression techniques to determine whether: (1) native and exotic species richness are related, (2) native and exotic species richness are related to the same island characteristics (e.g. island area, isolation, etc.), (3) residual variation in native-exotic richness relationships are associated with distinctive island characteristics, (4) invasion patterns are scaledependent. 


\section{3 - Methods}

Study site

New Zealand consists of two main islands (hereafter referred to as the "mainland") and hundreds of smaller, surrounding islands (Carter et al. 2020). In this study, I focused on 264 islands located off the northern coast of the North Island. The study system spans $4^{\circ}$ of latitude and $7^{\circ}$ of longitude $\left(34-38^{\circ} \mathrm{S}, 172-179^{\circ} \mathrm{E}\right)$. Six hundred kilometres separate the northwesternmost and southeasternmost islands (Figure 2.1).

The studied islands range from 0.00002 to $277.21 \mathrm{~km}^{2}$ in size. Some islands are barely isolated and can be reached by foot at low tide, while others are located over $50 \mathrm{~km}$ from the mainland. Just over half the islands are volcanic in origin (51.51\%), while others are sedimentary in origin (46.21\%). A small number of islands are of mixed composition geologically (2.27\%). Most islands were connected to the mainland during the last glacial maximum, except for the Poor Knight Islands (separated c. 1 Mya; Fleming, 1979).

Before human arrival, most islands supported warm temperate rain forest (Wilmshurst et al. 2014). This forest type dominates low latitudes of New Zealand $\left(34^{\circ} 20^{\prime}-41^{\circ} 40^{\prime} \mathrm{S}\right.$, Grubb et al., 2013), particularly in wetter, more productive areas (Dawson 1988). Since first settlement 740 years ago, humans have had a marked effect on many islands. On some islands, the natural vegetation was cleared, burnt and replaced by an agricultural landscape (Bellingham et al. 2010). Some of these islands have since been abandoned and are now undergoing succession naturally, others are still being farmed. Currently, 41 islands (15.5\%) are inhabited. Other islands were only visited occasionally by people and their floras were less heavily impacted. 


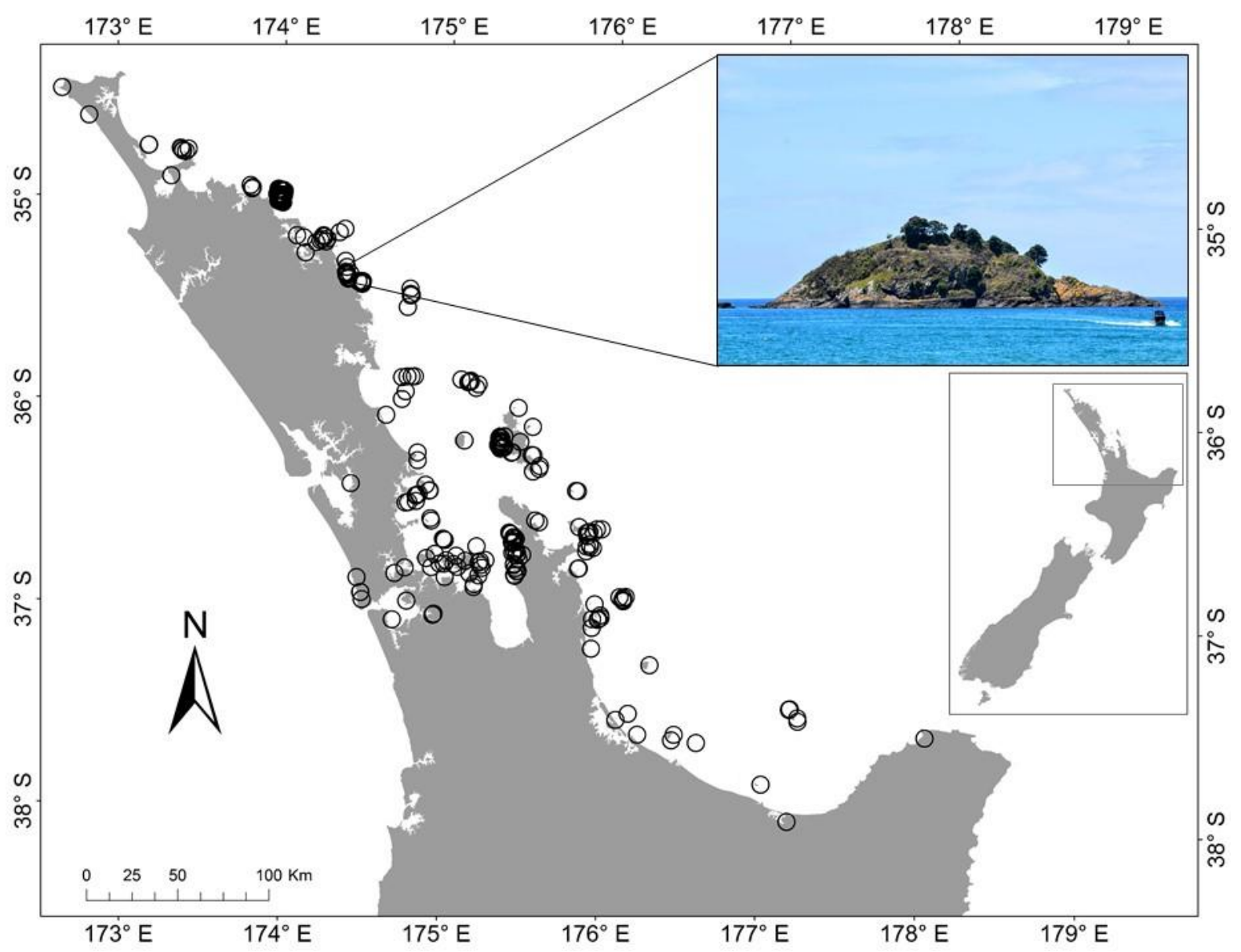

Figure 2.1 - Map of the study area off the Northern coast of the North Island of New Zealand and a photograph of a typical island.

\section{Island species richness}

A comprehensive botanical reconnaissance of vascular plants has been conducted on each of the 264 islands. Most were conducted after 1970, and my study includes published species lists (Appendix 1) and previously unpublished lists (by EKC and AEW for $12.9 \%$ of the islands). Several islands were surveyed multiple times and often studies collated previous records, dating back to the end of the $19^{\text {th }}$ century (e.g. Wright 1980; Cameron \& Davies 2013). I collated complete records for each island, from comprehensive lists and subsequent update lists for some (e.g. de Lange \& McFadden 1995; Cameron \& Young 2019). I applied consistent, updated nomenclature 
(https://nzflora.landcareresearch.co.nz, accessed in July 2018) for all lists for each island. Permits were obtained for all unpublished surveys, issued by either the New Zealand's Department of Conservation or Māori and private island owners.

A total of 1677 vascular species were recorded during island censuses. All species were classified as either native to New Zealand, or having evolved elsewhere (i.e. 'exotic'). Just over half of all species on islands were exotic (50.96\%), most of which were of European origin, but others come from temperate regions worldwide, notably Australia and South Africa. Due to taxonomic uncertainties, 18 species could not be unambiguously determined as either native or exotic and were excluded from analyses.

\section{Island characteristics}

The physical geography of islands was characterised using geographic software (ArcGIS 10.5.1, ESRI, 2011), as follows:

- Island area was quantified as total surface area when viewed vertically $\left(\mathrm{km}^{2}\right)$.

- Isolation is typically quantified as the shortest distance between an isolate and the mainland (MacArthur and Wilson 1967). However, in more crowded archipelagos, adjacent islands may act as source pools of dispersing propagules, in addition to the mainland (Diver 2008). Therefore, I chose a landscape measure of isolation, which characterises isolation as the total amount of land located in concentric belts surrounding each island (Diver 2008, Negoita et al. 2016, Carter et al. 2020). I derived a series of 'buffers' with radii of $250,500,1000,1500,2000,2500,3000 \mathrm{~m}$ and calculated the proportion of land within each one (\%). By removing this value from the total area surrounding an island, I ensure that larger values match greater island isolation.

- Disturbances of oceanic origin were defined as the effect of waves, storm surges, wind shears and salt spray. Exposure to ocean-borne disturbances was quantified following Burns \& Neufeld (2009) as the angle between two straight lines diverging from the centre of each island to the 
edge of the nearest landmasses (mainland and islands larger than 5,000 ha) in QGIS 2.18.20

(QGIS Development Team 2018). The magnitude of the angle indicates the extent of open ocean fronted by an island.

- Latitude and longitude were included as a proxy for geographic gradients in species diversity and climate ( $2^{\text {nd }}$ decimal place) (Arianoutsou et al. 2010, Kueffer et al. 2010).

- To account for topographic complexity, I quantified, as proxies, elevation and perimeter (Kreft et al. 2008, Yu et al. 2012).

- One of the main sources of naturalising exotic species in New Zealand are gardens around dwellings, so the number of exotic species declines with distance from private gardens (Sullivan et al. 2005), huts (Lloyd et al. 2006) and towns (Timmins and Williams 1991). Therefore, I measured the shortest distance $(m)$ from the nearest urban area, which I defined as having a population of 1,000 people or more (Statistics NZ Tatauranga Aotearoa 2018).

\section{Variables pre-selection}

The isolation radius was chosen by regressing each buffer against the residuals of the species-area relationship (Negoita et al. 2016). I computed the Akaike information criterion aiming to retain the metric with higher probability of predicting native and exotic species richness (Appendix 2, Table A.2.1) and, on this basis, I selected a 1500 m radius.

Before inclusion in the model, I used a Pearson correlation coefficient to test for independence among geographic variables, setting 0.8 as a cut-off (Appendix 2, Figure A.2.2) (Berry and Feldman 1985). Three variables were then excluded due to multicollinearity: elevation and island perimeter, both highly positively correlated with area (Pearson $r=0.82$ and 0.99 , respectively), and longitude, positively correlated with latitude (Pearson $r=0.88$ ) (Appendix 2, Figure A.2.3). I retained island area as a more complex proxy of topographic complexity than either elevation or perimeter 
alone. Latitude was preferred over longitude because it betters reflects global changes in environmental conditions.

I tested for spatial autocorrelation of dependent and independent variables, using Moran's I coefficients. There was no evidence of spatial autocorrelation in island area (Appendix 2, Table A.2.2). Islands were positively spatially autocorrelated, or clustered, with respect to native and exotic species richness, isolation, and distance from urban area, but with low but significant Moran's I values. Islands were also clustered with respect to ocean-borne disturbances but showed high and significant Moran's I values (Appendix 2, Table A.2.2).

\section{Statistical analyses}

Covariation in native and exotic species richness on islands was investigated by using simple linear regression. Native species richness was employed as an independent variable and exotic species richness as the dependent variable. Both variables were logarithm transformed prior to analyses to conform to normality assumptions. I added a value of 1 prior transformation to avoid undefined values.

To identify whether native and exotic species richness covary with similar island characteristics, I conducted two analogous linear models. Species richness was used as the dependent variable in both. Island area $\left(\mathrm{km}^{2}\right)$, isolation $(\%$,$) , exposure to ocean-borne disturbances$

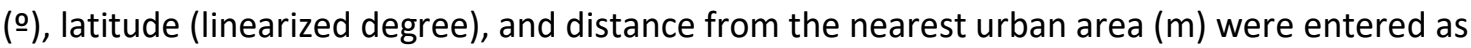
independent variables. All variables were transformed where necessary to conform to assumptions (Table 2.1 and Appendix 2, Figure A.2.1).

To investigate uncorrelated variation in the native-exotic richness relationship, I explored residual variation in the native-exotic richness relationship. While covariation between native and exotic species richness suggests a similar relationship with island characteristics, unexplained 
variation (residuals) indicates otherwise. Islands with increasingly positive (or negative) residuals are more (or less) heavily invaded than expected, suggesting exotics respond differently to island characteristics. By exploring only uncorrelated variation in the native exotic relationship, I remove the component of island characteristics that has a similar effect on both sets of species. If exotics respond distinctively from natives to geographic variables, relationships should emerge between the residuals of the native - exotic relationship and island characteristics. To do so, I conducted a linear model using the residuals of the native-exotic richness relationship as the dependent variable and island characteristics as independent variables.

I used two analytical procedures to investigate the scale-dependency of relationships between species richness and island characteristics. Both techniques assessed how relationships between species richness, island area, isolation and exposure to ocean-borne disturbances vary among different island sizes. The first, 'sequential deletion' technique began by regressing species richness against each of the three island characteristics separately using the whole dataset $(n=264$ islands). Islands were then ranked according to their area (largest to smallest) and the test was repeated with the largest island removed from the dataset. Afterwards, the test was repeated after the largest two islands were removed from the remaining dataset. This procedure was then repeated sequentially until there were only 70 islands left in the dataset. A similar analysis was conducted after ranking islands from smallest to largest. The second, 'moving window' procedure was calculated similarly, except that each test was restricted to only 70 islands, such that the sample size was identical in all analyses (Menegotto et al. 2020). The first test included only the 70 largest islands in the database, and each subsequent test was conducted after removing the largest island and including the next smallest island in the dataset. The test was repeated until only the 70 smallest islands remained in the database. In each iteration of both procedures, the coefficient of determination $\left(r^{2}\right)$ was obtained for each independent variable to identify the best predictor of species richness among islands of different size. Native and exotic species were analysed separately to determine whether they had similar scale-dependent responses to island characteristics. All 
analyses were performed in the $\mathrm{R}$ environment ( $\mathrm{R}$ Core Team 2020). The moving window procedure was conducted using the Zoo package (Zeileis and Grothendieck 2005).

\section{$2.4-$ Results}

Exotic species richness on islands was strongly related to native species richness $\left(\log -\log r^{2}=0.720\right.$, $p<0.001$; Figure 2.2 and Appendix 2, Figure A.2.4). Total richness in both groups increased with island area, and declined with island isolation (radius $=1500 \mathrm{~m}$ ) and exposure to ocean-borne disturbances (Table 2.1 and Appendix 2, Figure A.2.5). However, while exotic species richness also declined with latitude and distance from the nearest urban area, native species richness was unrelated to both (Table 2.1 and Appendix 2, Figure A.2.5).

Table 2-1 - Results from linear regression models exploring the relationship between native and exotic species richness and island characteristics on 264 islands off the coast of New Zealand. Entries are estimate, standard error, $t$ and $p$ values. In bold are significant relationships. The last row shows the adjusted $r$-squared for each model. Statistical significance: $* \mathrm{P}<0.05, * * \mathrm{P}<0.01, * * * \mathrm{p}<0.001$.

$$
\log (1+\text { Natives })
$$

\begin{tabular}{|c|c|c|c|c|c|c|c|c|}
\hline \multirow[b]{2}{*}{ Variables } & & \\
\hline & Estimate & $\begin{array}{c}\text { Standard } \\
\text { error }\end{array}$ & $\mathrm{t}$-value & $p$-value & Estimate & $\begin{array}{c}\text { Standard } \\
\text { error }\end{array}$ & t-value & $p$-value \\
\hline $\log ($ Area $)$ & 0.315 & 0.018 & 17.294 & $<=0.001$ & 0.373 & 0.021 & 18.099 & $<=0.001$ \\
\hline $\begin{array}{l}\operatorname{arc} \\
\left.\text { sine(Isolation }{ }_{1500}\right)\end{array}$ & -0.466 & 0.185 & -2.516 & 0.0125 & -0.981 & 0.209 & -4.682 & $<=0.001$ \\
\hline Exposure & -0.002 & 0.001 & -2.297 & 0.0224 & -0.006 & 0.001 & -5.995 & $<=0.001$ \\
\hline Latitude & -0.044 & 0.063 & -0.705 & 0.4816 & -0.171 & 0.071 & -2.41 & 0.0166 \\
\hline $\begin{array}{l}\text { square } \\
\operatorname{root}(U r b a n)\end{array}$ & 0.000 & 0.001 & -0.367 & 0.7137 & -0.003 & 0.001 & -3.158 & 0.0018 \\
\hline $\begin{array}{l}\text { Adjusted r- } \\
\text { squared }\end{array}$ & & 0.5 & & & & & 0.61 & \\
\hline
\end{tabular}


Unexplained variation in the native-exotic richness relationship increased with area and declined with island isolation, exposure to ocean-borne disturbances, latitude and distance from the nearest urban area (

3). Therefore, exotic species richness was greater than native species richness on large, sheltered, high-latitude islands that were close to other landmasses and urban areas.

Relationships between plant species richness, island area, isolation and exposure to oceanborne disturbances were scale-dependent; more strongly for exotic species (Figure 2.4). Area was a better predictor of plant species richness than isolation and exposure in larger island size classes, while isolation and exposure became increasingly important predictors of plant species richness as island area declined. The 'sequential deletion' method showed that in native species, the predicting power of area declined the smaller the islands were, while that of isolation and exposure increased. However, area remained the best predictor throughout. For exotics, isolation outweighed area after removing the 95 largest islands (mean area of samples removed for this iteration $=0.0145 \mathrm{~km}^{2}$, range $0.00002-0.0622 \mathrm{~km}^{2}$ ), whereas exposure surpassed area after removing the 66 largest islands $\left(\bar{x}=0.0295 \mathrm{~km}^{2}\right.$, range $\left.0.00002-0.1784 \mathrm{~km}^{2}\right)$. Results were consistent by ranking the islands from smallest to largest instead (Appendix 2, Figure A.2.6). The 'moving window' analytical approach yielded similar results. For native species, area was outweighed by isolation at the $108^{\text {th }}$ iteration (mean area $=0.021 \mathrm{~km}^{2}$, range $\left.0.0072-0.0516 \mathrm{~km}^{2}\right)$ and by exposure at the $107^{\text {th }}\left(\bar{x}=0.0216 \mathrm{~km}^{2}\right.$, range $\left.0.0072-0.0520 \mathrm{~km}^{2}\right)$. Both trends inverted after 171 iterations $\left(\bar{x}=0.004 \mathrm{~km}^{2}\right.$, range $0.0012-$ $\left.0.0086 \mathrm{~km}^{2}\right)$. In exotics, area and isolation overlapped at $75^{\text {th }}$ iteration $\left(\bar{x}=0.0544 \mathrm{~km}^{2}\right.$, range $\left.0.0180-0.1301 \mathrm{~km}^{2}\right)$, the former was outweighed at the $93^{\text {rd }}$ iteration $\left(\bar{x}=0.0318 \mathrm{~km}^{2}\right.$, range $0.0105-$ $\left.0.0698 \mathrm{~km}^{2}\right)$. Exposure surpassed area after 32 iterations $\left(\bar{x}=0.2745 \mathrm{~km}^{2}\right.$, range $0.0573-0.9485$ $\left.\mathrm{km}^{2}\right)$, the two overlapped after 50 iterations and exposure overridden area again at the $68^{\text {th }}$ iteration 
$\left(\bar{x}=0.0679 \mathrm{~km}^{2}\right.$, range $\left.0.0214-0.1719 \mathrm{~km}^{2}\right)$. In both cases, the scale-dependency of island isolation and exposure to ocean-borne disturbances were better predictors of exotic species richness.

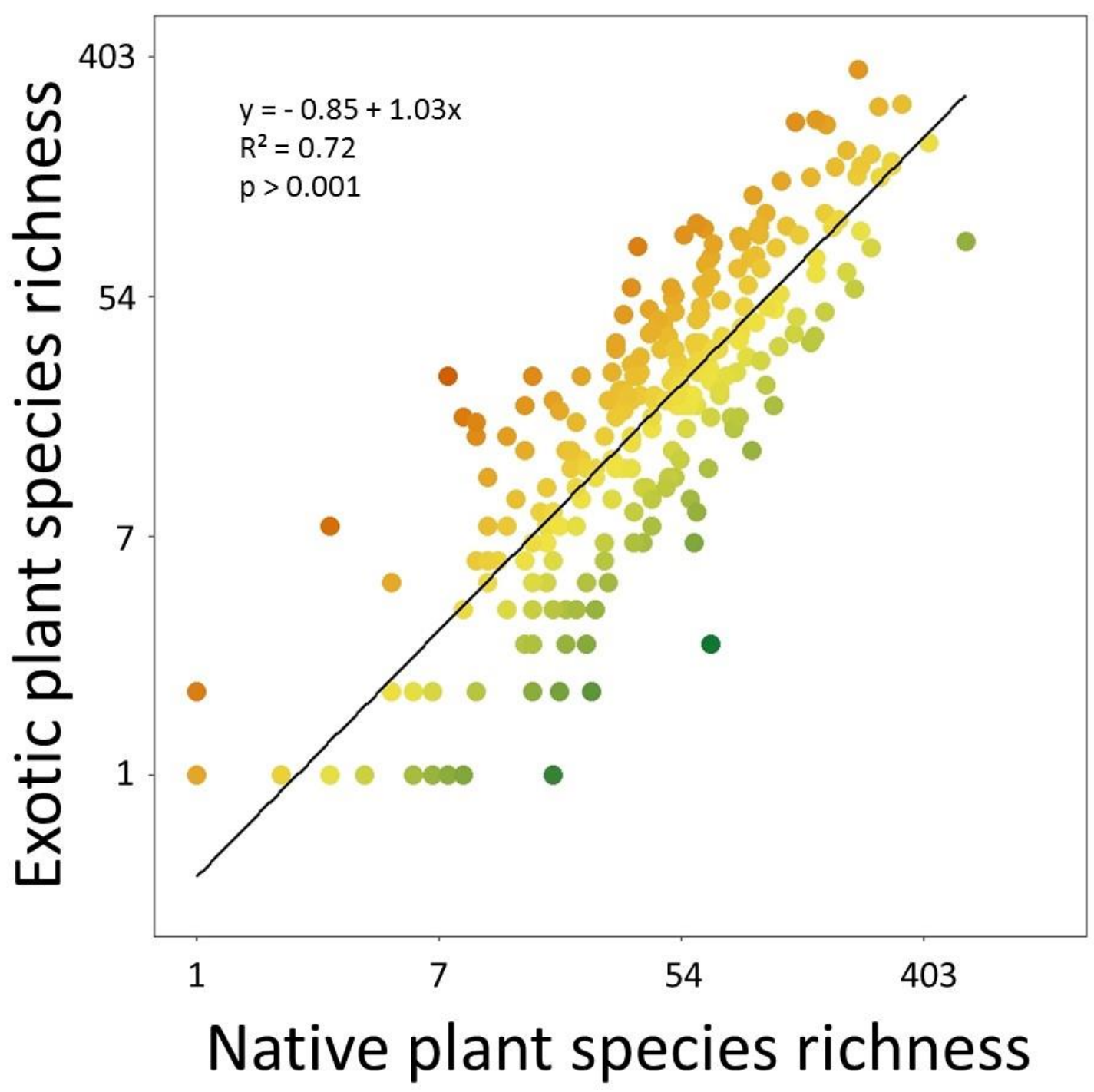

Figure 2.2 - Positive relationship between exotic plant species richness and native plant species richness on 264 islands off the north coast of New Zealand. Symbol colours represent unexplained (residual) variation in exotic plant species richness. Heavily invaded islands are coloured red, while relatively under-invaded islands are coloured green. Both axes are logarithm (+1) transformed to conform to assumptions. 


\section{5 - Discussion}

Over $70 \%$ of the variation in exotic plant species richness across northern New Zealand islands was related to native plant species richness. Positive native-exotic richness relationships are commonly observed across large spatial scales, particularly on islands (Fridley et al. 2007, Sax and Gaines 2008). My results are also consistent with previous work indicating that positive native-exotic richness relationships result from both groups of species responding similarly to particular island characteristics (Fridley et al. 2007, Long et al. 2009, Carpio et al. 2017).

In this study, both native and exotic plant species richness increased with island area and declined with island isolation and exposure to ocean-borne disturbances (e.g. salt spray, wave action, storms). Positive relationships between species richness and island area are among the most commonly observed patterns in nature and can be generated by a variety of processes (Arrhenius 1921, Rosenzweig 1995, Turner and Tjørve 2005, Baiser and Li 2018, Guo et al. 2020). Larger islands are more likely to intercept randomly dispersing propagules (Gilpin and Diamond 1976, McGuinness 1984, Lomolino 1990). They can also support larger populations, which are more buffered from extinction (Lomolino and Weiser 2001, Turner and Tjørve 2005). Larger islands can also contain more habitats, hence more habitat specialists (Triantis and Sfenthourakis 2012, Chen et al. 2020). Speciesisolation relationships are also commonplace and likely arise from the negative effect that geographic isolation often has on rates of island colonisation (MacArthur and Wilson 1967). Although the effects of disturbances on the number of species inhabiting islands are more poorly understood, previous work indicates that more exposed islands often exhibit higher extinction rates and impoverished floras (Morrison and Spiller 2008, Burns et al. 2009, Burns 2016b). 


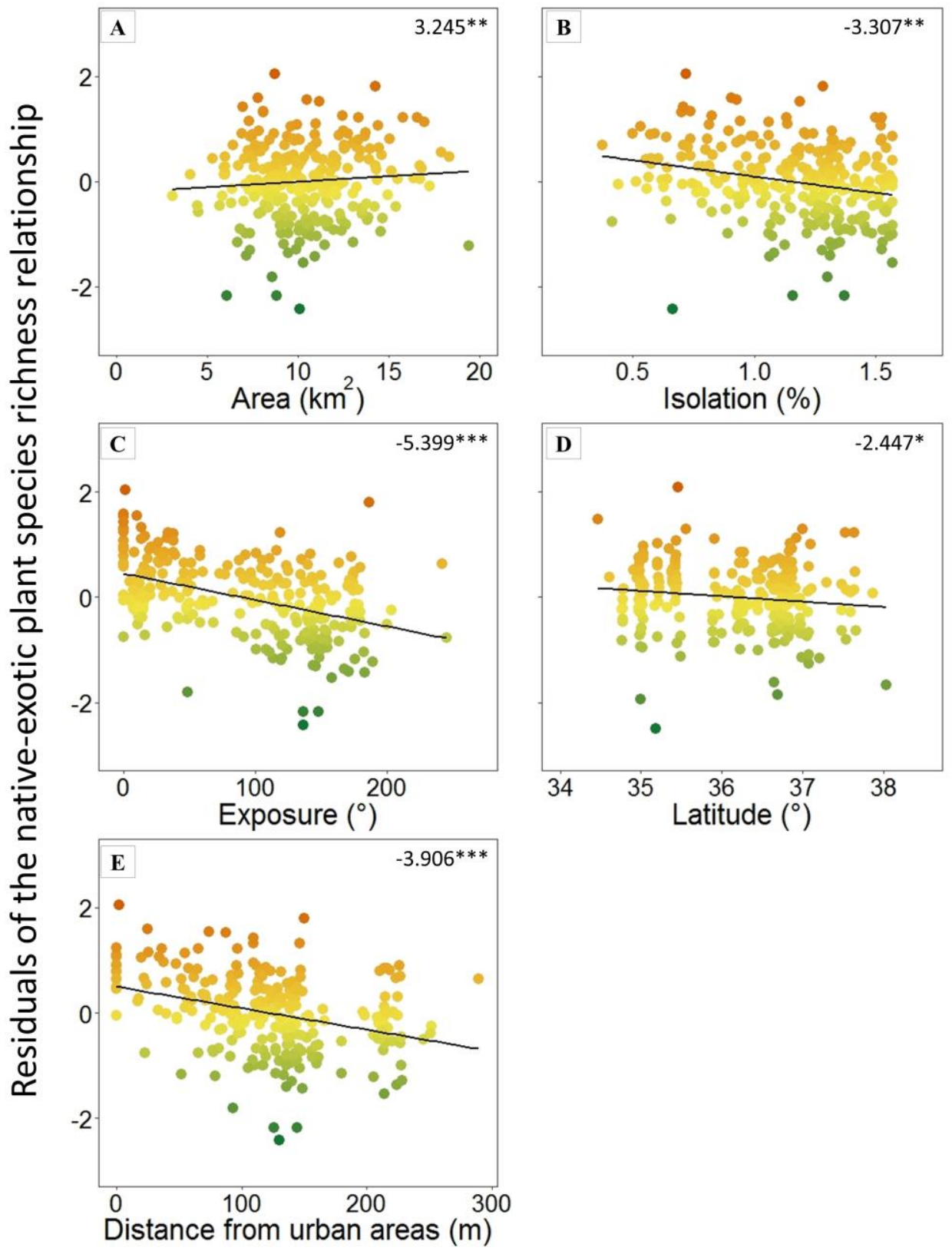

Figure 2.3 - Relationships between uncorrelated (residual) variation in the native-exotic richness relationship and island (A) area, (B) isolation, (C) exposure to ocean born disturbances, (D) latitude and (E) distance from the nearest urban area on 264 islands off the north coast of New Zealand. Symbol colours represent unexplained (residual) variation in exotic plant species richness. Heavily invaded islands are coloured red, while relatively uninvaded islands are coloured green. For each graph, the coefficient and the significance of its t-test are given (level of statistical significance: ${ }^{*} \mathrm{P}<0.05, * * \mathrm{P}<0.01, * * * \mathrm{P}<0.001$ ). To conform to assumptions, area was log-transformed, isolation arcsine-transformed and distance from the nearest urban area root squared-transformed. 
Although exotic species plant richness was positively related to native species richness, $28 \%$ of the variation in exotic species was unrelated to that of natives. This result aligns with several previous studies both on islands (Lonsdale, 1999; Denslow et al., 2009; Long et al., 2009; Burns, 2016; but see Sax \& Gaines, 2008) and on continents (Kumar et al. 2006, Qian and Ricklefs 2006, Seabloom et al. 2007, Bartomeus et al. 2012), suggesting that native-exotic richness relationships might mask subtle biogeographic dynamics between native and exotic species. Residuals of nativeexotic richness relationships in my study showed that exotic species respond slightly differently to island area, isolation, exposure, latitude and distance from urban areas.

Exotic species were disproportionately abundant on large, less isolated islands. New Zealand was one of the last landmasses to be discovered by humans and most exotic plant species were introduced into New Zealand in the last 150 years (Williams and Cameron 2006). Many exotic species may still be in the process of dispersing to islands within my study system. Therefore, the more pronounced effect of area and isolation in exotic species might stem from a time-lag in the invasion process (i.e. ongoing invasion). Large islands offer a greater surface, increasing chances of being intercepted by colonizing propagules (Lomolino 1990). Conversely, less isolated islands present a weaker barrier to colonisation (MacArthur and Wilson 1967). During the initial stages of island colonisation, large and less isolated islands are more likely to be colonized first, as was shown in a study of plant invasions on New Zealand's two main islands, where the number of provinces colonized by exotic species increased with their time since introduction (Williams \& Cameron 2006). Because species richness data for some islands in my study are up to 50 years old, some recent range expansions (or contractions) for some species might have gone undetected. In addition, islands located in close proximity are likely to share similar species (see Appendix 2, Table A.2.2). More detailed analyses are required to examine this possibility. 
Sheltered islands also had disproportionately more exotic plant species. Most exotic species in this study evolved on continents and were adapted to human agricultural and horticultural practices (Lloret et al. 2005), and may be poorly adapted to rocky, windblown habitats with saline soils, which generally characterise island environments (Burns 2019). Therefore, disturbances of oceanic origins may be too frequent or too severe for exotic species to successfully establish and persist on exposed islands (Burns 2016b). On the other hand, plant species that are native to my study system are well-adapted to coastal habitats in New Zealand (Cockayne 1958). Islands were also clustered with respect to exposure to ocean-borne disturbances, a potential source of error that requires further investigation.

Exotic plant species were also disproportionately abundant on islands located closer to urban areas. Human settlements are often foci for plant invasions and denser populations of people may be serving as source pools for island emigrants (Castro \& Jaksic 2008; Kueffer et al. 2010; Pretto et al. 2012; Paudel et al. 2017; Schmack et al. 2019 c.f. Löfgren \& Jerling, 2002; Stohlgren et al., 2006). Exotic species were also disproportionately abundant on islands located at higher latitudes. Climatic conditions become warmer and wetter in more northerly regions of my study system. Therefore, exotic species may be disproportionately diverse on lower latitude islands, due to elevated levels of primary productivity (Lawrence and Fraser 2020). Why native species fail to exhibit a similar trend is unclear. While direct measurements of climate conditions (e.g. temperature, precipitations) would probably improve my predictions, these data are unavailable for most islands in my study; the few data available are biased towards larger, inhabited islands.

Exotic plant richness is often related to human disturbance, as measured by numbers of buildings, lengths of roads, or the extent of agricultural fields (Seabloom et al. 2007, Pretto et al. 2012, Paudel et al. 2017). While I could have applied such an analysis across my islands, only $15.5 \%$ of the islands in my study are currently inhabited with variables like these that could be quantified. This would almost certainly underestimate effects of past human disturbance. Many of the islands in 
my study were either permanently or temporarily settled by Mãori (Holdaway et al. 2019) and many others burned (Bellingham et al. 2010). Others were farmed briefly after European settlement, then abandoned (Bellingham et al. 2010). More data are needed to quantify past disturbance across the islands in my study to permit an appraisal of human disturbance on native and exotic species richness.

Relationships between species richness and island characteristics were also scaledependent. Results showed that the relative influence of island area on species richness declined with island area, while that the influence of island isolation and exposure strengthened. This is consistent with a 'small island effect', a situation where species richness varies more or less independently of sample area on small island size classes (MacArthur and Wilson 1967, Lomolino and Weiser 2001, Dengler 2010). A similar, multi-variable approach to that used here (i.e. sequential deletion, moving window) might be useful in future studies, as they alleviate some of the problems of previously used analytical techniques (Burns et al. 2009, Dengler 2010, Menegotto et al. 2020, Schrader et al. 2020).

The scale-dependent effect of island isolation may be explained by the target-area effect, which predicts that island immigration rates increase with island area, because bigger islands are bigger 'targets' for dispersing propagules (Gilpin and Diamond 1976, McGuinness 1984, Lomolino 1990). If bigger islands have higher immigration rates than smaller islands in my study system, the potential effects of island isolation on immigration rates might increase as the size of islands declines. Given that many exotic plant species are still in the process of invading islands within my study system, this process should be particularly strong in exotic species. However, other potential drivers of the area-isolation interaction might exist (e.g. stepping stones, island clustering, see MacArthur \& Wilson, 1967). Future studies should explore this aspect with more appropriate tools (Weigelt and Kreft 2013). 

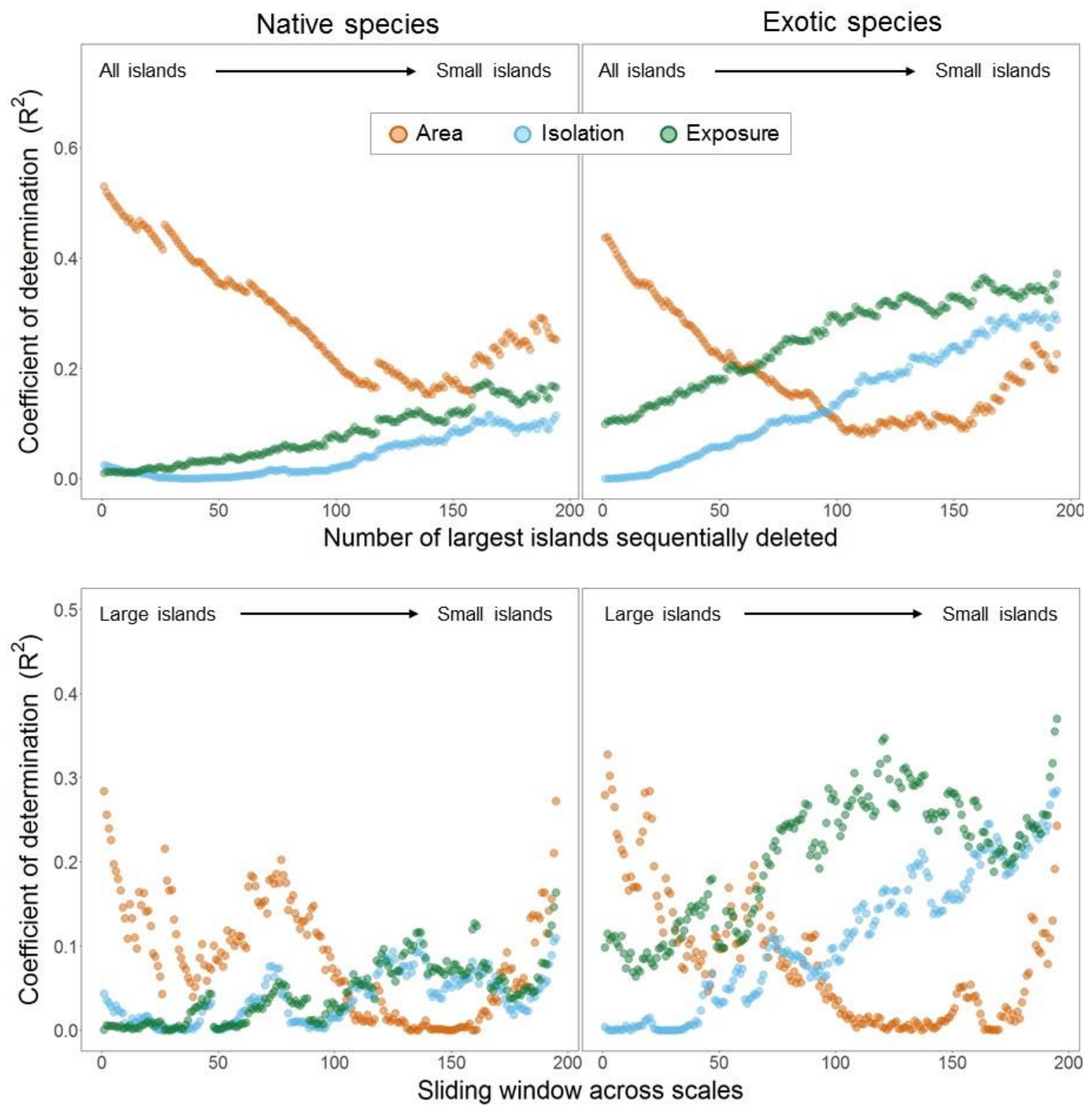

Figure 2.4 - Scale-dependent variation in relationships between plant species richness, island area (vermilion points), isolation (blue points) and exposure to ocean-borne disturbances (green points) on 264 islands off the north coast of New Zealand. Analyses of native species richness are shown at left and analyses of exotic species are shown at right. The top set of graphs illustrates the 'sequential deletion' method. Each point represents a separate linear model with the largest islands in the study system sequentially deleted. The bottom set of graphs illustrates the 'moving window' method. Each point represents a separate linear model on just 70 islands. Each point, moving left to right along the x-axis, represents a new set of 70 islands, wherein the largest island in the set was replaced with the next smallest in the following island in the series. The coefficient of determination $(r 2)$ is shown on the $y$-axes of all four graphs. On the top row, the $x$-axis shows the number of islands removed at each regression, while the bottom row represents the number of separate analysis conducted. 
As island area declines, the effects of ocean-borne disturbances are likely to increase as well, because shorter distances separate the ocean from the interior of an island. Therefore, the effects of ocean-borne disturbances extend deeper into the centre of small islands, due to larger perimeter to area ratios (McGuinness 1984, Morrison and Spiller 2008, Neufeld et al. 2017). Ocean-borne disturbances structure plant communities on small islands in my study system (e.g. Gillham, 1960) and may act as a filter on invasions by exotic plants. The strong effects of disturbance on exotic species richness on very small islands may be because the total pool of exotic species, selected by people for agriculture and as ornamentals, has fewer species adapted to these conditions than native species. Small, isolated islands prone to ocean-borne disturbances in my study system also disproportionately contain large populations of breeding seabirds (Bellingham et al. 2010). These birds cause high levels of disturbance and their guano enriches soil nutrients, imposing a further strong filter on plant communities (Grant-Hoffman et al. 2010, Ellis et al. 2011) to which I expect proportionately fewer exotic plant species of the total pool are adapted.

In conclusion, my results indicate that while positive native-exotic plant species richness relationships reflect broadly similar distributional patterns between native and exotic species, they mask subtler trends in invasion patterns. This might stem from a time-lag in the invasion process and a strong link with human occupancy, climate and environmental filtering. My results underscore the importance of investigating the residual variation in native-exotic richness relationships and including the effect of scale to uncover differences in species distribution that are otherwise undetectable (Sax et al. 2002). Invasive species management should not rely solely on native species richness to predict the number of invasive species, as exotic species exhibit distributional patterns on islands similar, yet distinct, from native species. 


\section{Chapter 3. Functional traits explain species richness and island occupancy of exotic plants on northern New Zealand islands}

Adapted from: Mologni F, Bellingham PJ, Cameron EK, Dinh K, Wright AE, Burns KC (revised \& resubmitted) Functional traits explain species richness and island occupancy of exotic plants on northern New Zealand islands. Biological Invasions. 


\section{1 - Abstract}

Functional traits vary strongly among exotic plant species. Interrelationships between traits and invasion success have been explored in several studies, but only a few have integrated relationships within the island biogeography theoretical framework. I explored relations between functional traits and plant distributions to assess which traits are distinctive of the species that invade most islands, test whether exotic richness and seed mass of growth forms and dispersal modes vary differently with island characteristics (e.g. area, isolation, exposure to ocean-borne disturbances, distance from the nearest urban area and conservation areas) and if results differ from native species. I assembled a database of 264 northern New Zealand offshore islands, amalgamating species lists from field surveys and previously published data, and comprising 822 native and 855 exotic species. I appraised several island characteristics and obtained values for functional traits from available databases. Exotic graminoids occurred on islands more frequently than forbs and woody species, and wind-, animal-dispersed species and those with unspecialized dispersal more than species with shortdistance dispersal modes. Most differences among trait categories of exotic species were associated with human-related variables (i.e. distance from the nearest urban area and conservation areas); however, species displaying high occupancy were often unrelated to them. Overall, successful invaders (i.e. exotics with high occupancy) displayed both rates of occupancy and patterns in richness and seed mass similar to natives. My results illustrate that integrating trait-based approaches in the island biogeography framework can be a useful tool in understanding and predicting plant invasions. 


\section{2 - Introduction}

Islands worldwide are often heavily invaded by species from other biogeographical regions (i.e. exotic species) (Pyšek and Richardson 2006, Denslow et al. 2009, Kueffer et al. 2010, Paudel et al. 2017). On some islands, exotic species richness equals that of native species (e.g. Hawai'i, New Zealand, and several other islands, see Sax and Gaines 2008). Therefore, identifying the traits of successful invasive exotic species before they invade is crucial for island conservation (Towns et al. 1990, Seabloom et al. 2007, Harris and Timmins 2009, Guo 2014).

Species in similar environments often exhibit similar morphological, physiological and phenological features, known as functional traits (Pérez-Harguindeguy et al. 2013, Ottaviani et al. 2020). Species with similar suites of traits employ analogous strategies, which influence their fitness (Pérez-Harguindeguy et al. 2013, Reich 2014). Functional traits and strategies have been extensively used to address many ecological and evolutionary questions (Bellingham and Sparrow 2000, Caccianiga et al. 2006, Grime and Pierce 2012, Burns 2016a, May et al. 2017), especially in the field of invasion ecology (Van Kleunen et al. 2010b, a, Guo et al. 2018, Hulme and Bernard-Verdier 2018a, b). This large body of research has prompted some authors to advocate for using functional traits in the context of island biogeographic theory (Patiño et al. 2017, Ottaviani et al. 2020). To date, only a few studies have employed this approach (Lloret et al. 2004, 2005, Whittaker et al. 2014, Negoita et al. 2016, Schrader et al. 2020, Taylor et al. 2021).

Some plant traits can be rapidly and easily assessed. Classifying plants into 'growth forms' (graminoids, forbs and woody plant species) provides a useful proxy for suites of functional traits and phylogenetic backgrounds (Pérez-Harguindeguy et al. 2013, Schrader et al. 2020). For example, many herbaceous species have relatively short lifespans, small stature, high seed production per unit biomass, and better dispersal capabilities (Ellenberg and Müller-Dombois 1967, Qiaoling et al. 2005, Pérez-Harguindeguy et al. 2013, Schrader et al. 2020). Conversely, woody species have longer lifespans, higher stature and lower dispersal potential (Pérez-Harguindeguy et al. 2013). By 
amalgamating suites of functional traits, plant growth forms may be an effective determinant of invasion success.

The successful colonization of an island often requires overwater dispersal (Carlquist 1974, Heleno and Vargas 2015, Arjona et al. 2018). However, plants can vary greatly in their dispersal ability (van der Pijl 1982). Species with long range-dispersal might colonize more islands, because they have greater chances of reaching remote ones (Carlquist 1974, Heleno and Vargas 2015, Arjona et al. 2018). In contrast, species with poor dispersal capabilities likely colonize fewer, less isolated islands (Higgins et al. 2003). Dispersal distance can be estimated categorizing species by their dispersal mode (i.e. wind-dispersed, animal-dispersed, etc.) (Tamme et al. 2014, Liu et al. 2018).

If species are selected for traits associated with better dispersal ability, islands might contain a biota that is unbalanced in its functional composition (Lomolino 1984, Negoita et al. 2016, Ottaviani et al. 2020). Colonization of new habitats is promoted by allocating more resources to reproduction (Lloret et al. 2005, Hayes and Barry 2008) while investing in vegetative growth favours population persistence after colonisation (Bellingham and Sparrow 2000, Lloret et al. 2005). For instance, a good disperser might invest in a large number of seeds, to maximize chances of colonization, while reducing its size (Cody and Overton 1996, Burns 2019). However, smaller seeds result in fewer resources available to support a new individual's growth (Moles and Westoby 2004, Butler et al. 2007, Hodgson et al. 2020). By selecting for better dispersal, islands might contain a disproportionate number of species lacking in traits associated with persistence.

Islands vary greatly in their characteristics, which may favour certain functional traits. For instance, large, topographically complex islands contain more species (MacArthur and Wilson 1967, Triantis and Sfenthourakis 2012, Tjørve and Tjørve 2017), resulting in these islands have a greater variety of functional traits. However, islands can also be variably disturbed. For instance, islands disturbed frequently by salt spray, storms and waves (Abbott 1977), might favour species better 
adapted to rugged coastal environments. Conversely, frequent and intense disturbance of human origin typically favours generalist species (Moles et al. 2012, Blackburn et al. 2016).

In this study, I explored how traits influence invasion success in exotic plant species inhabiting islands off the northern coast of New Zealand. Naturalized exotic species comprise $43.9 \%$ of New Zealand's total vascular plant flora of 4097 species (Brandt et al. 2021). I compiled a database of 264 islands distributed across more than $4^{\circ}$ of latitude and $7^{\circ}$ of longitude. For each island, I inventoried plant species richness using field and literature surveys and quantified their geographic characteristics using geospatial software, so that I could answer the following questions about the functional traits of successful invasive exotic plant species in the context of island biogeographic theory: (1) Which functional traits are distinctive of the species that invade most islands? (2) Does exotic richness of growth forms and dispersal modes vary differently with island characteristics (area, isolation, exposure to ocean-borne disturbances, and distance from nearest urban area)? If so, how? (3) Do exotics' seed masses, by different growth forms and dispersal modes, vary differently with island characteristics? If so, how? (4) Finally, do native species differ from exotic species in their functional traits, occupancy and in their relationships with island characteristics?

\section{3 - Methods}

\section{Study site}

The two main islands of New Zealand (hereafter referred to as the "mainland") are surrounded by 890 smaller islands (Carter et al. 2020). This study focused on 264 of these islands, located between $34-38^{\circ} \mathrm{S}$ and $172-179^{\circ} \mathrm{E}$, off the northern North Island. Six hundred kilometres separate the northwesternmost and southeasternmost islands.

The islands span 7 orders of magnitude in size $\left(0.000021-277.21 \mathrm{~km}^{2}\right)$. Some are intertidal islands; others are situated over $50 \mathrm{~km}$ from the mainland. Of the 264 islands, 136 (51.5\%) are of 
volcanic origin, ranging in age from 10 million years to currently active (Campbell and Landis 2009), $122(46.2 \%)$ are of sedimentary origin, and $6(2.3 \%)$ are of mixed composition. Most were connected to the mainland during the last glacial maximum (Fleming 1979). The sole exceptions are the Poor Knights Islands, which have been unconnected to the mainland for at least 1 my (Fleming 1979), and the two youngest volcanic islands, Rangitoto and Whakaari/White Island that formed during the Holocene (Clarkson et al. 1986, Campbell and Landis 2009).

New Zealand's climate is oceanic and temperate, which provides suitable conditions for the development of warm temperate rain forest on the study islands (Peel et al. 2007, Wilmshurst et al. 2014). This forest type is dominated by evergreen dicot tree species and some conifers, forming the canopy, and a lower tier of broadleaved small trees and shrubs. The understorey is composed primarily of ferns, monocots (mostly sedges) and non-vascular species, and few grasses (Wardle 1991). Higher elevation forests on a few, very large islands support a mixed montane cloud forest that is distinct but floristically poorer (Cameron and Young 2019).

After human settlement 740 years ago, these islands became the focus of many anthropic activities (Atkinson 2004, Bellingham et al. 2010, Wilmshurst et al. 2014). Māori burned the original vegetation cover of many islands to facilitate access for harvesting seabirds and to plant crops (Daugherty et al. 1990, Bellingham et al. 2010). After Europeans colonized, from c. 1840 onwards, some islands were extensively farmed and grazed (Bellingham et al. 2010, Wilmshurst et al. 2014). Of these islands, some were subsequently abandoned and secondary succession to woody vegetation is common (Bellingham 1984, Atkinson 2004), whereas others are still being farmed. On recent volcanic islands, Whakaari/White Island and Rangitoto, vegetation is in a process of primary succession (Clarkson and Clarkson 1994, Shane et al. 2013). Presently, 41 islands (15.5\% of all islands) are inhabited. 
The total number of vascular plant species occupying each island was established via field surveys and by carefully searching the literature. Two of us (EKC and AEW) have been studying island floras in the study system for decades. During this time, inventories of plant communities were conducted on as many islands as possible. Plant species lists were also obtained from the literature (Appendix 1 in supplementary material). Plant species lists for most islands were often obtained using both methods (i.e. field surveys and from published sources) in which cases, the cumulative number of species encountered in all censuses was obtained. In total, 264 islands were deemed to have adequate censuses and included in analyses.

All species encountered were classified as either 'native' to New Zealand or 'exotic', following Brandt et al. 2021. To account for differences in plant traits, each species was also classified according to its growth form and dispersal mode. Three structural categories were selected for growth forms: graminoids, forbs, and woody (Table 3.1). Dispersal modes were defined based on morphological adaptations of diaspores to long-distance dispersal (Negoita et al. 2016, Arjona et al. 2018, Burns 2019) as wind-dispersed, unspecialized, animal-dispersed, and diaspores with morphological adaptations for short-distance dispersal only (Table 3.1). Among growth forms, I excluded climbers (exotics $=45$, natives $=36$ ) and epiphytes $(e=2, n=7)$ due to the small sample size. For the same reason, water-dispersed species (producing diaspores with corky tissues or air chambers) were excluded from dispersal syndromes (e=17, $n=63)$. 
Table 3-1 - Species richness of exotic and native species with different growth forms and dispersal modes on 264 islands offshore New Zealand. A description for each category is provided.

Species richness

\section{Growth forms}

$$
\text { Graminoids }
$$

Exotics

Natives

Exotics

Forbs

Natives

Exotics

Woody species

Natives

Total

\section{Dispersal mode}

\begin{tabular}{|c|c|c|c|}
\hline \multirow{2}{*}{ Wind-dispersed } & Exotics & 157 & plumes, wings, dust diaspores \\
\hline & Natives & 408 & (anemochory) \\
\hline \multirow[t]{2}{*}{ Unspecialized } & Exotics & 290 & \multirow{2}{*}{$\begin{array}{l}\text { no evident or prevalent morphological adaptations } \\
\text { (unspecialized) }\end{array}$} \\
\hline & Natives & 119 & \\
\hline \multirow{3}{*}{ Animal-dispersed } & Exotics & 167 & \multirow{3}{*}{ fleshy fruits or adhesive barbs (endo and epizoochory) } \\
\hline & & & \\
\hline & Natives & 190 & \\
\hline \multirow[t]{2}{*}{ Short-distance } & Exotics & 185 & \multirow{2}{*}{$\begin{array}{l}\text { morphological adaptations for short-distance } \\
\text { dispersal only (ballochory, myrmecory). }\end{array}$} \\
\hline & Natives & 34 & \\
\hline Total & & 1550 & \\
\hline
\end{tabular}


Species seed mass

For each species, I also established the corresponding seed dry mass (mg). If data were unavailable, seed mass was estimated by seed length $(\mathrm{mm})$ using the following equation:

$$
m=0.1329 P^{2.2243},
$$

where " $m$ " indicates seed mass (mg), " $l$ " is seed length $(\mathrm{mm})$ and the two numeric values are constants (Sarah Richardson, personal communication, May 20, 2020). I gathered data from several sources, including literature (Thorsen et al. 2009, Grubb et al. 2013) and online databases (Kattge et al. 2020, Manaaki Whenua - Landcare Research 2020, New Zealand Plant Conservation Network 2020, Royal Botanic Gardens Kew 2020). Nomenclature followed recognised taxonomic authorities (https://nzflora.landcareresearch.co.nz, accessed in May 2020).

Island characteristics

I measured island area as the total surface of an island $\left(\mathrm{km}^{2}\right)$. Data were retrieved from available sources (Land Information New Zealand 2012) or manually digitized from aerial imagery (Google 2020). Isolation was defined by using a landscape measure of isolation, which incorporates both the mainland and adjacent islands as sources of dispersing propagules (Diver 2008). Isolation is measured by producing a series of concentric belts of different size surrounding each island (radii = $250,500,1000,1500,2000,2500,3000 \mathrm{~m}$ ) and computing the proportion of land within each of them (Diver 2008, Weigelt and Kreft 2013, Negoita et al. 2016, Carter et al. 2020). To ensure larger values indicate greater isolation, I subtracted the amount of land from the total area of each buffer. 
Table 3-2 - Seed mass of exotic and native species subdivided by growth forms and dispersal modes on 264 islands offshore New Zealand. Columns represent trait categories, species richness (after removing those lacking seed mass data), mean seed dry mass (geometric mean) and its geometric standard deviation. The last column includes t-values extracted from a generalized linear model (GLM) with quasipoisson distribution comparing exotic and native seed dry mass for each set trait (in bold when significant).

Species

richness

Mean seed dry mass
(mg)

Standard deviation ( \pm ) t-value

\section{Growth forms}

\begin{tabular}{|c|c|c|c|c|c|}
\hline \multirow{2}{*}{ Graminoids } & Exotics & 114 & 0.55 & 6.66 & \\
\hline & Natives & 111 & 0.55 & 5.65 & -0.643 \\
\hline \multirow{3}{*}{ Forbs } & Exotics & 396 & 0.92 & 7.60 & \\
\hline & & & & & -2.804 \\
\hline & Natives & 151 & 0.27 & 5.87 & \\
\hline \multirow{3}{*}{ Woody } & Exotics & 132 & 12.08 & 17.45 & \\
\hline & & & & & -2.526 \\
\hline & Natives & 161 & 3.62 & 13.26 & \\
\hline \multicolumn{2}{|l|}{ Total } & 1065 & & & \\
\hline \multicolumn{6}{|c|}{ Dispersal mode } \\
\hline \multirow{3}{*}{ Nind-dispersed } & Exotics & 128 & 1.21 & 10.16 & \\
\hline & & & & & -1.209 \\
\hline & Natives & 154 & 0.40 & 7.42 & \\
\hline \multirow{3}{*}{ Unspecialized } & Exotics & 244 & 0.72 & 9.58 & \\
\hline & & & & & -0.845 \\
\hline & Natives & 85 & 0.69 & 6.26 & \\
\hline \multirow{3}{*}{ nimal-dispersed } & Exotics & 141 & 6.67 & 11.74 & \\
\hline & & & & & -1.220 \\
\hline & Natives & 132 & 5.46 & 8.91 & \\
\hline \multirow{3}{*}{ Short-distance } & Exotics & 135 & 2.13 & 8.91 & \\
\hline & & & & & -1.940 \\
\hline & Natives & 30 & 0.68 & 5.91 & \\
\hline Total & & 1049 & & & \\
\hline
\end{tabular}


Storms, waves and salt spray characterise disturbances of oceanic origin. To quantify exposure to ocean-borne disturbances I identified the centre of each island and draw two lines connecting it to the edge of landmasses (either the mainland or islands larger than 5,000 ha). The angle comprised between these two lines represents the degree of exposure of an island to oceanborne disturbances (Burns and Neufeld 2009). Human impacts were quantified first as the shortest distance to the nearest urban area, as exotic species richness often increases with proximity to settlements (Timmins and Williams 1991, Sullivan et al. 2005, Lloyd et al. 2006). Urban areas were defined as having a population of 1,000 people or more (Statistics NZ Tatauranga Aotearoa 2018). Next, I assessed whether an island is a public land managed for conservation (conservation area) or not (Department of Conservation 2017). All spatial analyses were carried using ArcGIS 10 and QGIS 2 (ESRI 2011, QGIS Development Team 2018).

\section{Statistical analyses}

To test whether the number of islands occupied by exotic species can be predicted by plant traits, I subsetted exotic species richness by growth forms and dispersal modes. For each species, I calculated the number of islands occupied and amalgamated this information by trait. Differences in occurrences across islands of growth forms and dispersal mode were analysed using a set of generalized linear model (GLM) with quasipoisson distribution comparing each set of species separately (e.g. exotic graminoids vs exotic forbs, exotic wind-dispersed vs exotic short-distancedispersed, etc.). A Bonferroni correction was applied to significance levels to account for multicomparison.

To test whether exotic richness of growth forms and dispersal modes vary differently with island characteristics, I used a set of multiple linear regressions. Firstly, the richness of each subset of exotic species (e.g. graminoids, forbs, animal-dispersed, unspecialized, etc.) was set as the dependent variable, whereas area, isolation, exposure to ocean-borne disturbances and distance 
from the nearest urban area were the independent variables. Conservation areas (i.e. whether an island is public land managed as a conservation area or not) was excluded from this model as not significantly related to species richness, regardless of trait category and status (i.e. exotic or native). Next, I ran a similar model, but using the richness of all species and including growth forms and dispersal syndromes as an interaction term. To conform to assumptions, species richness and area were log-transformed, isolation arcsine-transformed and distance from the nearest urban area square root-transformed. Variable pre-selection was previously conducted for these island characteristics and an isolation radius of $1,500 \mathrm{~m}$ was chosen accordingly (Mologni et al., in press).

To test whether the seed mass of growth forms and dispersal modes vary differently with island characteristics for exotic species, I devised a second set of multiple linear regressions. Prior to analyses, I averaged seed dry mass per island separately for each growth form and dispersal mode. Mean seed mass of each subset of exotic species was then set as the dependent variable, while as predictors I used area, isolation, exposure, distance from the nearest urban area and conservation areas. Next, I ran a similar model, but using the mean seed mass of all species and including growth forms and dispersal syndromes as an interaction term. To conform to assumptions, species richness and area were log-transformed, isolation arcsine-transformed and distance from the nearest urban area square root-transformed.

The same set of analyses was run for native species. Afterwards, the number of islands occupied by exotic species was compared with that of native species within each trait (e.g. exotic graminoids vs native graminoid) using a GLM with quasipoisson distribution. Patterns in species richness and seed mass of exotic and native species were compared using a linear model setting species richness (of each trait separately, e.g. graminoid species richness) as the dependent variable and as predictors the same variables used in the previous analyses. The status of each species was included in the model as an interaction term. All analyses were run in the R environment ( $\mathrm{R}$ Core Team 2020). 


\section{$3.4-$ Results}

Of the total 1677 species across the islands, 855 (50.96\%) were exotic. There were more exotic forb species than either graminoid or woody species, which in turn were similar in richness (Table 3.1 and Appendix 2, Table A.2.3). Natives included fewer forbs and more woody species than exotics, but a similar number of graminoids (Table 3.1 and Appendix 2, Table A.2.3). Among dispersal modes, most exotic species were unspecialized, fewer species were either short-distance-dispersed, animaldispersed or wind-dispersed (Table 3.1 and Appendix 2, Table A.2.3). Natives included more winddispersed species than exotics, but fewer were unspecialized or short-distance-dispersed (Table 3.1 and Appendix 2, Table A.2.3). A similar number of exotic and native species was dispersed by animals (Table 3.1 and Appendix 2, Table A.2.3).

Of the 1127 species included in seed mass analysis, 59.98\% were exotic. Exotic forbs were the most represented growth form, followed by a similar number of graminoids and woody species (Table 3.2 and Appendix 2, Table A.2.4). The number of native and exotic graminoids were similar; but there were more native woody species and fewer native forbs than exotics (Table 3.2 and Appendix 2, Table A.2.4). Among dispersal modes, most exotic species were unspecialized, and the number of exotic species that were animal-dispersed, wind-dispersed or short-distance-dispersed was similar (Table 3.2 and Appendix 2, Table A.2.4). The number of native species that were animaldispersed was similar to that of exotics. Slightly more native species were wind-dispersed but fewer were either unspecialized or short-distance-dispersed (Table 3.2 and Appendix 2, Table A.2.4). Among growth forms, exotic forbs and woody species had heavier seeds than their native counterparts, but the seed masses of exotic and native graminoids were not significantly different (Table 3.2 and Appendix 2, Table A.2.4). The seed mass of exotic and native species did not differ among dispersal modes (Table 3.2). For both species richness and seed mass analyses, some species were omitted due to lack of data (Appendix 2, Table A.2.6). 


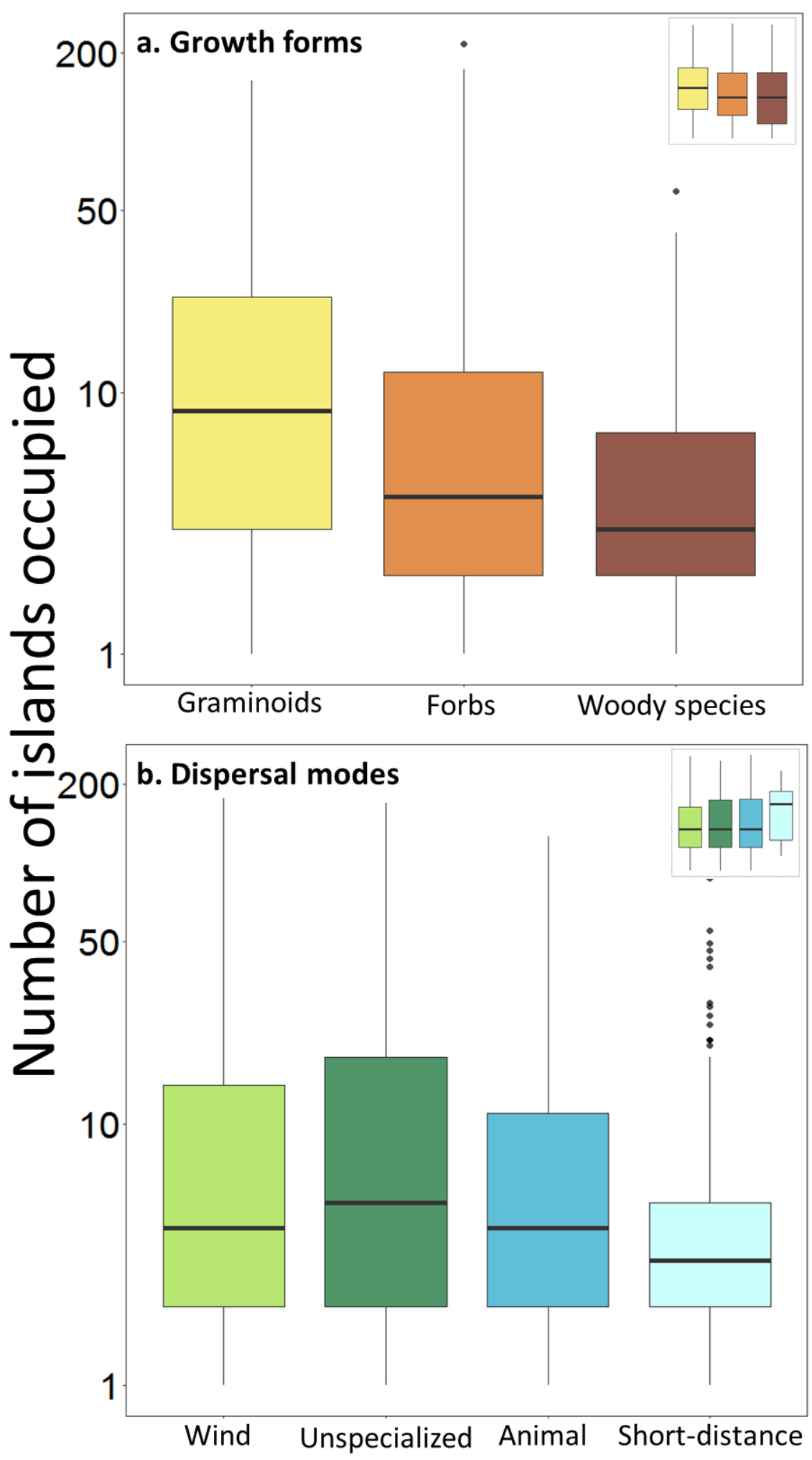

Figure 3.1 - Number of islands occupied by exotic species with different (a) growth forms and (b) dispersal modes. On the $y$-axis is the number of islands occupied by each species, log-transformed, while on the $\mathrm{x}$-axis are trait categories. In the box on the top right is a comparison with native species. 


\section{Island occupancy}

Exotic graminoid species occupied more islands than exotic forbs, which, in turn, occupied more islands than exotic woody species (Figure 3.1a and Appendix 2, Table A.2.7). Exotic graminoids also occupied a similar number of islands as native graminoids. Conversely, exotic forbs and woody species occurred on fewer islands than native forbs and graminoids. Among dispersal modes, exotic wind-dispersed and unspecialized species occupied a similar number of islands, more than shortdistance-dispersed species but comparable to animal-dispersed (Figure 3.1b and Appendix 2, Table A.2.7). However, exotic animal-dispersed species also occupied a similar number of islands as exotic short-distance-dispersed species. Exotic wind-dispersed species occupied a similar number of islands to native wind-dispersed species, whereas the other dispersal modes of exotic species occurred on fewer islands than their native counterparts.

\section{Patterns in species richness}

Exotic species richness increased with island area across all growth forms, but with different slopes (Figures 3.2a) (for more details see also Appendix 2, Table A.2.8 and Table A.2.12). Moreover, the richness of all exotic growth forms similarly declined with isolation (woody species excepted) and with exposure to ocean-borne disturbance (Figure 3.2b and 2c). Exotic forbs and woody plant richness declined with distance from the nearest urban area, but exotic graminoid richness showed no significant relationship (Figure 3.2d). Exotic graminoid richness only differed from natives in relationship to exposure (natives were unrelated to it; Figure 3.2c) (for more details see Appendix 2, Table A.2.8, Table A.2.12 and Figure A.2.8). In contrast, the richness of exotic forbs responded differently from natives to all island characteristics, increasing with area and declining with exposure more steeply than natives, and natives were unrelated to isolation and distance from nearest urban area (Figures 3.2). The slope of the positive relationship between exotic woody species richness and 
island area was less steep than for native woody species, and natives were also unrelated to distance from the nearest urban area (Figures 3.2a, 3.2d).

Regardless of their dispersal mode, the richness of all exotic species increased with area and declined with isolation similarly, even though animal-dispersed species were unrelated to island isolation (Figures 3.3a and 3.3b) (for more details see also Appendix 2, Table A.2.9 and Table A.2.12). Exotic species richness always declined with exposure but with different slopes (Figure 3.3c). The richness of short-distance-dispersed and animal-dispersed exotic species declined significantly with distance from the nearest urban area, but the richness of wind-dispersed and unspecialized exotic species showed no significant relationships (Figure 3.3d). Exotic wind-dispersed species differed from natives as they increased faster with island area (Figures 3.3a) (for more details see Appendix 2, Table A.2.9, Table A.2.12 and Figure A.2.9). Similarly, exotic unspecialized species differed from natives only in their relationship with exposure (natives were unrelated to it; Figures 3.3c). Compared to natives, exotic animal-dispersed declined more steeply with exposure and distance from the nearest urban area, while short-distance-dispersed exotics declined more steeply with isolation and distance from the nearest urban area (Figures 3.3b, 3.3c, 3.3d).

\section{Patterns in seed mass}

The mean seed mass of all exotic species across all growth forms increased with area and declined with exposure and distance from the nearest urban area, albeit with different slopes, but none was significantly related to island isolation (Figures $3.4 a, 3.4 b, 3.4 c$ and $3.4 d$ ) (for more details see also Appendix 2, Table A.2.10 and Table A.2.12). In conservation areas, the mean seed mass of graminoids was lower than on other islands, that of woody species higher, while the mean seed mass of forbs was not significantly different (Figure 3.4e). Exotic graminoids' mean seed mass declined more steeply with island exposure than that of natives (Figures 3.4c) (for more details see Appendix 2, Table A.2.10, Table A.2.12 and Figure A.2.10). The mean seed mass of exotic forbs 
increased with area and declined with exposure and distance from the nearest urban area more steeply than that of natives (Figures 3.4a, 3.4c, 3.4d), and the mean seed mass of exotic woody increased with area and declined with distance from the nearest urban area more steeply than that of natives (Figures 3.4a, 3.4d).

The mean seed mass of all exotic species across all dispersal modes increased with island area, although with different slopes (Figures 3.5a) (for more details see also Appendix 2, Table A.2.11 and Table A.2.12). Only the mean seed mass of exotic wind-dispersed and short-distancedispersed species declined with island isolation, however differences among groups were not significant (Figure 3.5b). Animal-dispersed and unspecialized alone declined with exposure, while the mean exotic seed mass also declined significantly with distance from the nearest urban area for all but wind-dispersed species (Figure 3.5c, 3.5d). Wind-dispersed and short-distance-dispersed had smaller seed on conserved areas, those of animal-dispersed were larger, while there was no significant difference was detected in the mean mass of unspecialized species on insular conservation areas (Figure 3.5e). Differently from exotics, native wind-dispersed species increased with area and declined with distance from the nearest urban area more steeply, exotics were unrelated to the latter (Figures 3.5a, 3.5d) (for more details see also Appendix 2, Table A.2.11, Table A.2.12 and Figure A.2.11). Exotic and native wind dispersed displayed a different relationship with exposure, although neither trend was significant (Figures 3.5c). Similarly, exotic unspecialized species differed from native only in their relationship with area and exposure, as natives were unrelated to them (Figures 3.5a, 3.5c). Exotic animal-dispersed declined more steeply with exposure and distance from the nearest urban area and had greater seed mass on conservation areas, while natives did not (Figures 3.5c, 3.5d, 3.5e). In contrast to exotics, short-distance-dispersed natives did not decline to isolation and distance from the nearest urban area, and they increased more steeply with island area (Figures 3.5a, 3.5b, 3.5d). 


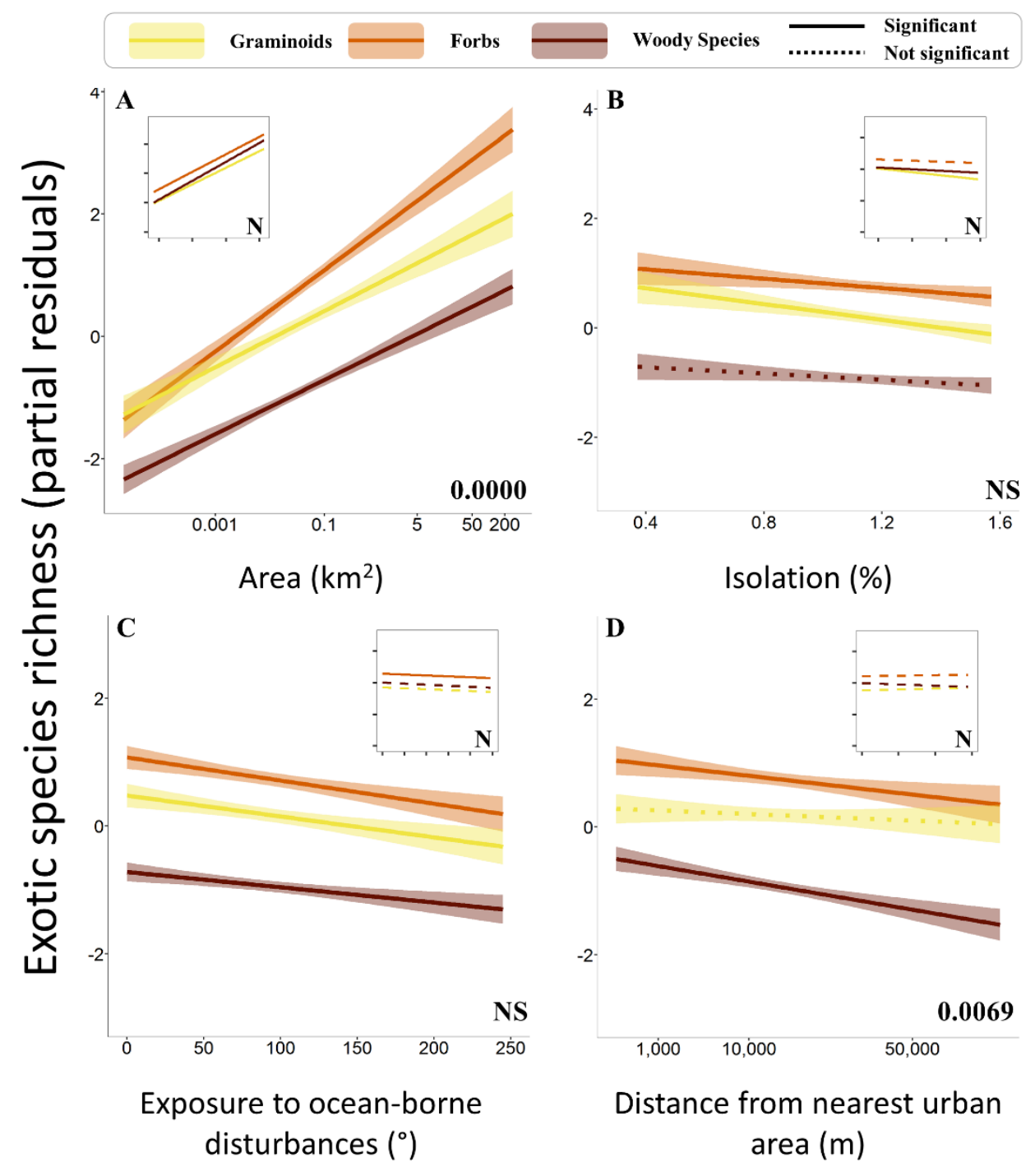

Figure 3.2 - Linear models illustrating relationships between exotic species richness with different growth forms and island characteristics on $264 \mathrm{New}$ Zealand offshore islands. On the $y$-axis is species richness (partial residuals), while on the $x$-axis are island (A) area (log scale), (B) isolation, (C) exposure to ocean born disturbances, and (D) distance from the nearest urban area. Trendline (model predicted slope) and relative confidence interval (95\%) colours represent graminoid (yellow), forb (vermilion) and woody species (brown). Trendline types indicate significant (solid, $\mathrm{P}<0.05$ ) or non-significant (dotted) relationships. $\mathrm{P}$-values for significant $(\mathrm{P}<0.05)$ or not significant (NS) differences among trends are at the bottom right. To conform to assumptions, species richness was $\log (+1)$ transformed, area log-transformed, isolation arcsine-transformed and distance from the nearest urban area squared-transformed. In the box on the top right is a comparison with native species (N). 


\section{5- Discussion}

\section{Island occupancy}

Functional traits predicted occurrence patterns in exotic plant species across northern New Zealand islands. Exotic herbs (i.e. graminoid and forb) occupied a larger number of these islands than exotic woody species. Exotic herbs generally have a relatively short lifespan, high seed production and better dispersal capabilities (Ellenberg and Müller-Dombois 1967, Qiaoling et al. 2005, PérezHarguindeguy et al. 2013, Díaz et al. 2016, Negoita et al. 2016, Schrader et al. 2020). However, many islands in my study system were farmed and perhaps a higher proportion of grasses and perhaps some forbs were directly introduced by humans. Among the exotic herbaceous species, graminoids invaded more islands than forbs, even though there are more species of the latter (Table 3.1). Perhaps many forbs were introduced for gardens (see Sullivan et al. 2005), suggesting a different invasion strategy (e.g. vegetative expansion) (Hodkinson and Thompson 1997). My results contrast with Mediterranean islands where growth forms of exotic species were unrelated to their occupancy (Lloret et al. 2005), which suggests that observed patterns may differ according to the island system investigated. For example, components of some isolated island floras can be under-represented or even lacking compared with continental floras (Carlquist 1974). For instance, annuals are poorly represented in the New Zealand native flora, but well represented among exotics (Brandt et al. 2021). Thus, islands offshore New Zealand might be especially prone to invasion by exotic annuals.

Wind and animal dispersal modes are generally associated with high dispersal potential (Carlquist 1974, Lloret et al. 2005, Tamme et al. 2014). Correspondingly, native and exotic species with wind or animal dispersal had high occupancy rates across islands in my study. Instead, species with unspecialized or short-distance-dispersed diaspores often have low island occupancy rates (Negoita et al. 2016, Arjona et al. 2018). However, species with multiple dispersal modes occurred on a large number of islands in my study system. Estimating dispersal potential from dispersal 
modes is challenging. First, dispersal distances can vary strongly within dispersal modes (Thomson et al. 2011, Tamme et al. 2014). Second, vectors are typically context-dependent. For instance, many birds that disperse seeds within fleshy fruits and berries typically avoid islands that lack perching trees (Ferguson and Drake 1999, Negoita et al. 2016). Finally, dispersal modes do not account for non-standard means of dispersal, namely vectors that are different from what a diaspore's morphology suggests (Higgins et al. 2003, Nogales et al. 2012, Negoita et al. 2016, Arjona et al. 2018). Many non-hydrochorous species might successfully benefit from water-mediated pathways (Kowarik and Säumel 2008), especially in island systems.

Patterns in species richness

Positive species-area relationships are among the most common patterns in nature (Arrhenius 1921, Lomolino 2000a, Tjørve and Tjørve 2017), and have been identified previously both for exotic species (Baiser and Li 2018, Guo et al. 2021) and among growth forms (Schrader et al. 2020). I found consistent positive species-area relationships for exotic species with different dispersal modes and growth forms across northern New Zealand islands. Dispersal probabilities to islands typically decrease with island isolation, resulting in a decline in species richness (MacArthur and Wilson 1967, Weigelt and Kreft 2013). Since the maximum dispersal distance of a species is related to both growth forms and dispersal syndromes (Tamme et al. 2014), this could be expected to lead to differences in representation within growth forms and dispersal syndromes in relation to island isolation. However, in my study, negative richness-isolation relationships in exotic species did not differ significantly among growth forms or among dispersal syndromes. 


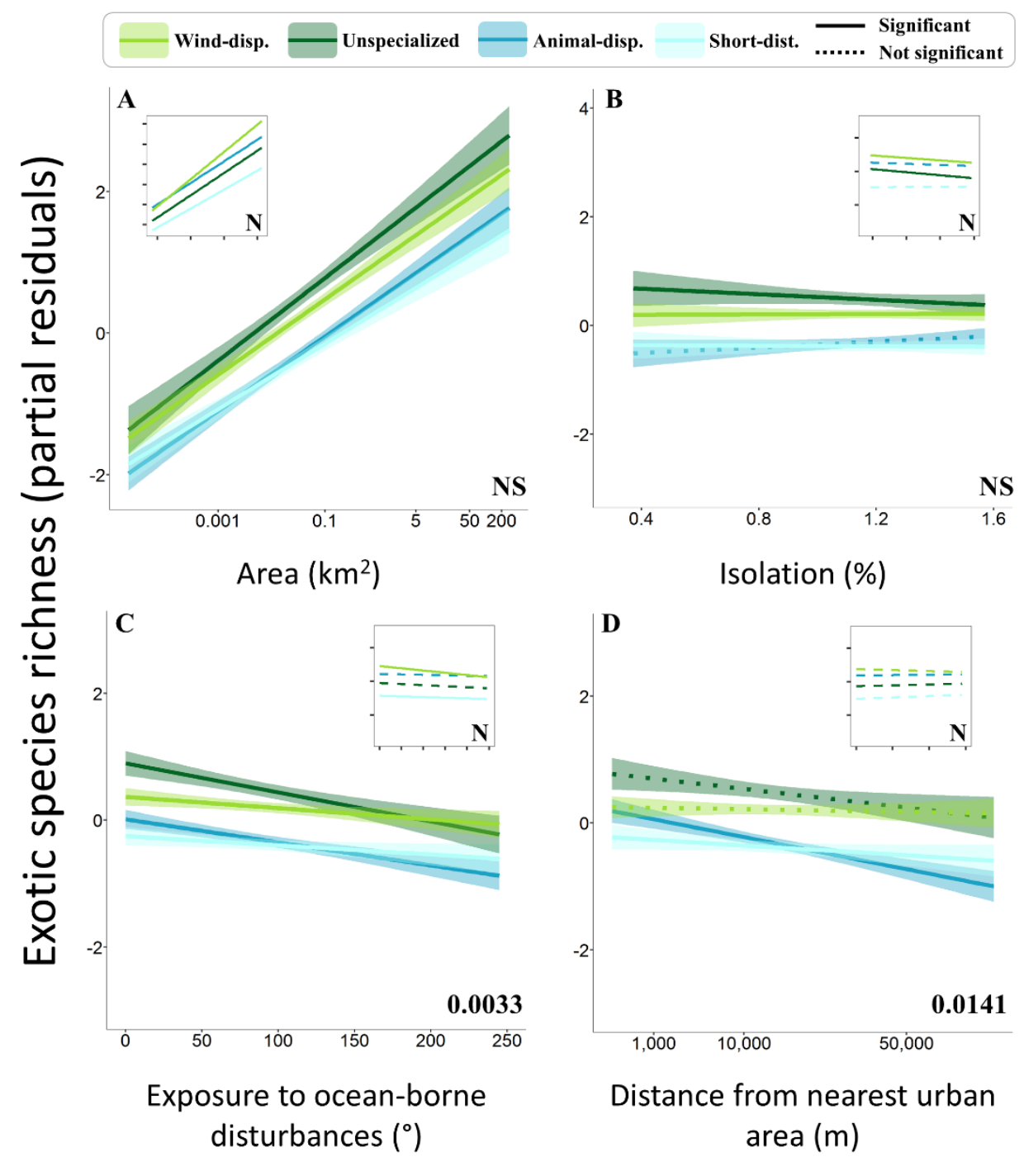

Figure 3.3 - Linear models illustrating relationships between exotic species richness with different dispersal modes and island characteristics on 264 New Zealand offshore islands. On the y-axis is species richness (partial residuals), while on the $\mathrm{x}$-axis are island (A) area (log scale), (B) isolation, (C) exposure to ocean born disturbances, and (D) distance from the nearest urban area. Trendline (model predicted slope) and relative confidence interval (95\%) colours represent animal-dispersed (dark blue), unspecialized (dark green), shortdistance (light blue), and wind-dispersed species (light green). Trendline types indicate significant (solid, $\mathrm{P}<0.05)$ or non-significant (dotted) relationships. $\mathrm{P}$-values for significant $(\mathrm{P}<0.05)$ or not significant (NS) differences among trends are at the bottom right. To conform to assumptions, species richness was log $(+1)$ transformed, area log-transformed, isolation arcsine-transformed and distance from the nearest urban area squared-transformed. In the box on the top right is a comparison with native species (N). 
Similarly, exotic species declined with exposure independently of trait categories. Exposed coastal habitats are particularly susceptible to storms and waves originated in the ocean, generating depauperate floras that are more subject to extinctions (Abbott 1977, Morrison and Spiller 2008, Burns and Neufeld 2009). Moreover, contrasting atmospheric conditions can limit wind currents and the movement patterns of dispersal vectors (Whitehead and Jones 1969, Tackenberg 2003).

The dispersal of exotic species is often determined by human activities. Surprisingly though, the richness of graminoid, wind-dispersed and unspecialized exotic species was unrelated to distance from the nearest urban area. After introduction, plants can utilize different anthropogenic pathways for dispersal, which often depend upon traits (Hodkinson and Thompson 1997). My metric might only encapsulate dispersal pathways associated with human habitation, such as escaping from gardens (Sullivan et al. 2005). Instead, graminoid, wind-dispersed and unspecialized species might exploit pathways associated with agricultural practice (e.g. disturbance of topsoil and vehicle movement). These trait categories though also exhibited high rates of island occupancy and thus might be at a later stage of invasion. As the invasion process progresses, exotics may be increasingly independent of humans for their dispersal (González-Moreno et al. 2017, Coutts et al. 2018). In addition, current estimates of human disturbance, such as current inhabitation, are likely to be confounded with island area, since larger islands are preferentially inhabited (mean area inhabited islands $=15 \mathrm{~km} 2, \overline{\mathrm{x}}$ uninhabited $\left.=0.12 \mathrm{~km}^{2}, \chi^{2}=14.64, \mathrm{p}=0.0001\right)$. Past disturbances, such as fires, may be underestimated and require better resolution in my study system, hence I believe better proxies for estimating human disturbance are needed to predict plant invasions more accurately (Mologni et al. 2021).

\section{Patterns in seed mass}

Regardless of growth form and dispersal mode, mean seed mass was higher on larger islands. Heavy, large seeds tend to result in larger plants (Butler et al. 2007), which also occupy a 
larger amount of space. Thus, some islands may be too small to match the minimum area requirements of large plant species (Turner and Tjørve 2005). In addition, large seeds require more maternal resources, often leading to a reduction of total seed number (Moles and Westoby 2004, 2006, Hodgson et al. 2020). Fewer propagules reduce the chances of intercepting islands during dispersal (Lonsdale 1999), especially when islands are small in area (Lomolino 1990).

Lighter seeds are often associated with long dispersal distances (Muller-Landau et al. 2008, Auffret et al. 2017). However, most exotic species did not display a negative relationship between seed mass and isolation. Having heavier seeds though does not necessarily diminish dispersal potential (Thomson et al. 2011, Tamme et al. 2014), suggesting other factors, such as vectors' behaviour and human pathways, might be important (Hodkinson and Thompson 1997, Negoita et al. 2016, Sinclair et al. 2020). Most exotic species showed negative relationships between seed mass and exposure. Seed mass often correlates with leaf area (Butler et al. 2007), and large leaves are more susceptible to mechanical damage and physiological stress caused by wind and waves (Burns and Neufeld 2009, Anten et al. 2010). Only the mean seed mass of wind-dispersed and shortdistance-dispersed species though did not decline with exposure. Strong, contrasting wind currents on exposed islands might favour some dispersal syndromes, regardless of their seed mass (Whittaker 1995).

The mean seed mass of exotic species increased with levels of human occupation, except for wind-dispersed species. One explanation for this relationship is that species that produce heavier seeds, also produce larger fruits (Benavides et al. 2021), which are sought preferentially in agriculture and horticulture. Garden escapes also increase with human habitation (Sullivan et al. 2005), and popular garden species typically have larger seeds than other exotics (Hodkinson and Thompson 1997). In contrast, wind-dispersed species might contain a high proportion of pasture species, chosen for their biomass productivity rather than for their seed production. However, wind- 


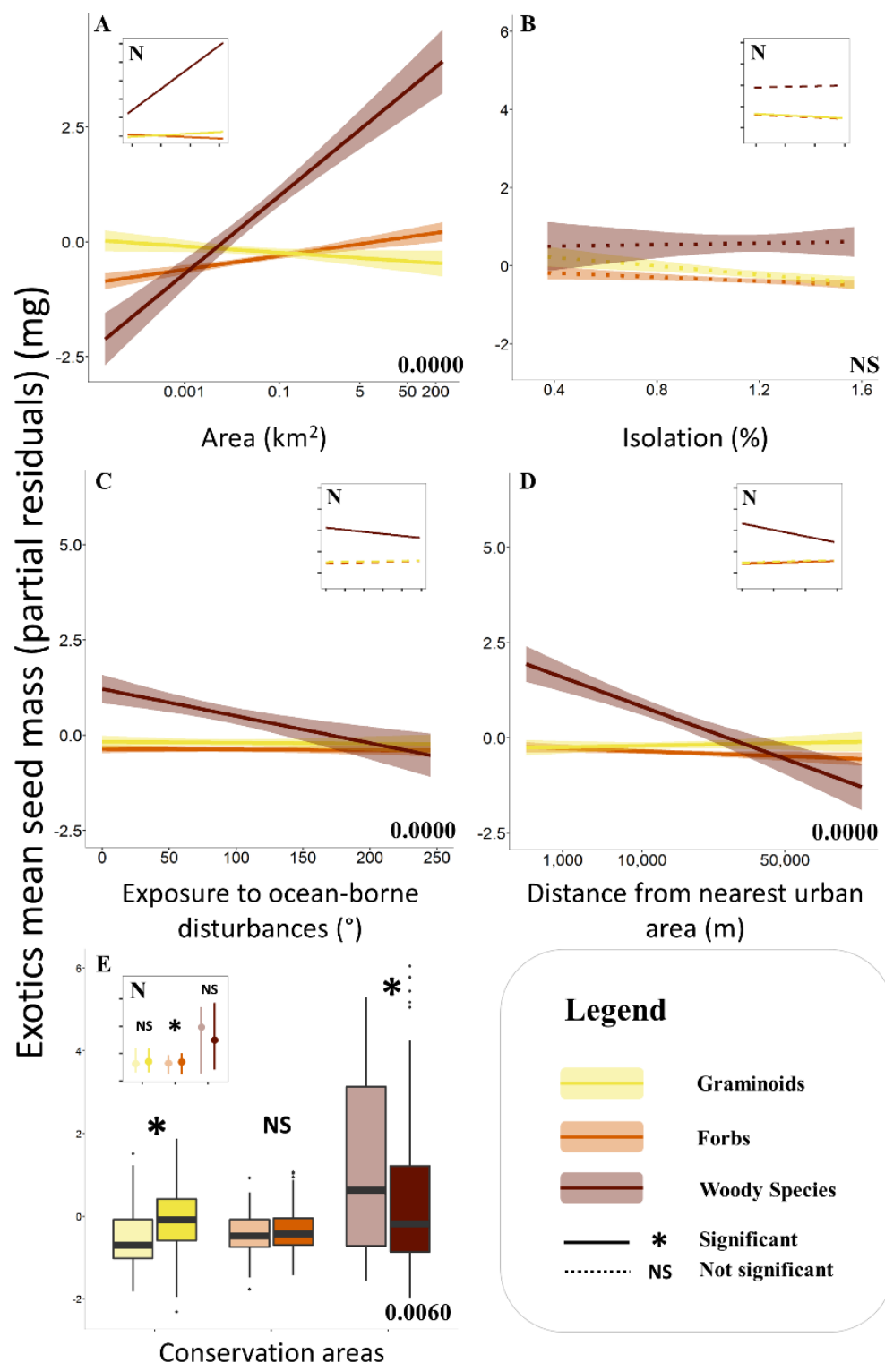

Figure 3.4 - Linear models illustrating relationships between the average seed mass of exotic and native species with different growth forms and island characteristics on 264 New Zealand offshore islands. On the $y$-axis is average seed mass (partial residuals), whereas on the $x$-axis are island (A) area (log scale), (B) isolation, (C) exposure to ocean born disturbances, (D) distance from the nearest urban area and (E) conservation areas. Colours represent graminoid (yellow), forb (vermilion) and woody species (brown). In plots $A$ to $D$, trendline (model predicted slope) and relative confidence interval (95\%) are represented. In plot E, light hues indicated publicly managed conservation areas, dark hues other islands. Significant relationships $(P<0.05)$ are illustrated by solid trendline $(A-D)$ and asterisks (E). P-values for significant $(\mathrm{P}<0.05)$ or not significant (NS) differences among trends are at the bottom right. To conform to assumptions, species richness was log $(+1)$ transformed, area logtransformed, isolation arcsine-transformed and distance from the nearest urban area squaredtransformed. In the box on the top right is a comparison with native species (N). 
dispersed pasture species might also contain many Asteraceae species, which are generally smallseeded: future work should account for phylogeny.

Mean seed mass displayed contrasting trends with conservation areas depending on trait categories. On islands that are conservation areas, the lower seed mass of graminoids, wind- and short-distance-dispersed species, and greater seed mass of woody and animal-dispersed species may be a by-product of biosecurity measures and control measures against exotic species. For instance, small-seeded, lower-mass species might be less effectively detected by preventive measures. It is unclear though why the seed mass of other trait categories displayed an opposite trend or none at all. Altering biotic components of islands might have complex, multi-level indirect effects, to date poorly understood (Fukami et al. 2006, Bergstrom et al. 2009). Finally, I inferred seed mass from seed length for many species, and despite a strong allometric link between the two, this might be a potential source of error.

\section{Differences with native species}

Exotic and native species often show different distributional patterns on islands (Moser et al. 2018, Rojas-Sandoval et al. 2020, Guo et al. 2021, Mologni et al. 2021). Here, discrepancies between the species richness of exotic and native species hinged on functional traits. Exotic species with traits associated with high invasion rates (e.g. wind-dispersal and the graminoid growth form) were also more similar to native species both in occupancy and in their relationships with island characteristics. This suggests that the distribution of successful invaders (i.e. those with high occupancy rates) is shaped by similar processes to natives. Native patterns in seed mass differed from exotics with regards to area; however, with contrasting trends. Exotics generally declined more strongly with exposure, perhaps because native species are better adapted to rugged, coastal environments (Cockayne 1958, Burns 2016b). Surprisingly, some native species also declined in seed 
mass with human habitation, although often less strongly than exotics, suggesting that natives might utilize similar dispersal pathways to exotics (Valery et al. 2009).

Future directions

My study was conducted at the regional scale, in a study system that spans $4^{\circ}$ of latitude and $7^{\circ}$ of longitude, and may not reflect local-scale and global-scale biogeographic dynamics. Future work may benefit from comparing invasion success at different scales (Lloret et al. 2005). Moreover, my results pinpoint plant traits associated with high invasion rates, which might not necessarily match those favouring the initial establishment in a new biogeographical region (Sinclair et al. 2020). In addition, disentangling whether growth form or dispersal mode was a greater influence was especially problematic in the case of exotic animal-dispersed species, as $50 \%$ of them are woody, and $60 \%$ of exotic woody species are animal-dispersed (Table S3.3). The importance of interactions among functional plant traits in determining the distribution of exotic species remains poorly understood and would be a fruitful avenue of future research (Negoita et al. 2016).

Exotic plant species are often favoured by soil enrichment (Huenneke et al. 1990, King and Buckney 2002, Blumenthal et al. 2017), especially when short-lived (Prober and Wiehl 2012). In my study system, both geological and biological factors can contribute to soil fertility. For instance, volcanic islands have generally richer soils, which favour island invasions (Pretto et al. 2012). Similarly, seabird guano augments soil nutrients across many islands in my study system, both of volcanic and sedimentary origin, and seabirds also create high disturbance levels through burrowing (Grant-Hoffman et al. 2010), which likely favours invasion by some exotic species (Hobbs and Huenneke 1992). Integrating geological and other biotic elements might give further insights into how traits influence plant invasions on islands. 


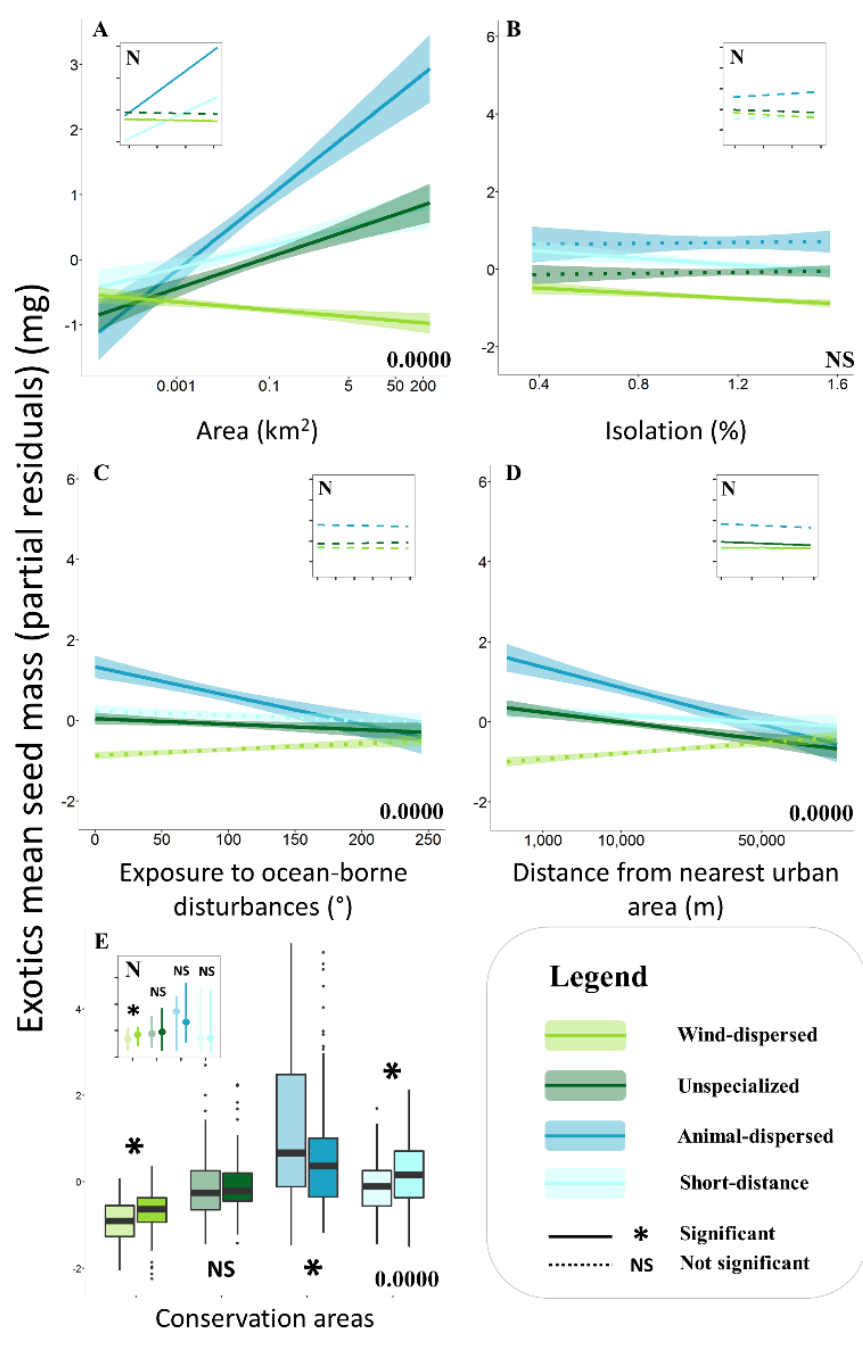

Figure 3.5 - Linear models illustrating relationships between the average seed mass of exotic and native species with different dispersal modes and island characteristics on 264 New Zealand offshore islands. On the $y$-axis is average seed mass (partial residuals), whereas on the $x$-axis are island (A) area (log scale), (B) isolation, (C) exposure to ocean born disturbances, (D) distance from the nearest urban area and (E) conservation areas. Colours represent animal-dispersed (dark blue), unspecialized (dark green), short-distance (light blue), and wind-dispersed species (light green). In plots A to D, trendline (model predicted slope) and relative confidence interval (95\%) are represented. In plot E, light hues indicated publicly managed conservation areas, dark hues other islands. Significant relationships $(P<0.05)$ are illustrated by solid trendlines $(A-D)$ and asterisks $(E)$. P-values for significant $(\mathrm{P}<0.05)$ or not significant $(\mathrm{NS})$ differences among trends are at the bottom right. To conform to assumptions, species richness was log $(+1)$ transformed, area log-transformed, isolation arcsine-transformed and distance from the nearest urban area squared-transformed. In the box on the top right is a comparison with native species $(\mathrm{N})$. 


\section{Conclusions}

Plant functional traits (growth forms, dispersal modes, and seed mass) were predictors of exotic species that were successful invaders (i.e. displaying high island occupancy rates) of northern New Zealand islands (graminoid, wind-dispersed and unspecialized species) and these, in turn, were related to island characteristics. Differences in species richness and seed mass among traits were mostly associated with human-related variables (i.e. distance from the nearest urban area and conservation areas), with successful invaders often unrelated to them. Moreover, exotics with high rates of island occupancy showed distributional patterns similar to natives, suggesting comparable processes regulate both sets of species. Management of exotics on islands should focus on graminoid, wind-dispersed and species with unspecialized diaspores. Future work should concentrate on unravelling the complexity of indirect effects of island management on plant seed mass. Overall, my results illustrate that integrating trait-based approaches in the island biogeography framework (e.g. Aikio et al. 2020; König et al. 2020; Ottaviani et al. 2020) can be a useful tool in understanding and predicting plant invasions. 


\section{Chapter 4. Different levels of disturbance influence the distributional patterns of native but not exotic species on New Zealand small islands}




\section{1 - Abstract}

Disturbances of oceanic origin can severely affect plant communities on islands, but it is unclear whether they promote or deter biological invasions. Here, I explored 97 small islands subject to different levels of ocean-borne disturbances (i.e. inside and outside Wellington Harbour, New Zealand). First, I tested how relationships between the richness of native and exotic species and island characteristics (e.g. area, isolation, height, elevation, slope, nearest dwelling) changed depending on island location. Next, I assessed compositional differences on inner and outer islands for both native and exotic species, and how they vary with geographic distance (i.e. distance-decay). Results show that native species richness was differently related to slope (i.e. the steepness of an island) depending on island location, but not to other island characteristics. Natives declined in number with slope only on outer, more disturbed islands. Moreover, natives on outer islands were floristically more homogenous, and compositional differences changed less strongly with distance than on inner islands. In stark contrast, exotics exhibited no differences in their distributional patterns depending on island location. Different levels of ocean-borne disturbances might explain distinct distributional patterns in native species. Conversely, results for exotic species might reflect a lack of coastal specialists in the species pool. Perhaps time-lags in the invasion process and nonequilibrium dynamics play a role as well. Conservation bodies should similarly manage islands sustaining different levels of ocean-borne disturbances. 


\section{2 - Introduction}

Disturbances can have devastating effects on insular floras (Whittaker 1995, 2000, Morrison and Spiller 2008, Burns and Neufeld 2009). Perturbations can remove plant biomass (Grime and Pierce 2012), increase extinction rates (Whittaker 1995), and change the compositional structure of insular communities (Morrison 2014). However, whether disturbance promotes island invasion is still poorly understood.

The notion that disturbances facilitate biological invasions is debated (Hobbs and Huenneke 1992, Moles et al. 2012, Jauni et al. 2015). Earlier work shows that context, type of disturbance and its frequency and severity are all crucial factors (Moles et al. 2012). On islands, one of the most pervasive types of disturbance are those of oceanic origin, such as waves, storms and wind shear (Whittaker 1995). Ocean-borne disturbances can severely influence insular floras (Whittaker 2000, Morrison and Spiller 2008). In protected locations, disturbance events are generally less intense and frequent, and conditions more lenient for vascular plants (Abbott 1977, Morrison 2014). Results to date though are contrasting whether exotic species are facilitated (Bellingham et al. 2005, Burns 2016b) or deterred (Mologni et al. 2021, see chapter 2) by ocean-borne disturbances.

Species richness on islands often decline with ocean-borne disturbances (Abbott 1977, Mologni et al. 2021). Waves and winds can reduce the habitable surface area of an island (Neufeld et al. 2017). Thus, given two islands of similar size and height, those in more disturbed locations will have fewer species (Abbott 1977, Neufeld et al. 2017, Mologni et al. 2021). Additionally, species on smaller islands are more prone to extinction, a process enhanced by perturbation (Whittaker 1995). After each extinction event, species need to recolonize (MacArthur and Wilson 1967). Then, populations in disturbed locations might more strongly depend on immigration from nearby communities. In addition, other factors might interplay with perturbations. Topography can influence water flow velocity, run-off and accumulation (Yu et al. 2015), regulating the amount and 
permanence of seawater on islands. Human activities might compound natural disturbances, further reducing species richness on islands.

Disturbances of oceanic origin can alter the compositional structure of the insular biota (Whitehead and Jones 1969, Morrison 2014). On the one hand, they open up space for colonization by new species (Grime and Pierce 2012). In parallel, they are likely to select specialists well adapted to disturbed islands (Whitehead and Jones 1969). By favouring species colonization, islands in more disturbed locations will have a more heterogeneous flora. However, if disturbances select for specialist species, disturbances will generate a more homogeneous flora. Either way, compositional differences increase with distance (i.e. distance-decay, Soininen et al. 2007). Therefore, a heterogeneous flora will show a stronger spatial turnover than a homogeneous flora.

In this study, I explored the insular distribution of native and exotic vascular plant species subject to different levels of ocean-borne disturbances. I selected 97 intertidal, small islands inside (less disturbed) and outside (more disturbed) Wellington Harbour, New Zealand. First, I used multiple linear regression to test whether the richness of native and exotic species have a different relationship with island characteristics depending on island location. Second, I calculated Jaccard similarity indexes to test whether floristic composition differs on inner and outer islands for the two sets of species. Third, I used generalized linear models to investigate distance-decay relationships inside and outside the harbour and how they differed for native and exotic species.

\section{3 - Methods}

\section{Study system}

The Wellington coastline $\left(41^{\circ} 16^{\prime} 47^{\prime \prime} \mathrm{S}, 174^{\circ} 49^{\prime} 56^{\prime \prime} \mathrm{E}\right)$ is surrounded by numerous small islands, situated in close proximity to the coast. Most of them emerged recently, during an intense earthquake that uplifted the coastline by approximately 6 meters in 1855 (Burns 2016b). The study 
system is homogeneous in its geological composition (i.e. greywacke) (Burns 2015) and contains several seabird colonies. The region is struck by numerous storms, mostly originating in southern latitudes (Pickrill and Mitchell 1979).
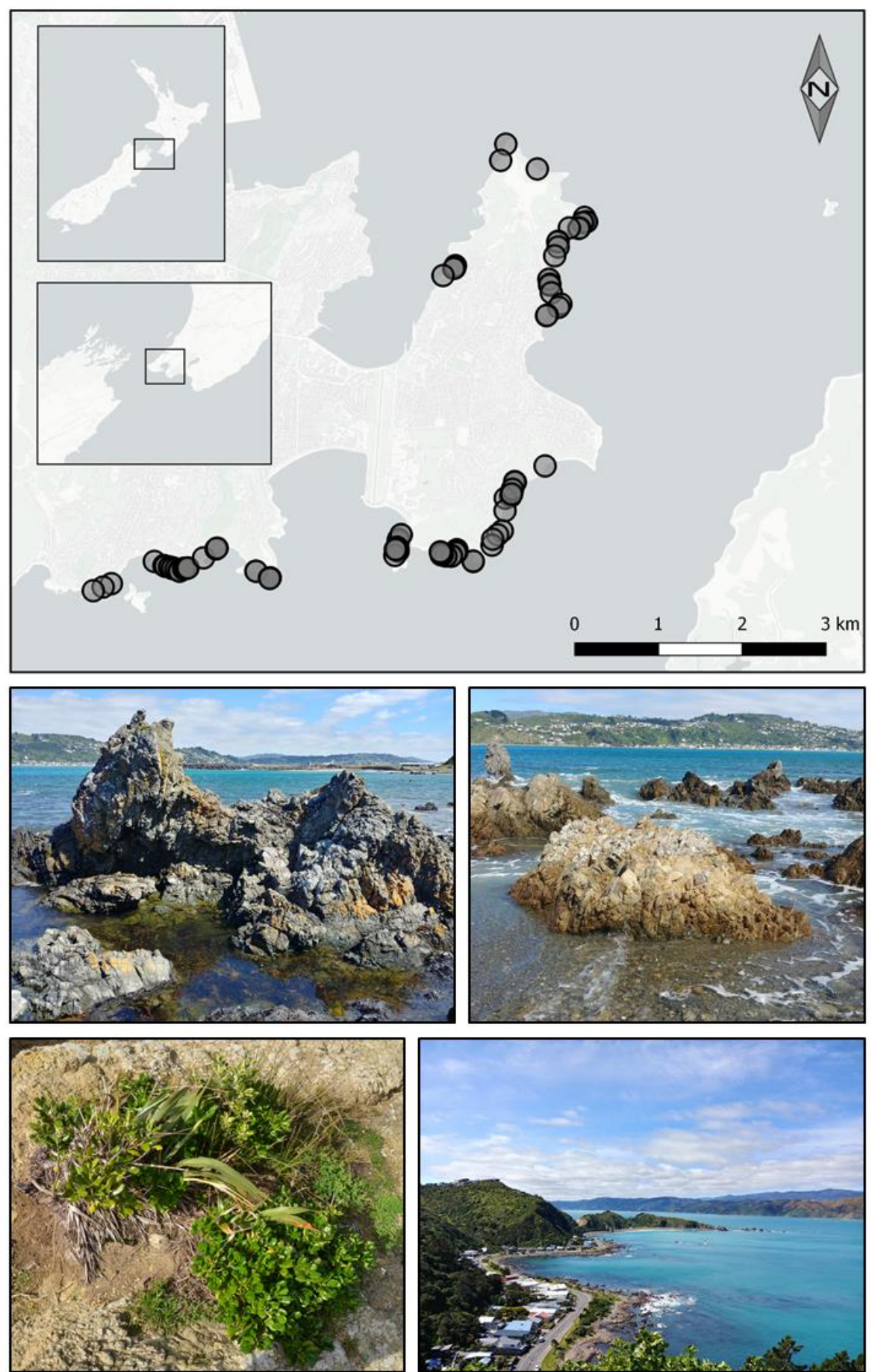

Figure 4.1 - Map of the study area (top), two of the surveyed islands (centre), a typical plant community (bottom left) and the landscape (bottom right) of the study system. 
In this study system, I surveyed 97 small, easily accessible intertidal islands (Appendix 2, Table A.2.14). They are mainly rocky outcrops, with small amounts of soil occasionally accumulating in rock cracks. Vegetation on rocky outcrops along the Wellington coast is dominated by a few low growing, stress-tolerant species, with leathery or succulent leaves (Dawson 1988). These islands are generally close to human settlement.

\section{Data collection}

I thoroughly surveyed each island and quantified the number of vascular plant species for a total of 38 (Appendix 2, Table A.2.13 \& S4.3). For each species, I assessed its origin (i.e. native or exotic). Species origin and nomenclature were compiled following the New Zealand Plant Conservation Network (New Zealand Plant Conservation Network 2021, accessed in January 2021).

Island characteristics were manually quantified in the field and by using geospatial software (ESRI 2011, QGIS Development Team 2018). I estimated island area $\left(\mathrm{m}^{2}\right)$ by multiplying islands' widths and lengths measured at the widest and longest point. Isolation was quantified as the shorter distance separating an island from the nearest plant community $(\mathrm{m})$. I calculated height as the vertical distance between the top of an island and the lower limit of the intertidal zone, delimited by the lowest lichen boundary. I also retrieved a digital elevation model (Geographx 2016) and extracted elevation from the mean sea level $(m)$ and, to account for topographic complexity, slope (i.e. the steepness of an island, ${ }^{\circ}$ ) and the rugosity index. Rugosity is a measure of landscape ruggedness and it is calculated as the ratio between surface and planar area (Jenness 2013), as in the following equation:

$$
R U=\frac{\text { Area }_{s}}{\text { Area }_{p}}=\frac{\sum_{i=\text { cell }}^{N}\left(c^{2} \cos \left(S\left(\frac{\pi}{180}\right)\right)\right)}{c^{2} * n}
$$


where $\mathrm{Area}_{s}$ and $\mathrm{Area}_{p}$ are, respectively, surface and planar area, $c$ is the cell size of a digital elevation model (DEM), $S$ is the slope of each cell and $n$ is the number of cells in the DEM. Lastly, I calculated the distance from the nearest dwelling (hereafter nearest dwelling) to account for human activities.

Compositional differences between pairs of islands were calculated using a Jaccard similarity index. I computed the index in R, using the Vegan package (Oksanen et al. 2020). Then, I measured the distance between each pair of islands using the proximity tool in ArcGIS 10 (ESRI 2011).

\section{Statistical analyses}

To test whether species richness responds differently to island characteristics inside and outside the harbour, I used a linear model with species richness as the independent variable and island characteristics (area, isolation, height, elevation, slope and nearest dwelling) as predictors. Location (inside/outside the harbour) was included as an interaction term. Species richness (+1), area, isolation and height were log-transformed, slope and nearest dwelling were square roottransformed, while elevation was not transformed. This analysis was run for native and exotic species richness separately.

Before inclusion in a model, I examined each independent variable using a Pearson correlation coefficient and a variance inflation factor (VIFs). I set as a cut-off 0.8 and 3 , respectively (Berry and Feldman 1985, Zuur et al. 2010). Rugosity and slope exceeded both thresholds (Appendix 2, Table A.2.16 and Figure A.2.12). As they both describe topographic complexity, I retained slope as the simplest measurement.

To test if islands inside and outside the harbour show compositional differences, I used a Jaccard similarity index. I then contrasted Jaccard indexes between islands inside and outside the 
harbour. Since Jaccard indexes were slightly right-skewed, I used both a linear and a quasipoisson model. Analyses were run separately for native and exotic species. Islands lacking in either native or exotic species were excluded (natives $=1$, exotics $=52$ ).

To test whether distance-decay relationships differ between inner and outer islands, I regressed the Jaccard similarity index between two islands with the distance separating them. I used both a linear and quasipoisson model and variables were not transformed. The same approach was employed for native and exotic species separately.

\section{$4.4-$ Results}

Native plant species richness across the islands displayed similar relationships with area, isolation, height, elevation, and nearest dwelling regardless of island location (Table 4.1). However, the number of native species declined with increased slope on outer islands, but not on inner islands (Table 4.1 \& Appendix 2, Table A.2.17 \& Figure A.2.13). The richness of exotic species exhibited similar relationships with all island characteristics irrespective of island location (Table 4.1 \& Appendix 2, Table A.2.17 \& Figure A.2.13).

Jaccard similarity indexes were significantly lower on outer islands for native species, indicating they vary less strongly in composition than inner islands (Figure 4.2a). On the other hand, compositional differences in exotic species did not differ between the inside or outside of the harbour (Figure 4.2b). Results were consistent using a linear or quasipoisson model (Appendix 2, Table A.2.19).

Negative distance-decay curves were observed on both inner and outer islands for native species (Figure 4.3a \& Appendix 2, Table A.2.18). However, Jaccard similarity indexes declined faster with the distance separating two islands on inner than outer islands. Conversely, distance-decay curves were not significant for exotic species and did not differ between inner and outer islands 
(Figure 4.3b \& Appendix 2, Table A.2.18). Results were consistent using a linear or a quasipoisson model (Appendix 2, Table A.2.19).

Table 4-1 - Differences in how the richness of native and exotic species respond to island characteristics on 97 islands inside and outside Wellington Harbour, New Zealand. T and p-values testing for discrepancies between inner and outer islands are reported (in bold if $p<0.05$ ). The last column specifies the typology of the relationship between species richness and island characteristics on inner and outer islands (for more details see Appendix, Table A.2.17 \& Figure A.2.13).

\begin{tabular}{|c|c|c|c|c|c|}
\hline & \multicolumn{2}{|c|}{ Native species } & \multicolumn{2}{|c|}{ Exotic species } & \multirow[b]{2}{*}{ Relationship } \\
\hline & t-value & $\mathrm{p}$-value & t-value & $\mathrm{p}$-value & \\
\hline Area & 0.873 & 0.3848 & -1.090 & 0.2788 & Positive \\
\hline Isolation & 1.455 & 0.1491 & 0.389 & 0.6980 & $\begin{array}{l}\text { Non-significant for native } \\
\text { species, negative for exotic } \\
\text { species }\end{array}$ \\
\hline Height & 0.548 & 0.5849 & -0.151 & 0.8803 & Positive \\
\hline Elevation & -1.410 & 0.1620 & -0.279 & 0.7807 & Non-significant \\
\hline Slope & -3.014 & 0.0034 & -0.765 & 0.4462 & $\begin{array}{l}\text { Negative, non-significant for } \\
\text { native species on inner } \\
\text { islands }\end{array}$ \\
\hline $\begin{array}{l}\text { Nearest } \\
\text { dwelling }\end{array}$ & -0.549 & 0.5842 & -0.707 & 0.4814 & Positive \\
\hline
\end{tabular}

\section{5-Discussion}

Native plant species richness responded differently to slope depending on island location, but not to other island characteristics. Natives declined in number with slope only on outer, more disturbed islands. Furthermore, natives were floristically more homogenous on outer than inner islands. Lastly, 
native species spatially turned over more rapidly inside than outside the harbour. In stark contrast, exotic species did not differ in either richness or composition depending on island location.

Relationships between species richness and both area and height were positive and similar between inner and outer islands, and for both native and exotic species. Large, tall islands typically have a greater surface; thus, they can accommodate more species (MacArthur and Wilson 1967). Additionally, I observed that islands greater in size and height have a larger proportion of soil accumulating in rock cracks. Even small amounts of sediments can allow several species to survive by providing anchorage, retaining water, and supplying nutrients. Future studies should consider including a measure of soil availability (Schrader et al. 2019). Tall, large islands are also less likely to be overtopped by waves (Abbott 1977, Whittaker 1995, Burns and Neufeld 2009). Species richness was related to height, manually quantified, but not to elevation, computed by geospatial software, suggesting the former is a better predictor of species richness in this study system.
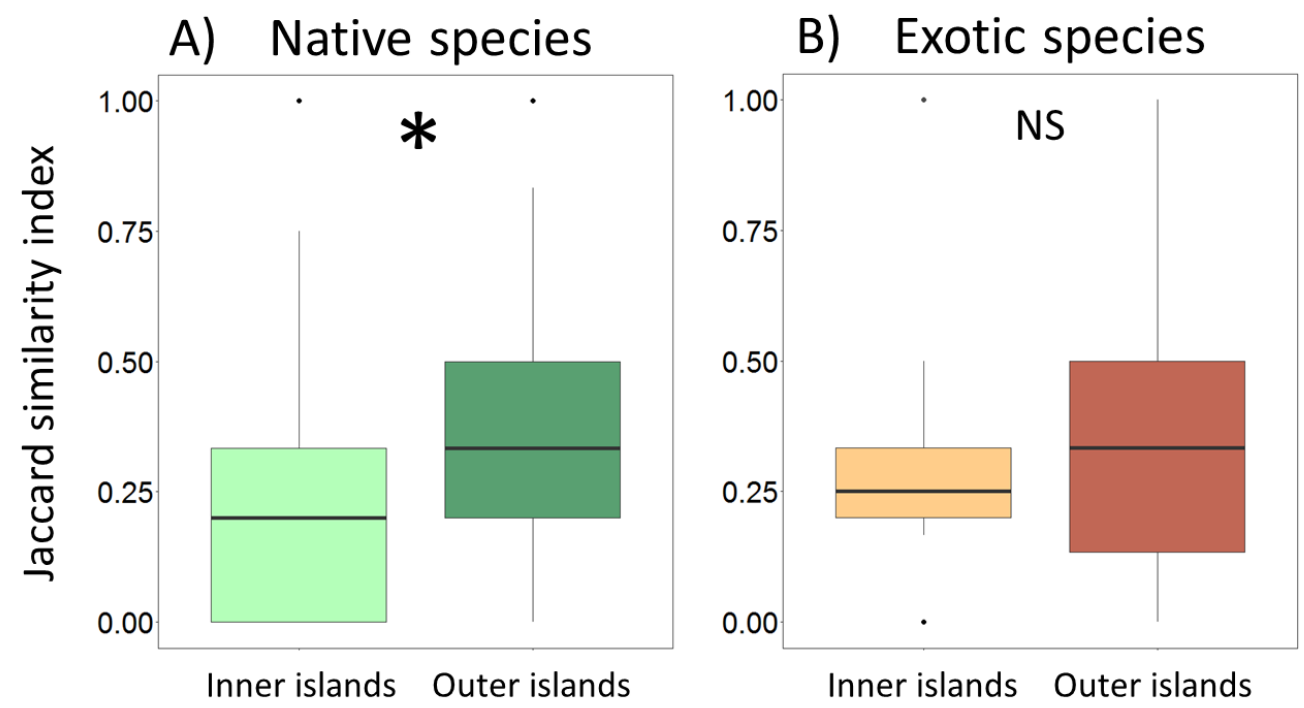

Figure 4.2 - Compositional differences among 97 islands off the coast of Wellington, New Zealand. On the $y$-axis are Jaccard similarity indexes, while on the $x$-axis are inner and outer islands. On top are all species (a), below native (b) and exotic (c) species. Symbol colours indicate all (greys), native (greens) and exotic (reds) species, whereas hues show inner (lights) and outer (darker) islands. Asterisks indicate significant differences between inner and outer islands. 
Relationships between richness and isolation were similar on inner and outer islands for both groups of species; however, exotics declined in number with it whereas natives did not. Species richness typically decreases with distance from the source pool due to reduced immigration rates (MacArthur and Wilson 1967). Islands within our study system though are very close to mainland plant communities, a possible explanation why natives were consistently unrelated to isolation. By contrast, negative exotic species-isolation relationships might reflect time-lags in the invasion process (González-Moreno et al. 2017, Coutts et al. 2018).

Both native and exotic species richness declined with proximity to the nearest dwelling, on inner and outer islands alike, which is surprising since proximity to humans usually favours biological invasions (Blackburn et al. 2008, Pretto et al. 2012, Chiarucci et al. 2017, Paudel et al. 2017). Here, only a very narrow stretch of land exists between the forested hills and the sea, which is the only available area for grasslands and specialized coastal communities. Most of this area is now in urban housing, which has reduced the propagule pressure from the mainland, thus lowering immigration rates (Shmida and Wilson 1985). Alternatively, I observed that islands distant from houses often host larger seabird communities (e.g. at Moa Point). Seabirds guano increase soil nutrients (GrantHoffman et al. 2010, Ellis et al. 2011), allowing more species to successfully colonize them. Additionally, seabirds might also act as seed dispersers (Abbott 1977, Ellis 2005, Magnússon et al. 2009, Calvino-Cancela 2011).

Native species richness declined with slope only on outer, more disturbed islands. Water run-up (i.e. maximum elevation reached by waves relative to shoreline position) on the foreshore is higher on steeper surfaces (Nielsen and Hanslow 1991, Ruggiero et al. 2004, Stockdon et al. 2006). Therefore, steep islands are more likely to be overtopped by waves. In addition, slope is also a proxy for topographic complexity (Yu et al. 2015), and irregular surfaces in this study system can accumulate seawater in rock pockets for prolonged periods, reducing the island's habitable area. On outer, more disturbed islands, these processes might have a much stronger impact. 
Natives on outer islands were compositionally more homogenous than on inner islands. If these islands are subject to more frequent or intense storms, waves and winds, only a few, specialized species might survive on them (i.e. environmental filtering, Gillham 1960b, Liu et al. 2019) Conversely, in more lenient conditions a larger number of species can establish a viable population (Abbott 1977), generating a greater compositional variability. Additionally, contrasting winds might favour the immigration of species with specific dispersal syndromes, such as water- or wind-dispersed (Abbott and Black 1980, Whittaker 1995). Where winds and storms are more frequent, species with such dispersal syndromes might be more common, homogenizing insular floristic composition.

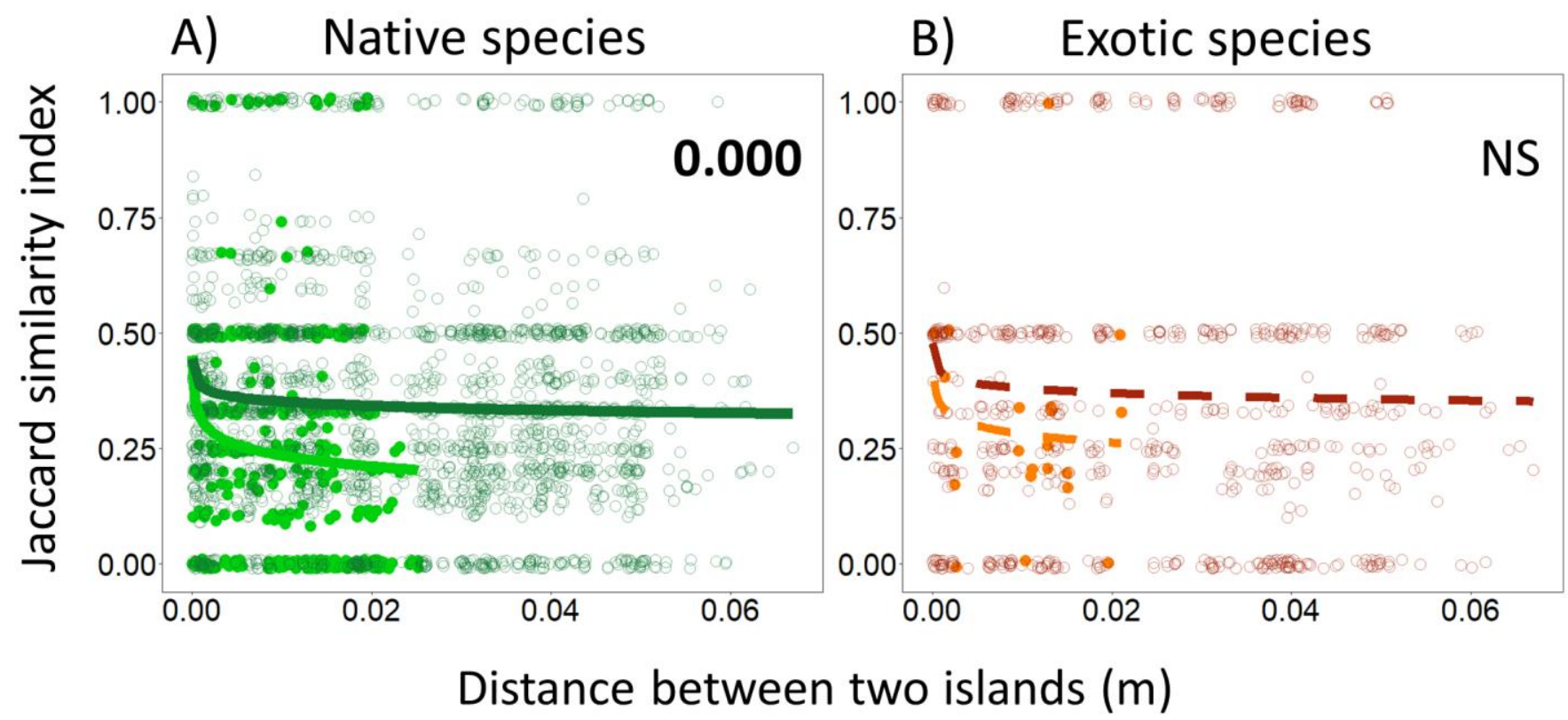

Figure 4.3 - Distance-decay relationships on 97 islands off the coast of Wellington, New Zealand. On the yaxis are Jaccard similarity indexes, while on the $x$-axis is the distance between each pair of islands. From the top are all (a), native (b) and exotic (c) species. Symbol colours illustrate all (greys), native (greens) and exotic (reds) species, whereas hues indicate inner (lights) and outer (darker) islands. On the top right are significant ( $p$-value in bold) or not significant (NS) differences between inner and outer islands.

Compositional differences in native species increased with distance among islands, and more so inside the harbour. This archipelago is composed of very small islands, which can only house a few species (Lomolino and Weiser 2001). Therefore, early colonization could be crucial for 
establishing a viable population. If so, species close to an island have more chances to be early, successful colonizers. Assuming floristic differences among mainland communities increase with distance as well, this process might generate insular distance-decay relationships in native species. Additionally, differences between inner and outer islands might be a product of a more homogenous flora on the former.

While the distributional patterns of native species differed on inner and outer islands, those of exotics did not. First, exotic richness declined with slope both on inner and outer islands, indicating that perhaps disturbances originated by the ocean are too severe or frequent for exotic species regardless of island location. Second, their composition was relatively homogeneous on both inner and outer islands and no significant distance-decay relationships were observed, a further indication that maybe only a few, well-adapted exotics can survive on these islands (Burns 2016b).

Results seem to indicate that differences in native and exotic species are the product of a lack of coastal specialists in the exotic species pool. Additionally, many exotic species might be still in the process of invading this archipelago (González-Moreno et al. 2017, Coutts et al. 2018). A previous study in the same location found the number of exotic species to increase through time (Burns 2015). However, almost a decade separates the two studies and the total number of exotics has not changed since. Perhaps then, exotics cyclically recolonize these islands after extinction following each major disturbance event (i.e. non-equilibrium dynamics, Whittaker 1995, 2000; Morrison 2010).

In this study, I identified differences in native and exotic plant species richness and composition on inner and outer islands. However, of 97 islands, only 27 were found inside the harbour. Thus, the analytical power of the model might be limited. Moreover, my database contains only islands occupied by vascular plant species. Previous studies though have highlighted the importance of empty islands as part of the among-island variation (Dengler 2010, Morrison 2014, Wang et al. 2016). Future studies should consider islands devoid of species. 
Overall results show that both native richness and composition changed depending on island location in Wellington Harbour. This pattern might derive from differences in the frequency and intensity of disturbances originated by the ocean on inner and outer islands. In striking contrast, distributional patterns of exotic species did not differ depending on island location. One possibility is a lack of coastal specialists in the exotic species pool (Hulme 2020). Alternatively, this result might stem from time-lags in the invasion process (Coutts et al. 2018) or non-equilibrium dynamics (Whittaker 1995, 2000). Exotic species management should not treat islands differently depending on their level of ocean-borne disturbances. 


\section{Chapter 5. The Island Biogeography of Humans}




\section{$5.1-$ Abstract}

For decades, biogeographers have sought a better understanding of how organisms are distributed among islands, yet the island biogeography of humans is still largely unknown. Here, I investigate how human population size varies with island area, elevation, isolation, latitude and longitude in 10 archipelagos across the globe. Results illustrate that, similar to plants and animals, populations of humans on islands are strongly structured geographically. Humans consistently preferred larger islands. However, relationships with elevation, isolation, latitude and longitude varied idiosyncratically among archipelagos, and were often associated with specific social, political and historical circumstances. Despite underlying similarities in their distribution, overall results from this study suggest the island biogeography of humans may be different from that of other organisms. 


\section{2 - Introduction}

Humans occupy virtually every island on the planet. However, some archipelagos are densely populated (e.g. New York Harbour, Singapore), while others are nearly uninhabited (e.g. Svalbard Islands, Tristan da Cunha). Although the geographic correlates of human population sizes are well known on continents (Cohen and Small 1998, Small et al. 2000, Small and Naumann 2001, Small and Cohen 2004, Yue et al. 2005, Gaughan et al. 2013), an overarching explanation for global variation in insular population sizes has yet to be established (Keegan and Diamond 1987, Cherry and Leppard 2018, c.f. Gavin and Sibanda 2012).

Other species occupy islands in predictable ways (MacArthur and Wilson 1967, Hanski 1999). Larger islands typically support bigger populations. On the other hand, remote islands are more difficult to disperse to, and have correspondingly smaller populations (MacArthur and Wilson 1967, Hanski 1999). Differences in insular population size may also be related to other island characteristics, including altitudinal and climatic variation (Small and Cohen 2004, Arianoutsou et al. 2010, Kerkhoff et al. 2014, Lawrence and Fraser 2020, Hollenbeck and Sax 2021). While these drivers of island distributional patterns have been thoroughly explored for other species (Lomolino 1990, Bell et al. 2005, Kalmar and Currie 2006, Helmus et al. 2014, Pinheiro et al. 2017, Donghao et al. 2020, Schmack et al. 2020, Mologni et al. 2021), they remain largely unknown for humans (Keegan and Diamond 1987, Gavin and Sibanda 2012).

Humans though differ from most other species. We are characterised not just by our biological traits, but also by cultural traits (Darwin 1871, Cavalli-Sforza and Feldman 1981, Boyd and Richerson 1988). Cultural traits are social attributes that both originate and transmit through nongenetic pathways (Cavalli-Sforza and Feldman 1981, Mesoudi et al. 2006). When sets of cultural traits are shared among individuals, distinct societies are generated (Whiten 2019). Societies turnover through both space and time (Mesoudi et al. 2006, Mesoudi 2016), often resulting in 
complex economic, historical and political circumstances (Gray et al. 2009, Gavin and Sibanda 2012). Thus, cultural differences may affect spatial variation in human population size on islands.

Here, I investigate the island biogeography of humans on 10 archipelagos across the globe. I characterized the geography of 486 islands and used generalized linear models to assess how: (1) humans occupy islands differing in area, isolation, elevation, latitude and longitude, and (2) how these relationships vary among archipelagos.

\section{3 - Methods}

Study system and island characteristics

I selected 10 archipelagos across the globe, to encompass a wide range of climatic, environmental and geographic conditions (total $n=486$ islands, Table 1 ). Population size was extracted from the latest available census (Appendix 1, Table S1). Census information was unavailable for small islands in Northern New Zealand, so in this instance I assayed human population size by the total number of dwellings visible from aerial imagery.

To examine relationships between human population size and island geography, I measured five island characteristics (see Appendix 1, Table S2). Estimates of island area $\left(\mathrm{km}^{2}\right)$ and elevation $(\mathrm{m})$ were obtained from freely available sources (Kueffer et al. 2010). When estimates of island area were not available, islands were manually digitized and their total planar area calculated using geospatial software (ESRI 2011). Isolation was measured as the shortest distance from the mainland $(\mathrm{km})$, which I defined as the closest landmass to the archipelago that was at least three orders of magnitude larger. The latitude and longitude of each island was extracted from digitized mapping. 
Table 5-1 - List of archipelagos investigated and associated number of islands, hemisphere, continent and climate.

\begin{tabular}{|c|c|c|c|c|}
\hline Archipelago & $\begin{array}{l}\text { Number of } \\
\text { islands }\end{array}$ & Hemisphere & Continent & Climate \\
\hline $\begin{array}{l}\text { Northern New } \\
\text { Zealand }\end{array}$ & 70 & Southern & Oceania & Temperate to subtropical \\
\hline Seychelles & 79 & Southern & Africa & Tropical \\
\hline Samoa & 22 & Southern & Oceania & Tropical \\
\hline Channel Islands & 40 & Northern & Europe & Temperate \\
\hline Hawaii & 45 & Northern & Oceania & Tropical \\
\hline Zhoushan & 66 & Northern & Asia & Temperate to subtropical \\
\hline Kuril Islands & 33 & Northern & Asia & $\begin{array}{l}\text { Continental to } \\
\text { subantarctic }\end{array}$ \\
\hline Virgin Islands & 48 & Northern & America & Tropical \\
\hline Ionian Islands & 48 & Northern & Europe & Temperate/Mediterranear \\
\hline Shetland & 35 & Northern & Europe & Temperate to subpolar \\
\hline Total & 486 & & & \\
\hline
\end{tabular}




\section{Statistical analyses}

To determine the geographic correlates of human population size within each archipelago, I conducted separate generalized linear models. I used population size as the dependent variable and island characteristics (i.e. area, isolation, elevation, latitude and longitude) as independent variables. I employed generalized linear models because the dependent variables consisted of counts and therefore followed a Poisson distribution. In cases of overdispersion, I used quasipoisson models (Appendix 1, Table A.2.22). Predictors were variously transformed to conform to assumptions. Island area and elevation were log-transformed, except for elevation in the Kuril Islands. Isolation, latitude and longitude conformed to assumptions without transformation. Isolation was square roottransformed for Northern New Zealand and Hawaii, and log-transformed for the lonian Islands) (Appendix 1, Figure A.2.14). All analyses were conducted in the R environment (R Core Team 2020).

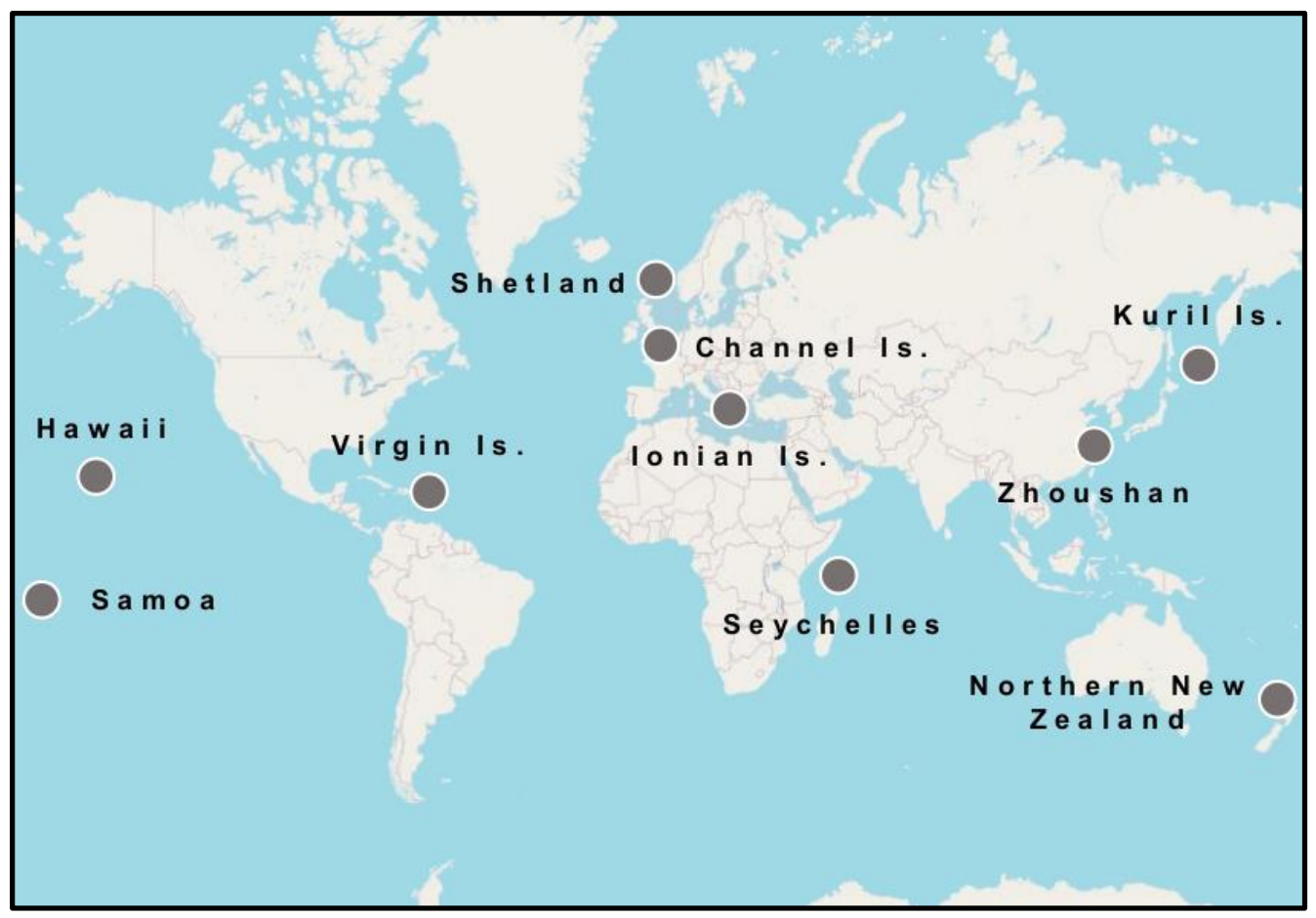

Figure 5.1 - Map of the globe displaying the investigated archipelagos.

Prior to analyses, I tested for multi-collinearity among predictors using Pearson's product motion correlation, with cut-offs at $r=0.80$ (Berry and Feldman 1985). Elevation was often 
correlated with area, and both latitude and longitude were commonly correlated with isolation (Appendix 1, Figure A.2.14). In these circumstances, I chose area and isolation because they are the most commonly used variables in island biogeography (MacArthur and Wilson 1967, Hanski 1999). Analyses of multi-collinearity using Variance Inflation Factors yield consistent results.

\section{$5.4-$ Results}

Population sizes increased with island area in all 10 archipelagos (Table 5.2, Figure 5.2). Elevation was strongly correlated with island area in most cases and was therefore only included in two models. Population size declined with it in the Kuril Islands but not in the Seychelles. In 5 archipelagos, the number of people declined with isolation (i.e. Northern New Zealand, Samoa, Kuril Islands, Ionian Island and Shetland). However, in the other 5 archipelagos human-isolation relationships were either positive (i.e. Channel Islands, Zhoushan) or non-significant (i.e. Seychelles, Hawaii, Virgin Islands). Latitude was included in six models and was not significant in 3 of them (i.e. Northern New Zealand, Virgin Islands, lonian Islands). Population size increased with latitude in Samoa and the Channel Islands, while declined with it in the Kuril Islands. Longitude was included only in one model, Shetland, and population size declined with it. 
Table 5-2 - Generalized linear models exploring the relationship between human occupancy and island characteristics on 10 study systems worldwide. Entries are estimates ( \pm standard errors) and t-values.
Area
Elevation
Isolation
Latitude
Longitude

Estimate t- Estimate t- Estimate t- Estimate t- Estimate t\pm S.E. value \pm S.E. value \pm S.E. value \pm S.E. value \pm S.E. value

\begin{tabular}{|c|c|c|c|c|c|c|c|c|}
\hline $\begin{array}{l}\text { Northern } \\
\text { New } \\
\text { Zealand }\end{array}$ & $\begin{array}{c}1.15 \pm \\
0.20\end{array}$ & 5.80 & & & $\begin{array}{c}-0.02 \pm \\
0.01\end{array}$ & -2.08 & $\begin{array}{c}-0.10 \pm \\
0.50\end{array}$ & -0.21 \\
\hline Seychelles & $\begin{array}{c}1.51 \pm \\
0.37\end{array}$ & 4.14 & $\begin{array}{c}0.31 \pm \\
0.43\end{array}$ & 0.70 & $\begin{array}{c}0.01 \pm \\
0.00\end{array}$ & 1.65 & & \\
\hline Samoa & $\begin{array}{c}0.97 \pm \\
0.07\end{array}$ & 14.92 & & & $\begin{array}{c}-0.04 \pm \\
0.01\end{array}$ & -6.47 & $\begin{array}{c}5.98 \pm \\
0.30\end{array}$ & 19.68 \\
\hline $\begin{array}{l}\text { Channel } \\
\text { Islands }\end{array}$ & $\begin{array}{c}1.92 \pm \\
0.02\end{array}$ & 116.10 & & & $\begin{array}{c}0.00 \pm \\
0.00\end{array}$ & 2.60 & $\begin{array}{c}2.57 \pm \\
0.1\end{array}$ & 28.69 \\
\hline Hawaii & $\begin{array}{c}0.61 \pm \\
0.16\end{array}$ & 3.78 & & & $\begin{array}{c}0.88 \pm \\
1.04\end{array}$ & 0.84 & & \\
\hline Zhoushan & $\begin{array}{l}1.37 \pm \\
0.05\end{array}$ & 30.43 & & & $\begin{array}{c}0.02 \pm \\
0.00\end{array}$ & 5.50 & & \\
\hline
\end{tabular}

$\begin{array}{ccccccccc}\text { Kuril } & 2.46 \pm & \mathbf{7 . 3 7} & -0.00 \pm & \mathbf{- 4 . 1 1} & -0.01 \pm & \mathbf{- 5 . 8 6} & -0.98 \pm & \mathbf{- 7 . 3 7} \\ \text { Islands } & 0.33 & & 0.00 & & 0.00 & & 0.13 & \\ & & & & & & & & \\ & & & & & & & & \\ \text { Virgin } & 1.55 \pm & \mathbf{4 . 7 4} & & & 0.01 \pm & 1.45 & 1.15 \pm & 1.53 \\ \text { Islands } & 0.33 & & & & 0.00 & & 0.76 & \end{array}$




\section{5 - Discussion}

The number of people inhabiting islands was strongly structured geographically. Similar to most species of plants and animals, humans were consistently more abundant on large islands. Positive relationships between population size and island area are among the most common patterns in ecology (Arrhenius 1921, Gleason 1922, Lomolino 2000b), and they can arise from a variety of processes (Turner and Tjørve 2005, Tjørve and Tjørve 2017). Perhaps the simplest explanation is that larger islands offer more inhabitable space (MacArthur and Wilson 1967, Hanski 1999, Tjørve and Tjørve 2017). So, if humans were distributed randomly across the globe, larger islands would house larger populations than smaller islands all else being equal (Tjørve and Tjørve 2017). Human population sizes in the Seychelles, Hawaii and Virgin Islands were associated only with island area.

Differently to island area, relationships between human population size and elevation, isolation, latitude and longitude varied markedly among archipelagos. Population sizes in Northern New Zealand and the Ionian Islands decreased with island isolation. Negative abundance-isolation relationships are also commonly observed in plants and animals (MacArthur and Wilson 1967, Hanski 1999, Burns 2019), and are typically attributed to the negative effect isolation has on immigration rates (MacArthur and Wilson 1967).

In the Samoan archipelago, population size declined with isolation, but also increased with latitude. The effect of latitude on population size is consistent with modern political boundaries. The Samoan archipelago is partitioned into two different political units, Samoa and American Samoa (The Editors of Encyclopaedia Britannica 2020), the latter located further south. Differences in foreign economic subsidy and immigration may therefore account for this result.

In the Channel Islands, population size increased with both isolation and latitude. This archipelago was disputed between the French and the English for centuries and was acquired by the latter in 1259 (Rothwell 1975). It has been a British crown dependency ever since (Beswick 2020). 


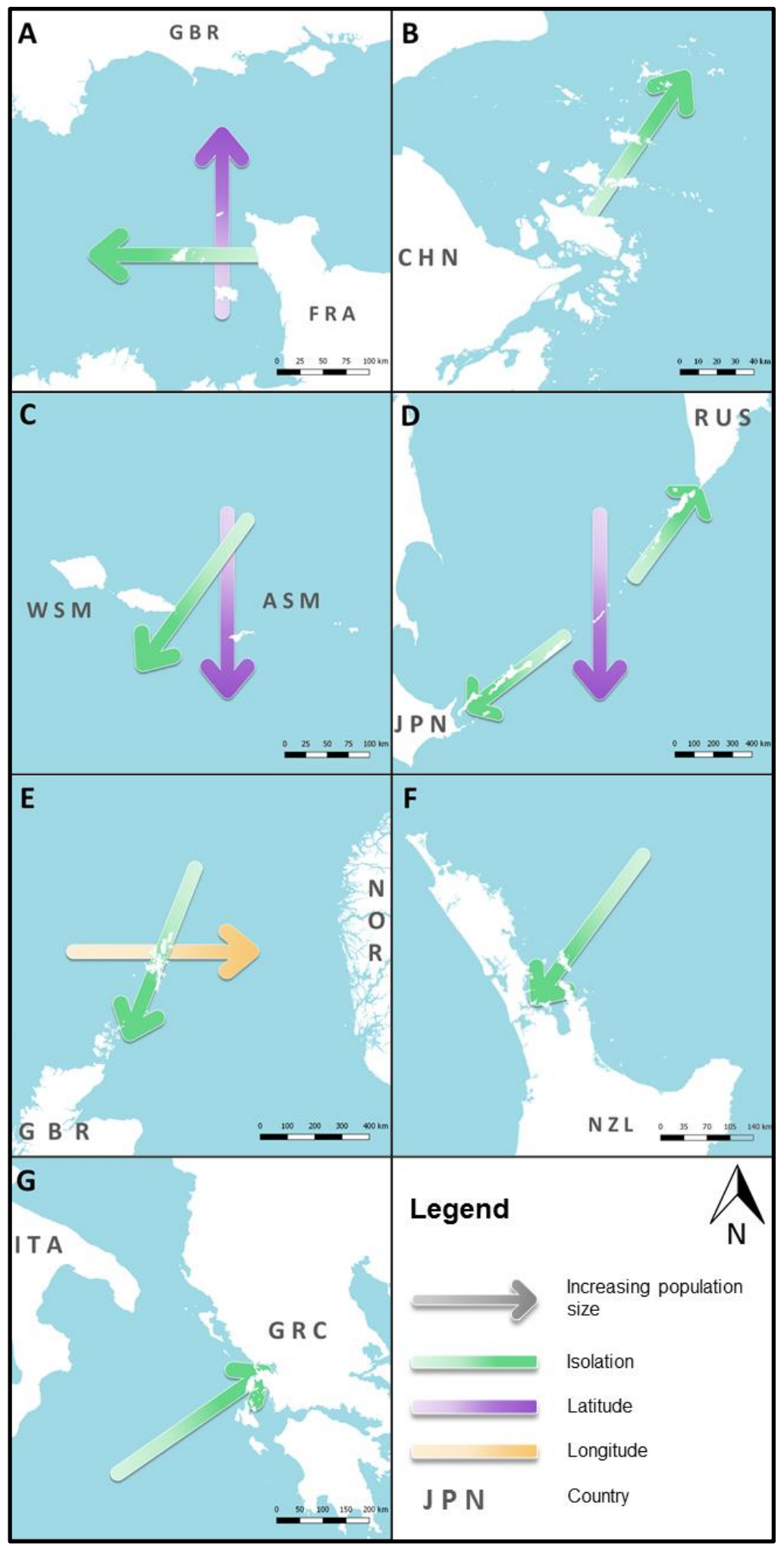

Figure 5.2 - Map representing the effect of isolation, latitude and longitude on human population size on archipelagos across the planet. From top left: Channel Islands (A), Zhoushan (B), Samoa (C), Kuril Islands (D), Shetland (E), Northern New Zealand (F), lonian Islands (G). Arrow direction and shade (light to dark) show increasing population size. Arrow colour show isolation (green), latitude (purple) and longitude (yellow). Country codes follow the International Organization for Standardization alphabetic codes (ISO 3 ). 
Population sizes were higher on islands closer to England perhaps because they were less exposed to potential invasions from continental Europe (Beswick 2020).

Positive population size - isolation relationships were detected also in the Zhoushan archipelago. Historically, these islands had a predominantly maritime economy, characterized by fishing and piracy (Gernet 1996). After suppressing piracy, Zhoushan became an important commercial port (The Editors of Encyclopaedia Britannica 2011). In this context, islands distant from mainland authorities and with easy access to the sea might had been preferred for settlement.

In the Kuril Islands, humans declined in number with isolation, elevation and latitude. Geographically, the Kuril Islands lie in a chain between Russia in the north and Japan in the south, and population sizes were higher on islands closer to both mainland source pools. Whereas elevation and latitudinal gradients may be explained by climatic conditions, which might be increasingly prohibitive for humans on taller islands located at higher latitudes.

Population sizes in the Shetland Islands declined with isolation and longitude. Islands in the northern part of this archipelago are located closer to the pole and perhaps more inhospitable. One explanation for higher population sizes in islands located in the eastern extremities of the archipelago is that they are less exposed to oceanic currents (Whittaker and Fernández-Palacios 2007). Alternatively, larger populations on southwestern islands might reflect two different immigration waves, one from the Scandinavian peninsula in the $9^{\text {th }}$ century, and a second from Scotland, which begun in the $13^{\text {th }}$ century (Fenton 1997).

Archipelagos were chosen for this study because they encompass a wide range of climatic, environmental and geographic conditions. Although this resulted in a total sample size of 486 islands, many more remain uninvestigated across the globe. Additionally, the use of islands by humans is likely to have changed radically through time, so investigating historical differences in island occupancy would be an interesting avenue of future research. Lastly, along with population size several other estimates of human land use can be measured, such as dwellings, docks and farms 
(Paudel et al. 2017, Sanchez-Ortiz et al. 2019, Schmack et al. 2020), which can potentially yield interesting information on how humans utilize islands.

Overall results illustrate that, similar to other species, insular distributional patterns of human populations are strongly structured geographically (MacArthur and Wilson 1967, Hanski 1999). However, trends varied idiosyncratically among most archipelagos and appear to be driven by site-specific cultural differences, resulting from social, political and historical factors (Gray et al. 2009, Gavin and Sibanda 2012). Therefore, the island biogeography of humans might differ fundamentally from that of other species. 
Chapter 6. Discussion 


\section{1 - Thesis summary}

This thesis combines with a growing body of work in the invasion ecology of islands, focusing particularly on how the distributional patterns of exotic vascular plants differ from those of natives. It also includes the first investigation of the human biogeography of islands. Results from chapter 2 show that the insular distributional patterns of native and exotic species richness are regulated by similar biogeographic principles. However, exotic species exhibited subtle, yet distinctive, invasion patterns. In chapter 3, I integrated interrelationships between traits and invasion success (i.e. high island occupancy rates) with the island biogeography theoretical framework. Results show that successful invaders were associated with specific life-history traits and displayed both rates of occupancy and patterns in richness and seed mass similar to natives. Moreover, most differences among trait categories in exotic species regarded relationships with human-related variables. In chapter 4, I explored how different levels of ocean-borne disturbances influence the richness and composition of native and exotic species on islands. Patterns in richness and composition varied depending on island location (i.e. inside the harbour and less disturbed or outside and more disturbed) for native species, but not for exotic species. In chapter 5 , I tested the island biogeography of humans on 10 archipelagos across the globe. Human population sizes on islands were strongly structured geographically, similar to other species. However, relationships often varied idiosyncratically among archipelagos.

Biological invasions are one of the main threats to the insular biota (Whittaker and FernándezPalacios 2007, Simberloff et al. 2013, Liao et al. 2020, Rojas-Sandoval et al. 2020). Exotic species often displace native species by monopolizing space and resources, a process that often leads to the local extinctions of natives and biotic homogenization (Pyšek and Richardson 2006, Qian and Ricklefs 2006, Castro and Jaksic 2008). However, plant invasions on islands are still poorly understood. Additionally, the invasion process is often facilitated by humans (Stohlgren et al. 2006, 
Seabloom et al. 2007). Despite a key role in biological invasions, the insular distributional patterns of humans are still largely unknown (Keegan and Diamond 1987).

Overall, this thesis significantly contributes to the fields of island biogeography and invasion ecology by highlighting previously overlooked aspects of the invasion process on islands. Results support that exotics have distinct distributional patterns from natives, providing indications on how to manage insular plant invasions. It also presents what is, to my knowledge, the first attempt to empirically evaluate global variation in human population sizes on islands, providing a start point for future studies in the field of island biogeography of humans.

\section{2 - Synthesis}

\subsubsection{Comparing native and exotic species}

Here, I compared the distributional patterns of native and exotic species to better understand plant invasions on islands. Trends in species richness were broadly similar in native and exotic species, in contrast with other studies (Long et al. 2009, Blackburn et al. 2016, Moser et al. 2018, RojasSandoval et al. 2020, Guo et al. 2021). However, several differences emerged at a more detailed analysis. For instance, in chapter 2 I found exotic species to prefer larger, less isolated islands more than natives. New Zealand was one of the last landmasses to be discovered by humans and most exotic plant species were introduced in the last 150 years (Williams and Cameron 2006). Many exotics might be still in the process of colonizing islands within this study system (i.e. ongoing invasion (González-Moreno et al. 2017, Coutts et al. 2018); thus, they would reach first larger, less isolated islands (MacArthur and Wilson 1967, Lomolino 1990).

Differences in the distribution of native and exotic species emerged also by investigating exotics with different life-history traits. Results show that successful invaders (e.g. high island 
occupancy rates) displayed both rates of occupancy and patterns in richness and seed mass similar to natives. Traits were largely used to explore invasion patterns (Van Kleunen et al. 2010b, a, Guo et al. 2018, Hulme and Bernard-Verdier 2018b, a), but less so in the context of the island biogeography theory (Patiño et al. 2017, Ottaviani et al. 2020). Here, using a trait-based approach helped understanding how the biogeography of islands differentially influence plant invaders with distinct traits. On the one hand, this result supports an ongoing invasion process. Species with specific traits (e.g. short life span, long-distance dispersal) might colonize islands within a new range faster than species lacking those traits. In contrast, these trends might simply reflect idiosyncratic differences in island occupancy among species with different life histories. Nonetheless, overall results strongly argue for integrating trait-based approaches in the theory of island biogeography framework (Ottaviani et al. 2020).

Relationships between species richness and island characteristics were also scale-dependent. Results showed that the relative influence of island area on species richness declined with island area, whereas the influence of other island characteristics, such as isolation and exposure to oceanborne disturbances, strengthened. Scale is a component of many ecological processes (Whittaker 2000, Fridley et al. 2007, Ladau and Eloe-Fadrosh 2019, King et al. 2020). However, studies in island biography typically focus on species-area relationships alone (Whitehead and Jones 1969, Lomolino and Weiser 2001, Turner and Tjørve 2005, Burns et al. 2009, Dengler 2010, Morrison 2014, Li 2020). These results combined with recent work assessing the scale-dependency of other biogeographic drivers of species richness on islands (Menegotto et al. 2020, Schrader et al. 2020). Additionally, scale-dependent relationships were stronger for exotic species, supporting the hypothesis of timelags in the invasion process. 


\subsubsection{Human proximity and species richness}

Human activities generally promote invasions (Stohlgren et al. 2006, Seabloom et al. 2007).

Accordingly, in Chapter 2 exotic species increased in number with human proximity. However, relationships between exotic species richness and human-related variables depended on life-history traits (see chapter 3). Exotic species with traits associated with high invasion success (i.e. high island occupancy rates) were less commonly related to human-related variables. One possible explanation is that species with specific traits (e.g. short life cycle, high seed production, long-distance dispersal) spread more rapidly (Pérez-Harguindeguy et al. 2013, Díaz et al. 2016, Arjona et al. 2018). As the invasion process progresses, these species might be increasingly independent of humans for their dispersal. Alternatively, successful invaders might rely upon humans only for their initial introduction.

In chapter 4, exotic species richness declined with proximity to human settlements instead. While human settlements are often foci for plant invasions (Castro \& Jaksic, 2008; Pretto et al., 2012; Paudel et al., 2017; Schmack et al., 2020 c.f. Löfgren \& Jerling, 2002; Stohlgren et al., 2006), here they reduce natural areas available to coastal communities, thus lowering source population sizes and immigration rates (i.e. reduced propagule pressure, Lockwood et al., 2005). Additionally, human disturbances are too frequent or severe for exotic species to take advantage of them.

Conversely, human activities generally disfavour native species (Paudel et al. 2017, Sanchez-Ortiz et al. 2019). Interestingly though, results from chapter 3 show that on some occasions native species increased in number with proximity to human settlements. It is possible that, just like exotics, also natives can opportunistically exploit human-mediated dispersal pathways (Valery et al. 2009). Perhaps plant-human relationships are more complex than previously thought, as for other aspects of invasion biology (Jeschke 2014).

Human disturbances are often measured by numbers of buildings, lengths of roads or extent of agricultural fields (Seabloom et al. 2007, Pretto et al. 2012, Paudel et al. 2017). In chapters 2, 3 
and 4 though, I explored human impacts mainly by measuring proximity to the nearest settlement, because most of the islands investigated are currently uninhabited and records of human impacts are unavailable. This likely underestimates the effect of current and past human disturbance. Uninhabited islands in New Zealand though are generally smaller in size than occupied islands, a trend consistent across the globe (see chapter 5). Thus, other archipelagos might present a similar issue. Additionally, uninhabited islands are likely to sustain lower human disturbances than occupied islands, suggesting that human impacts might vary with scale similar to other biogeographic drivers.

\subsubsection{The role of ocean-borne disturbances}

It is still contentious whether disturbances promote biological invasions (Denslow et al. 2009, Moles et al. 2012). Earlier work suggests different types of natural disturbance can either promote (Bellingham et al. 2005, Alba et al. 2015), prevent (Smith and Knapp 1999) or have no effect on plant invasions (Stohlgren et al. 1999, Suding and Gross 2006). In particular, ocean-borne disturbances were previously found to affect the distributional patterns of exotic species (Burns 2016b), but it is unclear how. In chapter 2, the richness of exotic species declined with exposure to ocean-borne disturbances, and more strongly than natives. Overall, this result was consistent among species with different life-history traits (chapter 3). In chapter 4, different levels of disturbance affected both the richness and composition of natives, but not that of exotic species. One explanation for these discrepancies is that the exotic species pool lacks coastal specialists. Exotic species are often selected by humans for agricultural and ornamental purposes (Lloret et al. 2005). Then, they might represent a subset of species poorly adapted to coastal habitats.

Other processes though, might be in play. For instance, a previous study in Wellington Harbour found the number of exotic species to increase through time (Burns 2015), suggesting a progressive invasion of the study system. However, after almost a decade since that census, the 
total number of exotics remained unchanged. Exotics were also previously found to turnover more rapidly on exposed islands (Burns 2016b). Perhaps then exotic species cyclically recolonize these islands after extinction following each major disturbance event (i.e. non-equilibrium dynamics, Whittaker 1995, 2000, Morrison and Spiller 2008). A similar process might be at work in Northern New Zealand as well. All in all, these results seem to indicate that disturbances of oceanic origin prevent biological invasions.

\subsubsection{The island biogeography of humans}

Human distributions on islands were strongly structured geographically. Similar to other species, population sizes increased with island area consistently across the globe. Positive relationships with area are one of the most common patterns in ecology (Arrhenius 1921, MacArthur and Wilson 1967, Lomolino 2000b, Tjørve and Tjørve 2017), and might be explained by several processes (Turner and Tjørve 2005). For instance, larger islands can offer more species and a greater amount and variety of resources (Turner and Tjørve 2005, Tjørve and Tjørve 2017).

Human population sizes often declined with isolation. Negative abundance-isolation relationships are also commonly observed in plants and animals (MacArthur and Wilson 1967, Hanski 1999, Burns 2019), and are typically attributed to the negative effect isolation has on immigration rates (MacArthur and Wilson 1967). However, in many cases, abundance-isolation relationships were either positive or non-significant. Similarly, relationships with elevation, latitude and longitude often varied idiosyncratically among archipelagos. While in some cases trends can be interpreted as a product of climatic, geographic and ecological gradients, in others a distinct suite of factors may be at work.

For instance, some relationships between human population size and island characteristics may be interpreted in light of current political circumstances. Archipelagos subdivided into different 
political units might undergo distinct economic and social processes. Other relationships appeared to reflect historical factors. Archipelagos that were long disputed might display human distributional patterns that reflect main invasion pathways (Fenton 1997, Beswick 2020). Lastly, some results seemed to be linked to economic factors. Archipelagos with distinctive economic circumstances might exhibit distributional patterns that vary accordingly (Gernet 1996, The Editors of Encyclopaedia Britannica 2011). In all these cases, processes that are political, economic or historical may account for human insular distributions. Overall results suggest that, despite underlying similarities in their distribution, the island biogeography of humans may be fundamentally different from that of other organisms.

\section{3- Conclusions \& future directions}

This thesis combines a growing body of research on plant invasions on islands (Burns 2016b, CelestiGrapow et al. 2016, Paudel et al. 2017, Moser et al. 2018, Butt et al. 2020, Fois et al. 2020, RojasSandoval et al. 2020). It provided a fresh perspective on the subject by assessing previously overlooked aspects of the invasion process, such as the scale-dependency of the relationships between native and exotic species richness and island characteristics. Moreover, it integrated a traitbased approach in the theory of island biogeography framework. Lastly, this work includes what is, to my knowledge, the first attempt to empirically evaluate global variation in human population sizes on islands.

In chapters 2, 3 and 4, I found that native and exotic species displayed broadly similar biogeographical patterns; however, with some differences. Discrepancies hinged on scaledependent processes, life-history traits and varying levels of ocean-borne disturbances. Comparing the distribution of native and exotic species might help conservation bodies in better focusing their efforts in controlling plant invasions on islands (Rojas-Sandoval et al. 2020). Future studies though should consider integrating other factors, both biotic and abiotic. One example is seabirds, whose 
burrowing activities and guano can modify the physical and chemical characteristics of the substrate (Bellingham et al. 2010, Ellis et al. 2011). Similarly, the amount and type of soil might act as environmental filters (Schrader et al. 2019).

In chapter 3, I used a trait-based approach to explore patterns of island invasions by exotic plant species. In particular, I used easily accessible traits, such as growth forms and dispersal syndromes. However, several other aspects of the life history of a plant can be explored, such as their introduction history. For example, exotic species can exploit several human-related pathways (Hodkinson and Thompson 1997). Forecasting preferential invasion pathways may enable us to prevent new introductions altogether (Sinclair et al. 2020). Moreover, traits such as time since first introduction are important determinants of invasion success (Williams \& Cameron, 2006; Ni et al., 2021). Lastly, the biogeographic origin of a species is often a good predictor of impact severity (Ni et al. 2021). For instance, species evolved in areas matching the climatic conditions of the new range generally have better chances to become successful invaders (Hayes and Barry 2008, Brandt et al. 2021).

In chapter 5, I found that similar to other species, insular distributional patterns of human populations are strongly structured geographically (MacArthur and Wilson 1967, Hanski 1999). In many cases though, results were perhaps better explained by political, economic and historical factors. To better understand how interrelationships among humans might influence our patterns of island occupancy, I am now integrating specific measures of human aggregation. Additionally, human population sizes varied idiosyncratically among archipelagos. Currently, I am investigating whether similar changes in the relationships between human population size and island characteristics occur on a temporal scale.

Overall, this thesis significantly contributes to the fields of island biogeography and invasion ecology by highlighting previously overlooked aspects of the invasion process on islands. Results help further my understanding of complex and often unresolved relationships between plant species 
and island characteristics. It also presents what is, to my knowledge, the first attempt to empirically evaluate global variation in human population sizes on islands, providing a starting point for future studies in the field of the island biogeography of humans. 


\section{References}

Abbott, I. 1977. Species richness, turnover and equilibrium in insular floras near Perth, Western Australia. - Aust. J. Bot. 25: 193-208.

Abbott, I. and Black, R. 1980. Changes in species composition of floras on islets near Perth, Western Australia. - J. Biogeogr. 7: 399.

Aikio, S. et al. 2020. Island properties dominate species traits in determining plant colonizations in an archipelago system. - Ecography 43: 1041-1051.

Alba, C. et al. 2015. Native and exotic plant species respond differently to wildfire and prescribed fire as revealed by meta-analysis. - J. Veg. Sci. 26: 102-113.

Anderson, A. et al. 2014. Tangata Whenua: an illustrated histoy. - Bridget Williams Books.

Anten, N. P. R. et al. 2010. Wind and mechanical stimuli differentially affect leaf traits in Plantago major. - New Phytol. 188: 554-564.

Arianoutsou, M. et al. 2010. Comparing naturalized alien plants and recipient habitats across an east-west gradient in the Mediterranean Basin. - J. Biogeogr. 37: 1811-1823.

Arjona, Y. et al. 2018. Long-distance dispersal syndromes matter: diaspore-trait effect on shaping plant distribution across the Canary Islands. - Ecography 41: 805-814.

Arrhenius, O. 1921. Species and area. - J. Ecol. 9: 95-99.

Atkinson, I. A. E. 2004. Successional processes induced by fires on the northern offshore islands of New Zealand. - N. Z. J. Ecol. 28: 181-193.

Auffret, A. G. et al. 2017. Spatial scale and specialization affect how biogeography and functional traits predict long-term patterns of community turnover. - Funct. Ecol. 31: 436-443.

Baiser, B. and Li, D. 2018. Comparing species-area relationships of native and exotic species. - Biol. Invasions 20: 3647-3658.

Barajas-Barbosa, M. P. et al. 2020. Environmental heterogeneity dynamics drive plant diversity on oceanic islands. - J. Biogeogr. 47: 2248-2260.

Bartomeus, I. et al. 2012. Deconstructing the native-exotic richness relationship in plants. - Glob. Ecol. Biogeogr. 21: 524-533.

Bednarik, R. G. 1999. Maritime navigation in the Lower and Middle Palaeolithic. - Comptes Rendus l'Academie Sci. - Ser. Ila Sci. la Terre des Planetes 328: 559-563.

Bell, T. et al. 2005. Ecology: Larger islands house more bacterial taxa. - Science (80-. ). 308: 1884.

Bellingham, P. J. 1984. Forest regeneration on Lady Alice Island, Hen and Chickens Group. - Tane 30: 31-42.

Bellingham, P. J. and Sparrow, A. D. 2000. Resprouting as a life history strategy in woody plant communities. - Oikos 89: 409-416.

Bellingham, P. J. et al. 2005. Hurricane disturbance accelerates invasion by the alien tree Pittosporum undulatum in Jamaican montane rain forests. - J. Veg. Sci.: 675-684.

Bellingham, P. J. et al. 2010. New Zealand island restoration: seabirds, predators, and the importance of history. - N. Z. J. Ecol. 34: 115-136. 
Benavides, R. et al. 2021. The GenTree Leaf Collection: inter- and intraspecific leaf variation in seven forest tree species in Europe. - Glob. Ecol. Biogeogr.: 590-597.

Bergstrom, D. M. et al. 2009. Indirect effects of invasive species removal devastate World Heritage Island. - J. Appl. Ecol. 46: 73-81.

Berry, W. D. and Feldman, S. 1985. Multiple regression in practice (Quantitative applications in the social sciences). - SAGE Publications.

Beswick, J. 2020. Identity, language and belonging on Jersey (S Wright and H Kelly-Holmes, Eds.). Palgrave Macmillan.

Blackburn, T. M. et al. 2008. The island biogeography of exotic bird species. - Glob. Ecol. Biogeogr. 17: $246-251$.

Blackburn, T. M. et al. 2016. On the island biogeography of aliens: a global analysis of the richness of plant and bird species on oceanic islands. - Glob. Ecol. Biogeogr. 25: 859-868.

Blumenthal, D. M. et al. 2017. Composted manure application promotes long-term invasion of semiarid rangeland by Bromus tectorum. - Ecosphere 8: 1-12.

Boyd, R. and Richerson, P. J. 1988. Culture and the evolutionary process. - University of Chicago Press.

Brandt, A. J. et al. 2021. Naturalised plants transform the composition and function of the New Zealand flora. - Biol. Invasions 23: 351-366.

Brown, J. H. and Kodric-Brown, A. 1977. Turnover rates in insular biogeography: effect of immigration on extinction. - Ecology 58: 445-449.

Burns, K. C. 2015. A Theory of Island Biogeography for Exotic Species. - Am. Nat. 186: 441-451.

Burns, K. C. 2016a. Size changes in island plants: independent trait evolution in Alyxia ruscifolia (Apocynaceae) on Lord Howe Island. - Biol. J. Linn. Soc. 119: 847-855.

Burns, K. C. 2016b. Native-exotic richness relationships: a biogeographic approach using turnover in island plant populations. - Ecology 97: 2932-2938.

Burns, K. C. 2019. Evolution in isolation: the search for an island syndrome in plants. - Cambridge University Press.

Burns, K. C. and Neufeld, C. J. 2009. Plant extinction dynamics in an insular metacommunity. - Oikos 118: 191-198.

Burns, K. C. et al. 2009. The small-island effect: fact or artefact? - Ecography 32: 269-276.

Butler, D. W. et al. 2007. Biogeography of seed-dispersal syndromes, life-forms and seed sizes among woody rain-forest plants in Australia's subtropics. - J. Biogeogr. 34: 1736-1750.

Butt, N. et al. 2020. Predicting and managing plant invasions on offshore islands.: 1-14.

Caccianiga, M. et al. 2006. The functional basis of a primary succession resolved by CSR classification. - Oikos 112: 10-20.

Calvino-Cancela, M. 2011. Gulls (Laridae) as frugivores and seed dispersers. - Plant Ecol. 212: 11491157.

Cameron, E. K. and Davies, N. C. 2013. Changes in the wild vascular flora of Tiritiri Matangi Island, 1978-2010. - N. Z. J. Ecol. 37: 307-342. 
Cameron, E. K. and Young, M. E. 2019. Vegetation and vascular flora. - In: Wade, L. and Veitch, D. (eds), Hauturu - the history, flora and fauna of Te Hauturu-o-Toi Little Barrier. Massey University Press, pp. 166-213, 296-317.

Campbell, H. and Landis, C. A. 2009. New Zealand, Geology. - In: Encyclopedia of Islands. University of California Press, pp. 673-680.

Carlquist, S. 1974. Island Biology. - Columbia University Press.

Carpio, A. J. et al. 2017. An assessment of conflict areas between alien and native species richness of terrestrial vertebrates on a macro-ecological scale in a Mediterranean hotspot. - Anim. Conserv. 20: 433-443.

Carter, Z. T. et al. 2020. Determining the underlying structure of insular isolation measures. - J. Biogeogr. 47: 955-967.

Castro, S. A. and Jaksic, F. M. 2008. Role of non-established plants in determining biotic homogenization patterns in Pacific Oceanic Islands. - Biol. Invasions 10: 1299-1309.

Cavalli-Sforza, L. L. and Feldman, M. W. 1981. Cultural transmission and evolution: a quantitative approach. - Princeton University Press.

Celesti-Grapow, L. et al. 2016. Plant invasions on small Mediterranean islands: an overview. - Plant Biosyst. 150: 1119-1133.

Chen, C. et al. 2020. The role of habitat diversity in generating the small-island effect. - Ecography 43: 1241-1249.

Cherry, J. F. and Leppard, T. P. 2018. Patterning and its causation in the Pre-Neolithic colonization of the Mediterranean islands (Late Pleistocene to Early Holocene). - J. Isl. Coast. Archaeol. 13: 187-201.

Chiarucci, A. et al. 2017. Plant recording across two centuries reveals dramatic changes in species diversity of a Mediterranean archipelago. - Sci. Rep. 7: 1-11.

Chown, S. L. et al. 1998. Ecological biogeography of southern ocean islands: species-area relationships, human impacts, and conservation. - Am. Nat. 152: 562-575.

Clarkson, B. D. and Clarkson, B. R. 1994. Vegetation decline following recent eruptions on White Island (Whakaari), Bay of Plenty, New Zealand. - New Zeal. J. Bot. 32: 21-36.

Clarkson, B. D. et al. 1986. Vegetation destruction and recovery following recent eruptions on White Island (Whakaari), Bay of Plenty, New Zealand.

Cockayne, L. 1958. The Vegetation of New Zealand. - Hafner Publishing Company.

Cody, M. L. and Overton, J. M. 1996. Short-term evolution of reduced dispersal in island plant populations. - J. Ecol. 84: 53-61.

Cohen, J. E. and Small, C. 1998. Hypsographic demography: the distribution of human population by altitude. - Proc. Natl. Acad. Sci. 95: 14009-14014.

Coutts, S. R. et al. 2018. Invasion lags: the stories we tell ourselves and our inability to infer process from pattern. - Divers. Distrib. 24: 244-251.

Darwin, C. 1859. On the origin of species by means of natural selection, or the preservation of favoured races in the struggle for life (J Murray, Ed.).

Darwin, C. 1871. The descent of man, and selection in relation to sex. - John Murray. 
Daugherty, C. H. et al. 1990. The significance of the biological resources of New Zealand islands for ecological restoration (D. Towns, CH Daugherty, IAE Atkinson, and (Eds), Eds.). - Conserv. Sci. Pub. 2: 9-21.

Dawson, J. W. 1988. Forest vines to snow tussocks: the story of New Zealand plants. - Victoria University Press.

de Lange, P. J. and McFadden, I. 1995. Additions and comments on the flora and fauna of Motukahakaha Island, Hauraki Gulf, Auckland. - Auckl. Bot. Soc. J. 50: 22-26.

Denelle, P. et al. 2020. Generalist plants are more competitive and more functionally similar to each other than specialist plants: insights from network analyses. - J. Biogeogr.: 1-12.

Dengler, J. 2010. Robust methods for detecting a small island effect. - Divers. Distrib. 16: 256-266.

Denslow, J. S. et al. 2009. Invasive exotic plants in the tropical pacific islands: patterns of diversity. Biotropica 41: 162-170.

Department of Conservation 2017. DOC Public Conservation Areas.

Díaz, S. et al. 2016. The global spectrum of plant form and function. - Nature 529: 167-171.

Diver, K. C. 2008. Not as the crow flies: assessing effective isolation for island biogeographical analysis. - J. Biogeogr. 35: 1040-1048.

Donghao, W. et al. 2020. Island size affects wood decomposition by changing decomposer distribution. - Ecography 44: 456-468.

Dostál, P. et al. 2013. The impact of an invasive plant changes over time. - Ecol. Lett. 16: 1277-1284.

Dyer, E. E. et al. 2016. A global analysis of the determinants of alien geographical range size in birds. - Glob. Ecol. Biogeogr. 25: 1346-1355.

Ellenberg, H. and Müller-Dombois, D. 1967. A key to Raunkiaer plant life forms with revised subdivisions. - Berichte des Geobot. Institutes ETH Stift. Rübel 37: 56-73.

Ellis, J. C. 2005. Marine birds on land: a review of plant biomass, species richness, and community composition in seabird colonies. - Plant Ecol. 181: 227-241.

Ellis, E. C. 2019. Evolution: Biodiversity in the Anthropocene. - Curr. Biol. 29: R831-R833.

Ellis, J. C. et al. 2011. Effects of seabirds on plant communities. - In: Mulder, C.P.H., Anderson, W.B., Towns, D.R., Bellingham (eds), P. J. (ed), Seabird islands: ecology invasions, and restoration. Oxford University Press, pp. 177-211.

ESRI 2011. ArcGIS Desktop: release 10. in press.

Essl, F. et al. 2019. Drivers of the relative richness of naturalized and invasive plant species on Earth. - AoB Plants 11: 1-13.

Fattorini, S. 2010. The influence of geographical and ecological factors on island beta diversity patterns. - J. Biogeogr. 37: 1061-1070.

Fenton, A. 1997. The northern isles: Orkney and Shetland. - Tuckwell Press.

Ferguson, R. N. and Drake, D. R. 1999. Influence of vegetation structure on spatial patterns of seed deposition by birds. - New Zeal. J. Bot. 37: 671-677.

Ficetola, G. F. and Padoa-schioppa, E. 2009. Human activities alter biogeographical patterns of reptiles on Mediterranean islands. - Glob. Ecol. Biogeogr. 18: 214-222. 
Fleming, C. A. 1979. The geological history of New Zealand and its life. - Auckland University Press.

Fois, M. et al. 2020. Endemic and alien vascular plant diversity in the small Mediterranean islands of Sardinia: drivers and implications for their conservation. - Biol. Conserv. 244: 1-10.

Fridley, J. D. et al. 2007. The invasion paradox: reconciling pattern and process in species invasion. Ecology 88: 3-17.

Fukami, T. et al. 2006. Above- and below-ground impacts of introduced predators in seabirddominated island ecosystems. - Ecol. Lett. 9: 1299-1307.

Fung, T. et al. 2019. Spatial scaling of species richness-productivity relationships for local communities: analytical results from a neutral model. - Theor. Ecol. 13: 93-103.

Gaughan, A. E. et al. 2013. High resolution population distribution maps for Southeast Asia in 2010 and 2015. - PLoS One in press.

Gavin, M. C. and Sibanda, N. 2012. The island biogeography of languages. - Glob. Ecol. Biogeogr. 21: 958-967.

Geographx 2016. NZ 8m digital elevation model (2012).

Gernet, J. 1996. A history of Chinese civilization. - Cambridge University Press.

Giladi, I. et al. 2014. Scale-dependent species-area and species-isolation relationships: a review and a test study from a fragmented semi-arid agro-ecosystem. - J. Biogeogr. 41: 1055-1069.

Gillham, M. E. 1960a. Plant communities of the Mokohinau Islands, northern N.Z. - Trans. R. Soc. New Zeal. 8: 79-98.

Gillham, M. E. 1960b. Vegetation of Little Brother Island, Cook Strait, in Relation to spray-bearing Winds, Soil Salinity, and pH. - Trans. R. Soc. N;Z 88: 405-424.

Gilpin, M. E. and Diamond, J. M. 1976. Calculation of immigration and extinction curves from the species area distance relation. - Proc. Natl. Acad. Sci. U. S. A. 73: 4130-4134.

Glassman, S. I. et al. 2017. The theory of island biogeography applies to ectomycorrhizal fungi in subalpine tree "islands" at a fine scale. - Ecosphere in press.

Gleason, H. A. 1922. On the relation between species and area. - Ecology 3: 158-162.

González-Moreno, P. et al. 2017. The effects of landscape history and time-lags on plant invasion in Mediterranean coastal habitats. - Biol. Invasions 19: 549-561.

Grant-Hoffman, M. N. et al. 2010. Effects of invasive rats and burrowing seabirds on seeds and seedlings on New Zealand islands. - Oecologia 162: 1005-1016.

Gray, R. D. et al. 2009. Language phylogenies reveal expansion pulses and pauses in pacific settlement. - Science (80-. ). 323: 479-483.

Grime, J. P. 1977. Evidence for the existence of three primary strategies in plants and its relevance to ecological and evolutionary theory. - Am. Nat. 111: 1169-1194.

Grime, J. P. and Pierce, S. 2012. The evolutionary strategies that shape ecosystems. - WileyBlackwell.

Grubb, P. J. et al. 2013. Disturbance regimes, gap-demanding trees and seed mass related to tree height in warm temperate rain forests worldwide. - Biol. Rev. 88: 701-744.

Guo, Q. 2014. Species invasions on islands: searching for general patterns and principles. - Landsc. 
Ecol. 29: 1123-1131.

Guo, Q. 2015. Island biogeography theory: emerging patterns and human effects. - Elsevier Inc.

Guo, W. Y. et al. 2018. The role of adaptive strategies in plant naturalization. - Ecol. Lett. 21: 13801389.

Guo, Q. et al. 2020. Worldwide effects of non-native species on species-area relationships. - Conserv. Biol. 00: 1-30.

Guo, Q. et al. 2021. Worldwide effects of non-native species on species-area relationships. Conserv. Biol. 35: 711-721.

Hanski, li. 1994. Patch-occupancy dynamics in landscapes. - Trends Ecol. Evol. 9: 131-135.

Hanski, I. 1999. Metapopulation ecology. - Oxford University Press.

Harris, S. and Timmins, S. M. 2009. Estimating the benefit of early control of all newly naturalised plants. - Sci. Conserv.: 1-25.

Hayes, K. R. and Barry, S. C. 2008. Are there any consistent predictors of invasion success? - Biol. Invasions 10: 483-506.

Heleno, R. H. and Vargas, P. 2015. How do islands become green? - Glob. Ecol. Biogeogr. 24: 518526.

Helmus, M. R. et al. 2014. Island biogeography of the Anthropocene. - Nature 513: 543-546.

Higgins, S. I. et al. 2003. Are long-distance dispersal events in plants usually caused by nonstandard means of dispersal? - Ecology 84: 1945-1956.

Hjerpe, J. et al. 2001. Tropical rain forest recovery from cyclone damage and fire in Samoa. Biotropica 33: 249-259.

Hobbs, R. J. and Huenneke, L. F. 1992. Disturbance, diversity, and invasion: implications for conservation. - Conserv. Biol. 6: 324-337.

Hodgson, J. G. et al. 2020. Seed size, number and strategies in annual plants: a comparative functional analysis and synthesis. - Ann. Bot. 126: 1109-1128.

Hodkinson, D. J. and Thompson, K. 1997. Plant dispersal: the role of man. - J. Appl. Ecol. 34: 14841496.

Holdaway, S. J. et al. 2019. Māori settlement of New Zealand: the Anthropocene as a process. Archaeol. Ocean. 54: 17-34.

Hollenbeck, E. C. and Sax, D. F. 2021. Novel biogeographic patterns across latitudinal and elevational gradients: a case study with tropical montane epiphytes lends insights to conservation. - J. Biogeogr.: 1-12.

Hu, G. et al. 2011. Determinants of plant species richness and patterns of nestedness in fragmented landscapes: evidence from land-bridge islands. - Landsc. Ecol. 26: 1405-1417.

Huenneke, L. F. et al. 1990. Effects of soil resources on plant invasion and community structure in Californian serpentine grassland. - Ecology 71: 478-491.

Hulme, P. E. 2020. Plant invasions in New Zealand: global lessons in prevention, eradication and control. - Biol. Invasions 22: 1539-1562.

Hulme, P. E. and Bernard-Verdier, M. 2018a. Comparing traits of native and alien plants: can we do 
better? - Funct. Ecol. 32: 117-125.

Hulme, P. E. and Bernard-Verdier, M. 2018b. Evaluating differences in the shape of native and alien plant trait distributions will bring new insights into invasions of plant communities. - J. Veg. Sci.: 348-355.

Ihara, Y. et al. 2020. A demographic test of accidental versus intentional island colonization by Pleistocene humans. - J. Hum. Evol. 145: 102839.

James Dixon, E. 2001. Human colonization of the Americas: timing, technology and process. - Quat. Sci. Rev. 20: 277-299.

Jauni, M. et al. 2015. Non-native plant species benefit from disturbance: a meta-analysis. - Oikos 124: $122-129$.

Jenness, J. 2013. DEM surface tools for ArcGIS. in press.

Jeschke, J. M. 2014. General hypotheses in invasion ecology. - Divers. Distrib. 20: 1229-1234.

Kalmar, A. and Currie, D. J. 2006. A global model of island biogeography. - Glob. Ecol. Biogeogr. 15: $72-81$.

Kattge, J. et al. 2020. TRY plant trait database - enhanced coverage and open access. - Glob. Chang. Biol. 26: 119-188.

Keegan, W. F. and Diamond, J. M. 1987. Colonization of Islands by Humans: a Biogeographical Perspective. - Adv. Archaeol. Method Theory 10: 49-92.

Keeley, J. E. and Brennan, T. J. 2012. Fire-driven alien invasion in a fire-adapted ecosystem. Oecologia 169: 1043-1052.

Kerkhoff, A. J. et al. 2014. The latitudinal species richness gradient in New World woody angiosperms is consistent with the tropical conservatism hypothesis. - Proc. Natl. Acad. Sci. U. S. A. 111: $8125-8130$.

King, S. A. and Buckney, R. T. 2002. Invasion of exotic plants in nutrient-enriched urban bushland. Austral Ecol. 27: 573-583.

King, T. W. et al. 2020. The influence of spatial and temporal scale on the relative importance of biotic vs. abiotic factors for species distributions. - Divers. Distrib.: 1-17.

Kirch, P. V. and Joanna, E. 1994. Palaeoenvironmental evidence for human colonization of remote Oceanic islands. - Antiquity 68: 310-321.

König, C. et al. 2020. Source pools and disharmony of the world's island floras. - Ecography 43: 1-12.

Kowarik, I. and Säumel, I. 2008. Water dispersal as an additional pathway to invasions by the primarily wind-dispersed tree Ailanthus altissima. - Plant Ecol. 198: 241-252.

Kreft, H. et al. 2008. Global diversity of island floras from a macroecological perspective. - Ecol. Lett. 11: 116-127.

Kueffer, C. et al. 2010. A global comparison of plant invasions on oceanic islands. - Perspect. Plant Ecol. Evol. Syst. 12: 145-161.

Kumar, S. et al. 2006. Spatial heterogeneity influences native and nonnative plant species richness. Ecology 87: 3186-3199.

Ladau, J. and Eloe-Fadrosh, E. A. 2019. Spatial, temporal, and pylogenetic scales of microbial ecology. - Trends Microbiol. 27: 662-669. 
Land Information New Zealand 2012. NZ coastlines and islands polygons (Topo 1:50k).

Lawrence, E. R. and Fraser, D. J. 2020. Latitudinal biodiversity gradients at three levels: linking species richness, population richness and genetic diversity. - Glob. Ecol. Biogeogr. 29: 770-788.

Lear, G. et al. 2013. The biogeography of stream bacteria. - Glob. Ecol. Biogeogr. 22: 544-554.

Li, D. 2020. Species - area relationship and small-island effect of bryophytes on the Zhoushan Archipelago, China.: 978-992.

Liao, H. et al. 2020. Estimating non-native plant richness with a species-accumulation model along roads. - Conserv. Biol. 34: 472-481.

Liu, J. et al. 2018. Larger fragments have more late-successional species of woody plants than smaller fragments after 50 years of secondary succession. - J. Ecol.: 1-13.

Liu, J. J. et al. 2019. Environmental filtering underpins the island species-area relationship in a subtropical anthropogenic archipelago. - J. Ecol. 00: 1-9.

Lloret, F. et al. 2004. Local and regional abundance of exotic plant species on Mediterranean islands: are species traits important? - Glob. Ecol. Biogeogr. 13: 37-45.

Lloret, F. et al. 2005. Species attributes and invasion success by alien plants on Mediterranean islands. - J. Ecol. 93: 512-520.

Lloyd, K. M. et al. 2006. Takahe Valley Hut: a focal point for weed invasion in an isolated area of Fiordland National Park, New Zealand. - N. Z. J. Ecol. 30: 371-375.

Lockwood, J. L. et al. 2005. The role of propagule pressure in explaining species invasions. - Trends Ecol. Evol. 20: 223-228.

Löfgren, A. and Jerling, L. 2002. Species richness, extinction and immigration rates of vascular plants on islands in the Stockholm Archipelago, Sweden, during a century of ceasing management. Folia Geobot. 37: 297-308.

Lomolino, M. V. 1984. Immigrant selection, predation, and the distributions of Microtus pennsylvanicus and Blarina brevicauda on islands. - Am. Nat. 123: 468-483.

Lomolino, M. V. 1990. The target area hypothesis: the influence of island area on immigration rates of non-volant mammals. - Oikos 57: 297-300.

Lomolino, M. V. 2000a. A call for a new paradigm of island biogeography. - Glob. Ecol. Biogeogr.: 16.

Lomolino, M. V. 2000b. Ecology's most general, yet protean pattern: the species-area relationship. J. Biogeogr. 27: 17-26.

Lomolino, M. V. 2016. The unifying, fundamental principles of biogeography: understanding Island Life. - Front. Biogeogr. 8: 0-27.

Lomolino, M. V. and Weiser, M. D. 2001. Towards a more general species-area relationship: diversity on all islands, great and small. - J. Biogeogr. 28: 431-445.

Long, J. D. et al. 2009. Linking invasions and biogeography: isolation differentially affects exotic and native plant diversity. - Ecology 90: 863-868.

Lonsdale, W. 1999. Global patterns of plant invasions and the concept of invasibility. - Ecology 80: 811.

MacArthur, R. H. and Wilson, E. O. 1967. The Theory of Island Biogeography. - Princeton University 
Press.

Magnússon, B. et al. 2009. Developments in plant colonization and succession on Surtsey during 1999-2008. - Surtsey Res. 12: 57-76.

Manaaki Whenua - Landcare Research 2020. Ecotraits - Ecological Traits of New Zealand Flora.

Mason, R. A. B. et al. 2008. Reproductive output of invasive versus native plants. - Glob. Ecol. Biogeogr. 17: 633-640.

May, R. L. et al. 2017. Classification of intra-specific variation in plant functional strategies reveals adaptation to climate. - Ann. Bot. 119: 1343-1352.

McGlone, M. S. 2006. Becoming new zealanders: immigration and formation of the biota. - In: R.B. Allen \& W.G. Lee (Eds) (ed), Biological invasion in New Zealand. Springer, pp. 17-32.

McGuinness, K. A. 1984. Species-area curves. - Biol. Rev. 59: 423-440.

McKinney, M. L. and Lockwood, J. L. 1999. Biotic homogenization: a few winners replacing many losers in the next mass extinction. - Trends Ecol. Evol. 14: 450-453.

Menegotto, A. et al. 2020. A global test of the subsidized island biogeography hypothesis. - Glob. Ecol. Biogeogr. 29: 320-330.

Mesoudi, A. 2016. Cultural evolution: a review of theory, findings and controversies. - Evol. Biol. 43: 481-497.

Mesoudi, A. et al. 2006. Towards a unified science of cultural evolution. - Behav. Brain Sci. 29: 329347.

Moles, A. T. and Westoby, M. 2004. What do seedlings die from and what are the implications for evolution of seed size? - Oikos 106: 193-199.

Moles, A. T. and Westoby, M. 2006. Seed size and plant strategy across the whole life cycle. - Oikos 113: 91-105.

Moles, A. T. et al. 2012. Invasions: the trail behind, the path ahead, and a test of a disturbing idea. J. Ecol. 100: 116-127.

Mologni, F. et al. 2021. Similar yet distinct distributional patterns characterize native and exotic plant species richness across islands in New Zealand. - J. Biogeogr. 48: 1731-1745.

Moody, A. 2000. Analysis of plant species diversity with respect to island characteristics on the Channel Islands, California. - J. Biogeogr. 27: 711-723.

Morrison, L. W. 2010. Long-term non-equilibrium dynamics of insular floras: a 17-year record. - Glob. Ecol. Biogeogr. 19: 663-672.

Morrison, L. W. 2014. The small-island effect: empty islands, temporal variability and the importance of species composition. - J. Biogeogr. 41: 1007-1017.

Morrison, L. W. and Spiller, D. A. 2008. Patterns and processes in insular floras affected by hurricanes. - J. Biogeogr. 35: 1701-1710.

Moser, D. et al. 2018. Remoteness promotes biological invasions on islands worldwide. - Proc. Natl. Acad. Sci. U. S. A. 115: 9270-9275.

Muller-Landau, H. C. et al. 2008. Interspecific variation in primary seed dispersal in a tropical forest. J. Ecol. 96: 653-667. 
Napolitano, M. F. et al. 2019. Reevaluating human colonization of the Caribbean using chronometric hygiene and Bayesian modeling. - Sci. Adv. in press.

Negoita, L. et al. 2016. Isolation-driven functional assembly of plant communities on islands. Ecography 39: 1066-1077.

Neufeld, C. J. et al. 2017. Disturbance and diversity in a continental archipelago: a mechanistic framework linking area, height, and exposure. - Ecosphere in press.

New Zealand Plant Conservation Network 2020. New Zealand Plant Conservation Network.

$\mathrm{Ni}, \mathrm{M}$. et al. 2021. Invasion success and impacts depend on different characteristics in non-native plants. - Divers. Distrib.: 1-14.

Nielsen, P. and Hanslow, D. J. 1991. Wave runup distributions on natural beaches. - J. Coast. Res. 7: 1139-1152.

Nogales, M. et al. 2012. Evidence for overlooked mechanisms of long-distance seed dispersal to and between oceanic islands. - New Phytol. 194: 313-317.

Novosolov, M. et al. 2013. The island syndrome in lizards. - Glob. Ecol. Biogeogr. 22: 184-191.

Oksanen, J. et al. 2020. vegan: community Ecology Package. R package version 2.5-7. in press.

Olden, J. D. et al. 2004. Ecological and evolutionary consequences of biotic homogenization. - Trends Ecol. Evol. 19: 18-24.

Ottaviani, G. et al. 2020. Linking plant functional ecology to island biogeography. - Trends Plant Sci. 25: 329-339.

Patiño, J. et al. 2017. A roadmap for island biology: 50 fundamental questions after 50 years of The Theory of Island Biogeography. - J. Biogeogr. 44: 963-983.

Paudel, S. et al. 2017. Determinants of native and non-native plant community structure on an oceanic island. - Ecosphere 8: 1-18.

Peay, K. G. et al. 2007. A strong species-area relationship for eukaryotic soil microbes: island size matters for ectomycorrhizal fungi. - Ecol. Lett. 10: 470-480.

Peel, M. C. et al. 2007. Updated world map of the Koppen-Geiger climate classification. - Hydrol. Earth Syst. Sci. 11: 1633-1644.

Pérez-Harguindeguy, N. et al. 2013. New handbook for standardised measurement of plant functional traits worldwide. - Aust. J. Bot. 61: 167-234.

Pickrill, R. A. and Mitchell, J. S. 1979. Ocean wave characteristics around New Zealand. - New Zeal. J. Mar. Freshw. Res. 13: 501-520.

Pinheiro, H. T. et al. 2017. Island biogeography of marine organisms. - Nature 549: 82-85.

Powell, K. I. et al. 2013. Invasive plants have scale-dependent species-area relationships. - Science (80-. ). 339: 317-319.

Pretto, F. et al. 2012. Determinants of non-native plant species richness and composition across small Mediterranean islands. - Biol. Invasions 14: 2559-2572.

Prober, S. M. and Wiehl, G. 2012. Relationships among soil fertility, native plant diversity and exotic plant abundance inform restoration of forb-rich eucalypt woodlands. - Divers. Distrib. 18: 795807. 
Pyšek, P. and Richardson, D. M. 2006. The biogeography of naturalization in alien plants. - J. Biogeogr. 33: 2040-2050.

QGIS Development Team 2018. QGIS Geographic Information System 2. in press.

Qian, H. and Ricklefs, R. E. 2006. The role of exotic species in homogenizing the north American flora. - Ecol. Lett. 9: 1293-1298.

Qiaoling, Y. et al. 2005. Relationship of seed production, seed morphology and life form of plant species. - Acta Prataculturae Sin. 14: 21-28.

R Core Team 2020. R: A language and environment for statistical computing. in press.

Reich, P. B. 2014. The world-wide "fast-slow" plant economics spectrum: a traits manifesto. - J. Ecol. 102: 275-301.

Rojas-Sandoval, J. et al. 2020. Island biogeography of native and alien plant species: contrasting drivers of diversity across the Lesser Antilles. - Divers. Distrib.: 1539-1550.

Rosenzweig 1995. Species diversity in space and time. - Cambridge University Press.

Rothwell, H. 1975. The Treaty of Paris, 1259. - English Hist. Doc. Vol. III, 1189 - 1327

Royal Botanic Gardens Kew 2020. Seed Information Database (SID). Version 7.1.

Ruggiero, P. et al. 2004. Wave run-up on a high-energy dissipative beach. - J. Geophys. Res. C Ocean. 109: 1-12.

Russell, J. C. et al. 2004. Island biogeography and the species richness of introduced mammals on New Zealand offshore islands. - J. Biogeogr. 31: 653-664.

Safford, H. D. and Harrison, S. P. 2001. Grazing and substrate interact to affect native vs. exotic diversity in roadside grasslands. - Ecol. Appl. 11: 1112-1122.

Sampson, F. B. 1980. Island biogeography and the conservation of prarie birds. - Proc. Seventh North Am. Prarie Conf. 7: 293-299.

Sanchez-Ortiz, K. et al. 2019. Effects of land--use change and related pressures on alien and native subsets of island communities. - bioRxiv: 1-19.

Sandin, S. A. et al. 2008. Island biogeography of Caribbean coral reef fish. - Glob. Ecol. Biogeogr. 17: 770-777.

Santos, A. M. C. et al. 2021. The human dimension of biodiversity changes on islands. 491: 488-491.

Sax, D. F. and Gaines, S. D. 2008. Species invasions and extinction: the future of native biodiversity on islands. - Proc. Natl. Acad. Sci. 105: 11490-11497.

Sax, D. F. et al. 2002. Species invasions exceed extinctions on islands worldwide: a comparative study of plants and birds. - Am. Nat. 160: 1-18.

Schmack, J. M. et al. 2020. Biogeography and anthropogenic impact shape the success of invasive wasps on New Zealand's offshore islands. - Divers. Distrib. 26: 441-452.

Schrader, J. et al. 2019. Plants on small islands revisited: the effects of spatial scale and habitat quality on the species-area relationship. - Ecography 0: 1-10.

Schrader, J. et al. 2020. Species-area relationships on small islands differ among plant growth forms. - Glob. Ecol. Biogeogr. 29: 814-829. 
Seabloom, E. W. et al. 2007. Human impacts, plant invasion, and imperiled plant species in California. - Ecol. Appl. 16: 1338-1350.

Shane, P. et al. 2013. Longevity of a small shield volcano revealed by crypto-tephra studies (Rangitoto volcano, New Zealand): change in eruptive behavior of a basaltic field. - J. Volcanol. Geotherm. Res. 257: 174-183.

Shmida, A. and Wilson, M. V. 1985. Biological determinants of species diversity. - J. Biogeogr. 12: 120.

Simberloff, D. et al. 2013. Impacts of biological invasions: what's what and the way forward. - Trends Ecol. Evol. 28: 58-66.

Sinclair, J. S. et al. 2020. A framework for predicting which non-native individuals and species will enter, survive, and exit human-mediated transport. - Biol. Invasions 22: 217-231.

Small, C. and Naumann, T. 2001. The global distribution of human population and recent volcanism. Environ. Hazards 3: 93-109.

Small, C. and Cohen, J. E. 2004. Continental physiography, climate, and the global distribution of human population. - Curr. Anthropol. 45: 269-277.

Small, C. et al. 2000. Coastal hazards and the global distribution of human population. - Environ. Geosci. 7: 3-12.

Smith, M. D. and Knapp, A. K. 1999. Exotic plant species in a $\mathrm{C}_{4}$-dominated grassland: invasibility, disturbance, and community structure. - Oecologia 120: 605-612.

Smith, N. S. and Côté, I. M. 2019. Multiple drivers of contrasting diversity-invasibility relationships at fine spatial grains. - Ecology 100: 1-11.

Soininen, J. et al. 2007. The distance decay of similarity in ecological communities. - Ecography (Cop.). 30: 3-12.

Statistics NZ Tatauranga Aotearoa 2018. Urban Area 2017 (generalised version). - 22 Novemb.

Stockdon, H. F. et al. 2006. Empirical parameterization of setup, swash, and runup. - Coast. Eng. 53: 573-588.

Stohlgren, T. J. et al. 1999. How grazing and soil quality affect native and exotic plant diversity in Rocky Mountain grasslands. - Ecol. Appl. 9: 45-64.

Stohlgren, T. J. et al. 2006. Species richness and patterns of invasion in plants, birds, and fishes in the United States. - Biol. Invasions 8: 427-447.

Stohlgren, T. J. et al. 2007. The rich get richer: patterns of plant invasions in the United States. Front. Ecol. Environ. 1: 11-14.

Stotz, G. C. et al. 2019. Biotic homogenization within and across eight widely distributed grasslands following invasion by Bromus inermis. - Ecology 100: 1-13.

Suding, K. N. and Gross, K. L. 2006. Modifying native and exotic species richness correlations: the influence of fire and seed addition. - Ecol. Appl. 16: 1319-1326.

Sullivan, J. J. et al. 2005. Movement of exotic plants into coastal native forests from gardens in northern New Zealand. - N. Z. J. Ecol. 29: 1-10.

Swenson, N. G. et al. 2006. The problem and promise of scale dependency in community phylogenetics. - Ecology 87: 2418-2424. 
Tackenberg, O. 2003. Modeling long-distance dispersal of plant diaspores by wind. - Ecol. Monogr. 73: 173-189.

Tamme, R. et al. 2014. Predicting species' maximum dispersal distances from simple plant traits. Ecology 95: 505-513.

Taylor, A. et al. 2021. Functional traits are key to understanding orchid diversity on islands. Ecography 0: 1-12.

Terry, J. P. 2007. Tropical cyclones: climatology and impacts in the South Pacific. - Springer.

The Editors of Encyclopaedia Britannica 2011. Zhoushan Archipelago. - Encycl. Br.

The Editors of Encyclopaedia Britannica 2020. Samoa. - Encycl. Br.

Thomson, F. J. et al. 2011. Seed dispersal distance is more strongly correlated with plant height than with seed mass. - J. Ecol. 99: 1299-1307.

Thorsen, M. J. et al. 2009. Seed dispersal systems in the New Zealand flora. - Perspect. Plant Ecol. Evol. Syst. 11: 285-309.

Timmins, S. M. and Williams, P. A. 1991. Weed numbers in New Zealand's forest and scrub reserves. - N. Z. J. Ecol. 15: 153-162.

Tjørve, E. and Tjørve, K. M. C. 2017. Species-area relationships. - In: Ltd, eLS J. W. \& S. (ed), pp. 1-9.

Toft, C. A. et al. 2016. Abundance and diversity of orb spiders on 106 Bahamian islands: biogeography at an intermediate trophic level. - Oikos 41: 411-426.

Tomasetto, F. et al. 2019. Resolving the invasion paradox: pervasive scale and study dependence in the native-alien species richness relationship. - Ecol. Lett.: 1038-1046.

Towns, D. R. et al. 1990. Ecological restoration of New Zealand islands (DR Towns, CH Daugherty, and IAE Atkinson, Eds.). - Department of Conservation.

Triantis, K. A. and Sfenthourakis, S. 2012. Island biogeography is not a single-variable discipline: the small island effect debate. - Divers. Distrib. 18: 92-96.

Turner, W. R. and Tjørve, E. 2005. Scale-dependence in species-area relationships. - Ecography 28: 721-730.

Valery, L. et al. 2009. Invasive species can also be native... - Trends Ecol. Evol. 24: 585.

van der Pijl, L. 1982. Principles of dispersal in higher plants. - Springer-Verlag Berlin Heidelberg.

Van Kleunen, M. et al. 2010a. A meta-analysis of trait differences between invasive and non-invasive plant species. - Ecol. Lett. 13: 235-245.

Van Kleunen, M. et al. 2010b. Are invaders different? A conceptual framework of comparative approaches for assessing determinants of invasiveness. - Ecol. Lett. 13: 947-958.

Wallace, A. R. 1880. Island life. - MacMillan Publishing Company, Inc.

Walter, R. et al. 2017. Mass migration and the Polynesian settlement of New Zealand. - J. World Prehistory 30: 351-376.

Wang, Y. et al. 2016. On empty islands and the small-island effect. - Glob. Ecol. Biogeogr. 25: 13331345.

Wardle, P. 1991. Vegetation of New Zealand. - The Blackburn Press. 
Warren, B. H. et al. 2015. Islands as model systems in ecology and evolution: prospects fifty years after MacArthur-Wilson. - Ecol. Lett. 18: 200-217.

Weigelt, P. and Kreft, H. 2013. Quantifying island isolation - insights from global patterns of insular plant species richness. - Ecography 36: 417-429.

Whitehead, D. R. and Jones, C. E. 1969. Small islands and the Equilibrium Theory of Insular Biogeography. - Evolution (N. Y). 23: 171-179.

Whiten, A. 2019. Cultural evolution in animals. - Annu. Rev. Ecol. Evol. Syst. 50: 27-48.

Whittaker, R. J. 1995. Disturbed island ecology. - Trends Ecol. Evol. 10: 421-425.

Whittaker, R. J. 2000. Scale, succession and complexity in island biogeography. - Glob. Ecol. Biogeogr. 9: 75-86.

Whittaker, R. J. and Fernández-Palacios, J. M. 2007. Island biogeography: ecology, evolution, and conservation. - Oxford University Press.

Whittaker, R. J. et al. 2014. Functional biogeography of oceanic islands and the scaling of functional diversity in the Azores. - Proc. Natl. Acad. Sci. 111: 13709-13714.

Whittaker, R. J. et al. 2017. Island biogeography: taking the long view of natures laboratories. Science (80-. ). in press.

Wiens, J. A. 1989. Spatial scaling in ecology. - Funct. Ecol. 3: 385-397.

Williams, P. A. and Cameron, E. K. 2006. Creating gardens: the diversity and progression of european plan introductions. - In: R.B. Allen \& W.G. Lee (ed), Biological Invasion in New Zealand. Springer, pp. 33-48.

Wilmshurst, J. M. et al. 2014. Use of pollen and ancient DNA as conservation baselines for offshore islands in New Zealand. - Conserv. Biol. 28: 202-212.

Wright, A. E. 1980. Vegetation and flora of Fanal Island, Mokohinau Group. - Tane 26: 25-43.

$\mathrm{Yu}, \mathrm{M}$. et al. 2012. Richness and composition of plants and birds on land-bridge islands: effects of island attributes and differential responses of species groups. - J. Biogeogr. 39: 1124-1133.

Yu, F. et al. 2015. Multi-scale comparison of topographic complexity indices in relation to plant species richness. - Ecol. Complex. 22: 93-101.

Yue, T. X. et al. 2005. Surface modelling of human population distribution in China. - Ecol. Modell. 181: 461-478.

Zeileis, A. and Grothendieck, G. 2005. Zoo: S3 infrastructure for regular and irregular time series. - J. Stat. Softw. 14: 1-27.

Zimmerman, J. K. et al. 1996. Disturbance and Caribbean Ecosystems. - Biotropica 28: 414-423.

Zuur, A. F. et al. 2010. A protocol for data exploration to avoid common statistical problems. Methods Ecol. Evol. 1: 3-14. 


\section{Appendix 1}

\section{References for species richness sources (chapters 2 and 3 )}

Atkinson, I.A.E. (1962) Report on the smaller Mercury Islands and Ohena Island (Unpublished), Auckland, New Zealand.

Atkinson, I.A.E. (1962) The flora and vegetation of Old Man Rock, Mercury Islands Group. Transactions of the Royal Society of New Zealand: Botany, 1, 285-287.

Atkinson, I.A.E. (1972) Vegetation and flora of sail rock, hen and chickens Islands. New Zealand Journal of Botany, 10, 545-558.

Atkinson, I.A.E. (1964) The flora, vegetation, and soils of Middle and Green Islands, Mercury Islands group. New Zealand Journal of Botany, 2, 385-402.

Beadel, S. (2017) Matakana Island field trip 12 Nov 2016 + species list. Rotorua Botanical Society Newsletter, 68, 6-18.

Beadel, S. (1990) Indigenous vascular plants of an unnamed island Opoutere. Rotorua Botanical Society Newsletter, 19, 10.

Beever, R.E., Esler, A.E. \& Wright, A.E. (1984) Botany of the large islands of the Eastern Bay of Islands, northern New Zealand. Tane, 30, 251-273.

Beever, R.E., Parris, B.S. \& Beever, J.E. (1969) Studies of the vegetation of Cuvier Island. I. The plant communities and a vascular plant species list. Tane, 15, 53-68.

Benham, S. (1996) Auckland Botanical Society Field Visit to Motu Hawere (Goat Island) Rodney District Auckland 16th March 1996. Auckland Botanical Society Journal, 51, 49-52.

Benham, S., Wilcox, M., Davidson, G., Davidson, B., Waipara, N., Wilcox, M., Benham, S. \& Hutton, P. (2008) A visit to The Noises Islands, Hauraki Gulf. auckland Botanical Society Journal, 63, 18-21.

Cameron, E.K. \& Taylor, G.A. (2008) Vascular flora and birds of Horuhoru Rock (Gannet Rock), off northern Waiheke Island, Hauraki Gulf, Auckland. Auckland Botanical Society Journal, 63, 4247.

Cameron, E.K. \& Wright, A.E. (1990) Additional vascular plant records for Fanal Island, Mokohinau Islands. Tane, 32, 133-136.

Cameron, E.K. (1999) Botany of Whangapoua wetlands and dunes, north-east Great Barrier Island. Auckland Botanical Society Journal, 54, 56-67.

Cameron, E.K. (2013) Vascular flora (and some fauna) of islands/islets of the Hauraki Gulf. Auckland Botanical Society Journal, 68, 27-34.

Cameron, E.K. (2012) Mathesons Bay islet near Leigh, Auckland. Auckland Botanical Society Journal, 175-177.

Cameron, E.K. (2015) Vascular flora of an islet, Oruawharo, Medlands Beach, eastern Great Barrier Island. 2Auckland Botanical Society Journal, 70, 35-39.

Cameron, E.K. (2014) Updated flora and vegetation of Te Haupa (Saddle) Island, Mahurangi, Hauraki Gulf. 2Auckland Botanical Society Journal, 69, 127-142. 
Cameron, E.K. (2015) Flora and vegetation of Motuketekete, and updated flora of the Moturekareka group, Hauraki Gulf. Auckland Botanical Society Journal, 70, 77-104.

Cameron, E.K. (2013) Updated vascular flora of Wooded Island, off Tiritiri Matangi Island. Auckland Botanical Society Journal 68: 69-74. Auckland Botanical Society Journal, 68, 69-74.

Cameron, E.K. (2010) Updated vascular flora for the seven-island chain east and southeast of Waiheke Island. Auckland Botanical Society Journal, 65, 37-38.

Cameron, E.K. (1995) Notes on the vegetation and flora of Kaikoura Island. Auckland Botanical Society Journal, 50, 71-77.

Cameron, E.K. (1984) Vascular plants of the three largest Chickens (Marotere) Islands: Lady Alice, Whatupuke, Coppermine: north-east New Zealand. Tane, 30, 53-75.

Cameron, E.K., Lindsay, J. \& Wilcox, M.D. (2010) A Society visit to Motuora Island, Hauraki Gulf, 16 Oct 2010. Auckland Botanical Society Journal, 66, 67-71.

Cameron, E.K. \& Taylor, G.A. (1997) Flora and fauna of Sentinel Rock, Mangawhai Heads, northern New Zealand. Tane, 36, 15-25.

Cameron, E.K., Taylor, G.A., Tennyson, A.J.D., Wilcox, M.D. \& Young, M.E. (2011) Biota of Challenger and Little Markham Islands, off Kawau Island, Hauraki Gulf. Auckland Botanical Society Journal, 66, 112-121.

Cameron, E.K. \& Wilcox, M.D. (2012) Paratahi Island. Karekare - revisited. Auckland Botanical Society Journal, 67, 60-64.

Cameron, E.K. \& Wright, A.E. (1990) Vascular plants of Maori Rocks, Mokohinau Islands. Tane, 32, 131-132.

Cameron, E.K. \& Young, M.E. (2019) Vegetation and vascular flora. Hauturu - the history, flora and fauna of Te Hauturu-o-Toi Little Barrier (ed. by L. Wade) and D. Veitch), pp. 166-213, 296-317. Massey University Press, Auckland, New Zealand.

Cameron, E.K. (1991) Additional vascular plant records for the Chicken Islands, north-east New Zealand. Tane, 33, 87-88.

Cameron, E.K. (1990) Vascular plants of the main Northern Mokohinau Islands, North-east New Zealand. Tane, 32, 113-130.

Cameron, E.K. (2017) List of wild vascular plants for Moturoa Island in western Bay of Islands, and additional planted indigenous species. Auckland Botanical Society Journal, 72, 23-29.

Cameron, E.K. (1986) Vascular flora and vegetation of Rimariki and associated islands, Mimiwhangata, north-east New Zealand. Tane, 31, 47-74.

Cameron, E.K. (1999) Bot Soc trip to the Moturekareka group, Hauraki Gulf. Auckland Botanical Society Journal, 54, 8-13.

Cameron, E.K. (1999) Flora and fauna of a rocky islet, Waikawau Bay, Coromandel Peninsula. Tane, 37, 153-158.

Cameron, E.K. (1996) Flora of Kauritutahi Island, Awhitu. Auckland Botanical Society Journal, 51, 3436.

Cameron, E.K. (1998) Bot Soc trips to The Noises (Hauraki Gulf) and an updated species list. Auckland Botanical Society Journal, 53, 25-35. 
Cameron, E.K. (1992) Great Barrier Island: an addition. Auckland Botanical Society Journal, 47, 50.

Cameron, E.K. (1992) Motukaraka, Beachlands - trip observations. Auckland Botanical Society Journal, 47, 17-18.

Cameron, E.K. (1992) Vascular flora of Kawetoto Reef, Waikawau Bay, Coromandel Peninsula. Auckland Botanical Society Journal, 47, 29-31.

Cameron, E.K. (1991) Motumanawa (Pollen Island) trip observations. Auckland Botanical Society Journal, 46, 17.

Cameron, E.K. (1990) Flora and vegetation of Motumanawa (Pollen) Island, Waitemata Harbour, Auckland. Auckland Botanical Society Journal, 45, 9-17.

Cameron, E.K. (1988) Watchman Island - Waitemata Harbour. Auckland Botanical Society Journal, $43,58-60$.

Cameron, E.K. (2009) Updated Vascular Flora of Pakihi Island, with notes on fauna, geology and some history, Hauraki Gulf, Auckland. Auckland Botanical Society Journal, 64, 154-169.

Cameron, E.K. (2009) Te Matuku Bay catchment, Waiheke Island (ABS camp, January 1994). Auckland Botanical Society Journal, 64, 54-69.

Cameron, E.K. (2009) Great Barrier Island field trip, 5-9 February 2009. Auckland Botanical Society Journal, 64, 34-45.

Cameron, E.K. (2006) Vascular flora and fauna of twelve small northern New Zealand islands. Auckland Botanical Society Journal, 61, 99-108.

Cameron, E.K. (2007) The Vascular Flora of Motu Kaikoura, Fitzroy Harbour, Great Barrier Island. Auckland Botanical Society Journal, 62, 78-95.

Cameron, E.K. (2003) Vascular flora of 3 inshore islands, south-east coast Great Barrier Island. Auckland Botanical Society Journal, 51, 61-70.

Cameron, E.K. (2005) Flora and fauna of two islets at Opoutere, southeast Coromandel Peninsula. Auckland Botanical Society Journal, 60, 97-102.

Cameron, E.K. (1982) Vascular plants of an unclassified islet, Cape Brett Peninsula, northern New Zealand. Tane, 28, 213-220.

Cameron, E.K. (2000) Field trip to southern Ponui Island, Hauraki Gulf, Auckland. Auckland Botanical Society Journal, 55, 34-38.

Cameron, E.K. (2016) Vascular flora of two high-tide islets on Medlands Beach, eastern Great Barrier Island. Auckland Botanical Society Journal, 71, 35-40.

Cameron, E.K. (1990) Flora and vegetation of Middle Island, Mercury Islands Group, eastern Coromandel, northern New Zealand. Journal of the Royal Society of New Zealand, 20, 273-285.

Cameron, E.K. (2008) Orona Island, eastern Manukau Harbour, Auckland. Auckland Botanical Society Journal, 63, 33-38.

Cameron, E.K. \& Beard, C.M. (1990) Moturemu Island - Kaipara Harbour. Auckland Botanical Society Journal, 45, 5-8.

Cameron, E.K. \& Bellingham, P.J. (2005) Vascular flora of Rakitu (Arid Island): additions and comments. Auckland Botanical Society Journal, 60, 102-107.

Cameron, E.K. \& Davies, N.C. (2013) Changes in the wild vascular flora of Tiritiri Matangi Island, 
1978-2010. New Zealand Journal of Ecology, 37, 307-342.

Cameron, E.K., de Lange, P.J., McCallum, J., Taylor, G.A. \& Bellingham, P.J. (2007) Vascular flora and some fauna for a chain of six Hauraki Gulf islands east and southeast of Waiheke Island. Auckland Botanical Society Journal, 62, 136-156.

Cameron, E.K. \& de Lange, P.J. (2006) Vegetation and vascular flora of southern Ponui Island, Hauraki Gulf - a return visit. 16/10/05. Auckland Botanical Society Journal, 61, 3-14.

Cameron, E.K., Preston-Jones, H., Jane, G. \& Wilcox, M. (2002) Great Barrier Island, Anniversary Weekend 25-28 January 2002. Auckland Botanical Society Journal, 57, 76-84.

Cameron, E.K. \& Taylor, G.A. (1992) Flora and vegetation of an islet off Ponui Island, Hauraki Gulf, Auckland. Auckland Botanical Society Journal, 47, 23-29.

Cameron, E.K. \& Taylor, G.A. (1991) Flora and fauna of Motukokako (Piercy Island), Cape Brett, Northern New Zealand. Tane, 33, 121-142.

Cameron, E.K. \& Taylor, G.A. (1990) Flora and vegetation of Motukaraka (Flat Island) - Beachlands, South-east Auckland. Auckland Botanical Society Journal, 45, 62-70.

Cameron, E.K. \& Taylor, G.A. (1991) Flora and vegetation of Pudding Island - Mahurangi. Auckland Botanical Society Journal, 46, 20-23.

Cameron, E.K., Taylor, G.A. \& Beever, J.E. (1995) Flora and Vegetation of Taimoto and Nun Rock, South Piha, West Auckland. Auckland Botanical Society Journal, 50, 14-18.

Cameron, E.K., Taylor, G.A. \& Courtney, S.P. (2009) Vascular flora and vertebrate fauna of Saddle Island, Grey Group Islands, western Great Barrier Island. Auckland Botanical Society Journal, 64, 98-102.

Cameron, E.K. \& Wright, A.E. (1982) The vegetation and flora of Rakitu (Arid) Island, northern New Zealand. Tane, 28, 85-124.

Cashmore, P. (2010) Pataua Island Scientific Reserve and Opotiki Domain field trip. Rotorua Botanical Society Newsletter, 55, 46-54.

Cashmore, P. \& Crump, S. (2009) Motuotau (Rabbit) Island Scenic Reserve - an update. Rotorua Botanical Society Newsletter, 19-22.

Cashmore, P., Crump, S., Brill, S., Jones, A. \& Heaphy, J. (2009) Additions to vascular plant species list for Motuotau Island. Rotorua Botanical Society Newsletter, 52, 23.

Cashmore, P. (2008) Vegetation and flora of Volkner Rocks (Te Paepae Aotea) and Club Rock revisited. Rotorua Botanical Society Newsletter, 50, 28-32.

Clarkson, B.D., Bylsma, R.J., Efford, J.T., Clarkson, B.R. \& Kirby, C.L. (2014) Vegetation change (19682013) on a small rock stack adjoining Slipper Island (Whakahau), Coromandel, New Zealand. New Zealand Journal of Botany, 52, 453-459.

Clarkson, B.D., Clarkson, B.R. \& Juvik, J.O. (2015) Pattern and process of vegetation change (succession) on two northern New Zealand island volcanoes. Surtsey Research, 13, 45-48.

Clarkson, B.D., Clarkson, B.R. \& Smale, M.C. (1989) Appendix 1 - Vegetation destruction and recovery following recent eruptions on White Island (Whakaari), Bay of Plenty, New Zealand. New Zealand Geological Survey bulletin, 103, 137-138.

Clarkson, B.D., Clarkson, B.R. \& Smale, M.C. (1986) Vegetation destruction and recovery following recent eruptions on White Island (Whakaari), Bay of Plenty, New Zealand. 
Clarkson, B.D. \& Spring-Rice, B. (1992) Vegetation and flora of Motuotau Island, Bay of Plenty. Rotorua Botanical Society Newsletter, 26, 8-15.

Court, D.J., Wright, A.E., Hayward, B.W. \& Hayward, G.C. (1974) Botany of Shoe Island and the Slipper Island Group - Coromandel Peninsula. Tane, 20, 56-85.

Court, D.J., Hardacre, A.K. \& Lynch, P.A. (1973) The vegetation of the Aldermen Islands: a reppraisal. Tane, 19, 41-60.

De Lang, P.J. \& Murray, B.G. (1998) Senecio repangae (asteraceae): A new endemic species from the north-eastern North Island, New Zealand. New Zealand Journal of Botany, 36, 509-519.

de Lange, P.J. (1990) Additions and confirmations to the flora of Great Barrier. Auckland Botanical Society Journal, 45, 22-23.

de Lange, P.J. \& Cameron, E.K. (1999) The vascular flora of Aorangi Island, Poor Knights Islands, northern New Zealand. New Zealand Journal of Botany, 37, 433-468.

de Lange, P.J. \& Crowcroft, G.M. (1999) The vascular flora of Motuihe Island Recreation Reserve. Auckland Botanical Society Journal, 54, 19-30.

de Lange, P.J. \& Crowcroft, G.M. (1995) The vegetation and vascular flora of "Ihumatao Islet" a small artificial islet near Ihumatao, Manukau Harbour. Auckland Botanical Society Journal, 50, 50-52.

de Lange, P.J. \& de Lange, T.J. (2010) Vascular flora of Hauturu (Clarks Island), Whangamata. 2.

de Lange, P.J., Forester, L.J. \& Parrish, G.R. (1993) Vascular Flora of Walker Island Rangaunu Harbour. Auckland Botanical Society Journal, 48, 17-20.

de Lange, P.J., Cameron, E.K. \& Taylor, G.A. (1995) Flora and fauna of Tatapihi (Groper) Island, Mokohinau Islands. Tane, 35, 69-94.

de Lange, P.J. \& Cameron, E.K. (2011) Lepidium flexicaule - a new location from northern New Zealand. New Zealand Botanical Society Newsletter, 103, 17-18.

de Lange, P.J. \& McFadden, I. (1995) Additions and comments on the flora and fauna of Motukahakaha Island, Hauraki Gulf, Auckland. Auckland Botanical Society Journal, 50, 22-26.

Dickson, E.M. (1973) Stephensons Island, Whangaroa and Motukawanui, Cavalli Islands: vegetation report to Lands and Survey Dept., Auckland, New Zealand.

Esler, A.E. (1978) Botanical features of islands near the west coast of the Coromandel Peninsula, New Zealand. New Zealand Journal of Botany, 16, 25-44.

Esler, A.E. (1980) Botanical features of Motutapu, Motuihe, And Motukorea, Hauraki Gulf, New Zealand. New Zealand Journal of Botany, 18, 15-36.

Esler, A.E. (1977) The Grassland of Great Mercury Island. Tane, 23, 83-84.

Forester, L.J. (1993) Vascular plants and vegetation of Motuopao, Northland, New Zealand. Tane, 34, 33-44.

Forester, L.J. \& J., A.P. (1995) Vascular plants, vegetation and wildlife of Matapia Island, far north, New Zealand. Tane, 35, 39-50.

Gardner, R.O. (1993) Some plants of Kawau Island. Auckland Botanical Society Journal, 48, 23-27.

Goodwin, B. (2018) Vegetation of Motuarahi Island, Paihia, Bay of Islands. Auckland Botanical Society Journal, 73, 41-44. 
Gordon, D.P. \& Ballantine, W.J. (1977) Cape Rodney to Okakari Point marine reserve - Review of Knowledge and Bibliography to December 1976. Tane, 22, 1-146.

Hall, K.L. (2011) The botany of Kopuahingahinga Island, Pahurehure Inlet, Auckland. Auckland Botanical Society Journal, 66, 108-111.

Heiss-dunlop, S. \& Fillery, J. (2006) Vascular flora of Motuora Island, Hauraki Gulf. Auckland Botanical Society Journal, 61, 113-120.

Hicks, G.R.F., McColl, H.P., Meads, M.J., Hardy, G.S. \& Roser, R.J. (1975) An ecological reconnaissance of Korapuki Island. Notornis, 22, 195-220.

Lee, M. (1999) Biota of seven islets off Waiheke Island, inner Hauraki Gulf. Tane, 37, 99-136.

Lynch, P.A., Ferguson, E.J. \& Hynes, P. (1972) The Vegetation of Red Mercury Island. Part 1: The plant communities and a vascular plant species list. Tane, 18, 21-29.

Millett, J. (2010) Trip report: Kawau Island, 20 March 2010. Auckland Botanical Society Journal, 65, 74-76.

Ogle, C.C. (1990) Changes in the vegetation and vacscular flora of Motuhora (Whale Island) 19701986. Tane, 32, 19-48.

Ritchie, M.A. \& Ritchie, I.M. (1970) An ecological survey of Whatupuke Islands, Hen and Chickens Group. Proceedings of the New Zealand Ecological Society, 17, 57-65.

Russell, J.C., Cameron, E.K., Mackay, J.W.B., Dudley, J.L. \& Clout, M.N. (2006) Ecological survey of Motukaraka (Flat Island), Beachlands, Auckland. Auckland Botanical Society Journal, 61, 57-61.

Sander, W.W.E. (1975) Some botanical features of Simmonds Islands, Great Exhibition Bay. Tane, 21, 101-104.

Shaw, W. \& Clarkson, B. (1991) Vegetation of Taumaihi Island. Rotorua Botanical Society Newsletter, 23, 26-30.

Silvester, R.E. (1985) Easter weekend on Mayor Island. Auckland Botanical Society Journal, 40, 22.

Smith-Dodsworth, J. (1992) Additions to plant lists in "Botanical features of islands near the west coast of the Coromandel peninsula, New Zealand", Esler, A.E. 1978: NZ Journal of Botany (16) 25-44. Rotorua Botanical Society Newsletter, 26, 19.

Spring-Rice, B. (1991) Motiti Island field trip: 13 April 1991. Rotorua Botanical Society Newsletter, 23, 21-25.

Stanley, B., Todd, P. \& Wilson, G. (2003) Botanical features (with notes on fauna) of Aiguilles Island (Te Motu o Nga Tara Tara o Toi). Auckland Botanical Society Journal, 58, 119-122.

Taylor, G.A., Lovegrove, T.G., Miskelly, C.M., McFadden, I. \& Whitaker, A.H. (1997) An ecological survey of small islands in the Mercury Group. Tane, 36, 151-167.

Taylor, G.A. (1995) Flora and fauna of Needle Rock, Eastern Coromandel. Tane, 35, 51-56.

Taylor, G.A. (1990) Falora and fauna of a small stack off Whangaparaoa Beach, Cape Runaway. Tane, $32,149-150$.

Taylor, G.A. (1991) Flora and fauna of Plate (Motunau) Island, Bay of Plenty. Tane, 33, 113-120.

Taylor, G.A. \& Cameron, E.K. (1990) Kauwahaia Island - Te Henga, West Auckland. Auckland Botanical Society Journal, 45, 71-77. 
Taylor, G.A. \& Lovegrove, T.G. (1997) Flora and vegetation of Stanley (Atiu) Island, Mercury Islands. Tane, 36, 85-111.

Taylor, G.A. \& Tennyson, A.J.D. (1999) Flora and fauna of Wooded Island, inner Hauraki Gulf. Tane, $37,91-98$.

Tennyson, A.J. (1995) Flora of Karewa Island, Bay of Plenty. Tane', 35, 17-23.

Tennyson, A.J.D., Cameron, E.K. \& Taylor, G.A. (1997) Fauna, flora and history of Moturekareka, Motutara and Kohatutuara Islands, Hauraki Gulf. Tane, 36, 27-56.

Tennyson, A.J.D. \& Taylor, G.A. (1999) History, fauna and flora of Te Haupa (Saddle) Island, Hauraki Gulf. Tane, 37, 69-89.

Wilcox, M.D. (2007) Natural History of Rangitoto Island, (ed. by M.D. Wilcox) Auckland Botanical Society, Auckland, New Zealand.

Wilcox, M. (1999) Motuihe Island. Auckland Botanical Society Journal, 54, 42-43.

Wilcox, M., Donaghy, G., Haines, L., Jane, G., McSweeney, C. \& Young, M. (2005) Field Trip: Coromandel Peninsula, Auckland Anniversary Weekend 28/01/05 to 01/02/05. Auckland Botanical Society Journal, 60, 1-12.

Wilcox, M. \& Jane, G. (2009) Waiheke Island: Labour Weekend, October 2008. Auckland Botanical Society Journal, 64, 24-27.

Wilcox, M., Shanks, J. \& de Lange, P.J. (2012) A visit to Tuhua (Mayor Island). Auckland Botanical Society Journal, 67, 17-33.

Wilcox, M., Spence, A. \& White, P. (2002) Botanical features of Whakanewha Regional Park Waiheke Island. Auckland Botanical Society Journal, 57, 34-46.

Wilcox, M., Young, M., Beever, J. \& Kooperberg, R. (2004) Vegetation and flora of North Cove, Sandy Bay and Vivian Bay, Kawau Island. Auckland Botanical Society Journal, 59, 16-30.

Wilcox, M., Young, M., Cruickshank, G. \& Millett, J. (2005) Plant records from the Swansea Bay - Mt Taylor area, Kawau Island. auckland Botanical Society Journal, 60, 31-33.

Wright, A.J. (1982) Ngataurua Islets, Mimiwhangata. Auckland Botanical Society Journal, 37, 8-10.

Wright, A. (1991) Moturemu Island revisited. Auckland Botanical Society Journal, 46, 9.

Wright, A.E. (1980) Vegetation and flora of Fanal Island, Mokohinau Group. Tane, 26, 25-43.

Wright, A.E. (1981) Studies on the vegetation Cuvier Island. V. additional vascular plant species and a vegetation description for Scott's Monument. Tane, 27, 7-11.

Wright, A.E. (1979) Flora and vegetation of the Cavalli Islands (except Motukawanui), northern New Zealand. Tane, 25, 61-100.

Wright, A.E. (1979) Vascular flora of Motukawanui Island, Cavalli Group, northern New Zealand. Tane, 25, 101-108.

Wright, A.E. (1976) The vegetation of Great Mercury Island. Tane, 22, 23-49.

Wright, A.E. (1977) Vegetation and flora of the Moturoa Island Group, Northland, New Zealand. Tane, 23, 11-29.

Young, M. (2009) Botany of some of the islands in the eastern Bay of Islands, Northern New Zealand: an update. Auckland Botanical Society Journal, 64, 88-97. 
Young, M.E. (2012) A visit to Taranga (Hen) Island. Auckland Botanical Society Journal, 67, 64-82. 


\section{Appendix 2}

Table A.2.1 - Explained variance $\left(R^{2}\right)$, delta AIC ( $\left.\triangle A I C\right)$ and model probabilities (AICW) of isolation buffers for predicting the residuals of the species-area relationship. The isolation buffer with the highest model probability was retained.

\begin{tabular}{|c|c|c|c|}
\hline \multicolumn{4}{|c|}{ Native species } \\
\hline Isolation buffers & $\mathbf{R}^{2}$ & $\Delta \mathrm{AIC}$ & $\mathrm{AlCw}$ \\
\hline Arcsine $(1500 \mathrm{~m})$ & 0.0393 & 0.0000 & 0.3605 \\
\hline Arcsine $(1000 \mathrm{~m})$ & 0.0365 & 0.7500 & 0.2478 \\
\hline Arcsine $(500 \mathrm{~m})$ & 0.0347 & 1.2529 & 0.1927 \\
\hline Arcsine $(2000 \mathrm{~m})$ & 0.0288 & 2.8561 & 0.0864 \\
\hline Arcsine $(250 \mathrm{~m})$ & 0.0247 & 3.9593 & 0.0498 \\
\hline Arcsine $(2500 \mathrm{~m})$ & 0.0216 & 4.8106 & 0.0325 \\
\hline Arcsine $(3000 \mathrm{~m})$ & 0.0211 & 4.9567 & 0.0302 \\
\hline \multicolumn{4}{|c|}{ Exotic species } \\
\hline Isolation buffers & $\mathbf{R}^{2}$ & $\Delta \mathrm{AIC}$ & $\mathrm{AlCw}$ \\
\hline Arcsine $(1500 \mathrm{~m})$ & 0.1244 & 0.0000 & 0.4787 \\
\hline Arcsine $(3000 \mathrm{~m})$ & 0.1215 & 0.8686 & 0.3101 \\
\hline Arcsine $(2000 \mathrm{~m})$ & 0.1166 & 2.3483 & 0.1480 \\
\hline Arcsine $(2500 \mathrm{~m})$ & 0.1102 & 4.2332 & 0.0577 \\
\hline Arcsine $(1000 \mathrm{~m})$ & 0.0944 & 8.8995 & 0.0056 \\
\hline Arcsine $(500 \mathrm{~m})$ & 0.0401 & 24.2703 & 0.0000 \\
\hline Arcsine $(250 \mathrm{~m})$ & 0.0094 & 32.5657 & 0.0000 \\
\hline
\end{tabular}


Table A. 2.2 - Moran's Index for spatial autocorrelation of the variables employed in this study.

Entries are independent and dependent variables, Moran's Indexes, z-scores and p-values. Latitude was excluded as not suitable for testing.

\begin{tabular}{lccc}
\hline \multicolumn{1}{c}{ Variables } & Moran's Index & z-score & $\begin{array}{c}\mathrm{p} \text { - } \\
\text { value }\end{array}$ \\
\hline Area & 0.010 & 0.291 & 0.7705 \\
Isolation 1500 & 0.251 & 3.114 & $\mathbf{0 . 0 0 1 8}$ \\
Exposure & 0.951 & 11.614 & $\mathbf{0 . 0 0 0 0}$ \\
Urban & 0.506 & 6.219 & $\mathbf{0 . 0 0 0 0}$ \\
\hline Native richness & 0.246 & 3.113 & $\mathbf{0 . 0 0 1 8}$ \\
Exotic richness & 0.226 & 2.859 & $\mathbf{0 . 0 0 4 2}$ \\
\hline
\end{tabular}


Table A. 2.3 - Chi-square test of independence for the richness of growth forms and dispersal syndromes employed investigating patterns of species richness across 264 New Zealand offshore islands.

Growth forms

Exotic graminoids

Exotic graminoids

Exotic forbs

Exotic graminoids

Exotic forbs

Exotic woody
Exotic forbs

Exotic woody

Exotic woody

Native graminoids

Native forbs

Native woody

Dispersal mode

Exotic wind-dispersed

Exotic wind-dispersed

Exotic wind-dispersed

Exotic unspecialized

Exotic unspecialized

Exotic short-distance

Exotic wind-dispersed

Exotic unspecialized

Exotic short-distance

Exotic animal-dispersed

Exotic unspecialized
Exotic short-distance
Exotic animal-dispersed
Exotic short-distance
Exotic animal-dispersed
Exotic animal-dispersed
Native wind-dispersed
Native unspecialized
Native short-distance
Native animal-dispersed

39.57

0.0000

$2.29 \quad 0.1300$

$0.31 \quad 0.5785$

$23.21 \quad 0.0000$

$33.11 \quad 0.0000$

$0.92 \quad 0.3374$

$111.51 \quad 0.0000$

$71.49 \quad 0.0000$

$104.11 \quad 0.0000$

$1.48 \quad 0.2235$ 
Table A. 2.4 - Chi-square test of independence for the richness of growth forms and dispersal syndromes employed investigating patterns of species seed mass across 264 New Zealand offshore islands.

\section{Growth forms}

Exotic graminoids

Exotic graminoids

Exotic forbs

Exotic graminoids

Exotic forbs

Exotic woody

Exotic wind-dispersed

Exotic wind-dispersed

Exotic wind-dispersed

Exotic unspecialized

Exotic unspecialized

Exotic short-distance

Exotic wind-dispersed

Exotic unspecialized

Exotic short-distance

Exotic animal-dispersed
Exotic forbs

Exotic woody

Exotic woody

Native graminoids

Native forbs

Native woody

Dispersal mode

Exotic unspecialized

Exotic short-distance

Exotic animal-dispersed

Exotic short-distance

Exotic animal-dispersed

Exotic animal-dispersed

Native wind-dispersed

Native unspecialized

Native short-distance

Native animal-dispersed

$\begin{array}{cc}\begin{array}{c}\text { Chi- } \\ \text { squared }\end{array} & \text { p-value } \\ 155.93 & \mathbf{0 . 0 0 0 0} \\ 1.32 & 0.2511 \\ 132.00 & \mathbf{0 . 0 0 0 0} \\ 0.04 & 0.8415 \\ 2.87 & 0.0902 \\ 109.73 & \mathbf{0 . 0 0 0 0}\end{array}$

36.17

0.0000

$0.19 \quad 0.6660$

$0.63 \quad 0.4280$

31.35

0.0000

27.56

0.0000

$0.13 \quad 0.7180$

$2.40 \quad 0.1216$

$\begin{array}{ll}76.84 & \mathbf{0 . 0 0 0 0}\end{array}$

$\begin{array}{ll}66.82 & \mathbf{0 . 0 0 0 0}\end{array}$

$0.30 \quad 0.5860$ 
Table A. 2.5 - Contingency table of growth forms and dispersal syndromes for exotic and native species.

\section{Exotics}

wind

graminoids forbs woody total

$\begin{array}{lcccc}\text { unspecialized } & 61 & 192 & 29 & 282 \\ \text { animals } & 24 & 51 & 71 & 146 \\ \text { short-distance } & 21 & 134 & 19 & 174 \\ \text { total } & 125 & 476 & 153 & \end{array}$

\section{Natives}

graminoids forbs woody total

wind

$\begin{array}{llll}38 & 276 \quad 66 & 380\end{array}$

unspecialized

$\begin{array}{llll}54 & 38 & 24 & 116\end{array}$

$\begin{array}{lllll}\text { animals } & 15 & 31 & 133 & 179\end{array}$

short-distance

$\begin{array}{llll}2 & 22 & 10 & 34\end{array}$

total

$109 \quad 367 \quad 233$


Table A. 2.6 - Species omitted from analyses. Entries are the number of species omitted, the corresponding proportion of exotic and native species, the reason for exclusion and the analyses they were excluded from.

\section{Number of species omitted}

Exotic (\%) Native (\%)

Reason
Excluded from
13

NA

NA

49.0

99

114

167

370

95.2
51.0

Growth form cannot be classified as graminoid, forb or woody.

Dispersal syndrome cannot be

$43 . \quad 57.0$
Seedless vascular plants

Seed mass analyses only

Lack of data in seed mass

Growth form analyses only

Dispersal analyses only unspecialized or short-distance.

Seed mass analyses only 
Table A. 2.7 - List of generalized linear models (GLM) with quasipoisson distribution comparing the occurrence of species with different functional traits and origin (i.e. exotic and native). Columns are the compared set of species, $t$-value, $p$-value and the level of significance (alpha). Alpha levels are adjusted with a Bonferroni correction, or divided by the number of tests run in each case. Significant p-values are in bold.

\section{Growth forms}

Exotic graminoids

Exotic graminoids

Exotic forbs

Native graminoids

Native graminoids

Native forbs

Exotic graminoids

Exotic forbs

Exotic woody
Exotic forbs

Exotic woody

Exotic woody

Native forbs

Native woody

Native woody

Native graminoids

Native forbs

Native woody

$\begin{array}{ccc}\text { t-value } & \text { p-value } & \text { alpha } \\ 3.72 & \mathbf{0 . 0 0 0 2} & 0.0167 \\ -6.47 & \mathbf{0 . 0 0 0 0} & 0.0167 \\ -3.32 & \mathbf{0 . 0 0 1 0} & 0.0167 \\ 1.17 & 0.2430 & 0.0167 \\ -0.59 & 0.5560 & 0.0167 \\ 0.51 & 0.6110 & 0.0167 \\ 0.80 & 0.4240 & 0.0500 \\ 4.40 & \mathbf{0 . 0 0 0 0} & 0.0500 \\ 5.96 & \mathbf{0 . 0 0 0 0} & 0.0500\end{array}$

\section{Dispersal mode}

Exotic wind-dispersed

Exotic wind-dispersed

Exotic wind-dispersed

Exotic unspecialized

Exotic unspecialized

Exotic short-distance

Native wind-dispersed

Native wind-dispersed

Native wind-dispersed

Native unspecialized

Native unspecialized

Native short-distance

Exotic wind-dispersed

Exotic unspecialized

Exotic short-distance

Exotic animal-dispersed

Exotic unspecialized

Exotic short-distance

Exotic animal-dispersed

Exotic short-distance

Exotic animal-dispersed

Exotic animal-dispersed

Native unspecialized

Native short-distance

Native animal-dispersed

Native short-distance

Native animal-dispersed

Native animal-dispersed

Native wind-dispersed

Native unspecialized

Native short-distance

Native animal-dispersed $\begin{array}{lll}0.33 & 0.7400 & 0.0083\end{array}$

$\begin{array}{lll}3.28 & 0.0012 & 0.0083\end{array}$

$\begin{array}{lll}2.25 & 0.0253 & 0.0083\end{array}$

$\begin{array}{lll}3.78 & \mathbf{0 . 0 0 0 2} & 0.0083\end{array}$

$\begin{array}{lll}2.51 & 0.0123 & 0.0083\end{array}$

$\begin{array}{lll}-1.36 & 0.1750 & 0.0083\end{array}$

$\begin{array}{lll}-0.83 & 0.4060 & 0.0083\end{array}$

$\begin{array}{lll}-1.61 & 0.1080 & 0.0083\end{array}$

$\begin{array}{lll}-1.84 & 0.0657 & 0.0083\end{array}$

$\begin{array}{lll}-1.04 & 0.3030 & 0.0083\end{array}$

$\begin{array}{lll}-0.64 & 0.5240 & 0.0083\end{array}$

$\begin{array}{lll}0.51 & 0.6140 & 0.0083\end{array}$

$\begin{array}{lll}0.85 & 0.3970 & 0.0500\end{array}$

$\begin{array}{lll}2.17 & 0.0305 & 0.0500\end{array}$

$\begin{array}{lll}5.23 & \mathbf{0 . 0 0 0 0} & 0.0500\end{array}$

$\begin{array}{lll}4.44 & 0.0000 & 0.0500\end{array}$ 
Table A. 2.8 - Results from multiple linear regressions exploring the relationship between exotic and native species richness of different growth forms and island characteristics on 264 New Zealand offshore islands. To conform to assumptions, species richness was log $(+1)$ transformed, area logtransformed, isolation arcsine-transformed and distance from the nearest urban area squaredtransformed. $T$ and $p$ values are reported for each island characteristic. Statistical significance: ${ }^{*} \mathrm{P}<$ $0.05, * * \mathrm{P}<0.01, * * * \mathrm{P}<0.001$.

\begin{tabular}{|c|c|c|c|c|c|c|c|c|}
\hline & \multicolumn{2}{|c|}{ Area } & \multicolumn{2}{|c|}{ Isolation } & \multicolumn{2}{|c|}{ Exposure } & \multicolumn{2}{|c|}{ Urban } \\
\hline & $\mathrm{t}$-value & p-value & $t$-value & $p$-value & $t$-value & p-value & $t$-value & p-value \\
\hline Exotic & 12.519 & 0.0000 & -3.763 & 0.0002 & -4.895 & 0.0000 & -1.236 & 0.2175 \\
\hline Native & 16.895 & 0.0000 & -4.112 & 0.0000 & -1.825 & 0.0691 & 0.663 & 0.5082 \\
\hline Interaction & \multicolumn{2}{|c|}{0.2681} & \multicolumn{2}{|c|}{0.7774} & \multicolumn{2}{|c|}{0.0093} & \multicolumn{2}{|c|}{0.1697} \\
\hline Exotic & 17.296 & 0.0000 & -4.062 & 0.0000 & -5.145 & 0.0000 & -2.524 & 0.0122 \\
\hline Native & 17.211 & 0.0000 & -1.546 & 0.1232 & -2.659 & 0.0083 & 0.582 & 0.5609 \\
\hline Interaction & \multicolumn{2}{|c|}{0.0122} & \multicolumn{2}{|c|}{0.0216} & \multicolumn{2}{|c|}{0.0205} & \multicolumn{2}{|c|}{0.0305} \\
\hline Exotic & 13.412 & 0.0000 & -1.887 & 0.0603 & -3.914 & 0.0001 & -6.358 & 0.0000 \\
\hline Native & 18.161 & 0.0000 & -2.732 & 0.0067 & -1.869 & 0.0627 & -1.121 & 0.2635 \\
\hline Interaction & \multicolumn{2}{|c|}{0.0003} & \multicolumn{2}{|c|}{0.5247} & \multicolumn{2}{|c|}{0.1629} & \multicolumn{2}{|c|}{0.0003} \\
\hline
\end{tabular}


Table A. 2.9 - Results from multiple linear regressions exploring the relationship between exotic and native species richness of different dispersal syndromes and island characteristics on $264 \mathrm{New}$ Zealand offshore islands. To conform to assumptions, species richness was log $(+1)$ transformed, area log-transformed, isolation arcsine-transformed and distance from the nearest urban area squared-transformed. $T$ and $p$ values are reported for each island characteristic. Statistical significance: ${ }^{*} \mathrm{P}<0.05,{ }^{*} \mathrm{P}<0.01,{ }^{* * *} \mathrm{P}<0.001$.

\begin{tabular}{|c|c|c|c|c|c|c|c|c|}
\hline & \multicolumn{2}{|c|}{ Area } & \multicolumn{2}{|c|}{ Isolation } & \multicolumn{2}{|c|}{ Exposure } & \multicolumn{2}{|c|}{ Urban } \\
\hline & t-value & p-value & t-value & $p$-value & t-value & p-value & t-value & p-value \\
\hline Exotic & 18.517 & 0.0000 & -4.104 & 0.0000 & -4.602 & 0.0000 & -1.400 & 0.1630 \\
\hline Native & 17.689 & 0.0000 & -3.185 & 0.0016 & -3.234 & 0.0014 & 0.237 & 0.8128 \\
\hline Interaction & \multicolumn{2}{|c|}{0.0474} & \multicolumn{2}{|c|}{0.8971} & \multicolumn{2}{|c|}{0.6847} & \multicolumn{2}{|c|}{0.2854} \\
\hline Exotic & 14.303 & 0.0000 & -3.939 & 0.0001 & -5.229 & 0.0000 & -1.947 & 0.0527 \\
\hline Native & 18.210 & 0.0000 & -3.797 & 0.0001 & -1.880 & 0.0612 & 0.607 & 0.5445 \\
\hline Interaction & \multicolumn{2}{|c|}{0.1517} & \multicolumn{2}{|c|}{0.2777} & \multicolumn{2}{|c|}{0.0013} & \multicolumn{2}{|c|}{0.0521} \\
\hline Exotic & 15.562 & 0.0000 & -1.218 & 0.2240 & -5.636 & 0.0000 & -5.868 & 0.0000 \\
\hline Native & 15.994 & 0.0000 & -1.543 & 0.1240 & -1.143 & 0.2540 & -0.250 & 0.8030 \\
\hline Interaction & \multicolumn{2}{|c|}{0.9401} & \multicolumn{2}{|c|}{0.8445} & \multicolumn{2}{|c|}{0.0012} & \multicolumn{2}{|c|}{0.0000} \\
\hline Exotic & 14.584 & 0.0000 & -3.471 & 0.0006 & -2.969 & 0.0033 & -3.156 & 0.0018 \\
\hline Native & 15.609 & 0.0000 & 1.180 & 0.2391 & -3.035 & 0.0027 & 1.150 & 0.2513 \\
\hline Interaction & \multicolumn{2}{|c|}{0.1541} & \multicolumn{2}{|c|}{0.0006} & \multicolumn{2}{|c|}{0.7036} & \multicolumn{2}{|c|}{0.0016} \\
\hline
\end{tabular}


Table A. 2.10 - Results from multiple linear regressions exploring the relationship between exotic and native average seed mass of different growth forms and island characteristics on $264 \mathrm{New}$ Zealand offshore islands. To conform to assumptions, average seed mass and area were logtransformed, isolation arcsine-transformed and distance from the nearest urban area squaredtransformed. T and $p$ values are reported for each island characteristic. Statistical significance: ${ }^{*} \mathrm{P}<$ $0.05,{ }^{*} \mathrm{P}<0.01,{ }^{* * *} \mathrm{P}<0.001$.

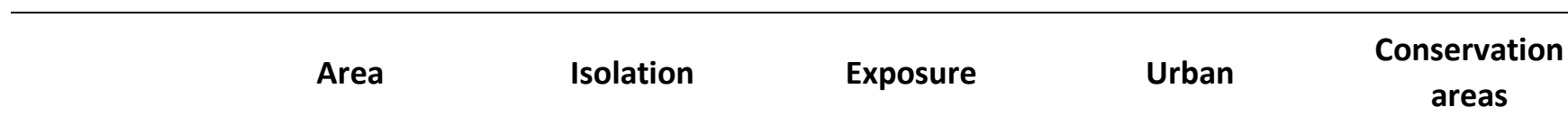

t-value $p$-value $t$-value $p$-value $t$-value $p$-value $t$-value $p$-value $t$-value $p$-value

\begin{tabular}{lllllllllll}
\hline Exotic & 2.346 & $\mathbf{0 . 0 1 9 6}$ & -0.421 & 0.6744 & -2.909 & $\mathbf{0 . 0 0 4 0}$ & -2.431 & $\mathbf{0 . 0 1 5 8}$ & -2.114 & $\mathbf{0 . 0 3 5 5}$
\end{tabular}

늠

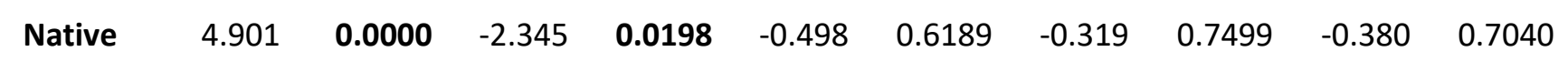

Interaction

0.2902

0.2858

0.0428

0.0799

0.1436

\begin{tabular}{|c|c|c|c|c|c|c|c|c|c|c|c|}
\hline \multirow{3}{*}{$\begin{array}{l}\text { o̊ } \\
\text { 훈 }\end{array}$} & Exotic & 11.273 & 0.0000 & -1.658 & 0.0986 & -3.572 & 0.0004 & -6.427 & 0.0000 & -0.146 & 0.8843 \\
\hline & Native & 3.322 & 0.0010 & -1.250 & 0.2124 & 0.829 & 0.4079 & -2.186 & 0.0297 & -3.538 & 0.0005 \\
\hline & Interaction & & 000 & \multicolumn{2}{|c|}{0.3786} & \multicolumn{2}{|c|}{0.0004} & \multicolumn{2}{|c|}{0.0000} & \multicolumn{2}{|c|}{0.1279} \\
\hline \multirow{3}{*}{ 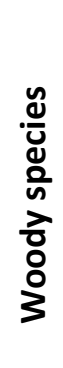 } & Exotic & 9.770 & 0.0000 & -1.845 & 0.0663 & -3.748 & 0.0002 & -5.475 & 0.0000 & 2.011 & 0.0454 \\
\hline & Native & 6.898 & 0.0000 & -0.973 & 0.3316 & -2.185 & 0.0298 & -3.036 & 0.0026 & 0.749 & 0.4543 \\
\hline & Interaction & \multicolumn{2}{|c|}{0.0072} & \multicolumn{2}{|c|}{0.4663} & \multicolumn{2}{|c|}{0.1798} & \multicolumn{2}{|c|}{0.0394} & \multicolumn{2}{|c|}{0.3168} \\
\hline
\end{tabular}


Table A. 2.11 - Results from multiple linear regressions exploring the relationship between exotic and native average seed mass of different dispersal syndromes and island characteristics on 264 New Zealand offshore islands. To conform to assumptions, average seed mass and area were logtransformed, isolation arcsine-transformed and distance from the nearest urban area squaredtransformed. $T$ and $p$ values are reported for each island characteristic. Statistical significance: ${ }^{*} \mathrm{P}<$ $0.05, * * P<0.01, * * * P<0.001$.

\begin{tabular}{lllll}
\hline Area & Isolation & Exposure & Urban & $\begin{array}{c}\text { Conservation } \\
\text { areas }\end{array}$
\end{tabular}

$t$-value $p$-value $t$-value $p$-value $t$-value $p$-value $t$-value $p$-value $t$-value $p$-value

$\begin{array}{cccccccccccc}\text { Exotic } & 5.299 & \mathbf{0 . 0 0 0 0} & -2.729 & \mathbf{0 . 0 0 6 8} & -1.930 & 0.0547 & -0.349 & 0.7270 & -2.477 & \mathbf{0 . 0 1 3 9} \\ \text { Native } & 5.594 & \mathbf{0 . 0 0 0 0} & -0.122 & 0.9031 & 0.1403 & 0.4028 & -2.880 & \mathbf{0 . 0 0 4 3} & -2.548 & \mathbf{0 . 0 1 1 4} \\ & & & & & & & & & & & \\ \text { Interaction } & \mathbf{0 . 0 0 1 3} & 0.3679 & \mathbf{0 . 0 3 7 0} & \mathbf{0 . 0 1 1 3} & 0.1492\end{array}$

\begin{tabular}{|c|c|c|c|c|c|c|c|c|c|c|}
\hline Exotic & 7.103 & 0.0000 & -0.070 & 0.9440 & -2.416 & 0.0164 & -5.704 & 0.0000 & 0.523 & 0.6013 \\
\hline Native & 0.851 & 0.3954 & 0.718 & 0.4732 & 1.470 & 0.1429 & -2.522 & 0.0123 & 0.502 & 0.6159 \\
\hline Interaction & \multicolumn{2}{|c|}{0.0000} & \multicolumn{2}{|c|}{0.5533} & \multicolumn{2}{|c|}{0.0054} & \multicolumn{2}{|c|}{0.0777} & \multicolumn{2}{|c|}{0.9645} \\
\hline Exotic & 8.329 & 0.0000 & -0.885 & 0.3770 & -5.970 & 0.0000 & -4.121 & 0.0000 & 2.960 & 0.0034 \\
\hline Native & 9.080 & 0.0000 & -0.471 & 0.6380 & -0.484 & 0.6290 & -0.255 & 0.7990 & 0.000 & 1.0000 \\
\hline Interaction & \multicolumn{2}{|c|}{0.2758} & \multicolumn{2}{|c|}{0.8038} & \multicolumn{2}{|c|}{0.0002} & \multicolumn{2}{|c|}{0.0099} & \multicolumn{2}{|c|}{0.0465} \\
\hline Exotic & 7.934 & 0.0000 & -2.971 & 0.0033 & -1.363 & 0.1741 & -3.049 & 0.0025 & -2.753 & 0.0063 \\
\hline Native & 9.431 & 0.0000 & 0.362 & 0.7180 & -0.964 & 0.3360 & 1.013 & 0.3120 & 0.075 & 0.9400 \\
\hline Interaction & \multicolumn{2}{|c|}{0.0465} & \multicolumn{2}{|c|}{0.0276} & \multicolumn{2}{|c|}{0.8769} & \multicolumn{2}{|c|}{0.0061} & \multicolumn{2}{|c|}{0.0651} \\
\hline
\end{tabular}


Table A. 2.12 - ANCOVA tests investigating how among exotic growth forms and dispersal syndromes relationships with island characteristics differ. Above is species richness, below is species seed mass. $F$ and $p$ values are reported for each island characteristic. Significant $p$-values in bold. To conform to assumptions, average seed mass and area were log-transformed, isolation arcsine-transformed and distance from the nearest urban area squared-transformed. Statistical significance: ${ }^{*} p<0.05,{ }^{* *} p<$ $0.01, * * * P<0.001$

Growth forms

Dispersal syndrome

\begin{tabular}{ccccc}
\hline & F-value & p-value & F-value & p-value \\
\hline Area & 9.644 & $\mathbf{0 . 0 0 0 0}$ & 1.737 \\
Isolation & 2.146 & NS & 2.403 & NS \\
Exposure & 1.005 & NS & 4.610 & $\mathbf{0 . 0 0 3 3}$ \\
Urban & 5.015 & $\mathbf{0 . 0 0 6 9}$ & 3.548 & $\mathbf{0 . 0 1 4 1}$ \\
\hline
\end{tabular}

Seed mass

\begin{tabular}{ccccc}
\hline Area & 87.460 & $\mathbf{0 . 0 0 0 0}$ & 42.122 & $\mathbf{0 . 0 0 0 0}$ \\
Isolation & 1.987 & NS & 1.488 & NS \\
Exposure & 21.835 & $\mathbf{0 . 0 0 0 0}$ & 26.451 & $\mathbf{0 . 0 0 0 0}$ \\
Urban & 15.229 & $\mathbf{0 . 0 0 0 0}$ & 7.935 & $\mathbf{0 . 0 0 0 0}$ \\
Conservation areas & 5.145 & $\mathbf{0 . 0 0 6 0}$ & 8.657 & $\mathbf{0 . 0 0 0 0}$
\end{tabular}


Table A. 2.13 - Plant species found on 97 islands during field surveys. Entries are species' family, binomial name and status (i.e. exotic or native).

Family
Primulaceae
Apiaceae
Asteracerae
Aspleniaceae
Amaranthaceae
Chenopodiaceae
Caryophyllaceae
Rubiaceae
Crassulaceae
Crassulaceae
Crassulaceae
Mesembryanthemaceae
Poaceae
Cyperaceae
Asteraceae
Poaceae
Fabaceae
Malvaceae
Fabaceae
Myrtaceae
Polygonaceae
Scrophulariaceae
Poaceae
Urticaceae
Asphodelaceae
Pittosporaceae
Plantaginaceae
Poaceae
Primulaceae
Amaranthaceae
Goodeniaceae
Asteraceae
Asteracerae
Caryophyllacee
Asteracerae
Caryophyllacee
Aizoaceae
Poaceae

\begin{tabular}{|c|c|}
\hline Species & Status \\
\hline Anagallis arvensis & Exotic \\
\hline Apium prostratum & Native \\
\hline Arctotheca calendula & Exotic \\
\hline Asplenium appendiculatum & Native \\
\hline Atriplex prostrata & Exotic \\
\hline Chenopodium triandrum & Native \\
\hline Colobanthus sp. & Native \\
\hline Coprosma repens & Native \\
\hline Cotyledon orbiculata & Exotic \\
\hline Crassula sieberiana & Native \\
\hline Crassula sp. & Exotic \\
\hline Disphyma australe & Native \\
\hline Ehrharta erecta & Exotic \\
\hline Ficinia nodosa & Native \\
\hline Gazania rigens & Exotic \\
\hline Lagurus ovatus & Exotic \\
\hline Lupinus arboreus & Exotic \\
\hline Malva arborea & Exotic \\
\hline Melilotus indicus & Exotic \\
\hline Metrosideros excelsa & Native \\
\hline Muehlenbeckia complexa & Native \\
\hline Myoporum laetum & Native \\
\hline Parapholis incurva & Exotic \\
\hline Parietaria judaica & Exotic \\
\hline Phormium sp. & Native \\
\hline Pittosporum crassifolium & Native \\
\hline Plantago coronopus & Exotic \\
\hline Poa cita & Native \\
\hline Samolus repens & Native \\
\hline Sarcocornia quinqueflora & Native \\
\hline Selliera radicans & Native \\
\hline Senecio elegans & Exotic \\
\hline Senecio lautus & Native \\
\hline Silene uniflora & Exotic \\
\hline Sonchus oleraceus & Exotic \\
\hline Spergularia sp. & Exotic \\
\hline Tetragonia implexicoma & Native \\
\hline Trisetum antarcticum & Native \\
\hline
\end{tabular}


Table A. 2.14 - List of parameters used to investigate patterns in species richness on 97 small islands off the coast of Wellington, New Zealand. For each parameter, unit of measurement, range, mean, standard deviation and description are provided. Values for range, mean and standard deviation are provided for all islands (all), islands inside (inner) and outside (outer) the harbour.

\begin{tabular}{|c|c|c|c|c|c|c|c|c|c|c|c|}
\hline \multirow{2}{*}{ Variable } & \multirow{2}{*}{$\begin{array}{c}\text { Unit of } \\
\text { measurement }\end{array}$} & \multicolumn{3}{|c|}{ Range } & \multicolumn{3}{|c|}{ Mean } & \multicolumn{3}{|c|}{ SD } & \multirow{2}{*}{ Description } \\
\hline & & All & Inner & Outer & All & Inner & Outer & All & Inner & Outer & \\
\hline Area & $\begin{array}{l}\text { Squared } \\
\text { metre }\end{array}$ & $\begin{array}{l}0.825 \\
-166\end{array}$ & $\begin{array}{l}0.825 \\
-166\end{array}$ & $\begin{array}{c}0.980- \\
89.8\end{array}$ & 18.9 & 18.5 & 19.1 & 22.5 & 34.1 & 16.4 & $\begin{array}{c}\text { Island area } \\
\text { in squared } \\
\text { meters }\end{array}$ \\
\hline Isolation & meters & $\begin{array}{c}0.00 \\
- \\
41.3\end{array}$ & $\begin{array}{c}0- \\
30.9\end{array}$ & $1-41.3$ & 8.81 & 5.86 & 9.95 & 8.28 & 7.15 & 8.45 & $\begin{array}{l}\text { Distance } \\
\text { from the } \\
\text { nearest } \\
\text { plant } \\
\text { community }\end{array}$ \\
\hline Height & meters & $\begin{array}{c}0.200 \\
- \\
5.00\end{array}$ & $\begin{array}{l}0.200 \\
-2.6\end{array}$ & $\begin{array}{c}0.250- \\
5.00\end{array}$ & 1.44 & 1.25 & 1.51 & 0.917 & 0.701 & 0.984 & $\begin{array}{l}\text { Height } \\
\text { above the } \\
\text { lowest } \\
\text { lichens } \\
\text { boundary }\end{array}$ \\
\hline $\begin{array}{l}\text { Nearest } \\
\text { dwelling }\end{array}$ & meters & $\begin{array}{l}20- \\
840\end{array}$ & $\begin{array}{l}20- \\
840\end{array}$ & $25-610$ & 228.76 & 190.00 & 243.71 & 210.84 & 209.60 & 210.91 & $\begin{array}{l}\text { Distance } \\
\text { form } \\
\text { nearest } \\
\text { dwelling }\end{array}$ \\
\hline Elevation & meters & $\begin{array}{c}-0.38 \\
- \\
4.31\end{array}$ & $\begin{array}{c}-0.13 \\
- \\
3.85\end{array}$ & $\begin{array}{c}-0.38- \\
4.31\end{array}$ & 1.14 & 1.30 & 1.08 & 0.84 & 0.96 & 0.79 & $\begin{array}{c}\text { Max } \\
\text { elevation } \\
\text { above mean } \\
\text { sea level }\end{array}$ \\
\hline Rugosity & - & $\begin{array}{c}1.00 \\
- \\
2.14\end{array}$ & $\begin{array}{c}1.00 \\
- \\
1.73\end{array}$ & $1.00-2.14$ & 1.17 & 1.19 & 1.17 & 0.19 & 0.18 & 0.20 & $\begin{array}{c}\text { Ratio } \\
\text { surface to } \\
\text { planar area }\end{array}$ \\
\hline Slope & $\circ$ & $\begin{array}{c}0.45 \\
- \\
64.04\end{array}$ & $\begin{array}{c}3.32 \\
- \\
53.34\end{array}$ & $\begin{array}{l}0.45- \\
64.04\end{array}$ & 25.41 & 27.52 & 24.60 & 14.59 & 14.99 & 14.47 & Slope \\
\hline
\end{tabular}


Table A. 2.15 - Native and exotic species richness on 97 small islands off the coast of Wellington. For each group, range, mean and standard deviation are provided. Values are provided for all islands (all), islands inside (inner) and outside (outer) the harbour.

\begin{tabular}{lcccccccccc} 
& & \multicolumn{3}{c}{ Range } & \multicolumn{3}{c}{ Mean } & & SD \\
& Number & All & Inner & Outer & All & Inner & Outer & All & Inner & Outer \\
Natives & 20 & $0-9$ & $1-9$ & $0-9$ & 2.9 & 2.7 & 3 & 2.1 & 2.2 & 2 \\
Exotics & 18 & $0-5$ & $0-5$ & $0-5$ & 0.9 & 0.7 & 1 & 1.3 & 1.4 & 1.3
\end{tabular}


Table A. 2.16 - Variance inflation factor for the variables included in the two models. Values above 3 indicates high collinearity between two variables.

\begin{tabular}{ll} 
& VIF \\
Area & 1.571 \\
Isolation & 1.514 \\
Height & 1.745 \\
Elevation & 1.408 \\
\hline Rugosity & 3.460 \\
Slope & 3.097 \\
Nearest dwelling & 1.340
\end{tabular}


Table A. 2.17 - Results from multiple linear regression models exploring the relationship between the plant richness of native and exotic species and island characteristics on 97 islands off the coast of Wellington, New Zealand. Entries are $t$ and $p$ values on inner and outer islands for each group of species. Statistical significance: ${ }^{*} \mathrm{P}<0.05,{ }^{* *} \mathrm{P}<0.01,{ }^{* *} \mathrm{P}<0.001$.

$\begin{array}{cccccc}\text { Area } & \text { Isolation } & \text { Height } & \text { Elevation } & \text { Slope } & \text { Nearest dwelling } \\ \text { Inner } \quad 3.37^{* *} & -1.78 & 2.47^{*} & 1.75 & 1.45 & 3.15^{* *}\end{array}$

Native

$\begin{array}{lllllll}\text { Outer } & 4.50^{* * *} & -0.26 & 3.08^{* *} & 1.63 & -2.54^{*} & 2.73^{* *} \\ & & & & & & \\ \text { Inner } & 5.33^{* * *} & -3.33^{* *} & 1.51 & 1.85 & -0.92 & 3.63^{* *}\end{array}$

Exotic

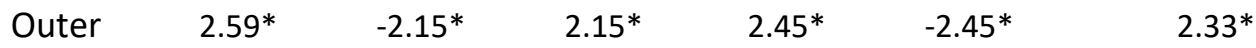


Table A. 2.18 - Distance-decay relationships of native and exotic species on inner and outer islands. Entries are $t$ and $p$ values. Significant differences are reported in bold. Significant relationships are in bold.

\begin{tabular}{|c|c|c|c|c|}
\hline & & & & \\
\hline & t-value & $\mathrm{p}$-value & t-value & $\mathrm{p}$-value \\
\hline Inner & -4.009 & 0.0000 & -3.909 & 0.0001 \\
\hline ative & & & & \\
\hline Outer & -3.84 & 0.0001 & -3.838 & 0.0001 \\
\hline Inner & -0.117 & 0.9080 & -0.117 & 0.9081 \\
\hline
\end{tabular}

Exotic

$\begin{array}{lllll}\text { Outer } & -1.825 & 0.0684 & -1.824 & 0.0686\end{array}$


Table A. 2.19 - Results of linear and quasipoisson models contrasting Jaccard similarity indexes and distance-decay relationships of inner and outer islands for all, native and exotic species. Entries are $t$ and $p$ values. Significant differences are reported in bold.

Jaccard similarity indexes

linear

quasipoisson

linear

quasipoisson

t-value $p$-value $t$-value $p$-value $t$-value $p$-value $t$-value $p$-value

$\begin{array}{lllllllll}\text { Natives } & 7.482 & \mathbf{0 . 0 0 0 0} & 7.373 & \mathbf{0 . 0 0 0 0} & 3.503 & \mathbf{0 . 0 0 0 5} & 4.244 & \mathbf{0 . 0 0 0 0}\end{array}$

$\begin{array}{lllllllll}\text { Exotics } & 1.185 & 0.237 & 1.183 & 0.237 & -0.033 & 0.9736 & -0.009 & 0.9928\end{array}$ 
Table A. 2.20 - Full list of online sources consulted for population sizes, island area and elevation. For island area and elevation, the Island Directory (http://islands.unep.ch/isldir.htm, Dahl 1991) and a topographic map (https://en-nz.topographic-map.com/, Yamazaki et al. 2017) were also consulted.

\author{
Archipelago Population \\ Northern \\ New Zealand \\ Seychelles https://www.nbs.gov.sc/ \\ Samoa https://www.usa.gov/statistics, \\ https://www.census.gov/en.html \\ Channel https://www.gov.gg/, \\ Islands https://www.gov.je/Pages/default.aspx \\ http://dbedt.hawaii.gov/economic/, \\ Hawaii https://www.usa.gov/statistics, \\ https://www.census.gov/en.html \\ Zhoushan \\ Kuril Islands https://eng.rosstat.gov.ru/ \\ Virgin https://bvi.gov.vg/statistics, \\ https://www.usa.gov/statistics, \\ https://www.census.gov/en.html \\ Ionian https://www.statistics.gr/en/home/ \\ Shetland https://www.shetland.gov.uk/ \\ Area, elevation \\ https://data.linz.govt.nz/layer/50 \\ 768-nz-contours-topo-150k/ \\ Yu et al. 2019 (https://doi.org/10.1016/j.baae.2019.05.002), Yu et al. 2020 \\ (https://doi.org/10.1111/jbi.13790) \\ https://www.burkemuseum.org/ \\ static/okhotskia/ikip/index.htm
}

\title{
References
}

Dahl, Arthur Lyon. 1991. Island Directory. UNEP Regional Seas Directories and Bibliographies No. 35. UNEP, Nairobi (573 pp.)

Yamazaki D., D. Ikeshima, R. Tawatari, T. Yamaguchi, F. O'Loughlin, J.C. Neal, C.C. Sampson, S. Kanae \& P.D. Bates (2017) A high accuracy map of global terrain elevations. Geophysical Research Letters, vol.44, pp.5844-5853, 2017 doi: 10.1002/2017GL072874

Yu J, Shen L, Li D, Guo S (2019) Determinants of bryophyte species richness on the Zhoushan Archipelago, China. Basic Appl Ecol 37:38-50.

Yu J, Li D, Zhang Z, Guo S (2020) Species-area relationship and small-island effect of bryophytes on the Zhoushan Archipelago, China. J Biogeogr 1-15. 
Table A. 2.21 - Island characteristics of 10 archipelagos across the globe. Entries are mean and standard deviation for area, elevation, isolation, latitude and longitude.

\begin{tabular}{|c|c|c|c|c|c|c|c|c|c|c|c|c|}
\hline \multirow[t]{2}{*}{ Archipelago } & \multicolumn{2}{|c|}{ Population } & \multicolumn{2}{|c|}{ Area $\left(\mathrm{km}^{2}\right)$} & \multicolumn{2}{|c|}{ Elevation (m) } & \multicolumn{2}{|c|}{ Isolation (km) } & \multicolumn{2}{|c|}{ Latitude } & \multicolumn{2}{|c|}{ Longitude } \\
\hline & mean & sd & mean & sd & mean & sd & mean & sd & mean & sd & mean & sd \\
\hline Northern & & & & & & & & & & & & \\
\hline $\begin{array}{c}\text { New } \\
\text { Zealand }\end{array}$ & 77.59 & 440.56 & 8.92 & 35.42 & 115.14 & 124.00 & 9.00 & 11.79 & 36.22 & 0.82 & 174.94 & 0.78 \\
\hline Samoa & 11138.00 & 32967.94 & 137.63 & 422.06 & 316.47 & 469.19 & 2778.18 & 75.50 & 13.88 & 0.67 & 171.23 & 0.970 \\
\hline Channel Is. & 4086.85 & 18166.54 & 5.01 & 21.06 & 24.08 & 54.72 & 28.87 & 12.37 & 49.51 & 0.18 & 2.28 & 0.19 \\
\hline Zhoushan & 16399.59 & 79399.27 & 17.79 & 63.19 & 151.48 & 122.02 & 45.94 & 25.43 & 30.44 & 0.38 & 122.45 & 0.25 \\
\hline Kuril Is. & 581.46 & 1811.04 & 314.63 & 709.11 & 770.00 & 665.21 & 368.33 & 182.28 & 47.03 & 2.54 & 151.23 & 3.61 \\
\hline Virgin Is. & 3036.94 & 10776.35 & 13.54 & 38.22 & 112.60 & 132.00 & 355.79 & 30.82 & 18.30 & 0.18 & 64.94 & 31.87 \\
\hline Ionian Is. & 5055.15 & 17001.23 & 104.90 & 361.32 & 248.18 & 330.97 & 13.30 & 15.47 & 38.37 & 0.94 & 20.87 & 0.80 \\
\hline
\end{tabular}


Table A. 2.22 - Overdispersion parameter and model chosen for statistical analyses for 10 archipelagos across the globe.

$\begin{array}{lll}\text { Archipelago } & \text { Overdispersion parameter } & \text { Model } \\ \text { Northern New Zealand } & 209.49 & \text { Quasipoisson } \\ \text { Seychelles } & 3765.52 & \text { Quasipoisson } \\ \text { Samoa } & 177.23 & \text { Quasipoisson } \\ \text { Channel Islands } & 0.23 & \text { Poisson } \\ \text { Hawaii } & 89062.43 & \text { Quasipoisson } \\ \text { Zhoushan } & 2124.9 & \text { Quasipoisson } \\ \text { Kuril Islands } & 96.92 & \text { Quasipoisson } \\ \text { Virgin Islands } & 2523.36 & \text { Quasipoisson } \\ \text { lonian Islands } & 4095.68 & \text { Quasipoisson } \\ \text { Shetland } & 191.20 & \text { Quasipoisson }\end{array}$



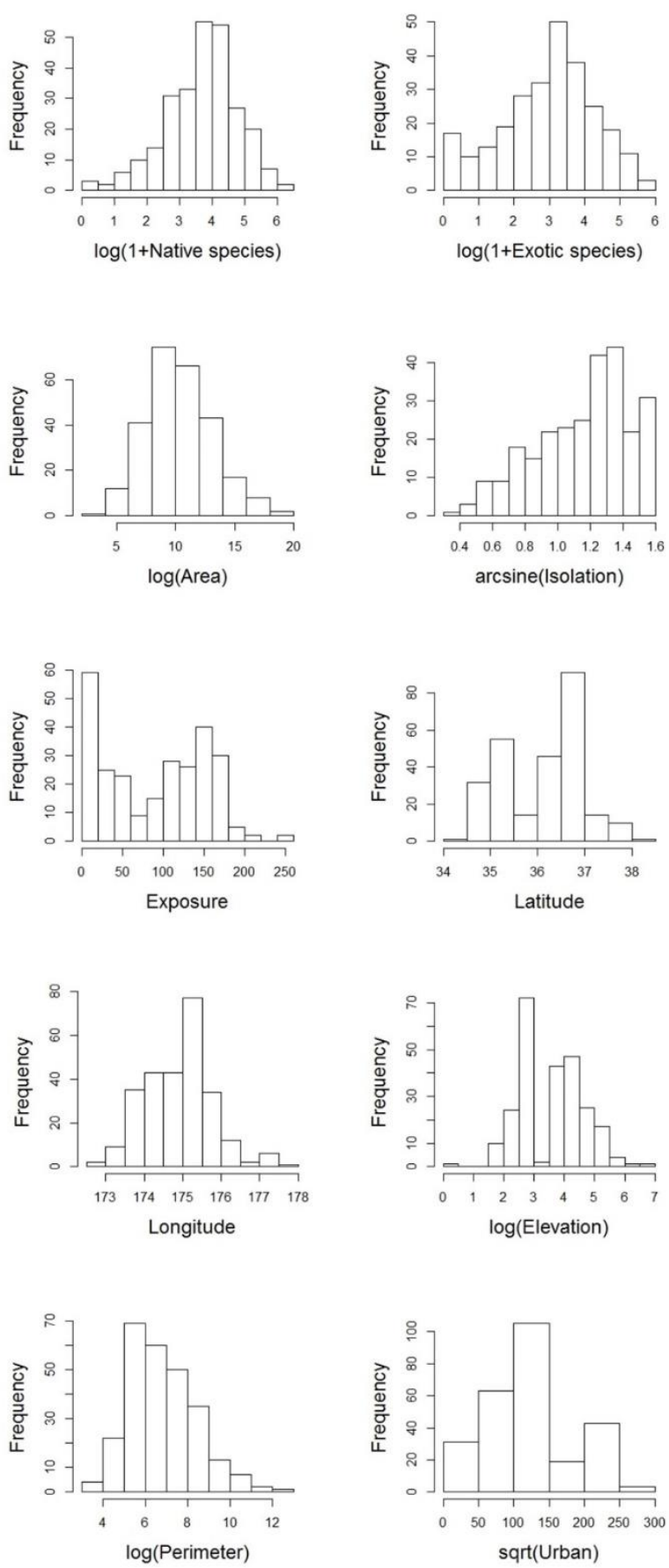

Figure A.2.1 - Frequency plots for plant species richness (native and exotic) and island characteristics of 264 islands off the north coast of New Zealand. 


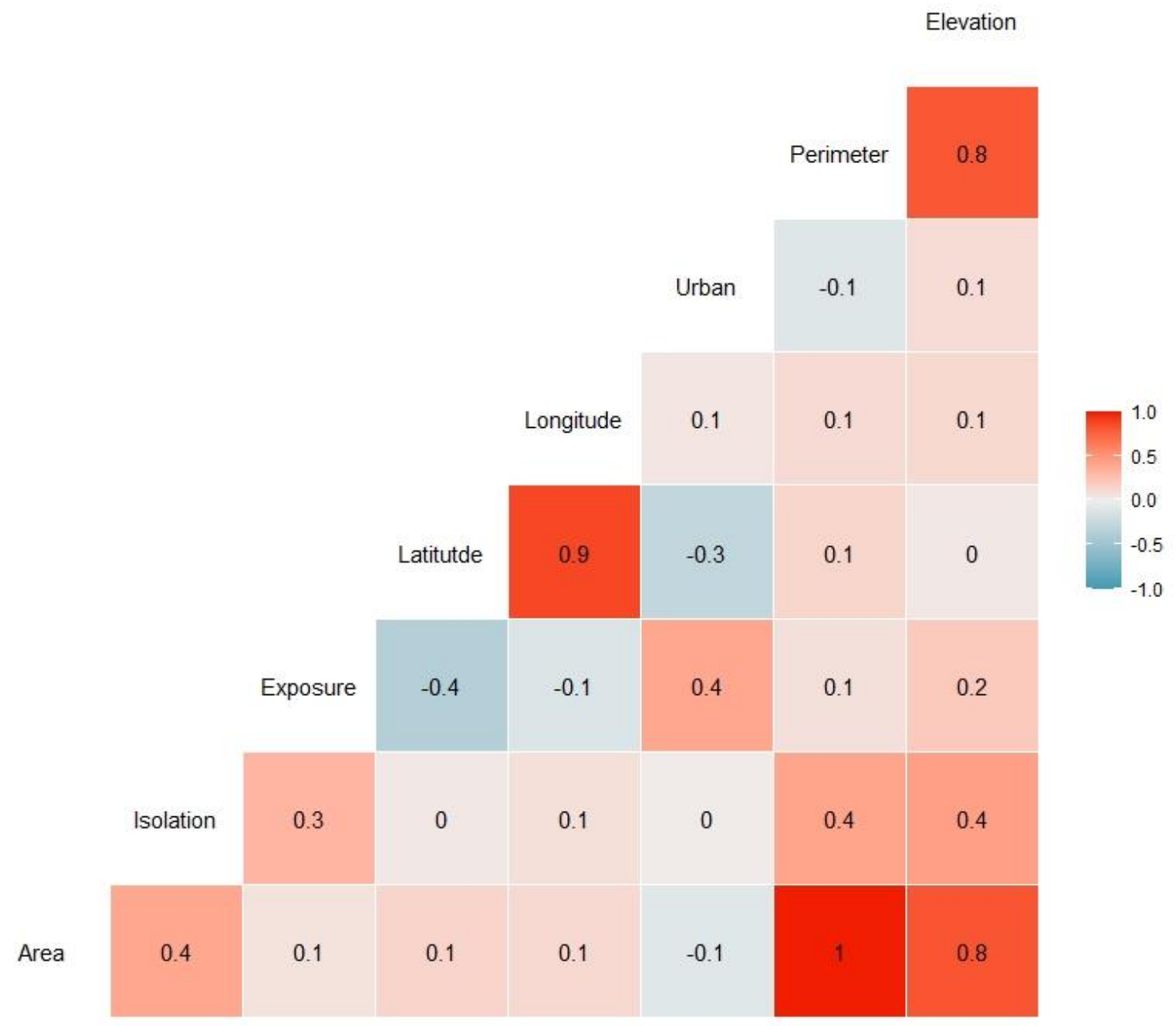

Figure A.2.2 - Correlation matrix displaying the Pearson's correlation coefficient between island characteristics of 264 islands off the north coast of New Zealand. Only one variable was retained if the coefficient was above 0.80 . Correlation was tested on transformed variables. Area, perimeter and elevation are log-transformed, isolation arcsine-transformed and urban is squared-transformed. Isolation is the total amount of landmasses surrounding each island within a radius of $1.500 \mathrm{~m}$, minus the value of 1 . Urban is distance from the nearest urban area. 

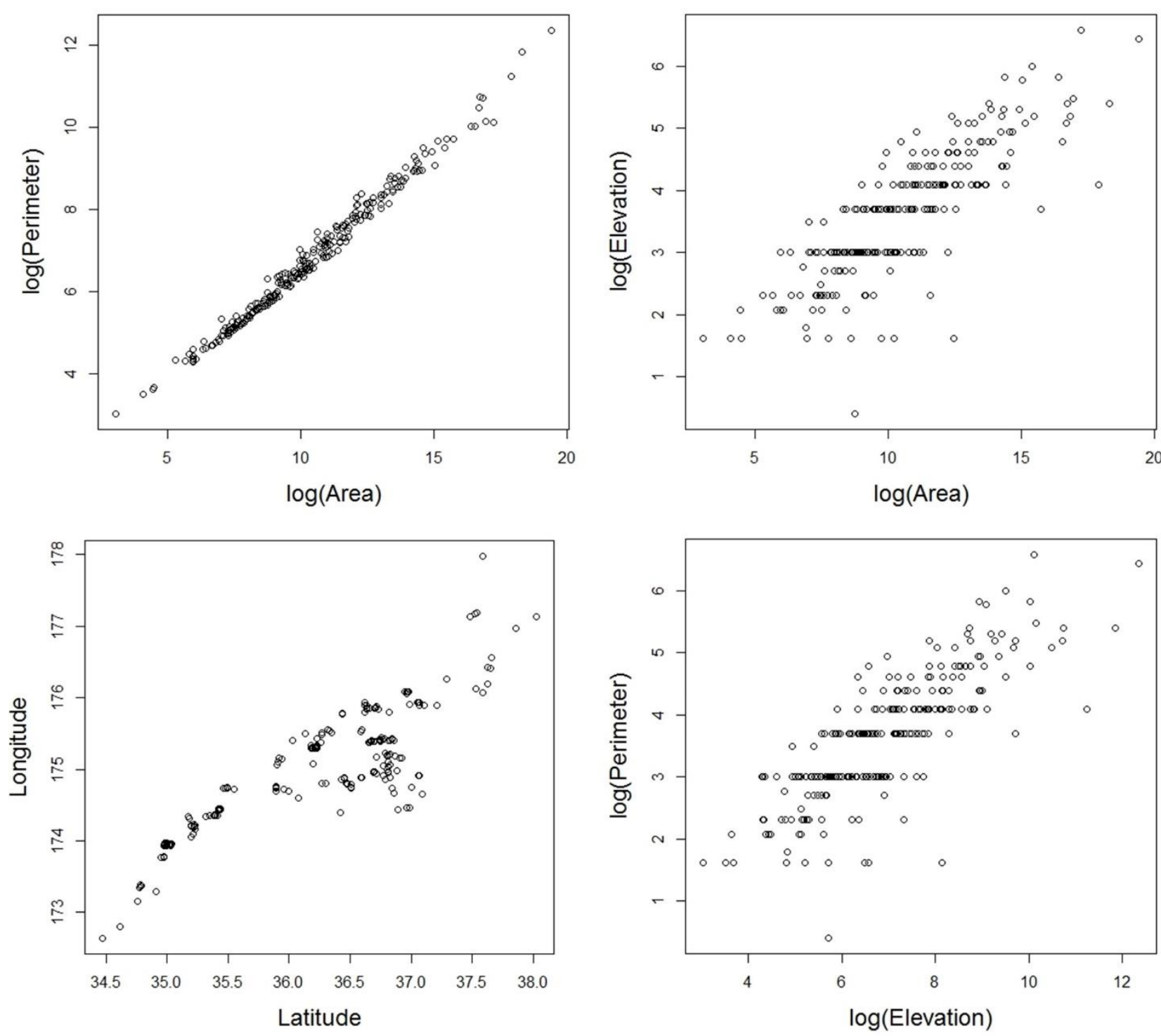

Figure A.2.3 - Correlation plots for island characteristics displaying a Pearson's correlation coefficient above 0.80 . 


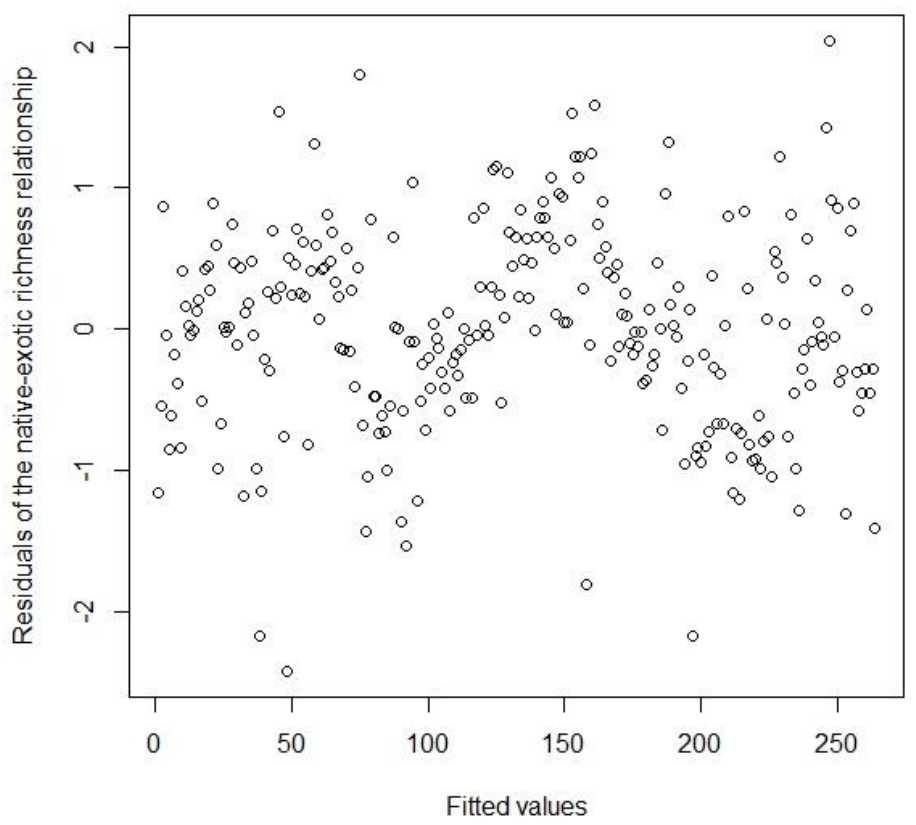

Figure A.2.4 - Residuals plot of the native-exotic richness relationship for 264 islands off the north coast of New Zealand. 

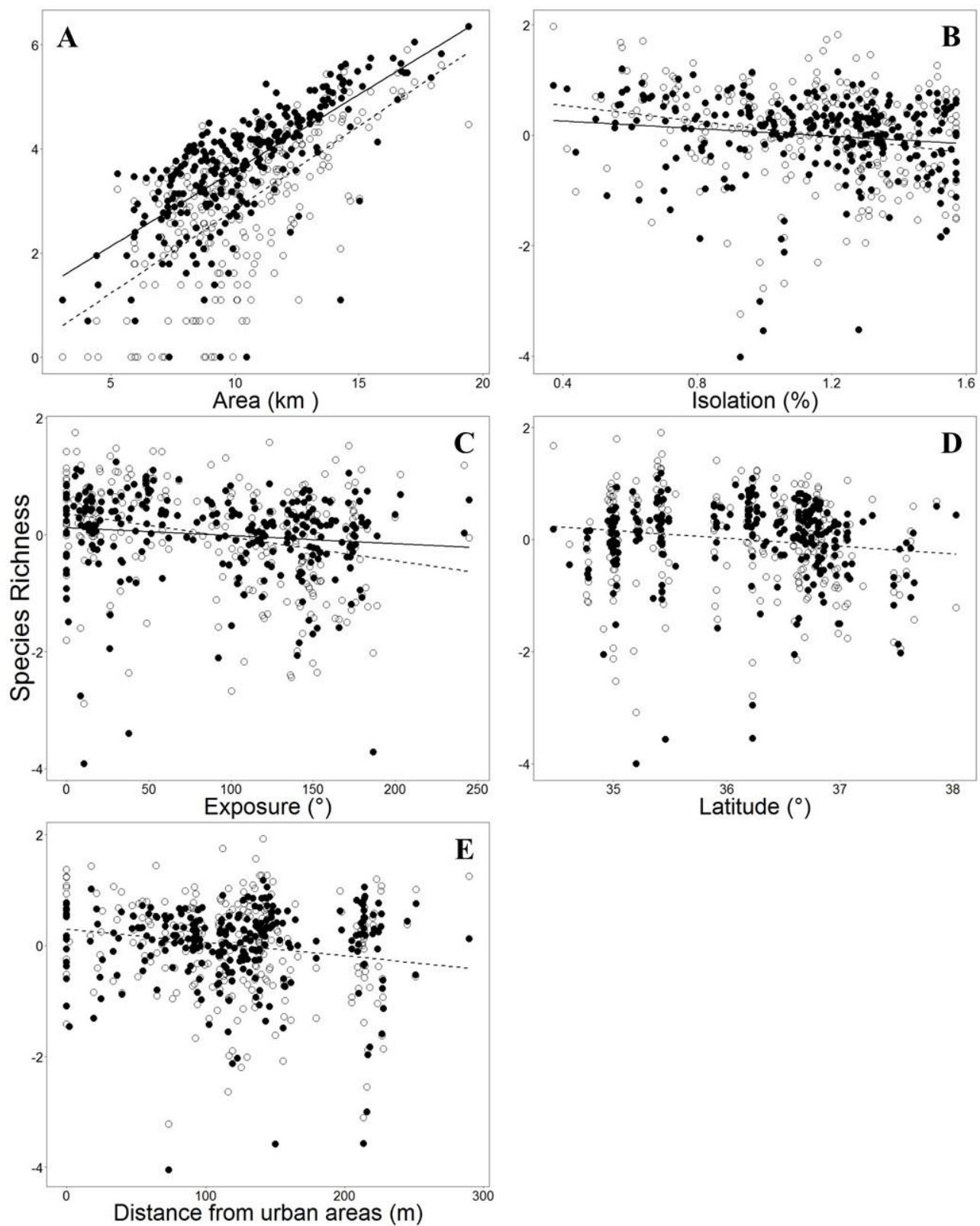

Figure A.2.5 - Relationships between native and exotic plant species richness and island characteristics on $264 \mathrm{New}$ Zealand offshore islands. On the $y$-axis is species richness and on the $x$-axis are island (A) area, (B) isolation, (C) exposure to ocean born disturbances, (D) latitude and (E) distance from the nearest urban area. Trendline types indicate native (solid) and exotic (dashed) species. Trendline are represented only for significant relationships. To conform to assumptions, species richness was log $(+1)$ transformed, area log-transformed, isolation arcsine-transformed and distance from the nearest urban area squared-transformed. 


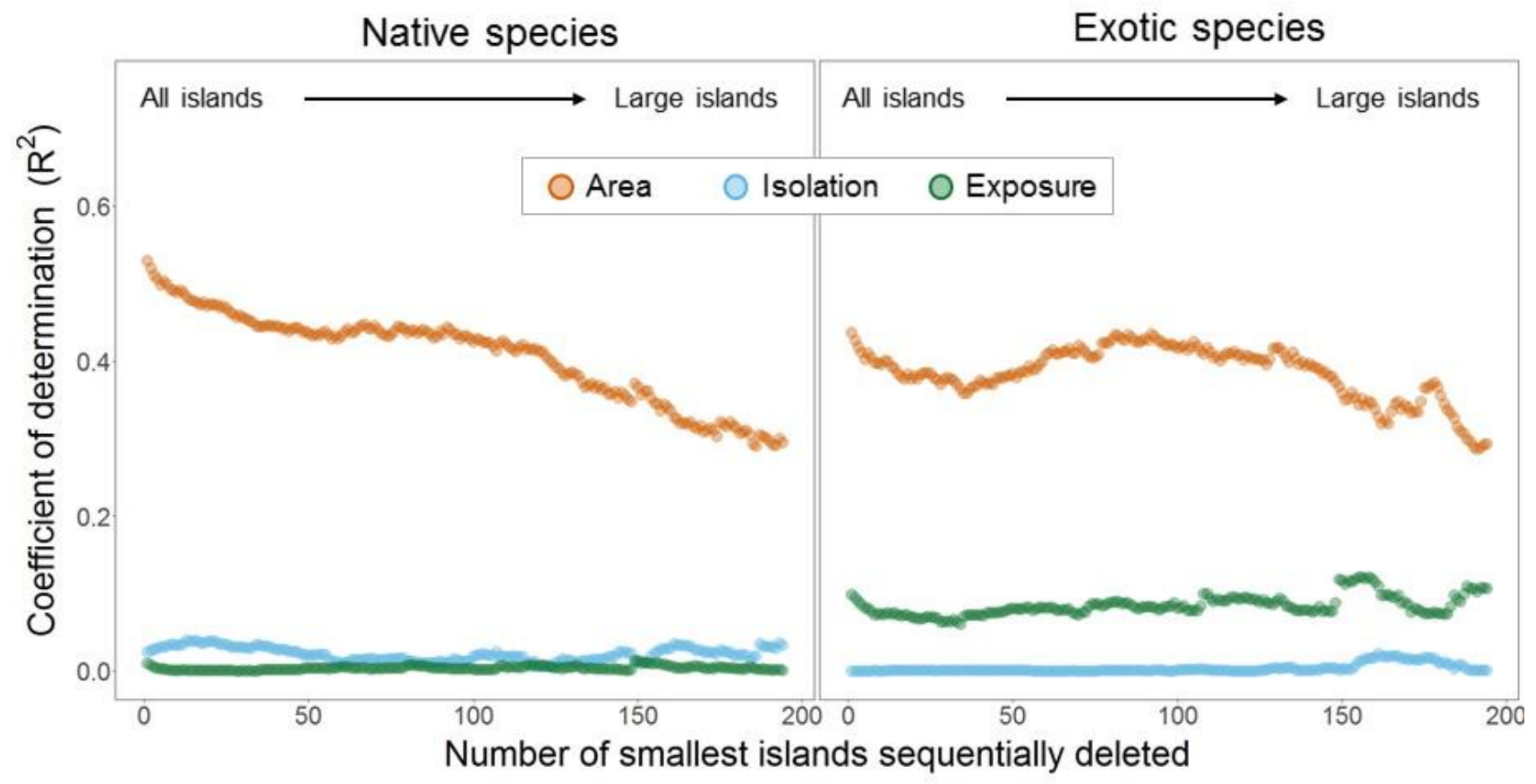

Figure A.2.6 - Scale-dependent variation in relationships between plant species richness, island area (vermilion points), isolation (blue points) and exposure to ocean-borne disturbances (green points) on 264 islands off the north coast of New Zealand. Analyses of native species richness are shown at left and analyses of exotic species are shown at right. The graphs illustrate an analysis similar to the 'sequential deletion' method. In this case though, islands are ranked from smallest to largest. Each point represents a separate linear model with the smallest islands in the study system sequentially deleted. The coefficient of determination $(r 2)$ is shown on the $y$-axis while the $x$-axis shows the number of islands removed at each regression. 


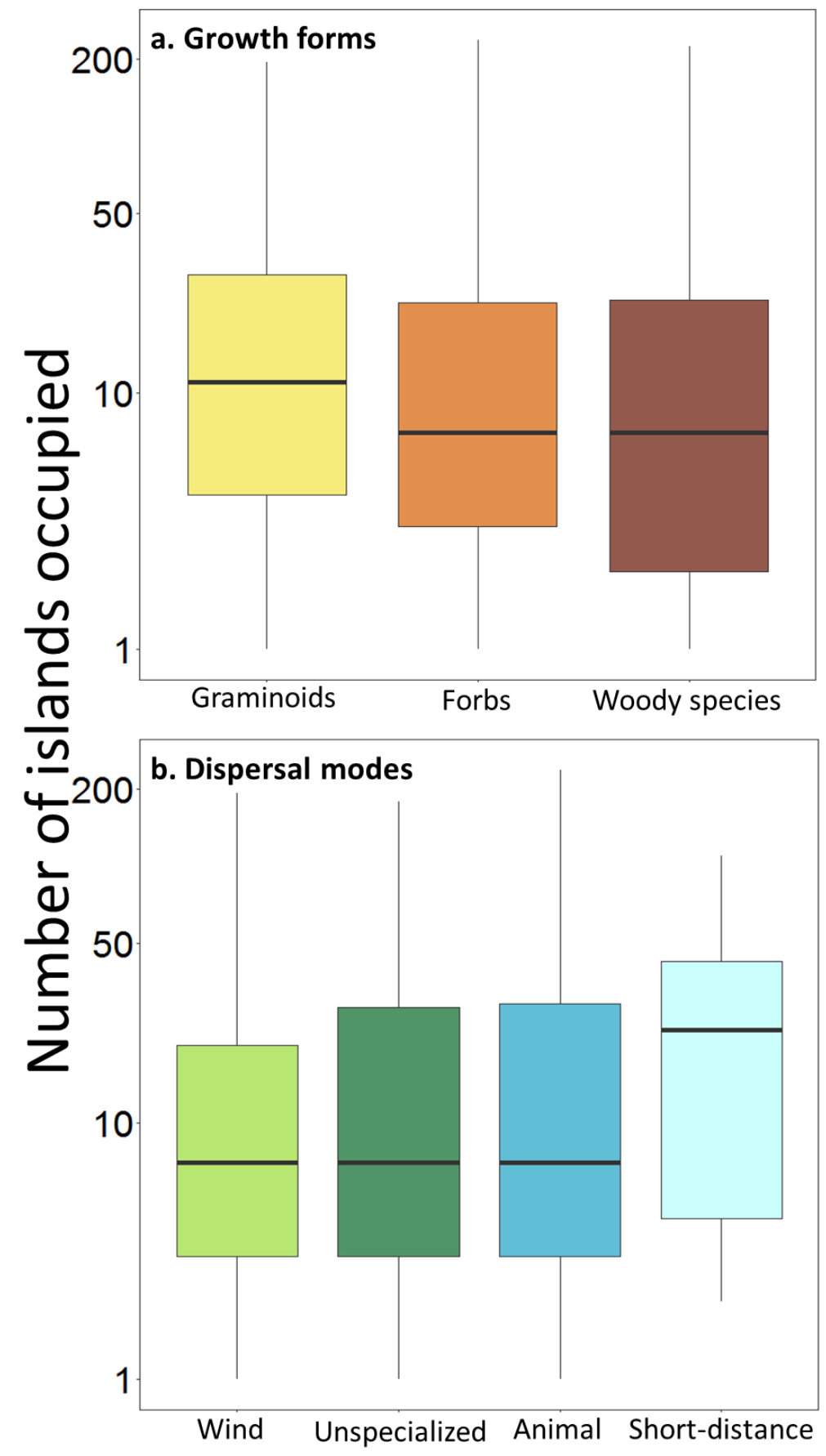

Figure A.2.7 - Number of islands occupied by native species with different (a) growth forms and (b) dispersal modes. On the $y$-axis is the number of islands occupied by each species, logtransformed, while on the $\mathrm{x}$-axis are trait categories. 


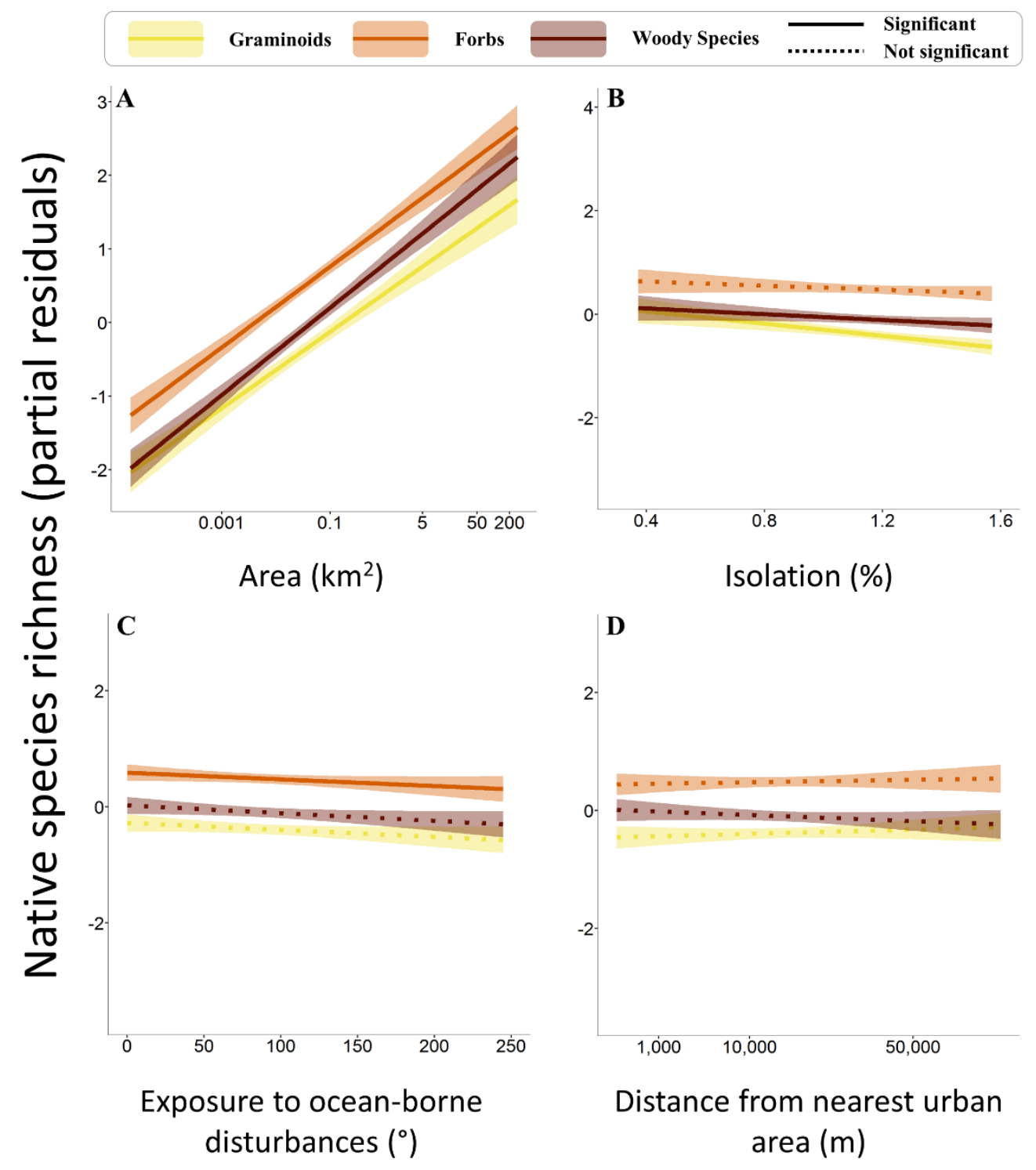

Figure A.2.8 - Linear models illustrating relationships between native species richness with different growth forms and island characteristics on 264 New Zealand offshore islands. On the $y$-axis is species richness (partial residuals), while on the $x$-axis are island (A) area (log scale), (B) isolation, (C) exposure to ocean born disturbances, and (D) distance from the nearest urban area. Trendline (model predicted slope) and relative confidence interval (95\%) colours represent graminoid (yellow), forb (vermilion) and woody species (brown). Trendline types indicate significant (solid, $\mathrm{P}<0.05$ ) or non-significant (dotted) relationships. To conform to assumptions, species richness was log (+1) transformed, area log-transformed, isolation arcsinetransformed and distance from the nearest urban area squared-transformed. 

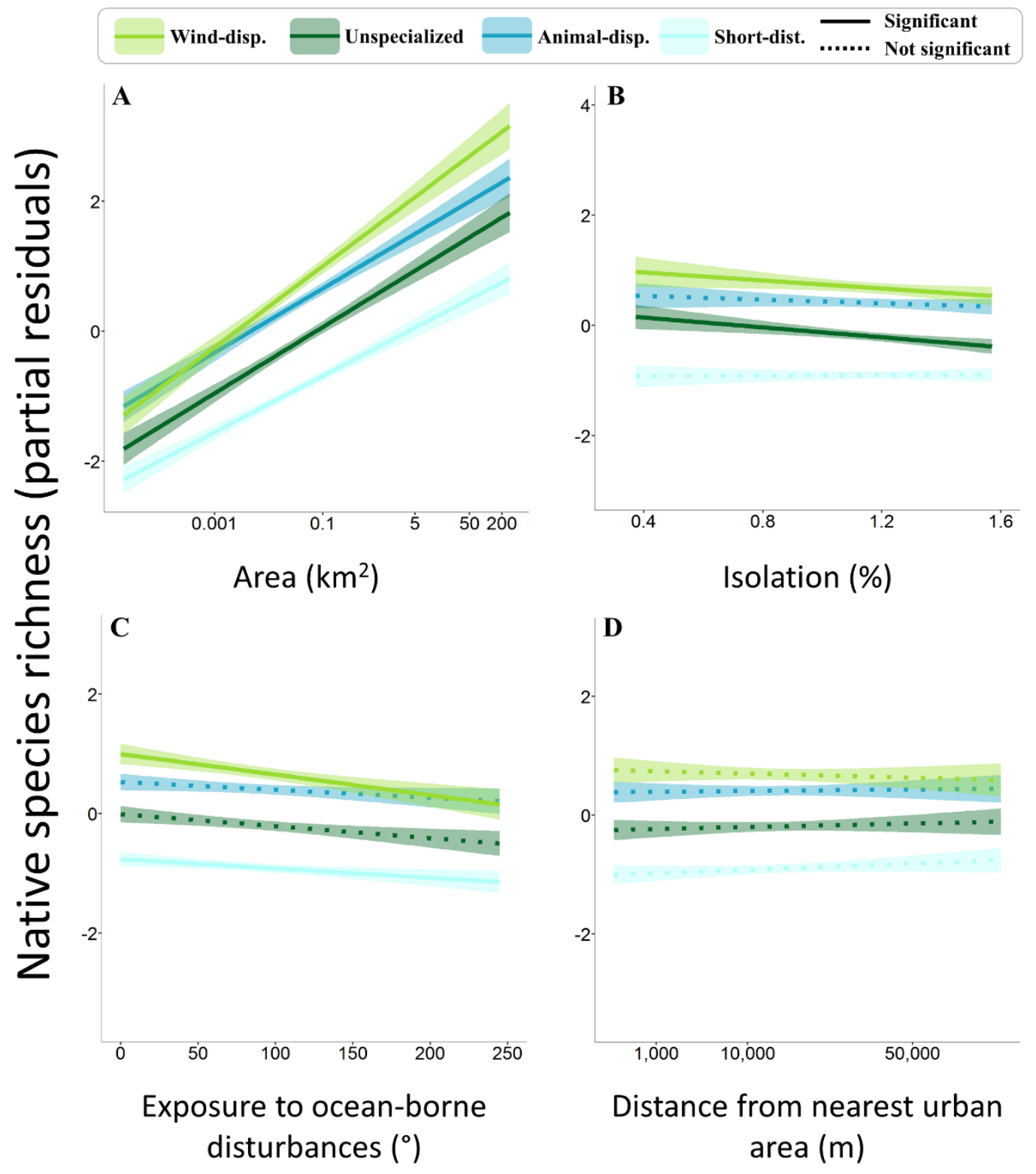

Figure A.2.9 - Linear models illustrating relationships between native species richness with different dispersal modes and island characteristics on 264 New Zealand offshore islands. On the $y$-axis is species richness (partial residuals), while on the $x$-axis are island (A) area (log scale), (B) isolation, (C) exposure to ocean born disturbances, and (D) distance from the nearest urban area. Trendline (model predicted slope) and relative confidence interval (95\%) colours represent animal-dispersed (dark blue), unspecialized (dark green), short-distance (light blue), and wind-dispersed species (light green). Trendline types indicate significant (solid, $\mathrm{P}<0.05$ ) or non-significant (dotted) relationships. To conform to assumptions, species richness was log $(+1)$ transformed, area log-transformed, isolation arcsine-transformed and distance from the nearest urban area squared-transformed. 

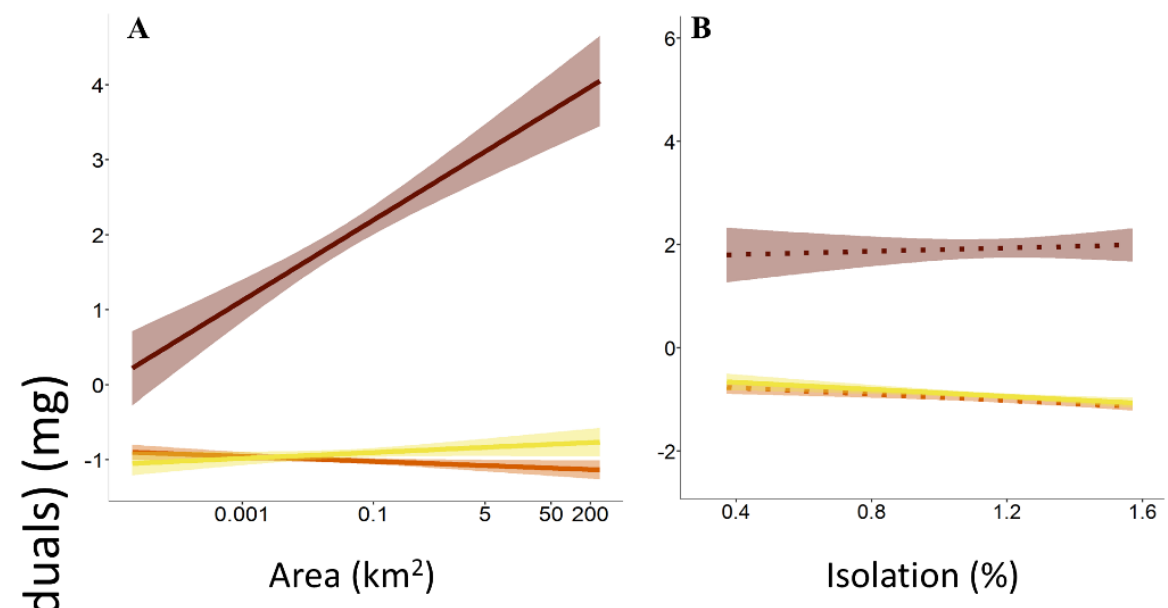

C
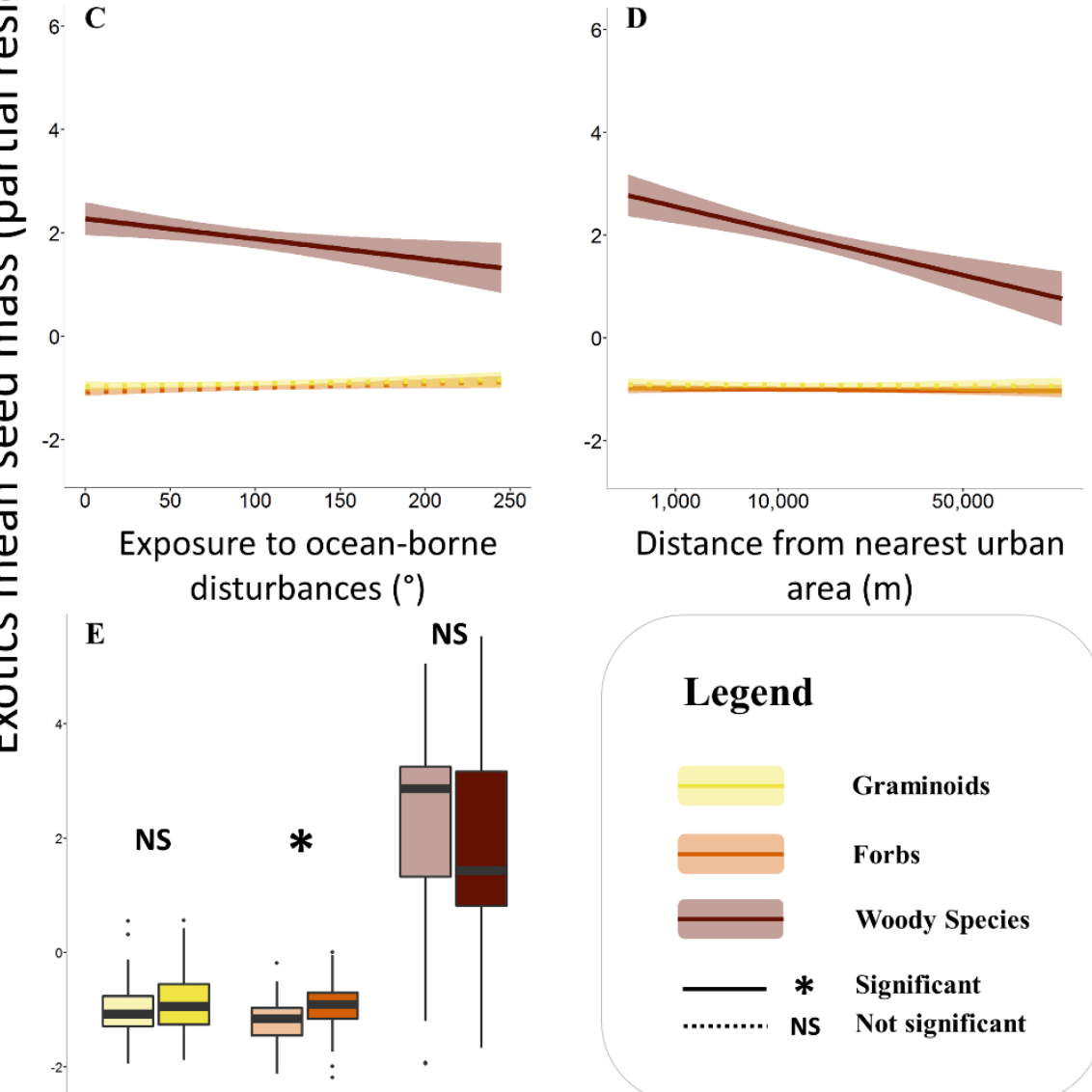

area $(m)$

\section{Legend}

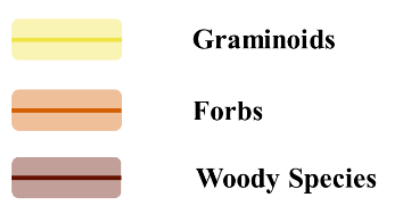

— $*$ Significant

.......... NS Not significant

\section{Conservation areas}

Figure A.2.10 - Linear models illustrating relationships between the average seed mass of native species with different growth forms and island characteristics on 264 New Zealand offshore islands. On the $y$-axis is average seed mass (partial residuals), whereas on the $x$-axis are island (A) area (log scale), (B) isolation, (C) exposure to ocean born disturbances, (D) distance from the nearest urban area and (E) conservation areas. Colours represent graminoid (yellow), forb (vermilion) and woody species (brown). In plots $A$ to $D$, trendline (model predicted slope) and relative confidence interval (95\%) are represented. In plot $E$, light hues indicated publicly managed conservation areas, dark hues other islands. Significant relationships $(P<0.05)$ are illustrated by solid trendline $(A-D)$ and asterisks (E). To conform to assumptions, species richness was log $(+1)$ transformed, area log-transformed, isolation arcsine-transformed and distance from the nearest urban area squared-transformed. 


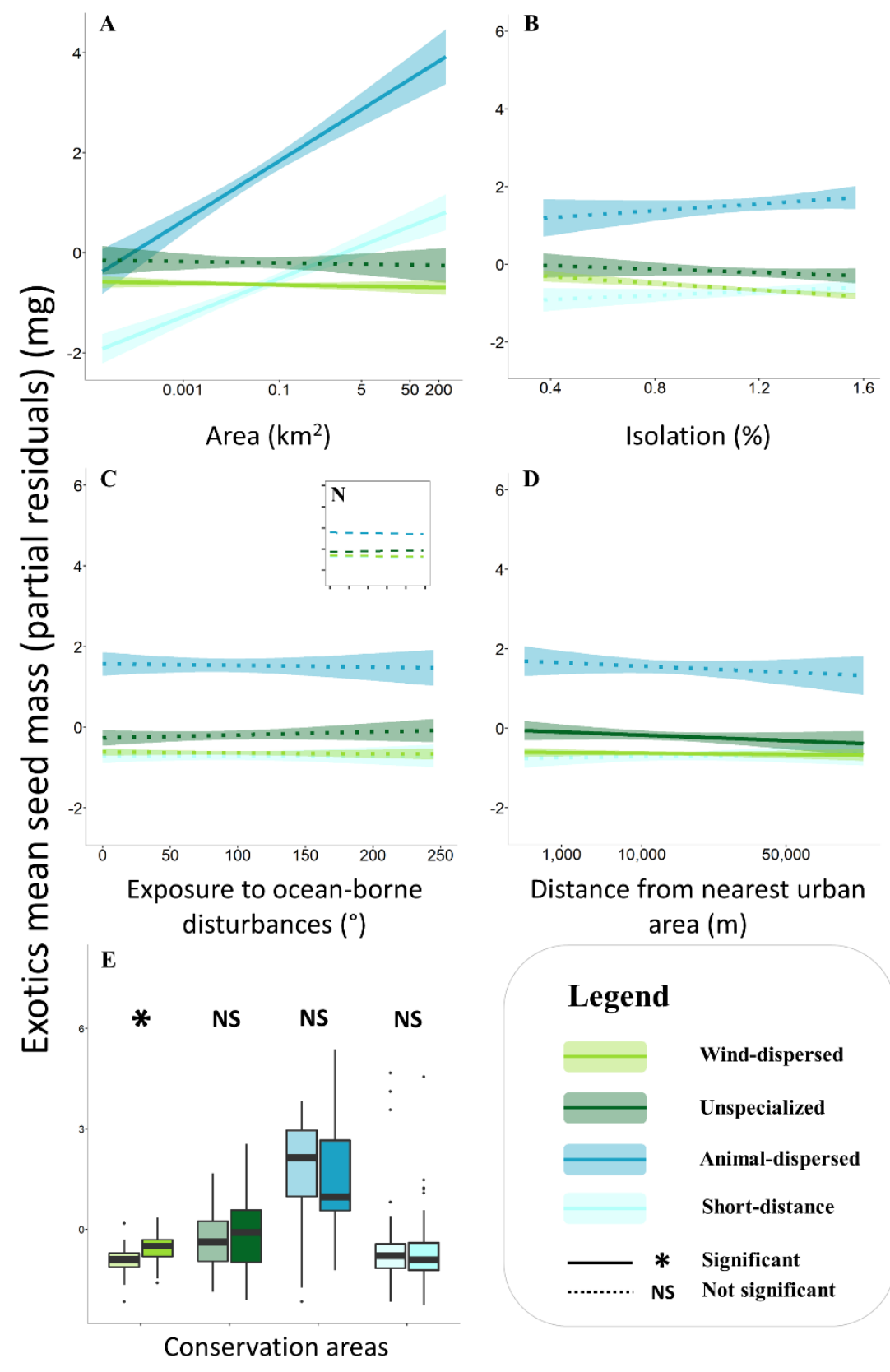

Figure A.2.11 - Linear models illustrating relationships between the average seed mass of native species with different dispersal modes and island characteristics on 264 New Zealand offshore islands. On the $y$-axis is average seed mass (partial residuals), whereas on the $x$-axis are island (A) area (log scale), (B) isolation, (C) exposure to ocean born disturbances, (D) distance from the nearest urban area and (E) conservation areas. Colours represent animal-dispersed (dark blue), unspecialized (dark green), short-distance (light blue), and wind-dispersed species (light green). In plots $A$ to $D$, trendline (model predicted slope) and relative confidence interval (95\%) are represented. In plot $E$, light hues indicated publicly managed conservation areas, dark hues other islands. Significant relationships $(P<0.05)$ are illustrated by solid trendlines $(A-D)$ and asterisks $(E)$. To conform to assumptions, species richness was log $(+1)$ transformed, area log-transformed, isolation arcsine-transformed and distance from the nearest urban area squared-transformed. 


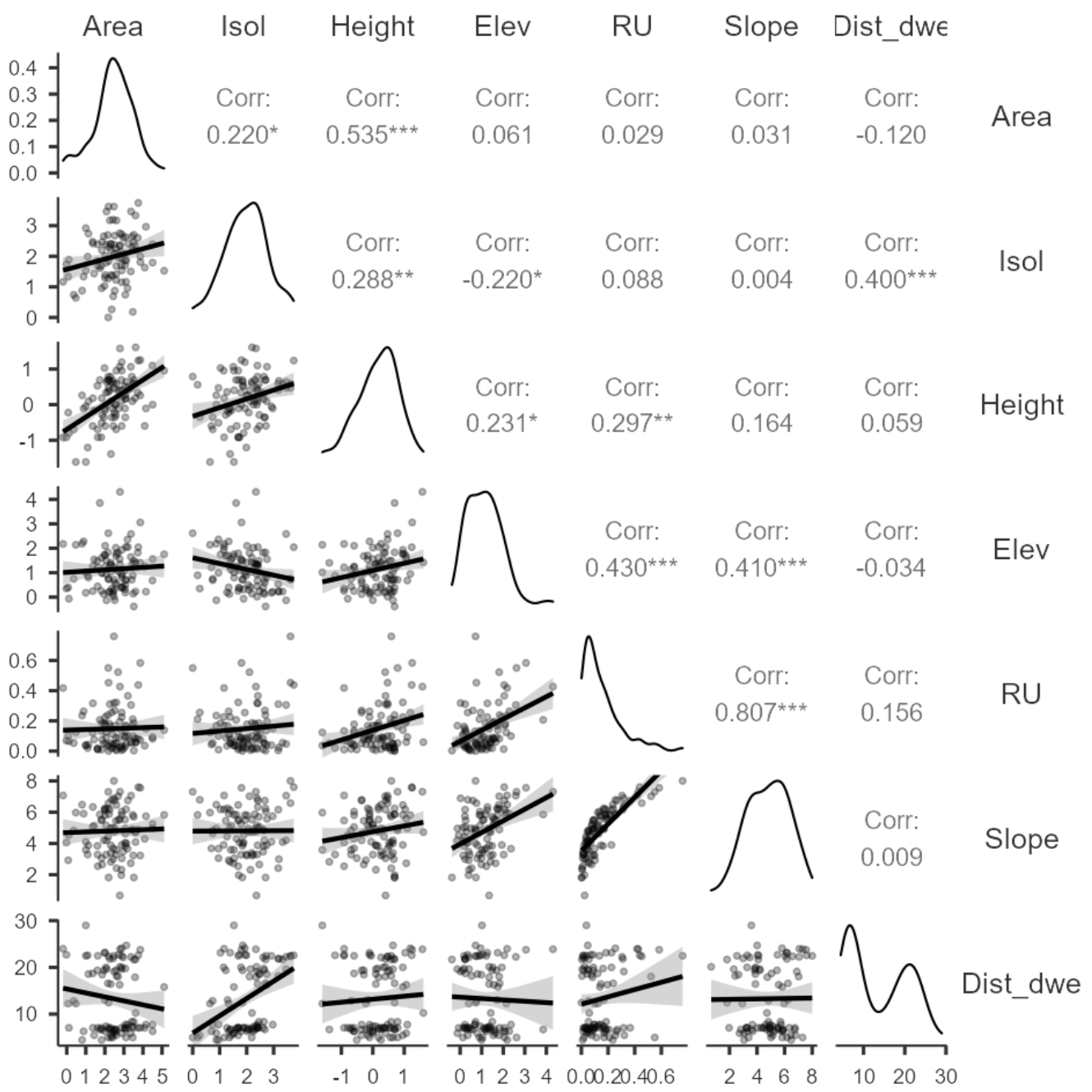

Figure A.2.12 - Correlation matrix displaying the Pearson's correlation coefficient (upper right) and relative correlation plots (lower left) between island characteristics of 97 islands off the coast of Wellington, New Zealand. Variables were retained only with coefficients lower 0.80 . In the centre are frequency plots for each island characteristics. Area, dist (distance), height and RU (rugosity) were log-transformed, slope and dist_dwe (nearest dwelling) square root-transformed while elev (elevation) was not transformed. 

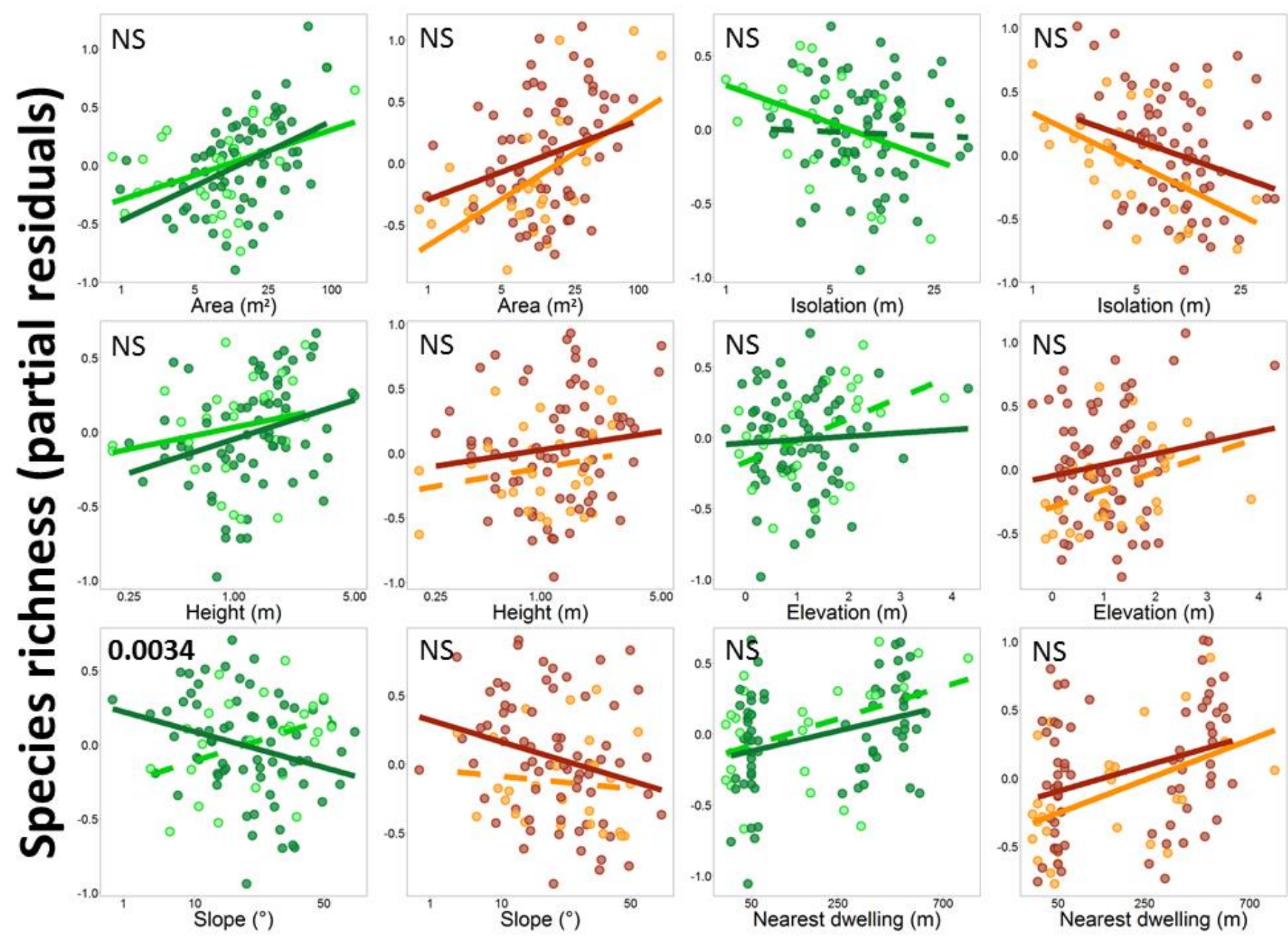

Figure A.2.13 - Relationships between native and exotic species richness (partial residuals) and island area, isolation, height, exposure, elevation, slope and nearest dwelling on 97 islands off the coast of Wellington, New Zealand. Green and red colour illustrate native and exotic species, respectively, while light and dark colours indicate inner and outer islands, respectively. Solid lines indicate significant relationships, while dashed lines display non-significant relationships. In each graph is displayed the coefficient of significance of an ANCOVA test between inner and outer islands (significant t-test are in bold). To conform to assumptions, species richness $(+1)$, area, isolation and height were log-transformed, slope and nearest dwelling were square root-transformed and exposure and elevation were not-transformed. 


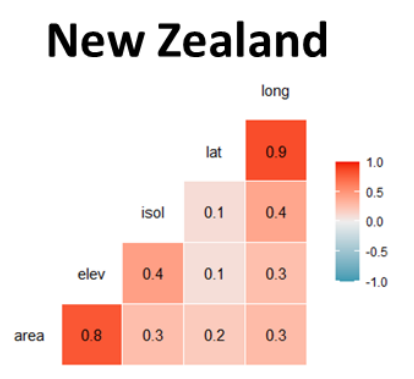

Samoa

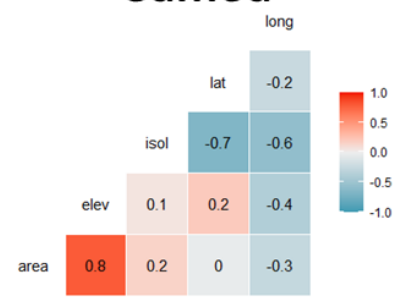

Hawaii

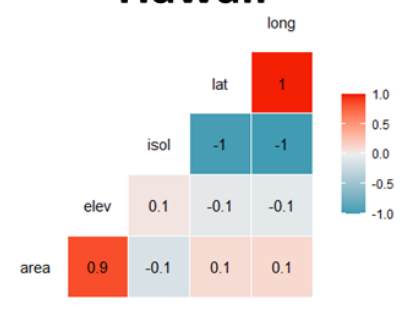

Kuril Is.

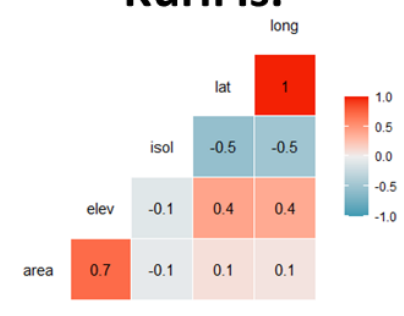

\section{Ionian Is.}

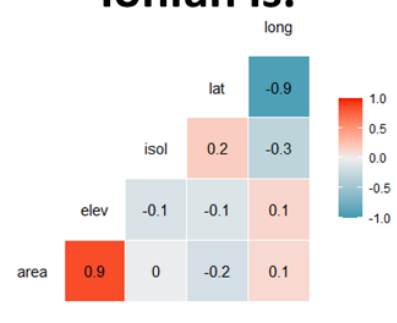

Seychelles

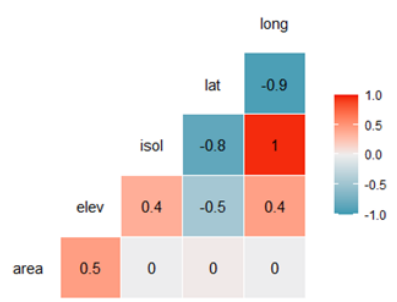

Channel Is.

\begin{tabular}{l|l|l|l|} 
elev & 0.2 & -0.2 & 0.2 \\
\hline
\end{tabular}

\begin{tabular}{|l|l|l|l|}
0.9 & 0.2 & -0.2 & 0.2
\end{tabular}

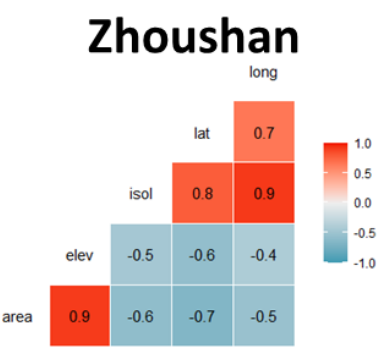

Virgin Is.

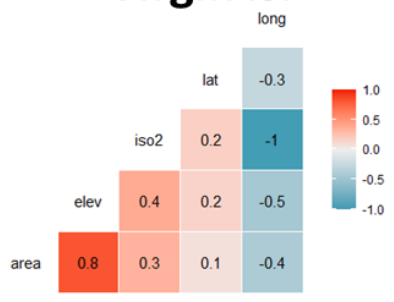

Shetland

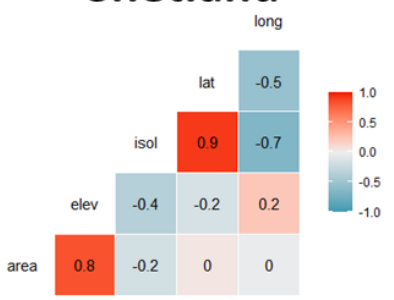

Figure A.2.14 - Correlation matrices for 10 archipelagos across the globe. Variables were removed from model with correlation coefficients above 0.8 . Area was always preferred over elevation and isolation over latitude or longitude. Latitude was preferred over longitude. Elevation though was maintained in the model if the effect was opposite from that of island area (i.e. positive effect of area, negative of elevation). Island area and elevation were log-transformed (but elevation was not transformed for the Kuril Islands), isolation, latitude and longitude were not transformed (except for isolation, square root-transformed for Northern New Zealand and Hawaii, log-transform. 


\section{Appendix 3}

Table A.3.1 - Characteristics of 264 islands offshore northern New Zealand. Island locations (longitude and latitude) are not publicly available due to private ownership and issues of data sovereignty of concern to Māori. The data is publicly available from the Manaaki Whenua data repository at https://doi.org/10.7931/ndkt-zw49.

\begin{tabular}{|c|c|c|c|c|c|c|c|c|c|}
\hline Island name & $\begin{array}{l}\text { Native } \\
\text { species }\end{array}$ & $\begin{array}{c}\text { Exotic } \\
\text { species }\end{array}$ & $\begin{array}{l}\text { Area } \\
\left(\mathrm{m}^{2}\right)\end{array}$ & $\begin{array}{c}\text { Isolation } \\
\text { (\%) }\end{array}$ & $\begin{array}{c}\text { Exposure to } \\
\text { ocean-borne } \\
\text { disturbances }\left({ }^{\circ}\right)\end{array}$ & $\begin{array}{l}\text { Elevation } \\
\text { (m) }\end{array}$ & $\begin{array}{c}\text { Perimeter } \\
\text { (m) }\end{array}$ & $\begin{array}{l}\text { from nearest } \\
\text { urban area } \\
\text { (m) }\end{array}$ & $\begin{array}{c}\text { Conservation } \\
\text { status } \\
(\mathrm{Y}=1 / \mathrm{N}=0)\end{array}$ \\
\hline Terakau-tuhaka & 26 & 3 & 24470.9 & 97.62 & 113.4 & 20 & 847.88 & 32238.9 & 1 \\
\hline Motu Puruhi & 39 & 10 & 30705.3 & 97.25 & 113 & 40 & 819.83 & 32229.4 & 1 \\
\hline Walker Island & 10 & 11 & 209120 & 87.21 & 26.2 & 20 & 2331.5 & 14248 & 1 \\
\hline Tuputuputungahau/Whale & 62 & 28 & 127632 & 97.6 & 112.9 & 40 & 2274.65 & 23491.9 & 0 \\
\hline Moturoa & 24 & 4 & 109451 & 99.34 & 142.2 & 40 & 2073.18 & 26084.2 & 0 \\
\hline Trig & 15 & 3 & 2505.82 & 97.56 & 115.2 & & 214.67 & 25927.5 & 0 \\
\hline Sugarloaf & 17 & 6 & 23886.9 & 97.9 & 124.7 & 20 & 669.85 & 24411.8 & 0 \\
\hline Green & 18 & 5 & 48488.7 & 98.52 & 130.2 & 40 & 1296.76 & 24762.8 & 0 \\
\hline Rocky & 14 & 2 & 23809.6 & 96.1 & 163.4 & 40 & 862.09 & 24524.1 & 0 \\
\hline $\begin{array}{l}\text { Stephenson Island (Ririwha } \\
\text { or Mahinepua Island) }\end{array}$ & 130 & 97 & 1124760 & 99.39 & 150.1 & 120 & 8403.05 & 12253 & 0 \\
\hline Ririwh?iti (Come I) & 61 & 34 & 69751.9 & 93.88 & 152.6 & 80 & 1561.23 & 14283.2 & 0 \\
\hline $\begin{array}{l}\text { Easternmost Woolshed } \\
\text { Bay Islet }\end{array}$ & 26 & 12 & 1634.53 & 84.33 & 15.1 & & 163.93 & 12782.2 & 0 \\
\hline West Woolshed Islet & 17 & 7 & 1479.53 & 84.25 & 16.6 & & 147.66 & 12814.2 & 0 \\
\hline Milktree Islet & 35 & 16 & 2157.65 & 85.19 & 15.1 & & 201.51 & 12475.3 & 0 \\
\hline P? Point Islet & 16 & 8 & 380.34 & 84.06 & 12.7 & 20 & 75.22 & 12726.6 & 0 \\
\hline Motukawanui & 179 & 109 & 3820850 & 97.16 & 169.9 & 160 & 15763 & 13082.1 & 1 \\
\hline Algal Rocks & 17 & 4 & 11148.6 & 91.39 & 107.9 & & 621.77 & 13567.7 & 0 \\
\hline Hamaruru & 63 & 46 & 85429.8 & 91.55 & 174.2 & 40 & 1970.38 & 16202.8 & 0 \\
\hline Haraweka & 38 & 28 & 62212.8 & 86.63 & 174.2 & 60 & 965.08 & 16535.2 & 0 \\
\hline Horonui & 17 & 10 & 7069.94 & 97.65 & 174.2 & 20 & 361.47 & 16156 & 0 \\
\hline Kahangaro & 41 & 48 & 55663.6 & 93.69 & 115.9 & 40 & 1262.83 & 12419.1 & 0 \\
\hline Kahangaroiti & 35 & 30 & 1429.21 & 92.26 & 123.4 & & 148.6 & 12663.8 & 0 \\
\hline Kaitirehe & 5 & 0 & 1188.9 & 77.65 & 108.2 & & 157.73 & 13646.2 & 0 \\
\hline Motuharakeke (Flax Island) & 28 & 6 & 54160.4 & 99.33 & 154.3 & 40 & 1242.35 & 16156.5 & 0 \\
\hline Motuhuia & 18 & 8 & 8237.12 & 93.75 & 125.7 & 20 & 378.59 & 13864.8 & 0 \\
\hline Motukahakaha & 8 & 3 & 5218.63 & 96.85 & 103.8 & & 285.9 & 12140.5 & 0 \\
\hline Motukaroro & 18 & 8 & 7696.27 & 74.48 & 95.1 & 20 & 356.18 & 14148.2 & 0 \\
\hline Motukawaiti & 87 & 89 & 459122 & 98.46 & 110.7 & 100 & 4315.89 & 13089.2 & 0 \\
\hline Motumahanga & 45 & 34 & 6821.41 & 64.44 & 88.8 & 20 & 358.34 & 13717.7 & 0 \\
\hline Motumuka & 68 & 29 & 25023.4 & 86.28 & 98.2 & 40 & 639.88 & 13709.5 & 0 \\
\hline Moturahurahu & 37 & 27 & 10521.6 & 56.9 & 73 & 20 & 505.62 & 14574.4 & 0 \\
\hline Motutakupu & 20 & 2 & 10135.2 & 97.21 & 175.9 & 20 & 547.51 & 17775.6 & 0 \\
\hline Motutapere & 49 & 26 & 52042.5 & 96.93 & 174.5 & 80 & 985.78 & 16369.7 & 0 \\
\hline
\end{tabular}




\begin{tabular}{|c|c|c|c|c|c|c|c|c|c|}
\hline Nukutaunga & 63 & 36 & 130065 & 95.84 & 175.9 & 100 & 1769.5 & 17449.7 & 0 \\
\hline Panaki & 63 & 49 & 153132 & 92.61 & 174.9 & 60 & 2630.96 & 16612.3 & 0 \\
\hline Piraunui & 30 & 13 & 26648.9 & 97.67 & 103.1 & 40 & 686.42 & 11896.3 & 0 \\
\hline Tarawera & 5 & 0 & 8705.93 & 87.22 & 100.5 & & 387.3 & 13529.8 & 0 \\
\hline Te Anaputa & 18 & 0 & 6857.03 & 91.63 & 136.3 & 20 & 312.44 & 15818.2 & 0 \\
\hline Te Anaputaiti & 6 & 0 & 769.19 & 96.65 & 148.8 & & 110.22 & 16157.7 & 0 \\
\hline Te Karo & 33 & 12 & 2459.4 & 71.34 & 7.8 & & 189.96 & 13121.7 & 0 \\
\hline Te Toi & 33 & 20 & 1961.86 & 59.94 & 123.7 & & 169.85 & 15154.9 & 0 \\
\hline Tuturowae & 22 & 7 & 6838.09 & 93.35 & 175.8 & 40 & 328.69 & 17499 & 0 \\
\hline Whatapuke & 41 & 39 & 10744.6 & 88.41 & 105.1 & & 483.61 & 13618 & 0 \\
\hline Whatapukeiti & 23 & 13 & 19479.6 & 89.64 & 106 & 20 & 556.49 & 13205.7 & 0 \\
\hline Motupapa Island & 0 & 1 & 35702.7 & 80.1 & 10.5 & 20 & 1049.14 & 5418.72 & 1 \\
\hline Moturoa Island & 262 & 178 & 1592680 & 96.51 & 43.8 & 80 & 7739.09 & 3505.81 & 0 \\
\hline $\begin{array}{l}\text { Motukokako (Piercy } \\
\text { Island) }\end{array}$ & 83 & 18 & 65187.5 & 95.31 & 245 & 140 & 1076.71 & 20380.6 & 0 \\
\hline Unnamed near Cape Brett & 69 & 2 & 24466.6 & 61.73 & 136.8 & 40 & 582.55 & 16840.4 & 0 \\
\hline Urupukapuka Island & 194 & 160 & 2228080 & 92.31 & 125.2 & 100 & 13432.6 & 8271.91 & 1 \\
\hline Moturua Island & 144 & 90 & 1621920 & 95.98 & 112.8 & 80 & 8140.22 & 5036.88 & 1 \\
\hline $\begin{array}{l}\text { Motuarohia (Roberton } \\
\text { Island) }\end{array}$ & 96 & 74 & 653516 & 97.45 & 96.5 & 60 & 6783.51 & 2842.34 & 0 \\
\hline Waewaetorea & 109 & 109 & 512048 & 85.63 & 134.9 & 60 & 4240.7 & 8369.69 & 1 \\
\hline Motukiekie & 94 & 59 & 335742 & 83.55 & 120.8 & 80 & 3539.83 & 6763.62 & 0 \\
\hline Okahu & 101 & 92 & 277120 & 94.13 & 139.7 & 60 & 2598.22 & 8471.78 & 1 \\
\hline Poroporo Island & 60 & 36 & 81984.9 & 91.01 & 111.7 & 20 & 2010.36 & 7633.6 & 1 \\
\hline Motungarara Island & 28 & 5 & 13287.6 & 87.51 & 134.3 & 20 & 474.23 & 8232.1 & 0 \\
\hline Motutara (Henry Island) & 61 & 44 & 12389.8 & 91.54 & 96.7 & 20 & 635.98 & 22068.2 & 0 \\
\hline Motuti & 9 & 16 & 3173.9 & 64.57 & 0 & 20 & 226.6 & 21327.8 & 0 \\
\hline Motukehua (Nops Island) & 65 & 57 & 41748.3 & 71.69 & 79.2 & 40 & 1419.4 & 19832 & 0 \\
\hline Motukowhai & 57 & 29 & 13689.4 & 53.5 & 83 & 40 & 481.35 & 19178.3 & 0 \\
\hline Moturahurahu & 20 & 14 & 1777.06 & 52.71 & 77.1 & 10 & 171.78 & 19125.3 & 0 \\
\hline Omahu Islets (Twin Rocks) & 33 & 24 & 196.68 & 54.54 & 52.6 & 10 & 76.96 & 20815.6 & 0 \\
\hline $\begin{array}{l}\text { Okiore Point/ Rugged } \\
\text { Point }\end{array}$ & 69 & 75 & 21424.9 & 67.09 & 39.4 & 20 & 1143.88 & 21677 & 0 \\
\hline "Rapata" Islet & 29 & 22 & 1737.94 & 67.1 & 60.3 & 12 & 169.92 & 20733.8 & 0 \\
\hline Whitikau Rock & 30 & 28 & 616.02 & 64.99 & 26.7 & & 101.25 & 21705.4 & 0 \\
\hline Rimariki Island & 119 & 81 & 181021 & 90.53 & 171.5 & 40 & 4001.28 & 19341.3 & 1 \\
\hline Cocker's Rock & 52 & 31 & 3225.77 & 93.87 & 171.7 & 20 & 212.33 & 19997.4 & 0 \\
\hline Motuwharariki & 42 & 17 & 5666.55 & 97.12 & 175.7 & 20 & 336.62 & 19697.9 & 0 \\
\hline Otawhanga & 52 & 21 & 15501.2 & 94.79 & 178.2 & 40 & 599.84 & 18318.5 & 0 \\
\hline Little Otawhanga & 22 & 18 & 2763.18 & 95.63 & 179.5 & 10 & 199.31 & 18535.6 & 0 \\
\hline Ngataurua I & 19 & 7 & 1469.59 & 84.92 & 134.1 & 20 & 157.42 & 20281.4 & 0 \\
\hline Ngataurua II & 9 & 5 & 380.57 & 85.38 & 138 & 20 & 73.08 & 20349.7 & 0 \\
\hline Ngataurua III & 12 & 3 & 554.17 & 85.72 & 139.4 & 20 & 100.4 & 20374.8 & 0 \\
\hline Ngataurua IV & 13 & 9 & 1137.82 & 86.05 & 134.5 & 20 & 208.1 & 20385.7 & 0 \\
\hline Tawhiti Rahi & 2 & 7 & 1559270 & 95.84 & 186.6 & 180 & 10718.1 & 22563 & 1 \\
\hline Aorangi & 228 & 57 & 1038380 & 96.06 & 183.2 & 200 & 5991.63 & 21279.2 & 1 \\
\hline Aorangaia & 60 & 6 & 55176.1 & 87.36 & 183.3 & 100 & 1355.42 & 22082 & 1 \\
\hline Archway & 58 & 9 & 60317.1 & 87.91 & 182.1 & 80 & 1674.52 & 21388.4 & 1 \\
\hline
\end{tabular}


North Pinnacle (High Peak rocks)

Taranga (Hen Island)

Lady Alice

Whatupuke

Coppermine

Mauitaha

Sail Rock

Fanal Island (Motukino)

Burgess Island (Pokohinu)

Hokoromea Island

Atihau Island

Lizard Isle

Maori Rocks (largest islet)

Tatapihi (Groper Island)

Goat Island

Mathesons Bay Islet

Little Barrier Island

(Hauturu)

Great Barrier Island

(Aotea)

Aiguilles Island

Rakitu Island (Arid Island)

Rosalie Bay islet

Te Pani

Motu Tohora

Kaikoura Island

Moturako

Saddle Island (Grey Group Islands)

Northern Inner Grey

Group Islet (west)

Northern Inner Grey

Group Islet (east)

Westernmost Inner Grey

Easternmost Inner Grey

Islet northeast of Opakau

(north)

Islet northeast of Opakau

(south)

Opakau

Islet between Opakau and

Motutaiko

Islet southeast of

Akatarere Point

Mahuki

Motutaiko

Papakuri

Rangiahua

North Junction

Middle Junction

West Junction

South Junction
14

262

214

163

178

109

39

138

103

70

69

24

3

19

123

12

422

572

$121 \quad 35$

$240 \quad 93$

$50 \quad 11$

$55 \quad 21$

$74 \quad 23$

$309 \quad 162$

$35 \quad 15$

$54 \quad 22$

61

56

51

40

57

59

93

31

53

$105 \quad 31$

$88 \quad 39$

$50 \quad 14$

$50 \quad 53$

$89 \quad 41$

$35 \quad 22$

$0 \quad 0$

189

$\begin{array}{cc}17966 & 99.87 \\ 4885880 & 99.98 \\ 1505640 & 95.92 \\ 989410 & 89.46 \\ 768196 & 93.46 \\ 247484 & 99.06\end{array}$

172.7

131.9

140.3

143.2

144.5

137.4

124.2

160.2

163.7

161.3

160.6

167.8

165.9

158.3

102.7

26.5

114.7

189.1

200.1

203.2

100.7

118.8

42

20.6

60.2

61.2

49.6

48.5

48.4

33.3

48.2

48.3

53

57.3

7.6

58.4

67.6

68.37

58.2

8.7

9.1

37.9

30.2
80

632.32

17316.1

13373.6

15374.6

7502.52

23151.1

6152.53

24138.1

6364.88

2600.19

25326.4

21761.7

715.87

5720.21

12165.4

48704.8

5267.09

49720.1

48989.2

48600.8

2514.15

500

500.99

50131.2

51482.6

691.78

1527.64

45754.6

2339.75

454.78

380.5

24708.8

22859.1

234036

42171.4

4887.28

60050.8

63253.9

45570.6

349.99

1112.73

43916.4

42190.3

46298.7

16488.8

372.38

974.45

360.88

241.82

469.52

206.95

257.33

285.63

732.19

294.33

242.09

3972.33

2683.25

264.68

6289.27

324.56

620.05

465.01

1361.62
45407.7

44970.9

45850.3

45932.3

45829.5

46111.2

45466.2

45442.3

44877.5

44363.9

45856.9

44204.8

43480

43640.3

44144.8

46070.1

46025.1

45650.7

45973.3

1

\section{1}

1

1

1

1

0

1

1

1

1

1

1
0

1

1

0

1

0

0

0

0

0

0

0

0

0

0

0

0

0

0 


\begin{tabular}{|c|c|c|c|c|c|c|c|c|c|}
\hline Whangara (Cliff) & 89 & 41 & 66855.4 & 75.25 & 4.2 & 60 & 1279.45 & 50366.9 & 0 \\
\hline $\begin{array}{l}\text { Small stack on south side } \\
\text { of Whangara }\end{array}$ & 35 & 22 & 820.83 & 80.49 & 5.1 & 10 & 111.1 & 50473.4 & 0 \\
\hline Rangitoto & 234 & 364 & 23256900 & 87.14 & 33 & 240 & 25744 & 3003.25 & 1 \\
\hline Pudding Island & 14 & 21 & 1443.9 & 80.83 & 16.5 & 10 & 138.31 & 658.07 & 0 \\
\hline Kawau & 233 & 149 & 20565500 & 99.9 & 48.7 & 180 & 45311.7 & 3662.05 & 0 \\
\hline Challenger Island & 69 & 19 & 28813.3 & 77.39 & 10.9 & 20 & 802.73 & 8487.52 & 0 \\
\hline Little Markham Island & 11 & 5 & 4714.46 & 77.1 & 32.7 & 20 & 264.25 & 8873.03 & 0 \\
\hline Motukaraka (Flat Island) & 65 & 95 & 57322.2 & 90.7 & 13.9 & 20 & 944.31 & 0 & 0 \\
\hline Motuketekete & 89 & 86 & 276743 & 97.8 & 33 & 40 & 2596.59 & 3794.44 & 0 \\
\hline Moturekareka & 100 & 76 & 180077 & 96.69 & 29.6 & 40 & 2354.97 & 2991.5 & 1 \\
\hline Motutara & 64 & 59 & 47333 & 97.15 & 27.4 & 20 & 1022.36 & 2697.55 & 1 \\
\hline Kohatutara (Rocky Islets) & 21 & 12 & 9266.39 & 96.21 & 28.5 & 10 & 579.08 & 3183.24 & 1 \\
\hline Motuora Island & 124 & 143 & 857467 & 100 & 31.4 & 60 & 5209.55 & 3314.93 & 1 \\
\hline Te Haupa (Saddle) & 86 & 68 & 59148.6 & 97.08 & 21.2 & 20 & 1510.88 & 0 & 1 \\
\hline Tiritiri Matangi Island & 277 & 266 & 1922310 & 99.96 & 51.1 & 80 & 7721.63 & 0 & 1 \\
\hline Wooded Island & 28 & 16 & 5967.55 & 85.57 & 51.4 & 20 & 288.46 & 288.18 & 0 \\
\hline Waiheke & 337 & 272 & 92242704 & 99.79 & 45.9 & 220 & 139381 & 0 & 0 \\
\hline $\begin{array}{l}\text { Horuhoru Rock (Gannet } \\
\text { Rock) }\end{array}$ & 10 & 4 & 12136.1 & 100 & 42.4 & 20 & 552.03 & 1593.57 & 0 \\
\hline Koi Island & 51 & 47 & 3431.79 & 76.05 & 0 & 15 & 285.84 & 468.48 & 0 \\
\hline $\begin{array}{l}\text { Papakohatu (Crusoe } \\
\text { Island) }\end{array}$ & 66 & 70 & 24002 & 97.03 & 29.8 & 15 & 995.79 & 0 & 0 \\
\hline Motukaha & 70 & 84 & 5924.78 & 55.71 & 0 & 15 & 292.27 & 0 & 0 \\
\hline $\begin{array}{l}\text { Passage Rock "Three } \\
\text { Sisters" }\end{array}$ & 51 & 54 & 4586.02 & 96.86 & 0 & & & 0 & 0 \\
\hline Nani Island & 46 & 42 & 2969.27 & 66.51 & 46.2 & 15 & 224.25 & 0 & 0 \\
\hline Te Whau (unnames islet) & 33 & 46 & 21333.7 & 72.71 & 0 & 20 & 874.91 & 0 & 0 \\
\hline $\begin{array}{l}\text { Kahakaha (Frenchmans } \\
\text { Cap) }\end{array}$ & 38 & 32 & 2571.98 & 92.58 & 0 & 20 & 188.44 & 1570.69 & 0 \\
\hline Tarahiki (Shag Island) & 91 & 49 & 60852.6 & 99.99 & 37 & 60 & 1229.38 & 2969.8 & 0 \\
\hline Pakatoa & 98 & 126 & 273888 & 96.89 & 0 & 60 & 2950.97 & 1401.93 & 0 \\
\hline Rotoroa Island & 180 & 228 & 892411 & 93.36 & 0 & 60 & 6815.48 & 2217.69 & 0 \\
\hline Ruthe/Motukahakaha islet & 76 & 38 & 13545 & 81.6 & 11.5 & 20 & 630.3 & 3643.8 & 0 \\
\hline Ponui Island & 280 & 147 & 17966900 & 98.8 & 0 & 160 & 35794.1 & 1117.1 & 0 \\
\hline $\begin{array}{l}\text { Pakihi Island (Sandspit } \\
\text { Island) }\end{array}$ & 159 & 147 & 1148760 & 98.21 & 0 & 120 & 6363.32 & 5910.35 & 0 \\
\hline Karamuramu & 37 & 82 & 71890.6 & 92.78 & 0 & 20 & 1027.62 & 7640.66 & 0 \\
\hline Motutapu & 140 & 234 & 15586000 & 90.59 & 38 & 120 & 22800.8 & 4255.43 & 1 \\
\hline Motuihe Island & 165 & 239 & 1805210 & 99.87 & 38 & 60 & 9074.09 & 1137.7 & 1 \\
\hline $\begin{array}{l}\text { Motukorea (Browns } \\
\text { Island) }\end{array}$ & 55 & 90 & 603734 & 99.74 & 34 & 60 & 3481.84 & 1321.47 & 1 \\
\hline Otata Island & 105 & 68 & 168036 & 98.93 & 48.7 & 60 & 2191.39 & 7991.36 & 0 \\
\hline Scott Island & 25 & 1 & 5370.55 & 96.4 & 48.8 & 5 & 305.71 & 8615.31 & 0 \\
\hline Motuhoropapa & 100 & 43 & 86080.1 & 97.95 & 49.9 & 40 & 1820.71 & 8921.39 & 0 \\
\hline $\begin{array}{l}\text { Pollen Island } \\
\text { (Motumanawa) }\end{array}$ & 35 & 58 & 258454 & 73.45 & 0 & 5 & 3458.79 & 0 & 1 \\
\hline Watchman Island & 8 & 19 & 2351.09 & 78.63 & 0 & 5 & 184.61 & 614.57 & 0 \\
\hline Wekarua & 44 & 44 & 60268.3 & 80.05 & 18.6 & 40 & 1324.15 & 9449.73 & 0 \\
\hline Tataweka (esler\#2) & 48 & 38 & 17418.5 & 73.72 & 17.6 & 40 & 566.81 & 9064.46 & 0 \\
\hline Rangipukea & 49 & 58 & 335250 & 94.69 & 19.4 & 60 & 3980.79 & 9132.68 & 0 \\
\hline Waimate & 103 & 90 & 695006 & 96.39 & 15.8 & 120 & 4553.12 & 5059.94 & 0 \\
\hline
\end{tabular}




\begin{tabular}{|c|c|c|c|c|c|c|c|c|c|}
\hline Cow Island & 33 & 23 & 9874.59 & 100 & 20.1 & & 598.66 & 8749.65 & 0 \\
\hline Motutapere & 166 & 65 & 456531 & 81.64 & 14.8 & 160 & 3105.26 & 5051.33 & 1 \\
\hline Motukopake & 75 & 52 & 132102 & 91.84 & 12.1 & 60 & 1893.05 & 4706.94 & 0 \\
\hline Calf Island & 10 & 7 & 391.94 & 99.34 & 20.3 & & 77.91 & 9211.21 & 0 \\
\hline Motukakarikitahi & 87 & 37 & 39125.8 & 89.43 & 7 & 60 & 855.13 & 2287 & 0 \\
\hline Motuokino & 24 & 12 & 6252.85 & 95.26 & 17.9 & 40 & 392.72 & 7369.16 & 0 \\
\hline Motumorirau & 38 & 23 & 4389.07 & 93.18 & 12 & 20 & 306.09 & 5165.6 & 0 \\
\hline Motukaramea & 43 & 22 & 9176.82 & 90.76 & 15 & 20 & 407.42 & 6181.59 & 0 \\
\hline Motuoruhi (Goat Island) & 166 & 74 & 558311 & 99.33 & 15 & 160 & 4553.97 & 5613.8 & 0 \\
\hline $\begin{array}{l}\text { Unnamed Ngamotukaraka } \\
\text { grp (Esler \#14) }\end{array}$ & 59 & 23 & 22899.3 & 96.47 & 15.3 & 40 & 655.66 & 8689.5 & 0 \\
\hline $\begin{array}{l}\text { Unnamed Ngamotukaraka } \\
\text { grp (Esler \#15) }\end{array}$ & 42 & 19 & 7193.42 & 96.06 & 15.6 & 20 & 354.28 & 9221.8 & 0 \\
\hline $\begin{array}{l}\text { Unnamed Ngamotukaraka } \\
\text { grp (Esler \#16) }\end{array}$ & 23 & 9 & 5510.54 & 96.01 & 15 & 20 & 318.58 & 8882.35 & 0 \\
\hline Moturua (Rabbit Island) & 73 & 34 & 269168 & 98.87 & 13.7 & 80 & 3459.29 & 8254.44 & 0 \\
\hline Unnamed (Esler \#18) & 30 & 9 & 1122.41 & 94.35 & 14 & 33 & 141.03 & 9520.1 & 0 \\
\hline $\begin{array}{l}\text { Motukaramarama (Bush } \\
\text { Island) }\end{array}$ & 85 & 28 & 104642 & 97.28 & 11.8 & 60 & 1904.6 & 9864.73 & 0 \\
\hline $\begin{array}{l}\text { Motuwinukenuke (Square } \\
\text { Island) }\end{array}$ & 43 & 23 & 20821.1 & 96.6 & 7.6 & 40 & 635.64 & 8748.36 & 0 \\
\hline Motuwi (Double Island) & 71 & 26 & 185286 & 98.83 & 8.7 & 60 & 3381.52 & 9267.34 & 0 \\
\hline Unnamed (Esler \#22) & 17 & 6 & 1957.26 & 96.05 & 10.6 & 33 & 222.77 & 10400.5 & 0 \\
\hline Motuwhakakewa & 32 & 24 & 13177.2 & 97.23 & 13.3 & 40 & 507.22 & 12560.3 & 0 \\
\hline $\begin{array}{l}\text { Motukahaua (Happy Jack } \\
\text { Island) }\end{array}$ & 47 & 22 & 178295 & 99.52 & 15.6 & 60 & 3274.27 & 12839.6 & 0 \\
\hline Motumakareta & 42 & 9 & 33677.4 & 97.59 & 16.5 & 40 & 780.72 & 13708.9 & 0 \\
\hline $\begin{array}{l}\text { Unnamed Matariki (Esler } \\
\text { \#26) }\end{array}$ & 18 & 22 & 2481.42 & 78.04 & 20.9 & 20 & 212.07 & 11999.4 & 0 \\
\hline $\begin{array}{l}\text { Unnamed Matariki (Esler } \\
\text { \#27) }\end{array}$ & 15 & 27 & 3235.93 & 67.3 & 13.3 & 20 & 225.1 & 11991.4 & 0 \\
\hline $\begin{array}{l}\text { Unnamed Matariki (Esler } \\
\# 28 \text { ) }\end{array}$ & 10 & 5 & 392.62 & 73.27 & 20.7 & 20 & 78.29 & 12194.1 & 0 \\
\hline Cuvier Island & 189 & 96 & 1693310 & 99.85 & 157.3 & 200 & 9795.67 & 38703.8 & 1 \\
\hline Scotts Monument & 26 & 11 & 4581.19 & 81.59 & 158.1 & 40 & 277.05 & 39197.1 & 1 \\
\hline Great Mercury Island & 241 & 162 & 18407800 & 99.78 & 143.7 & 220 & 46144.6 & 17438.4 & 0 \\
\hline Stanley Island/Kawhitu & 141 & 45 & 948518 & 99.84 & 150 & 120 & 5174.39 & 21693.4 & 1 \\
\hline Red Mercury Island & 116 & 21 & 2133300 & 99.4 & 155 & 140 & 7864.88 & 25549.9 & 1 \\
\hline Middle Island/Atiu & 69 & 26 & 109948 & 99.54 & 147.9 & 80 & 1987.33 & 20671.9 & 1 \\
\hline Arch Rock & 1 & 0 & 392.22 & 98.03 & 147.4 & 8 & 84.45 & 20536.2 & 1 \\
\hline Hole Rock & 18 & 0 & 432.87 & 98.03 & 147.7 & 8 & 79.19 & 20787.9 & 1 \\
\hline Haunted House & 20 & 3 & 893.22 & 98.05 & 147.6 & 16 & 118.47 & 20808.1 & 1 \\
\hline Double Island & 14 & 2 & 288864 & 94.74 & 152.7 & 100 & 3514.24 & 24335.7 & 1 \\
\hline Green Island & 42 & 7 & 22964.4 & 97.52 & 146 & 40 & 705.59 & 19648.3 & 1 \\
\hline Korapuki & 118 & 48 & 171697 & 99.68 & 145.2 & 80 & 2798.5 & 18010.8 & 1 \\
\hline Old Man Rock & 9 & 1 & 8280.77 & 100 & 141.3 & 60 & 367.36 & 14146.5 & 0 \\
\hline Ohinauiti & 51 & 11 & 52780.9 & 95.54 & 143.9 & 40 & 1389.66 & 16213.5 & 0 \\
\hline Flat Island & 21 & 14 & 27125.3 & 99.28 & 143 & 5 & 716.9 & 15522.8 & 0 \\
\hline Black Rocks & 35 & 12 & 4140.25 & 99.38 & 143.6 & 20 & 305.07 & 16189.4 & 0 \\
\hline Needle Rock & 36 & 8 & 15303.2 & 99.22 & 139.5 & 60 & 570.33 & 12392.8 & 0 \\
\hline Motueka Island & 78 & 27 & 55871.1 & 95.23 & 88.6 & 60 & 1175.19 & 6826.04 & 0 \\
\hline Poikeke Island & 48 & 11 & 6803.88 & 88.5 & 86 & 20 & 360.99 & 6602.43 & 0 \\
\hline
\end{tabular}




\begin{tabular}{|c|c|c|c|c|c|c|c|c|c|}
\hline Kawetoto Reef & 22 & 10 & 2261.54 & 58.11 & 92.7 & 10 & 178.52 & 15651 & 0 \\
\hline $\begin{array}{l}\text { Rocky islet (Waikawau } \\
\text { Bay) }\end{array}$ & 4 & 4 & 17300.6 & 72.31 & 92.4 & 5 & 663.42 & 15096.8 & 0 \\
\hline Plate Island (Motunau) & 15 & 2 & 42130.5 & 99.95 & 120.3 & 40 & 1743.86 & 11781 & 0 \\
\hline Shoe Island (Motuhoa) & 97 & 14 & 457156 & 99.91 & 120.3 & 120 & 3369.63 & 2642.35 & 0 \\
\hline Slipper Island (Whakahau) & 82 & 19 & 2345850 & 99.06 & 122.3 & 140 & 11640.4 & 5827.04 & 0 \\
\hline Penguin Island & 61 & 8 & 94738.1 & 90.28 & 119.4 & 60 & 1370.35 & 6249.31 & 0 \\
\hline Rabbit Island & 47 & 10 & 96107.9 & 98.63 & 118.2 & 40 & 1596.63 & 6024.32 & 0 \\
\hline $\begin{array}{l}\text { Motuhaua Rock (Opoutere } \\
\text { Beach) }\end{array}$ & 31 & 34 & 1683.35 & 59.68 & 100.8 & 10 & 193.22 & 4120.2 & 0 \\
\hline Hikunui (Opoutere Beach) & 12 & 7 & 1985.66 & 69.66 & 98.8 & 10 & 180.97 & 7996.15 & 0 \\
\hline Ruamahuanui & 83 & 17 & 303555 & 97.3 & 154.6 & 160 & 3092.03 & 20078.7 & 1 \\
\hline Ruamahuaiti & 67 & 12 & 237880 & 98.52 & 150.2 & 180 & 2616.19 & 18500.7 & 1 \\
\hline Hongiora & 36 & 6 & 155492 & 99.91 & 149.9 & 60 & 2430.22 & 16940.1 & 1 \\
\hline Middle Chain & 53 & 13 & 217600 & 94.93 & 152.6 & 100 & 4382.28 & 18630.2 & 1 \\
\hline Half Island & 22 & 3 & 12898.5 & 93.79 & 150.3 & 40 & 506.28 & 18374.9 & 1 \\
\hline Nga Horo ('Hernia' Island) & 18 & 3 & 35858.3 & 93.91 & 150.6 & 60 & 1136.83 & 18454.9 & 1 \\
\hline Mayor Island (Tuhua) & 309 & 167 & 13203600 & 99.96 & 134.7 & 340 & 22745.9 & 27116.8 & 0 \\
\hline $\begin{array}{l}\text { Hauturu Island (Clarks } \\
\text { Island) }\end{array}$ & 87 & 19 & 97212.5 & 81.48 & 91.3 & 80 & 1324.67 & 493.78 & 0 \\
\hline Karewa Island & 29 & 4 & 44790 & 99.99 & 111.1 & 60 & 1222.91 & 11027.9 & 1 \\
\hline Matakana Island & 213 & 184 & 60140900 & 95.23 & 104.8 & 60 & 75794.7 & 578.33 & 0 \\
\hline Motuotau Island & 36 & 27 & 31232.6 & 82.46 & 109.3 & 40 & 685.67 & 0 & 1 \\
\hline Motiti & 61 & 100 & 7013670 & 99.9 & 119 & 40 & 16524.3 & 9371.75 & 0 \\
\hline Taumaihi Island & 34 & 23 & 19557.2 & 95.64 & 117.1 & 20 & 626.63 & 8648.29 & 0 \\
\hline Motohora/Whale Island & 201 & 103 & 1738100 & 100 & 113.6 & 340 & 7638.35 & 7293.28 & 1 \\
\hline Pataua Island & 159 & 36 & 117124 & 40.17 & 0 & 40 & 1516.63 & 4219.32 & 1 \\
\hline White Island (Whakaari) & 19 & 20 & 3393300 & 99.9 & 141.7 & 320 & 8817.23 & 47568.6 & 0 \\
\hline West Volkner & 6 & 1 & 4082.26 & 99.66 & 143.3 & 40 & 260.53 & 51625.8 & 0 \\
\hline Volkner Central Stack & 5 & 0 & 1560.89 & 99.62 & 143.5 & 20 & 160.67 & 51869.9 & 0 \\
\hline East Volkner & 7 & 0 & 20312.5 & 99.89 & 143.6 & 100 & 564.53 & 52018.9 & 0 \\
\hline $\begin{array}{l}\text { Club Rock (off White } \\
\text { Island) }\end{array}$ & 2 & 0 & 6428.65 & 86.75 & 140.3 & 20 & 556.51 & 46985.4 & 0 \\
\hline Stack near Cape Runaway & 14 & 5 & 582.57 & 52.86 & 62 & 10 & 119.92 & 27686.2 & 0 \\
\hline Motuopao Island & 69 & 63 & 301037 & 92.69 & 242 & 100 & 2566.23 & 83913 & 1 \\
\hline Matapia Island & 15 & 4 & 21281.1 & 100 & 153 & 40 & 746.99 & 63130.9 & 0 \\
\hline Moturemu Island & 110 & 49 & 51634.1 & 100 & 6 & 40 & 945.44 & 17058.4 & 0 \\
\hline Kauwahaia Island & 51 & 34 & 6285.92 & 54.51 & 91.4 & 20 & 308.63 & 4983.92 & 0 \\
\hline Taitomo (Camel) Island & 62 & 31 & 26973 & 59.86 & 126 & 60 & 810.07 & 8272.29 & 0 \\
\hline Nun Rock & 15 & 6 & 1230.26 & 64.83 & 148 & 20 & 139.77 & 8501.11 & 0 \\
\hline Paratahi Island & 4 & 1 & 3101.78 & 58.76 & 150 & 10 & 264.45 & 10551.8 & 0 \\
\hline Kauritutahi Island & 9 & 18 & 1038.36 & 64.94 & 0 & 5 & 122.26 & 11975.5 & 0 \\
\hline Ihumatao Islet & 7 & 27 & 6256.84 & 65.93 & 1.2 & 1.5 & 304.56 & 4.35 & 0 \\
\hline Orona Island & 23 & 27 & 1014.93 & 47.81 & 0 & 6 & 127.32 & 0 & 0 \\
\hline Kopuahingahinga Island & 52 & 23 & 107548 & 42.53 & 0 & 10 & 1509.52 & 0 & 0 \\
\hline Leatherjacket Islet & 0 & 0 & 1571.43 & 83.47 & 8.5 & 20 & 149.82 & 46719.9 & 0 \\
\hline $\begin{array}{l}\text { Islet between Castle Peak } \\
\text { and Rangiahua }\end{array}$ & 74 & 24 & 7245.03 & 59.46 & 41 & 20 & 323.11 & 45411.9 & 0 \\
\hline Islet off slipper & 22 & 7 & 1956.41 & 80.2 & 121.7 & 20 & 169.81 & 7128.69 & 0 \\
\hline Green Stack & 15 & 1 & 1510.84 & 95.8 & 146 & 10 & 171.68 & 19618.6 & 0 \\
\hline
\end{tabular}




\begin{tabular}{|c|c|c|c|c|c|c|c|c|c|}
\hline Sentinel rock & 31 & 19 & 383.97 & 70.93 & 99.9 & 20 & 100.79 & 309.07 & 0 \\
\hline Oruawharo (Memory I) & 42 & 40 & 2049.4 & 36.43 & 88 & 15 & 196.08 & 51405.8 & 0 \\
\hline Stone Jetty & 31 & 36 & 1803.12 & 54.14 & 58 & 8 & 161.27 & 51211.4 & 0 \\
\hline Tern Islet & 5 & 1 & 4564.33 & 96.02 & 173.3 & 8 & 272.66 & 19261 & 0 \\
\hline Mid Stack & 3 & 0 & 89.71 & 95.12 & 172.8 & 5 & 39.9 & 19246.3 & 0 \\
\hline Tall Stack & 6 & 1 & 285.71 & 95.32 & 172.8 & 10 & 74.37 & 19247.4 & 0 \\
\hline East Pillar & 2 & 0 & 21.12 & 94.8 & 172.5 & 5 & 20.83 & 19293.2 & 0 \\
\hline West Pillar & 1 & 0 & 58.33 & 94.66 & 178.5 & 5 & 33.35 & 19285.3 & 0 \\
\hline East Stack & 6 & 1 & 84.45 & 95.72 & 179.7 & 8 & 37.89 & 18596.2 & 0 \\
\hline Second Stack & 2 & 0 & 335.99 & 95.89 & 179.9 & 8 & 88.76 & 18595.1 & 0 \\
\hline Holey Stack & 8 & 0 & 1297.14 & 96.66 & 170.6 & 8 & 170.61 & 18342.9 & 0 \\
\hline
\end{tabular}


Table A. 3.2 - Characteristics of 97 islands offshore Wellington harbour, New Zealand.

\begin{tabular}{|c|c|c|c|c|c|c|c|c|c|c|c|c|c|}
\hline Islands & Location & $\begin{array}{c}\text { All } \\
\text { species }\end{array}$ & $\begin{array}{l}\text { Native } \\
\text { species }\end{array}$ & $\begin{array}{l}\text { Exotic } \\
\text { species }\end{array}$ & South & East & $\begin{array}{l}\text { Area } \\
\left(\mathrm{m}^{2}\right)\end{array}$ & $\begin{array}{l}\text { Height } \\
(\mathrm{m})\end{array}$ & $\begin{array}{l}\text { Distance } \\
(\mathrm{m})\end{array}$ & $\begin{array}{c}\text { Exposure to } \\
\text { ocean-borne } \\
\text { disturbances } \\
\left({ }^{\circ}\right)\end{array}$ & Rugosity & Slope $\left({ }^{\circ}\right)$ & $\begin{array}{c}\text { Nearest } \\
\text { dwelling } \\
\text { (m) }\end{array}$ \\
\hline ISO01 & out & 9 & 5 & 4 & 41.33077 & 174.83074 & 37.2 & 5 & 8 & 115.05 & 1.0608 & 22.2681 & 105 \\
\hline ISO02 & out & 5 & 3 & 2 & 41.33300 & 174.82640 & 47.36 & 1.3 & 6.4 & 96.138 & 1.07643 & 10.3995 & 50 \\
\hline IS003 & out & 1 & 1 & 0 & 41.33307 & 174.82649 & 63.8 & 0.9 & 18.4 & 96.518 & 1.15833 & 32.9631 & 60 \\
\hline IS004 & out & 1 & 1 & 0 & 41.33308 & 174.82640 & 7.8725 & 1 & 9.78 & 96.231 & 1.13344 & 26.5789 & 55 \\
\hline ISO05 & out & 3 & 2 & 1 & 41.33410 & 174.82608 & 17.514 & 2 & 4.5 & 112.539 & 1.02363 & 3.88317 & 50 \\
\hline IS006 & out & 1 & 1 & 0 & 41.33511 & 174.82580 & 31.28 & 1.1 & 8.85 & 115.7 & 1.18439 & 24.075 & 55 \\
\hline ISO07 & out & 2 & 2 & 0 & 41.33538 & 174.82506 & 12.42 & 0.7 & 13.5 & 107.337 & 1.30868 & 45.453 & 45 \\
\hline IS008 & out & 3 & 3 & 0 & 41.34061 & 174.82397 & 9.18 & 2 & 9 & 147.905 & 1.19979 & 34.4519 & 45 \\
\hline IS009 & out & 2 & 2 & 0 & 41.34444 & 174.82048 & 14.76 & 1.48 & 7.2 & 140.714 & 1.68635 & 49.2768 & 325 \\
\hline IS010 & out & 2 & 2 & 0 & 41.34437 & 174.82047 & 36.05 & 1.2 & 9.41 & 139.717 & 1.08671 & 22.4822 & 320 \\
\hline IS011 & out & 5 & 3 & 2 & 41.33410 & 174.82610 & 8.806 & 1.43 & 2.57 & 112.304 & 1.03535 & 19.6216 & 50 \\
\hline IS012 & out & 2 & 2 & 0 & 41.33479 & 174.82593 & 6.3 & 1.2 & 8 & 114.343 & 1.20499 & 30.5231 & 45 \\
\hline IS013 & out & 1 & 1 & 0 & 41.33479 & 174.82596 & 3.9375 & 1.2 & 10.2 & 115.255 & 1.37177 & 40.1095 & 50 \\
\hline IS014 & out & 5 & 2 & 3 & 41.34124 & 174.82326 & 11.475 & 0.55 & 1 & 133.086 & 1.04498 & 13.563 & 40 \\
\hline IS015 & out & 3 & 2 & 1 & 41.34276 & 174.81815 & 5 & 1.7 & 5.35 & 102.366 & 1.01907 & 14.782 & 375 \\
\hline IS016 & out & 3 & 2 & 1 & 41.34277 & 174.81811 & 13.225 & 0.75 & 2.4 & 101.881 & 1.09371 & 29.6565 & 375 \\
\hline IS017 & out & 2 & 2 & 0 & 41.34310 & 174.81811 & 21.6 & 1.17 & 12.9 & 120.822 & 1.17635 & 14.7043 & 390 \\
\hline IS018 & out & 5 & 4 & 1 & 41.34306 & 174.81804 & 17.655 & 1.1 & 7.5 & 117.447 & 1.00637 & 5.34457 & 385 \\
\hline IS019 & out & 7 & 5 & 2 & 41.34315 & 174.81801 & 7.875 & 1.4 & 5 & 124.432 & 1.0948 & 10.7339 & 400 \\
\hline ISO20 & out & 6 & 5 & 1 & 41.34316 & 174.81797 & 16.2 & 1.5 & 9.6 & 125.159 & 1.02446 & 0.447133 & 405 \\
\hline IS021 & out & 9 & 5 & 4 & 41.34357 & 174.81736 & 33.75 & 2 & 13.9 & 146.862 & 1.00345 & 3.30675 & 470 \\
\hline IS022 & out & 4 & 2 & 2 & 41.34368 & 174.81735 & 9.6 & 1.5 & 22.9 & 148.137 & 1.36473 & 37.9744 & 475 \\
\hline ISO23 & out & 8 & 6 & 2 & 41.34366 & 174.81657 & 7.25 & 2.8 & 1.8 & 149.956 & 1.2018 & 38.1267 & 535 \\
\hline ISO24 & out & 10 & 6 & 4 & 41.34348 & 174.81606 & 47.47 & 3.5 & 5.1 & 145.434 & 1.79215 & 57.1474 & 565 \\
\hline ISO25 & out & 4 & 2 & 2 & 41.34316 & 174.81580 & 17.92 & 3.3 & 5.9 & 120.084 & 1.29004 & 33.8185 & 580 \\
\hline ISO26 & out & 13 & 8 & 5 & 41.34305 & 174.81578 & 16.34 & 4.85 & 9.4 & 116.513 & 1.53239 & 53.3884 & 570 \\
\hline IS027 & in & 13 & 9 & 4 & 41.29523 & 174.83637 & 17.98 & 2.6 & 2.15 & 185.804 & 1.25282 & 15.23 & 400 \\
\hline ISO28 & in & 3 & 3 & 0 & 41.29589 & 174.83642 & 11.9 & 1.6 & 9.85 & 183.863 & 1.37446 & 47.4378 & 365 \\
\hline IS029 & in & 3 & 3 & 0 & 41.29585 & 174.83667 & 8.06 & 1.9 & 30.9 & 190.066 & 1.04831 & 17.6342 & 385 \\
\hline IS030 & in & 1 & 1 & 0 & 41.29596 & 174.83608 & 13.6 & 1.8 & 22.8 & 189.567 & 1.00435 & 5.81851 & 330 \\
\hline IS031 & in & 1 & 1 & 0 & 41.29675 & 174.83567 & 10.08 & 1.1 & 10.1 & 140.369 & 1.15739 & 15.0516 & 270 \\
\hline IS032 & in & 14 & 9 & 5 & 41.29680 & 174.83556 & 165.675 & 2.6 & 3.6 & 137.635 & 1.14928 & 33.9445 & 250 \\
\hline IS033 & in & 3 & 2 & 1 & 41.29673 & 174.83420 & 9 & 2 & 5.3 & 78.66 & 1.00095 & 3.3174 & 155 \\
\hline IS034 & in & 1 & 1 & 0 & 41.29863 & 174.83260 & 13.09 & 1 & 8.5 & 106.048 & 1.01314 & 10.7493 & 40 \\
\hline IS035 & in & 2 & 2 & 0 & 41.29874 & 174.83255 & 12.42 & 1 & 1.4 & 106.536 & 1.18364 & 24.5833 & 35 \\
\hline IS036 & in & 3 & 3 & 0 & 41.29947 & 174.83260 & 5.67 & 2 & 4 & 115.901 & 1.22906 & 34.2174 & 45 \\
\hline IS037 & in & 4 & 4 & 0 & 41.30073 & 174.83212 & 24.72 & 1.5 & 10.2 & 121.695 & 1.44149 & 45.4849 & 50 \\
\hline IS038 & in & 2 & 2 & 0 & 41.30407 & 174.83129 & 10.58 & 0.7 & 0.3 & 120.418 & 1.29074 & 46.1318 & 30 \\
\hline IS039 & in & 1 & 1 & 0 & 41.30409 & 174.83129 & 11.1 & 0.9 & 2.9 & 120.07 & 1.11902 & 25.1119 & 25 \\
\hline ISO40 & in & 1 & 1 & 0 & 41.30479 & 174.83143 & 6.24 & 0.6 & 1.6 & 119.337 & 1.00987 & 9.32547 & 20 \\
\hline
\end{tabular}




\begin{tabular}{|c|c|c|c|c|c|c|c|c|c|c|c|c|c|}
\hline ISO41 & in & 2 & 2 & 0 & 41.30492 & 174.83139 & 2.24 & 1.3 & 1.4 & 117.476 & 1.26531 & 41.9562 & 20 \\
\hline ISO42 & in & 2 & 2 & 0 & 41.30601 & 174.83163 & 10.14 & 1.9 & 7.9 & 109.909 & 1.01934 & 11.4872 & 25 \\
\hline ISO43 & in & 9 & 6 & 3 & 41.30763 & 174.83299 & 90.75 & 1 & 5 & 144.236 & 1.08519 & 27.5128 & 40 \\
\hline ISO44 & in & 3 & 3 & 0 & 41.30808 & 174.83270 & 2.42 & 0.9 & 2.8 & 132.648 & 1.30114 & 34.8165 & 40 \\
\hline ISO45 & in & 4 & 3 & 1 & 41.30919 & 174.83104 & 32 & 1.75 & 0.2 & 99.209 & 1.23533 & 33.926 & 25 \\
\hline ISO46 & in & 6 & 4 & 2 & 41.30928 & 174.83095 & 8.84 & 2.2 & 0 & 96.04 & 1.73383 & 53.3423 & 25 \\
\hline ISO47 & out & 2 & 1 & 1 & 41.34760 & 174.76879 & 4.2 & 0.85 & 3.2 & 131.201 & 1.08028 & 26.3935 & 30 \\
\hline ISO48 & out & 1 & 0 & 1 & 41.34808 & 174.76761 & 12.15 & 0.8 & 7 & 133.163 & 1.04634 & 22.3542 & 45 \\
\hline ISO49 & out & 7 & 5 & 2 & 41.34861 & 174.76620 & 33.63 & 1.8 & 10.6 & 133.625 & 1.20367 & 32.4915 & 70 \\
\hline IS050 & out & 1 & 1 & 0 & 41.34442 & 174.77493 & 5.06 & 0.5 & 9.9 & 115.507 & 1.01418 & 10.7933 & 50 \\
\hline IS051 & out & 9 & 4 & 5 & 41.34501 & 174.77630 & 24.32 & 1.6 & 1.6 & 123.515 & 1.10482 & 13.4106 & 60 \\
\hline IS052 & out & 3 & 2 & 1 & 41.34512 & 174.77650 & 21.6 & 0.7 & 1.1 & 125.005 & 1.13956 & 21.4086 & 60 \\
\hline IS053 & out & 1 & 1 & 0 & 41.34522 & 174.77709 & 6.12 & 0.4 & 4.4 & 126.375 & 1.14247 & 29.8818 & 50 \\
\hline IS054 & out & 1 & 1 & 0 & 41.34525 & 174.77714 & 1.12 & 0.45 & 5.6 & 126.899 & 1.0675 & 20.4973 & 50 \\
\hline IS055 & out & 2 & 2 & 0 & 41.34534 & 174.77755 & 13.34 & 0.5 & 3.1 & 128.377 & 1.05346 & 12.911 & 45 \\
\hline ISO56 & out & 3 & 2 & 1 & 41.34533 & 174.77756 & 10.14 & 0.25 & 3 & 127.601 & 1.05415 & 7.95648 & 45 \\
\hline IS057 & out & 2 & 2 & 0 & 41.34538 & 174.77755 & 21.25 & 0.9 & 4.5 & 127.222 & 1.10236 & 30.4216 & 50 \\
\hline IS058 & out & 5 & 4 & 1 & 41.34545 & 174.77753 & 41.6 & 1.4 & 12.5 & 129.451 & 1.08589 & 23.8534 & 50 \\
\hline IS059 & out & 8 & 7 & 1 & 41.34554 & 174.77802 & 59.78 & 0.55 & 4.1 & 128.754 & 1.03666 & 18.4181 & 50 \\
\hline ISO60 & out & 11 & 9 & 2 & 41.34573 & 174.77843 & 89.79 & 3 & 10 & 129.416 & 1.09807 & 24.5693 & 60 \\
\hline IS061 & out & 6 & 5 & 1 & 41.34582 & 174.77853 & 30.4 & 2.2 & 13 & 128.445 & 1.05525 & 23.347 & 70 \\
\hline IS062 & out & 6 & 4 & 2 & 41.34540 & 174.77913 & 17.98 & 1.5 & 3.65 & 127.841 & 1.0375 & 9.27748 & 35 \\
\hline IS063 & out & 3 & 3 & 0 & 41.34549 & 174.77913 & 21.6 & 1.3 & 6.8 & 128.669 & 1.09585 & 24.614 & 45 \\
\hline IS064 & out & 5 & 4 & 1 & 41.34544 & 174.77951 & 32.76 & 1.8 & 8 & 128.967 & 1.10407 & 10.4066 & 50 \\
\hline ISO65 & out & 2 & 2 & 0 & 41.34540 & 174.77963 & 21.35 & 1.68 & 5.6 & 129.319 & 1.0293 & 16.3452 & 50 \\
\hline IS066 & out & 1 & 1 & 0 & 41.34536 & 174.77973 & 10 & 2.2 & 10 & 128.145 & 1.1767 & 24.6215 & 50 \\
\hline IS067 & out & 9 & 7 & 2 & 41.34391 & 174.78195 & 28.8 & 2.9 & 3.5 & 107.435 & 1.06138 & 7.44661 & 35 \\
\hline IS068 & out & 1 & 1 & 0 & 41.34264 & 174.78375 & 22.4 & 1.2 & 2.2 & 58.035 & 1.18487 & 38.2291 & 25 \\
\hline IS069 & out & 2 & 2 & 0 & 41.34259 & 174.78383 & 13.5 & 2.6 & 4.4 & 64.502 & 1.38027 & 41.7169 & 30 \\
\hline ISO70 & out & 1 & 1 & 0 & 41.34252 & 174.78389 & 7.5 & 0.55 & 6.5 & 74.48 & 1.19457 & 33.6806 & 40 \\
\hline IS071 & out & 1 & 1 & 0 & 41.34581 & 174.78942 & 6.435 & 0.75 & 10.8 & 128.046 & 1.07904 & 7.02959 & 340 \\
\hline IS072 & out & 1 & 1 & 0 & 41.34584 & 174.78947 & 3.12 & 1.1 & 14.5 & 127.403 & 1.04399 & 15.0198 & 345 \\
\hline IS073 & out & 10 & 6 & 4 & 41.34676 & 174.79148 & 29.16 & 1.6 & 30.9 & 128.789 & 1.35684 & 49.7991 & 495 \\
\hline ISO74 & out & 3 & 3 & 0 & 41.34683 & 174.79141 & 11.88 & 1.8 & 36.5 & 128.884 & 2.13673 & 64.0401 & 505 \\
\hline ISO75 & out & 3 & 2 & 1 & 41.34679 & 174.79138 & 8.96 & 1.6 & 36.5 & 129.976 & 1.57272 & 43.2828 & 500 \\
\hline ISO76 & out & 6 & 5 & 1 & 41.34687 & 174.79142 & 42.68 & 3.45 & 41.3 & 128.459 & 1.54908 & 57.8003 & 510 \\
\hline IS077 & in & 5 & 3 & 2 & 41.28830 & 174.82963 & 17.92 & 0.55 & 14.1 & 135.055 & 1.14454 & 36.4431 & 505 \\
\hline IS078 & in & 2 & 2 & 0 & 41.28476 & 174.82513 & 2.72 & 0.2 & 3.6 & 187.534 & 1.03785 & 12.877 & 840 \\
\hline IS079 & in & 2 & 2 & 0 & 41.28708 & 174.82440 & 0.825 & 0.4 & 2.2 & 157.551 & 1.51847 & 49.9696 & 575 \\
\hline IS080 & in & 1 & 1 & 0 & 41.30213 & 174.81793 & 1.44 & 0.5 & 1.1 & 98.921 & 1.05408 & 23.3625 & 165 \\
\hline IS081 & in & 1 & 1 & 0 & 41.30249 & 174.81783 & 1.61 & 0.2 & 0.9 & 97.422 & 1.13122 & 35.6565 & 150 \\
\hline IS082 & in & 1 & 1 & 0 & 41.30253 & 174.81769 & 1.08 & 0.8 & 2.8 & 106.934 & 1.10682 & 8.54284 & 150 \\
\hline IS083 & in & 1 & 1 & 0 & 41.30355 & 174.81616 & 7.44 & 0.85 & 2.65 & 117.906 & 1.18287 & 38.9936 & 170 \\
\hline ISO84 & out & 2 & 2 & 0 & 41.34146 & 174.80975 & 7 & 0.7 & 13.2 & 112.216 & 1.05154 & 17.6436 & 375 \\
\hline IS085 & out & 1 & 1 & 0 & 41.34125 & 174.80982 & 3.91 & 0.55 & 10.9 & 111.468 & 1.12925 & 25.5052 & 350 \\
\hline ISO86 & out & 3 & 3 & 0 & 41.34064 & 174.81018 & 8.64 & 2 & 13.8 & 62.66 & 1.26941 & 38.9645 & 275 \\
\hline
\end{tabular}




\begin{tabular}{|c|c|c|c|c|c|c|c|c|c|c|c|c|}
\hline IS087 & out & 2 & 2 & 0 & 41.34058 & 174.81018 & 16.12 & 2.9 & 14.7 & 65.32 & 1.21565 & 31.0212 \\
\hline IS088 & out & 9 & 7 & 2 & 41.34240 & 174.80959 & 36.9 & 1.8 & 27 & 115.291 & 1.05729 & 16.6944 \\
\hline IS089 & out & 8 & 6 & 2 & 41.34257 & 174.80961 & 19.25 & 1.3 & 12.6 & 114.372 & 1.01256 & 12.0572 \\
\hline 15090 & out & 5 & 5 & 0 & 41.34247 & 174.80969 & 11.4 & 1.95 & 23.4 & 117.25 & 1.02431 & 8.94758 \\
\hline IS091 & out & 1 & 1 & 0 & 41.34272 & 174.80975 & 2.72 & 0.95 & 17.5 & 116.994 & 1.04016 & 16.8218 \\
\hline IS092 & out & 1 & 1 & 0 & 41.34297 & 174.80974 & 7.5 & 0.9 & 3 & 116.925 & 1.25303 & 37.6046 \\
\hline IS093 & out & 5 & 4 & 1 & 41.34270 & 174.80935 & 15.34 & 0.9 & 6 & 116.454 & 1.09099 & 30.0709 \\
\hline ISO94 & out & 5 & 4 & 1 & 41.34357 & 174.80929 & 22.78 & 1.9 & 5.4 & 119.311 & 1.04878 & 16.0631 \\
\hline ISO95 & out & 3 & 2 & 1 & 41.34271 & 174.80954 & 5.1 & 0.4 & 4.4 & 116.595 & 1.01003 & 6.45984 \\
\hline IS096 & out & 2 & 1 & 1 & 41.34269 & 174.80950 & 3 & 0.3 & 6.3 & 115.992 & 1.02053 & 10.8067 \\
\hline IS097 & out & 1 & 1 & 0 & 41.34272 & 174.80936 & 0.98 & 0.4 & 4.7 & 116.29 & 1.07205 & 16.4391 \\
\hline
\end{tabular}




\section{Permits}

- Chapters 2 and 3: Permits were obtained for all unpublished surveys, issued by either the New Zealand's Department of Conservation or Māori and private island owners.

- Chapters 4: A regular permit was obtained from the Wellington City Council. Thanks also to local Iwi for permission to collect data in the Wellington area.

\section{Funding}

- Wellington Botanical Society Research Grant 2018

Funding assisted research for Chapter 2.

- Centre for Biodiversity and Restoration Ecology Student Grant 2019

Funding assisted research for Chapter 4.

- Victoria University of Wellington Doctoral \& Submission Scholarships $2018-2021$

All research carried out by FM was supported by these scholarships. 